\title{
DEVELOPMENT OF FRAMEWORK FOR IN-VEHICLE PASSING COLLISION WARNING SYSTEM CONSIDERING DRIVER CHARACTERISTICS
}

\author{
By: \\ Udai Hassein \\ Master of Applied Science, Ryerson University, Toronto, Ontario, Canada 2011 \\ Bachelor of Science, Al-Mustansiriya University, Baghdad, Iraq 1994
}

\author{
A dissertation \\ presented to Ryerson University \\ in partial fulfillment of the \\ requirements for the degree of \\ Doctor of Philosophy \\ in the Program of \\ Civil Engineering
}

Toronto, Ontario, Canada, 2017

(C) Udai Hassein 2017 


\begin{abstract}
AUTHOR'S DECLARATION
I hereby declare that I am the sole author of this dissertation. This is a true copy of the dissertation, including any required final revisions, as accepted by my examiners.

I authorize Ryerson University to lend this dissertation to other institutions or individuals for the purpose of scholarly research.

I further authorize Ryerson University to reproduce this dissertation by photocopying or by other means, in total or in part, at the request of other institutions or individuals for the purpose of scholarly research.
\end{abstract}

I understand that my dissertation may be made electronically available to the public. 


\title{
DEVELOPMENT OF FRAMEWORK FOR IN-VEHICLE PASSING COLLISION WARNING SYSTEM CONSIDERING DRIVER CHARACTERISTICS
}

\author{
by \\ Udai Hassein \\ Doctor of Philosophy, Civil Engineering \\ Ryerson University, Toronto, Ontario, Canada, 2017
}

\begin{abstract}
Passing collisions are one of the most serious traffic safety problems on two-lane highways. The purpose of this dissertation is to develop a framework for a passing collision warning system (PCWS) for two-lane highways that can help drivers avoid passing collisions by reducing the chance of human error. Specifically, the objectives of this research are: (1) to conduct a comprehensive literature review of existing collision warning systems, (2) to design driving simulator and field experiments for data collection, (3) to develop deterministic and reliabilitybased models for passing sight distance (PSD) that consider driver characteristics, (4) to develop an in-vehicle passing collision warning system, and (5) to develop a Simulink model that implements the proposed PCWS in a real time environment. A driving simulator was used to collect data from participants (males and females of different ages). The field study data were
\end{abstract}


collected on real highways using an in-vehicle video camera and a GPS data logger. The driving simulator and field data were used to develop the passing parameters for the proposed PSD model. The estimated parameters included initial time, passing time, and average acceleration rate. The results of the model were compared with those from existing models and design guidelines. The results revealed that the existing PSD models were either too liberal or too conservative. The reliability-based PSD model was developed using the First-Order Second-Moments method and a Monte Carlo Simulation was used to validate the model. The proposed PCWS uses a radar sensor placed in the passing vehicle to detect opposing vehicles travelling in the left lane and calculate their relative distance and speed in order to estimate the time to collision. This time is then compared with the time required for the passing vehicle to clear the path. The "safe pass" signal can assist passing drivers in preparing for a safe passing maneuver during the overtaking process. A Simulink MATLAB model was developed and used to implement the methodology of the proposed warning system. The different factors that affect system accuracy were examined. The application of the system was illustrated using an example. 


\section{ACKNOWLEDGMENTS}

I would like to express my most heartfelt appreciation to my supervisor Dr. Said Easa for his professionalism, wisdom, experience, suggestions, guidance, encouragement and patience throughout my dissertation. He also presented me with my thesis idea, the required software, and several references related to the software in order to assist me. Dr. Easa's unfailing optimism and continued support allowed me to overcome the difficulties involved in completing this research project. I am grateful to him for providing me with the knowledge required to understand the mathematical modeling to be applied to my thesis.

I am also grateful to all the members of my oral examination committee for their helpful and valuable comments. These include Dr. Lina Kattan from the University of Calgary, Dr. Ahmed Shaker, Dr. Lamya Amleh, Dr. Ziad Saghir, and Dr. Miljana Horvat from Ryerson University. I would also like to acknowledge the faculty and students in the Civil Engineering Department at the Ryerson University. I would also like to express my gratitude to towards Dr. Medhat Shehata, and Dr. Michael Chapman for providing me with guidance throughout my studies at Ryerson. I would like to say a special thank-you to my friends and colleagues at Ryerson University, for supporting my research and offering helpful suggestions throughout. Last but not least, I want to thank my family for their patience, especially my wife and children for their forbearance during my work. Without their understanding and moral support, I would not have been able to dedicate myself to my research and reach my goals. 


\section{DEDICATION}

This dissertation is dedicated to my wonderful wife and my lovely children who have sacrificed so much so that I could complete it. I would also like to thank my family and my best friends for all of their support throughout my life. Without them, this dissertation would not have been possible. 


\section{TABLE OF CONTENTS}

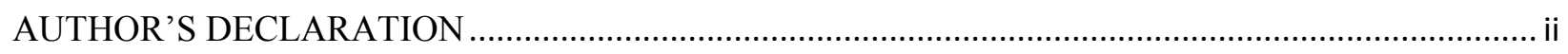

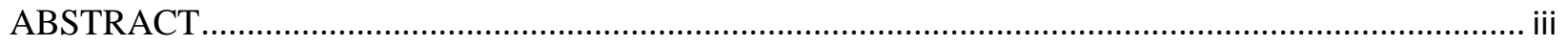

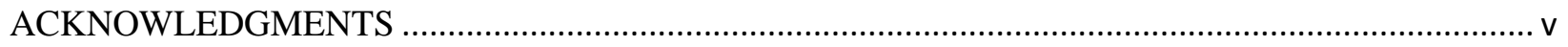

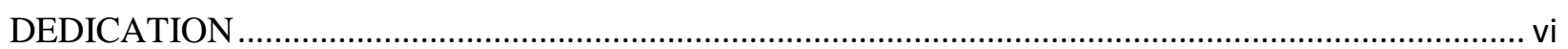

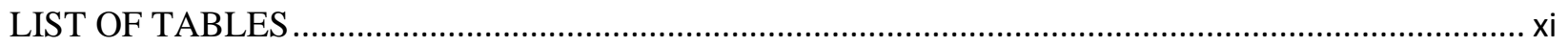

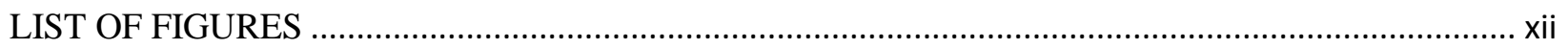

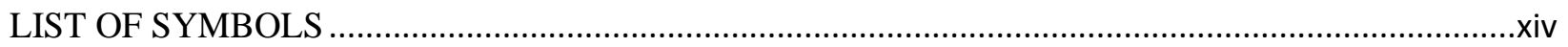

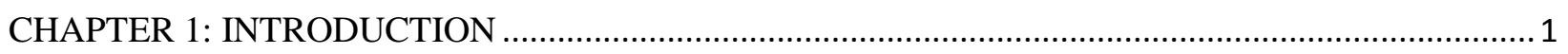

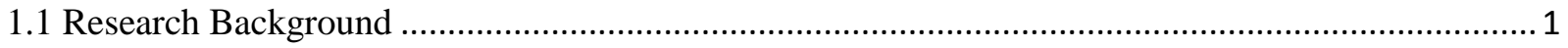

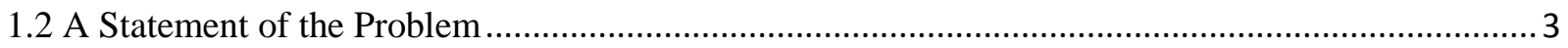

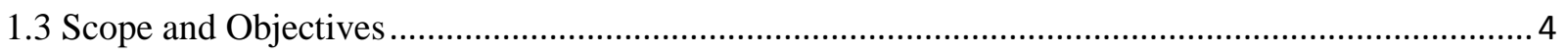

1.4 Dissertation Methodology and Organization ....................................................................... 5

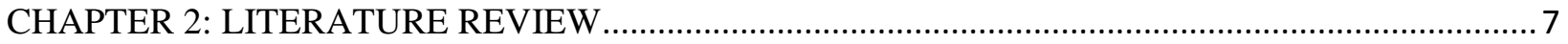

2.1 Human Factors and Collision Avoidance Systems .................................................................... 7

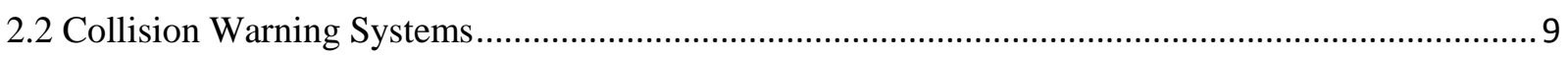

2.3 Existing Passing Sight Distance Models ................................................................................... 12

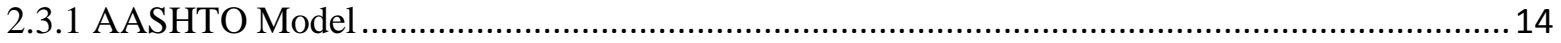

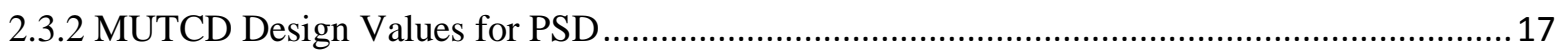

2.3.3 Hassan, Easa and Abd El Halim Model .......................................................................... 17

2.3.4 Comparison of Passing Sight Distance Models ...................................................................... 19

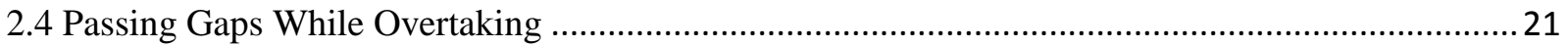

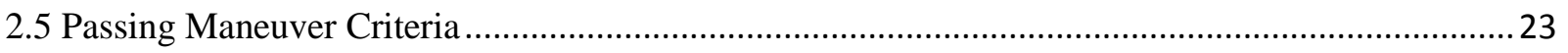

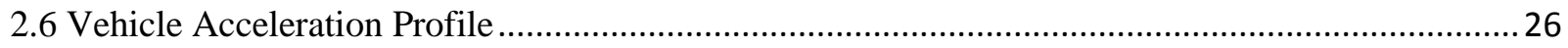

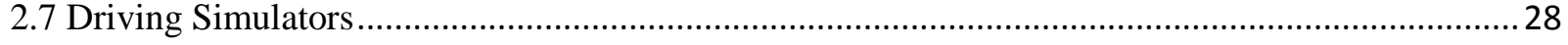

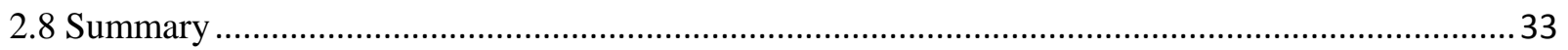

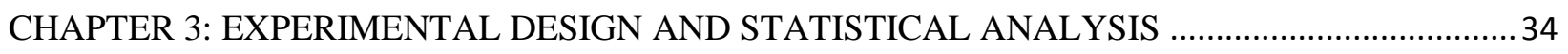

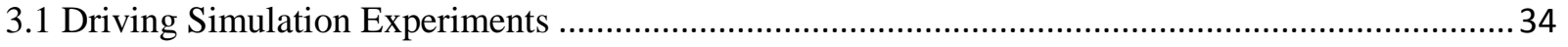

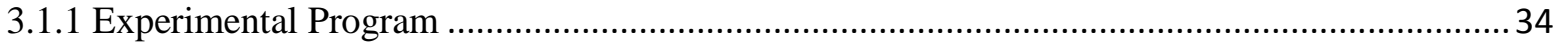




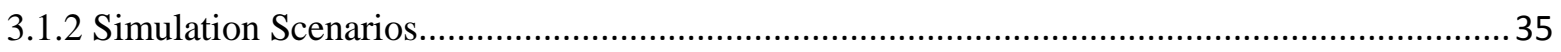

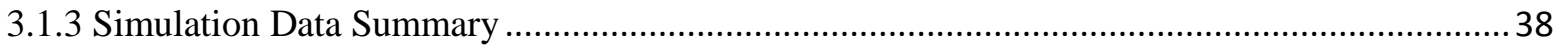

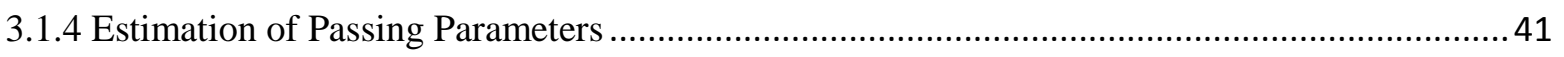

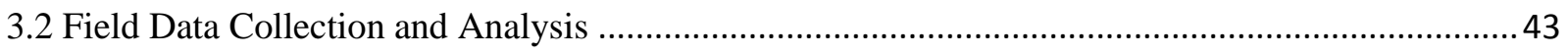

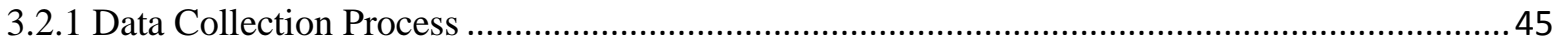

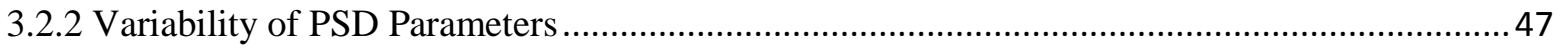

3.2.3 Comparison of Field and Driving Simulator Results ........................................................ 50

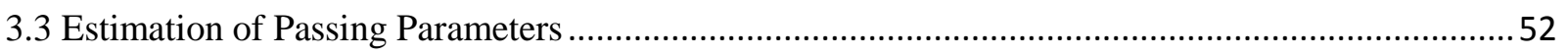

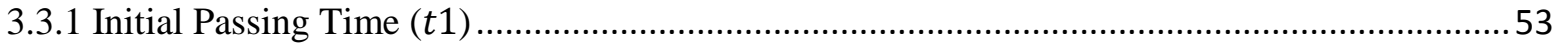

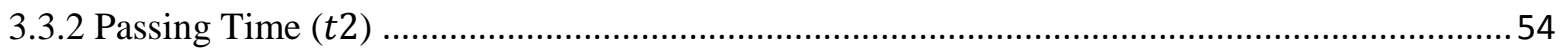

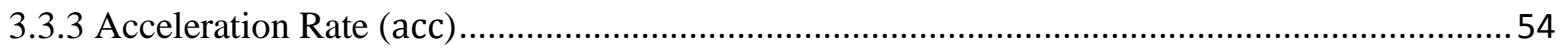

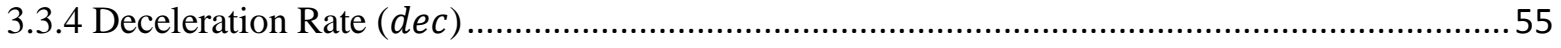

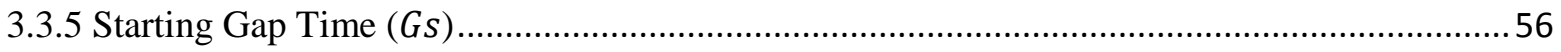

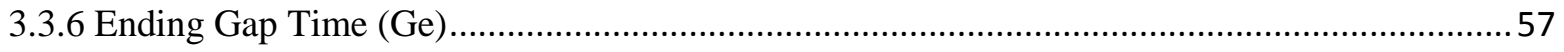

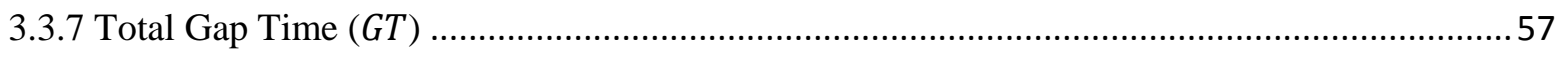

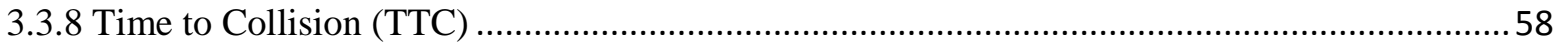

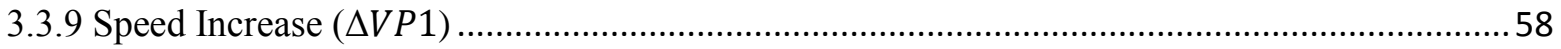

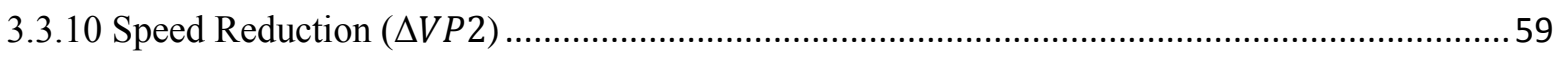

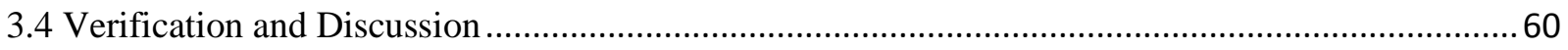

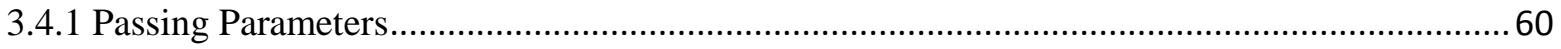

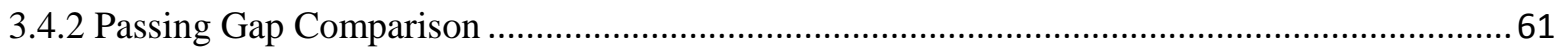

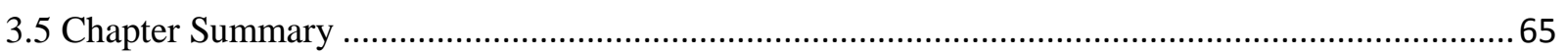

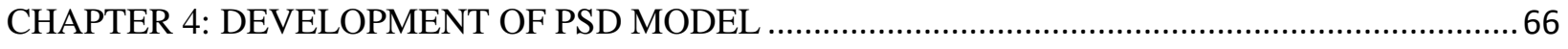

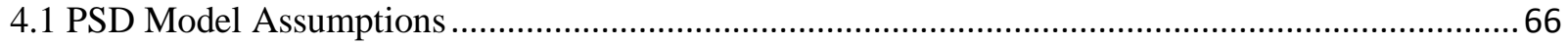

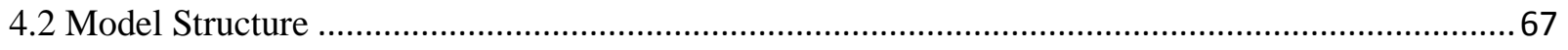

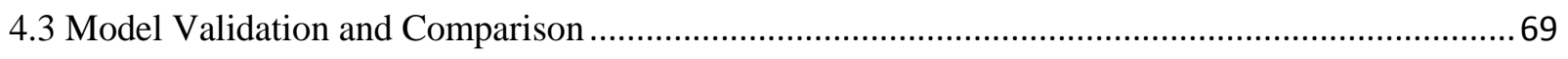

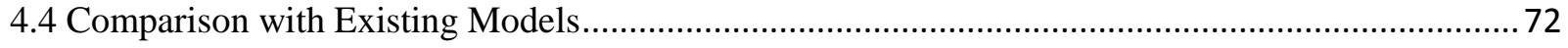

4.5 Validation of the Proposed PSD Model ...................................................................................... 74

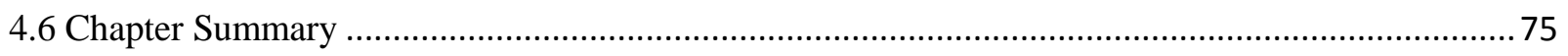

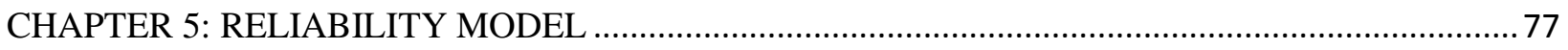

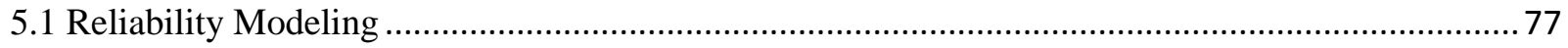




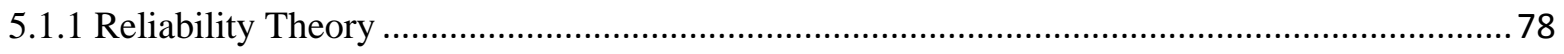

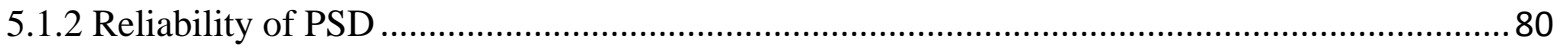

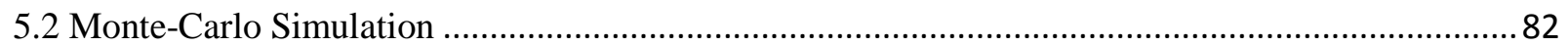

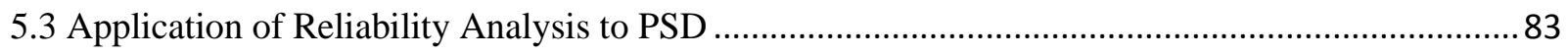

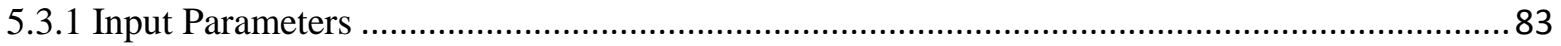

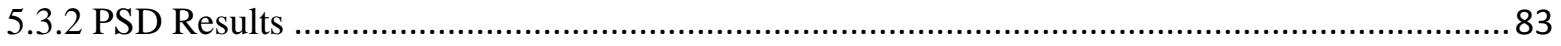

5.4 Application of the Monte Carlo Simulation Method ............................................................... 84

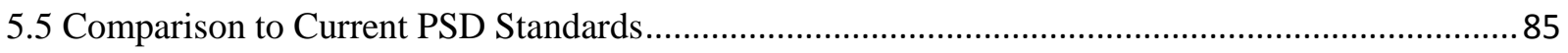

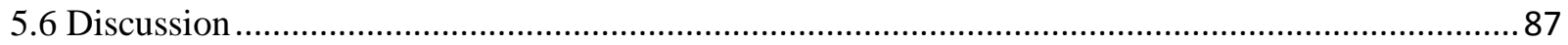

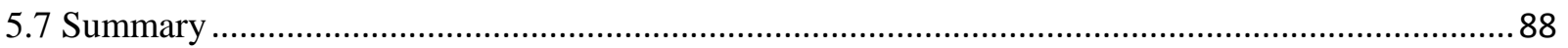

CHAPTER 6: DEVELOPMENT OF AN IN-VEHICLE PASSING COLLISION WARNING SYSTEM

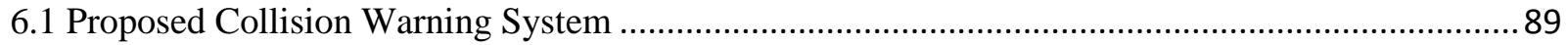

6.2 Algorithm for the Passing Collision Warning System ............................................................ 91

6.3 Determining the Location of the Opposing Vehicle .................................................................95

6.4 Determining the Location of the Passing Vehicle........................................................................... 98

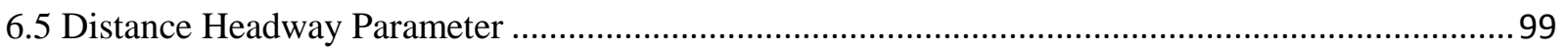

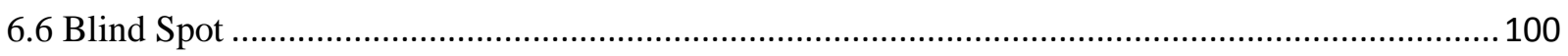

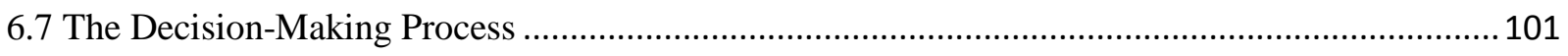

6.8 Alternative Method for Initial Decision................................................................................... 102

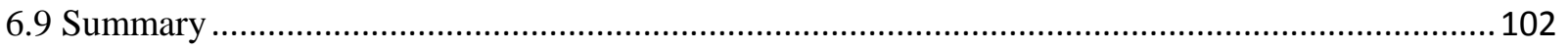

CHAPTER 7: DEVELOPMENT OF THE SIMULATION ENVIRONMENT AND VALIDATION ... 104

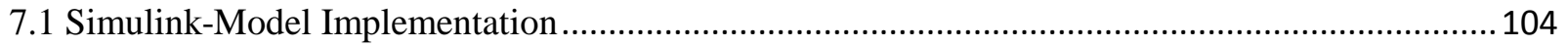

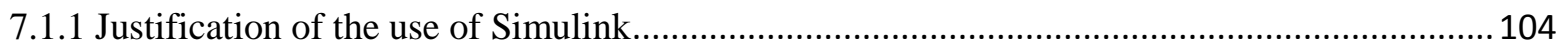

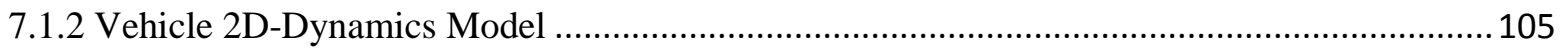

7.1.3 Simulink-Model of Vehicle Steerability ......................................................................... 106

7.1.4 Simulink Model Structure …......................................................................................... 111

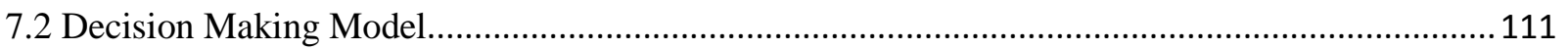

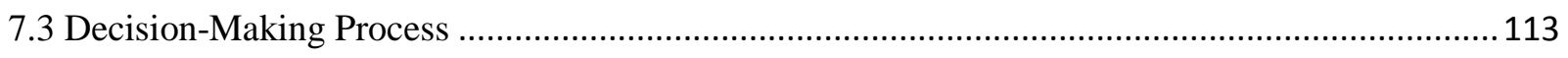

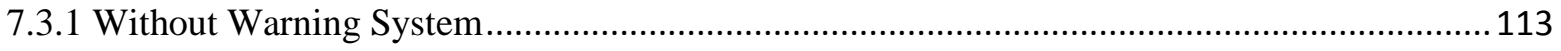

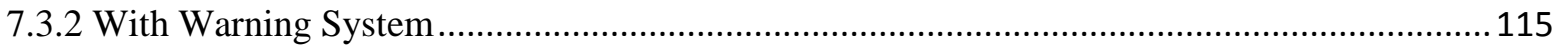


7.4 Application Example for Without Warning Model ................................................................. 116

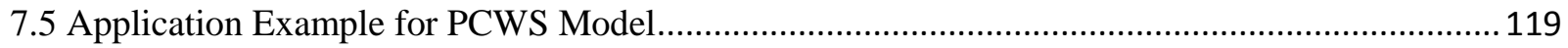

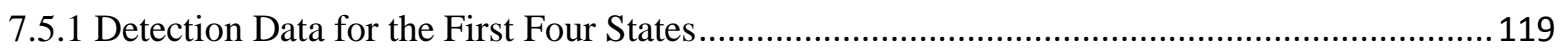

7.5.2 Passing Vehicle Overtaking Characteristics and Data Processing ........................................ 121

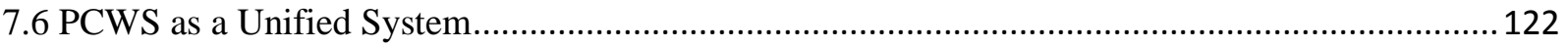

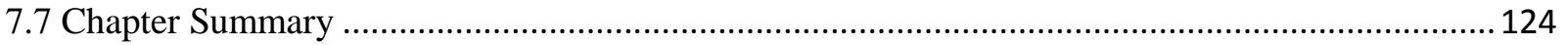

CHAPTER 8: CONCLUSIONS, CONTRIBUTIONS, AND RECOMMENDATIONS ........................125

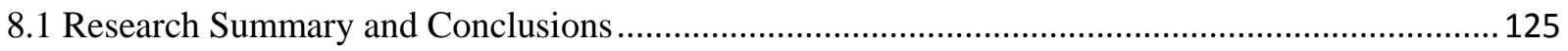

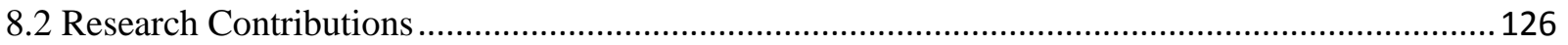

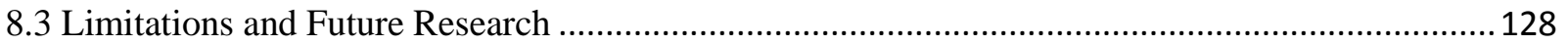

Appendix A: Copies of Consent Agreement and Driver Information Sheet......................................... 130

Appendix B: Questionnaire Form for Test Driver .......................................................................... 133

Appendix C: Simulation Scenarios 1 \& 2 for Passing Situation............................................................... 134

Appendix D: Simulation Scenarios 3 \& 4 for Passing Situation ......................................................... 155

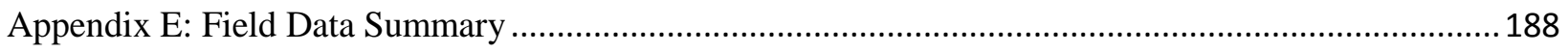

Appendix F: Simulink Library Model Description ........................................................................... 191

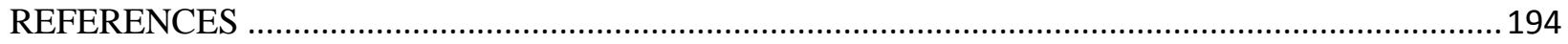




\section{LIST OF TABLES}

TABLE 2. 1: COMPARISON OF THE PSD VALUES (M) FROM VARIOUS PSD MODELS...................................................19

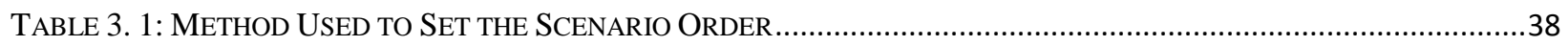

TABLE 3. 2: SUMMARY OF DRIVING PARAMETERS FROM STISIM (DESIGN SPEED 80 KM/H) ....................................39

TABLE 3. 3: COMPARISON OF DRIVING PARAMETERS FOR SCENARIOS With AND Without AUdible WARNingS

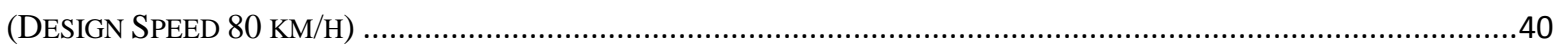

TABLE 3. 4: RESUltS FOR PASSING PARAMETERS USING DRIVING SiMULATIONS (DESIGN SPEED 80 KM/H) ...............41

TABle 3. 5: Results For PASSing PARAMETERS USING DRIVING Simulations (DESIGN SPEED 80 KM/H) ...............42

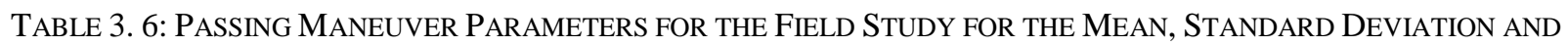

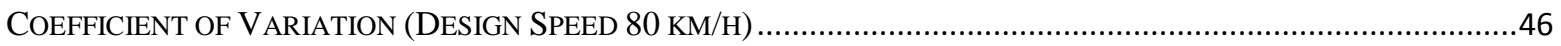

TABLE 3. 7: COMPARISON OF THE ELEMENTS OF THE PSD MODEL (DESIGN SPEED 80 KM/H) .................................47

TABle 3. 8: PASSING MANEUVER PARAMETERS FOR THE FIELD STUdY AND RESUlTS OF STATISTICAL SigNificANCE

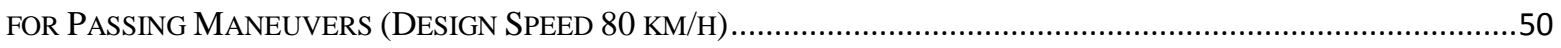

TABle 3. 9: COMPARISON BETWEen the DATABASES OF THE FIELD AND DRIVING SimUlator StUdies (Design

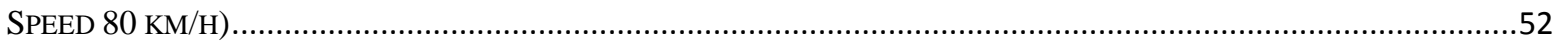

TABLE 3. 10: COMPARISON BETWEEN THE DATABASES FOR THE FIELD STUDY AND DRIVING SIMULATOR STUDY

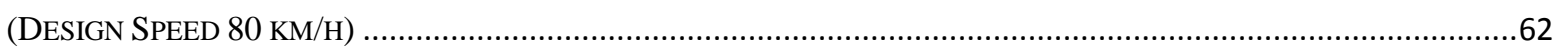

TABLE 3. 11: COMPARISON OF PASSING GAP PARAMETERS BETWEEN THE NO-WARNING AND WARNING SiMULATOR

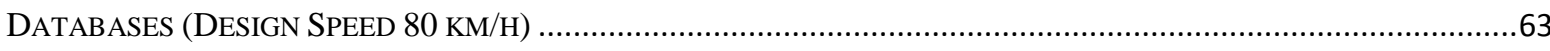

TABLE 3. 12: COMPARISON OF PASSING PARAMETERS BETWEEN THE NO-WARNING AND WARNING SiMULATOR

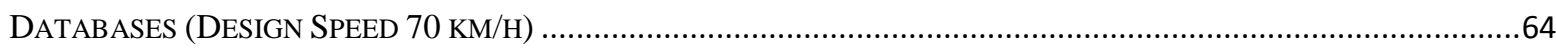

TABle 3. 13: COMPARISON OF PASSING PARAMETERS BETWEEN THE NO-WARNING AND WARNING SiMULATOR

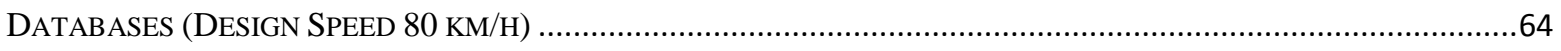

TABLE 3. 14: COMPARISON OF PASSING PARAMETERS BETWEEN THE NO-WARNING AND WARNING SIMULATOR

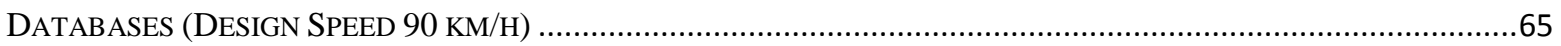

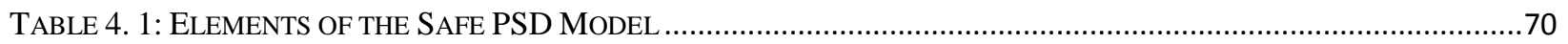

TABle 4. 2: COMPARISON BetweEn Estimated PSD Model AND OBSERVEd DRIVING SimUlator Data (Design

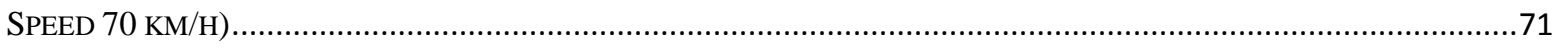

TABLE 4. 3: COMPARISON BETWEEN ESTIMATED PSD MODEL AND OBSERVED DRIVING SiMULATOR DATA (DESIGN

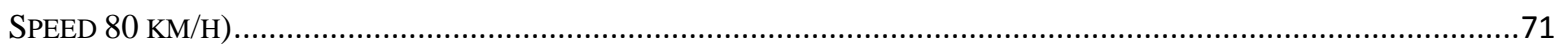

TABle 4. 4: COMPARISON BETWEen Estimated PSD MODEL AND OBSERVED DRIVING SiMUlator DATA (DESIGN

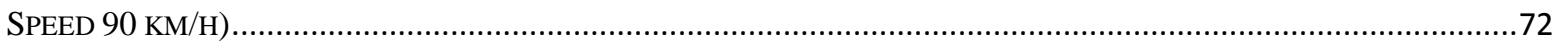

TABLE 4. 5: COMPARISON OF PSD VALUES (M) FROM VARIOUS PSD MODELS ......................................................73

TABLE 4. 6: COMPARISON BETWEEN THE ESTIMATED PSD MODEL AND THE OBSERVED FIELD DATA (DESIGN SPEED

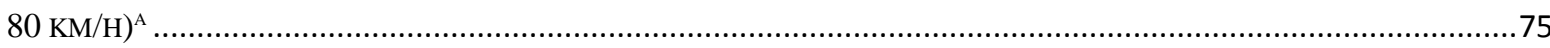

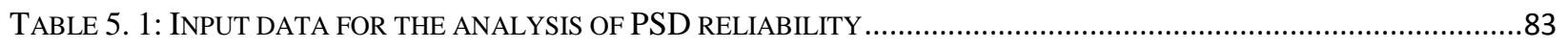

TABLE 5. 2: RESULTS OF THE RELIABILITY PSD SUPPLY VALUES AT DIFFERENT CONFIDENCE LEVELS .........................84

TABLE 5. 3: MONTE CARLO SiMULATION ReSUltS FOR PSD DESIGN VALUES ............................................................84

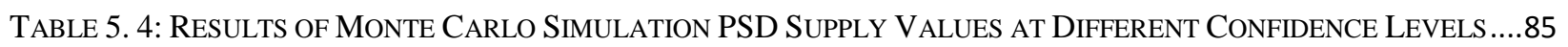

TABLE 5. 5: COMPARISON THE Proposed Reliability AND MONTE CARLo SiMUlation Models With DifFERENT

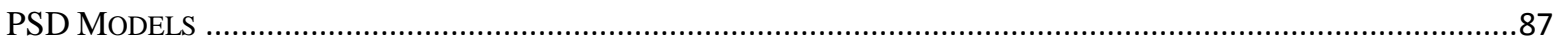

TABle 5. 6: Comparison OF REliability and Monte CARlo Simulation Model ReSUltS ..................................88 


\section{LIST OF FIGURES}

FIGURE 1. 1: RESEARCH METHODOLOGY FLOW CHART (THE NUMBER ABOVE THE BOX IS CHAPTER NUMBERS) .............6

FigURE 2.1: CRASH AVOIDANCE SYSTEM CATEGORIES (BURGETT, 1994) .....................................................................

FIGURE 2. 2: AASHTO MODELING FOR THE PASSING MANEUVER (AASHTO, 2004) ................................................15

FIGURE 2. 3: COMPARISON OF THE PSD VALUES FROM VARIOUS PSD MODELS (NCHRP, 2005) ............................20

FIGURE 2. 4: COMPONENTS OF THE PASSING SIGHT DISTANCE CRITERIA IN DIFFERENT COUNTRIES (HARWOOD ET AL.,

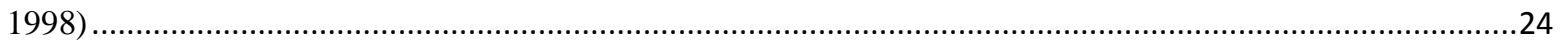

FIGURE 2. 5: THE EXPERIMENTAL CAR USED FOR SIMULATION AT RYERSON UNIVERSITY ..........................................32

FIGURE 2. 6: SCREEN SHOT FROM THE STISIM DRIVING SIMULATOR .......................................................................32

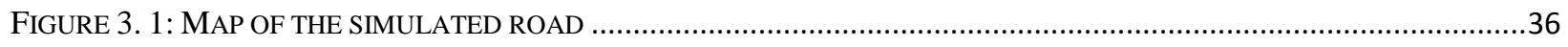

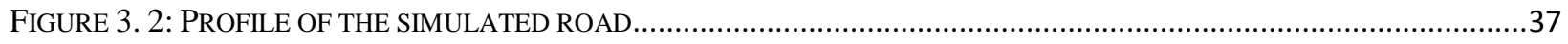

Figure 3. 3: Frequency Distributions of Observed Passing Maneuver Field Data: (A) Passing Vehicle SPeEd M/s; (B) Impeding Vehicle Speed m/s, (C) Opposing Vehicle Speed m/s, AND (D) THe Time of Initial MANEUVER SEC.

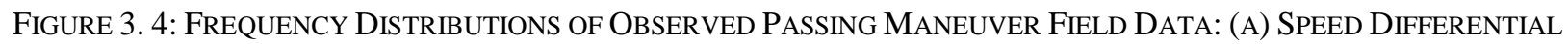
M/s; (B) Time Passing Vehicle Travels in the Left Lane SeC; (C) Average AcCeleration M/s²; (D)

StART GAP TIME SEC; (E) END GAP TIME SEC; AND (F) TIME TO COLLISION SEC ...........................................49

FIGURE 4. 1: COMPARISON OF PSD VALUES (M) FROM VARIOUS PSD MODELS ....................................................73

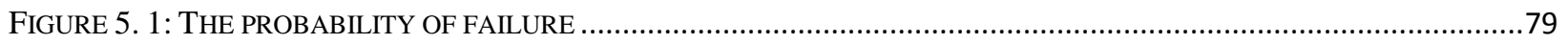

FigURE 5. 2: ORIGINAL SPACE AND STANDARD SPACE (HALDAR AND MAHADEVAN, 2000).....................................79

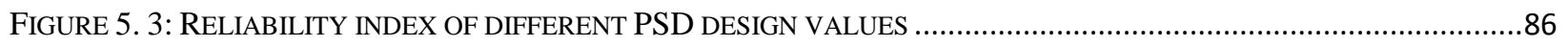

FIGURE 5. 4: COMPARISON OF PSD MODELS FOR DIFFERENT CONFIDENCE LEVELS ................................................86

FIGURE 6. 1 CALCULATING THE DISTANCE AND ANGLE AT EACH TIME INTERVAL ……..........................................90

FIGURE 6. 2: FLOW CHART FOR THE PASSING COLLISION WARNING ALGORITHM ......................................................94

FIGURE 6. 3: SCHEMATIC OPPOSING VEHICLE LOCATIONS AT DIFFERENT TIME INSTANCES.......................................96

FIGURE 6. 4: CALCULATING THE DISTANCE DF AND THE OFFSET WF

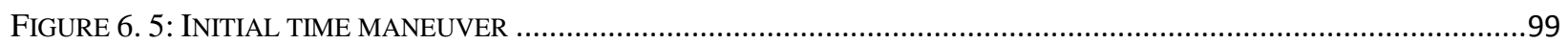

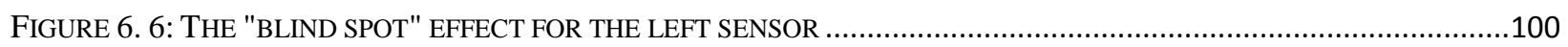

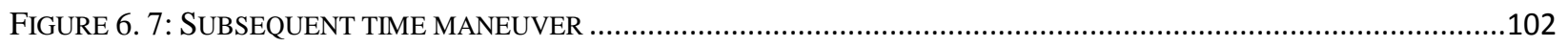

FiguRE 7. 1: SiMULINK MODEL FOR COLLISION WARNING SYSTEM DEVELOPMENT: (A) GENERAL INTERFACE OF 3-

VEHICLE MODEL, (B) SIMULINK STRUCTURE OF SINGLE VEHICLE PLANE MODEL .............................................108

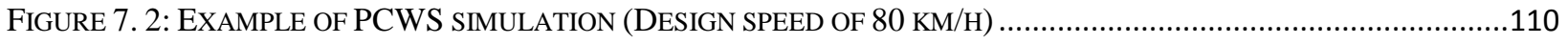

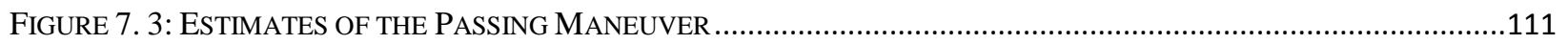

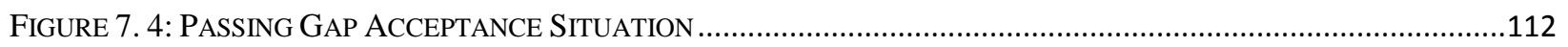

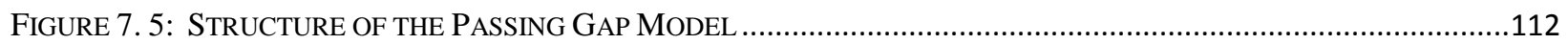

FigURE 7. 6: DeCISION MAKING AND STEERING CONTROL STATEFLOW: ..........................................................115

FiguRE 7. 7: SiMULATION OUTPUT DATA: (A) PASSING VEHICLE ACCELERATION WHILE OVERTAKING, (B) PASSING VEHICLE LATERAL DISPLACEMENT ON TWO-LANE HIGHWAY, (C) PASSING VEHICLE YAW TURNING, (D) LONGITUDINAL VEHICLE VELOCITIES, (E) DISTANCE BETWEEN THE PASSING AND OPPOSING VEHICLES .............118

FIGURE 7. 8: CALCULATING DISTANCE AND ANGLE AT EACH TIME INTERVAL …….................................................120

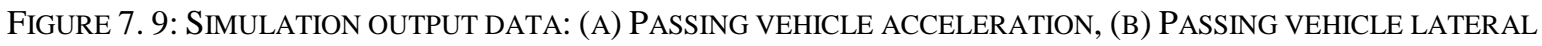


DISPLACEMENT ON TWO-LANE HIGHWAY, (C) PASSING VEHICLE YAW TURNING, (D) SENSOR MEASUREMENTS FOR APPROACHING VEHICLES, (E) OPPOSING VEHICLE VELOCITY, (F) VELOCITY ESTIMATION ERROR FOR THE OPPOSING VEHICLE, (G) PREDICTED SAFETY MARGIN TIME. 


\section{LIST OF SYMBOLS}

The following symbols are used in this thesis:

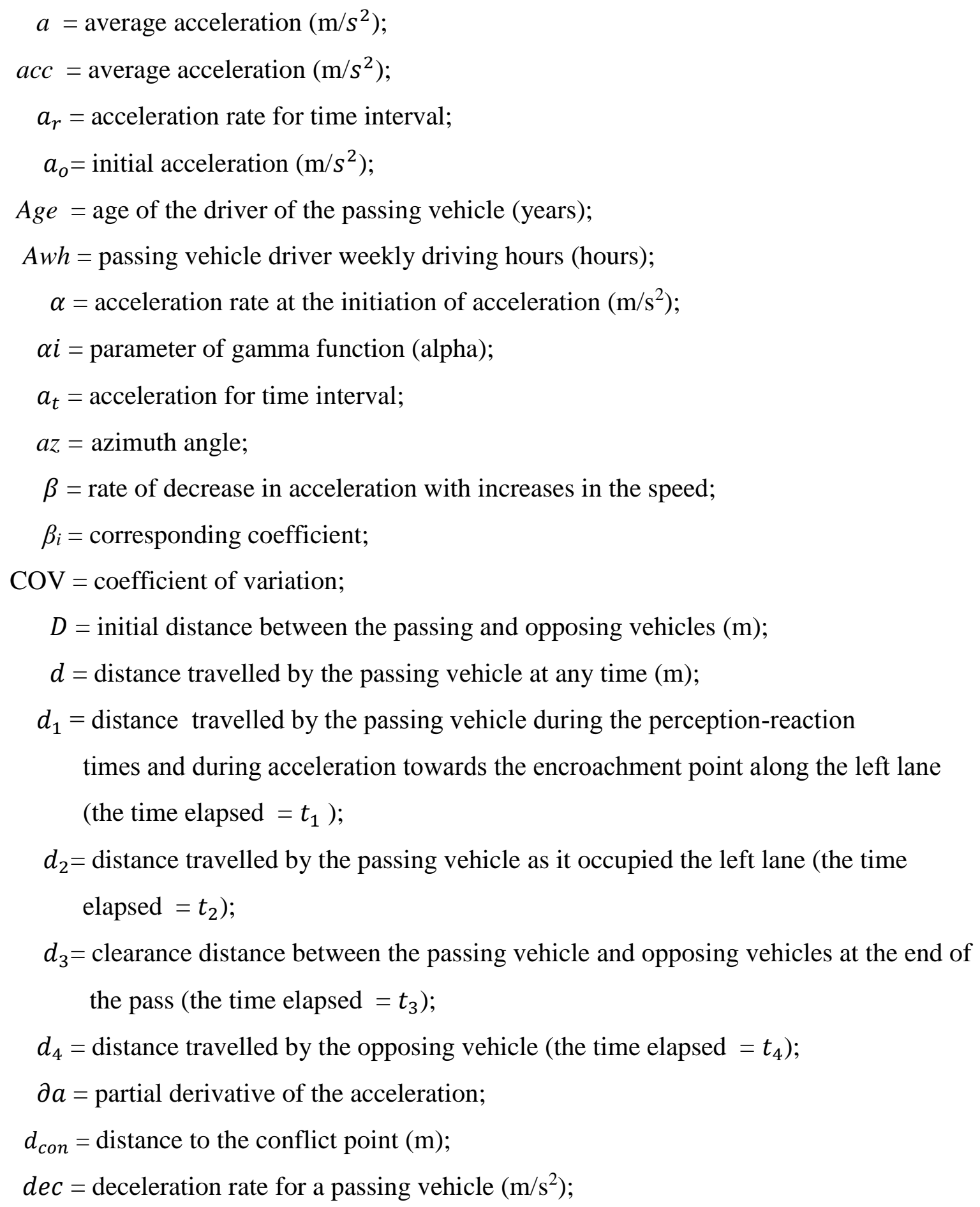


$d f=$ relative distance between the passing and opposing vehicles (m);

$d_{n}=$ distance crossed by the approaching vehicle in the time interval;

$d p_{n}=$ distance travelled by the passing vehicle during time interval;

$d_{o}=$ initial distance $(\mathrm{m})$;

$\delta_{\mathrm{r}}=$ the coefficient that takes into account the inertia of the transmission's rotating masses;

$d_{s}=$ angle of the detection sensor;

$d_{t}=$ distance for time interval;

$\partial t=$ partial derivative of the time;

$\partial v=$ partial derivative of the velocity;

$d v_{n}=$ distance travelled by the opposing vehicle during time interval;

$\Delta V_{P 1}=$ speed increase $(\mathrm{m} / \mathrm{s})$;

$\Delta V_{P 2}=$ speed reduction $(\mathrm{m} / \mathrm{s})$;

Exp = passing vehicle driver driving experience (years);

$\mathrm{F}^{(\mathrm{e})}{ }_{\mathrm{x}}=$ generalized external force factors along the vehicle $\mathrm{x}$-axis of the vehicle;

$\mathrm{F}^{(\mathrm{e})}{ }_{\mathrm{y}}=$ generalized external force factors along the vehicle $\mathrm{y}$-axis of the vehicle;

$\mathrm{g}=$ acceleration due to gravity $\left(9.81 \mathrm{~m} / \mathrm{s}^{2}\right)$;

$\mathrm{G}=$ grade in slope $(\%)$;

$D M(i)=$ choice indicator variable with a value of 1 if the driver wishes to pass and 0 if the driver does not wish to pass;

$G_{e}=$ ending gap (sec);

Gender $=$ gender of the driver of the passing vehicle ( 0 for males and 1 for females);

$G_{\mathrm{o}}=$ transition time at the end of the passing maneuver (s);

$G_{p}=$ latent variable for passing gap acceptance;

GPS = Global Positioning System;

$G_{s}=$ starting gap $(\mathrm{sec})$

$G_{T}=$ total passing gap (sec);

$\Gamma=$ gamma function;

$h=$ minimum headway involving passing vehicles and impeding vehicles along the end of completed or aborted passing maneuvers with a minimum headway among the passing and oncoming vehicles towards the end of the completed or the 


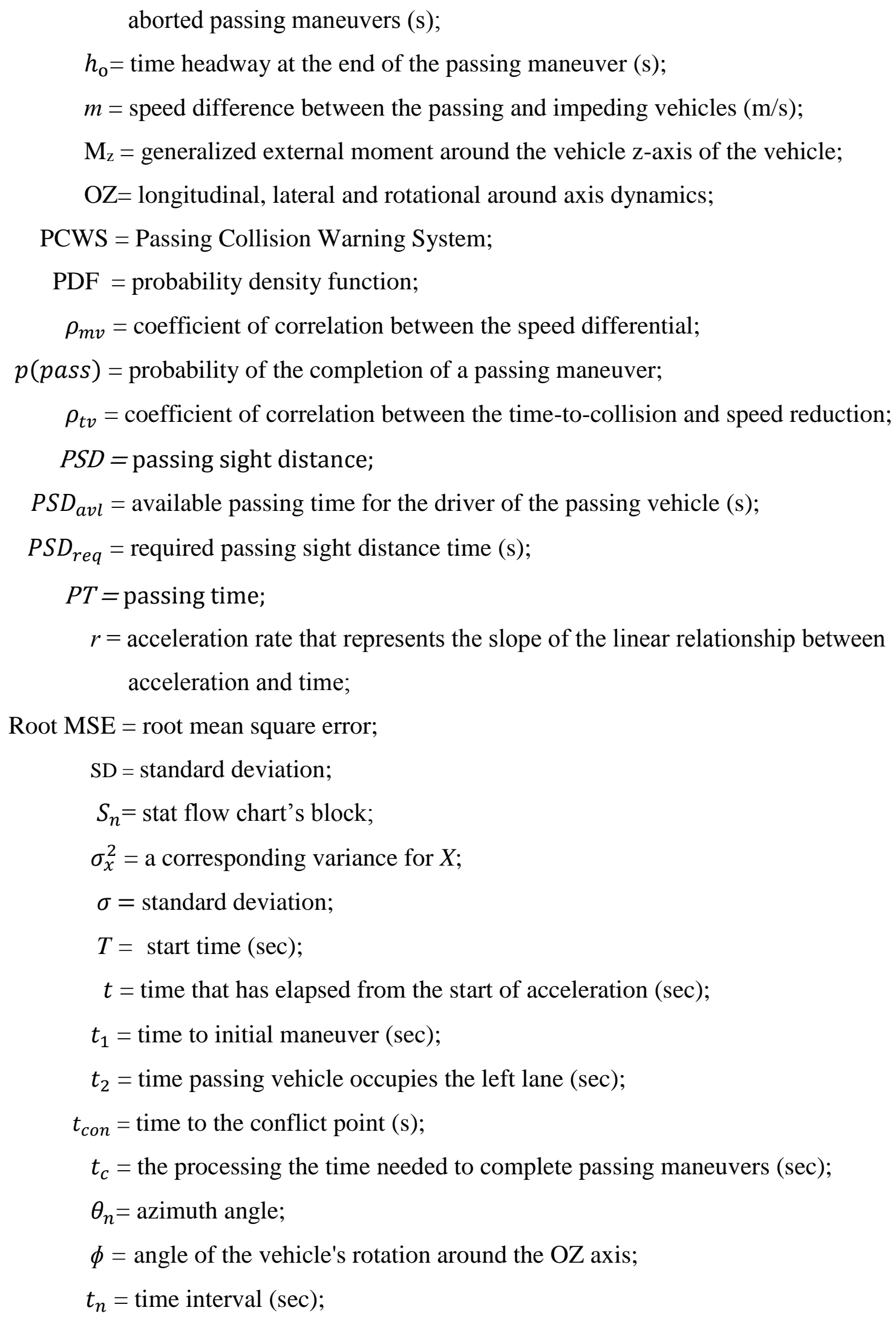


$t_{o}=$ opposing vehicle time $(\mathrm{sec})$

$t_{\text {opposing }}=$ estimate of the time required for each detected vehicle to reach the conflict point;

$t_{\text {passing }}=$ estimate of the time required for the passing vehicle to complete the passing maneuver;

$T T C=$ time to collision $(\mathrm{sec}) ;$

$\mu=$ mean value;

$\mu_{x}=$ the mean value;

$v=$ average speed of the passing vehicle $(\mathrm{km} / \mathrm{h})$;

$v_{\text {con }}=$ speed of the vehicle at the conflict point $(\mathrm{m} / \mathrm{s})$;

$v_{d}=\operatorname{design}$ speed $(\mathrm{km} / \mathrm{h})$;

$V_{i}=$ impeding vehicle speed $(\mathrm{m} / \mathrm{s})$;

$v_{0}=$ initial speed of the vehicle $(\mathrm{m} / \mathrm{s})$;

$v_{m}=$ maximum speed of the vehicle $(\mathrm{m} / \mathrm{s})$;

$V_{o}=$ opposing vehicle speed $(\mathrm{m} / \mathrm{s})$;

$v_{o p p}=$ opposing vehicle speed during the passing maneuver $(\mathrm{m} / \mathrm{s})$;

$V_{p}=$ passing vehicle speed $(\mathrm{m} / \mathrm{s})$;

$v_{t}=$ speed for time interval;

$\mathrm{V}_{\mathrm{Cx}}=$ velocities along the $\mathrm{x}$-axis of the local coordinate system in mass center $\mathrm{C}$;

$\mathrm{V}_{\mathrm{Cy}}=$ velocities along the $\mathrm{y}$-axis of the local coordinate system in mass center $\mathrm{C}$;

$w_{f}=$ the offset distance $(\mathrm{m})$;

$X_{i}=$ the independent variable;

$\mathrm{Z}=$ Kolmogorov-Smirnov test; 


\section{CHAPTER 1: INTRODUCTION}

This chapter presents the background, a statement of the problem, and the scope and objectives of this research study. The thesis organization and the research methodology used to achieve the study objectives are also described.

\subsection{Research Background}

Passing-related collisions are a serious traffic safety issue. Adequate passing sight distance (PSD) is necessary to ensure the safety of passing drivers on two-lane highways. The passing maneuver can be completed when there is a safe clearance distance between the passing and opposing vehicles and the driver is able to return to the right lane. Collisions occur when the driver of the passing vehicle misjudges the situation in regards to the response time, distance, and speed of the opposing vehicle. In other words, collisions occur as a result of miscalculating safe passing conditions. Two-lane highways are the most common type of highways in Canada. Canada has over a million kilometres of two-lane roads. The National Highway System (NHS) is composed of approximately 38,000 kilometres of these roads. Road transportation is critical for passenger and freight transportation, transportation within cities and between cities, transportation between provinces, and trade between Canada and the United States. The Canadian road transportation infrastructure faces many challenges. Some of these challenges, such as its wide land mass, harsh

climate, a large amount of urbanization, and high trade dependency, are unique to Canada. Others, such as road safety issues, environmental factors, and an aging road and highway infrastructures, are shared by other countries (Transport Canada, 2016).

There is always a risk of head-on collisions when conducting passing maneuvers. In Canada, passing (head-on) collisions accounted for approximately 30\% of all collisions reported in 2010 (Rural Road Safety in Canada, 2010). In the USA, head-on collisions accounted for approximately $20 \%$ of fatal collisions occurring on rural two-lane highways and passing is one of the primary 
causes of these types of collisions (Persaud et al., 2004). Passing maneuvers are also regarded as one of the most difficult maneuvers on rural two-lane highways (Mcknight et al., 1970) due to the changes in speed and position necessary for safe completion. Therefore, the design of adequate PSD for two-lane highways is critical (Farah, 2013).

Vehicle telematics are a contemporary type of intelligent transportation systems (ITS) intended to help with transport and traffic management. If improperly designed, these technologies can impair driving performance instead of helping (ITS America, 2002; TC, 2003). This study involves an ITS which includes a collision warning system installed in the passing vehicle to detect vehicles in the opposing lane of two-lane highways. The vehicles are detected using a radar sensor or laser scanner. Once a vehicle is detected, the system activates a warning message that is displayed for the driver, enabling them to avoid a head-on collision by taking the appropriate action (completing or aborting the passing maneuver).

The passing collision warning system (PCWS) is intended to help passing drivers detect a safe passing gap to complete the passing maneuver. The system identifies the closest impeding vehicle in the right lane of two-lane highways using a radar sensor or laser scanner, and measures its position and speed. The system also identifies the closest opposing vehicle in the left lane and measures its position and speed at four consecutive time intervals to determine its relative position and speed. The system algorithm then provides an estimation of the distance and time needed for the passing vehicle to accelerate and complete the passing maneuver. Safe driving requires drivers to be alert, constantly monitoring their environment and properly responding to the movements of other vehicles. Collisions result in costly property damage and the loss of human lives. Numerous driver handling factors can lead to collisions, including incorrect driver reaction time and driver inattention (Brown et al., 2001). The impact of these factors should be considered in passing collision warning systems (PCWS), improving road safety. 


\subsection{A Statement of the Problem}

Slow moving vehicles can cause delays for faster moving vehicles on two-lane highways. Passing maneuvers allow these fast moving vehicles to minimize these delays and travel at the speed they desire. In order to pass a slow moving vehicle, the fast moving vehicle must occupy the opposing lane. This is a safety and operation hazard as the driver must risk the possibility of collisions with opposing traffic. Accidents caused by passing maneuvers are generally more severe than accidents caused by other maneuvers (Molinero et al., 2008). In order to complete the passing maneuver, the driver of the passing vehicle must increase the speed of the vehicle to pass the slow moving vehicle and return to the right lane before colliding with oncoming traffic which may be travelling at high speeds.

The risk of collision during passing maneuvers is what makes driver behaviour different than in other situations (i.e. free-flow or following situations). Passing is only permitted in zones in which the passing sight distance (PSD) required is smaller than the available sight distance. PSD can be defined as the minimum distance needed to safely complete a passing maneuver when there is a vehicle approaching in the opposing lane. PSD is usually estimated using various passing maneuver models. These models vary widely in their assumptions regarding passing vehicle acceleration and speed variation and have not been evaluated using field data, making PSD difficult to determine.

When making the decision to pass, drivers take into account their own behaviour and past experiences, as well as their perception of the road and traffic conditions. Gray et al. (2005) claim that these passing decisions are based on the driver's perception of the time to collision and distance from oncoming traffic. Using a driving simulator experiment with only 18 participants, the authors observed that passing errors increased when the decision to pass was solely based on the perception of the distance from oncoming traffic. It is very difficult for drivers to gauge the speed of opposing vehicles due to the very low expansion rate of objects situated far away from the observer. Basilio et al. (2015) and Morice et al. (2015) proposed passing decision models based on passing ability affordance. Passing ability affordance is defined as the difference between the 
minimum speed needed to pass the impeding vehicle and the maximum speed of the vehicle at that particular time. Using a driving simulator experiment with only 16 participants, the authors observed that there was a decrease in passing attempts along with the possibility of safe passing maneuver and concluded that drivers are unable to accurately perceive whether or not it is safe to pass an impeding vehicle.

In this study, a passing sight distance equation based on the mechanics of passing maneuvers (used to evaluate PSD criteria) and the behaviour of passing drivers was developed. Reliability analysis was used to evaluate the performance of the proposed PSD equation using the application example. The results of the sensitivity analysis indicate that the proposed PSD equation is functioning properly. Once the required PSD has been predicted, the proposed passing collision warning system (PCWS) can be used. These systems can help reduce driver judgment errors during passing maneuvers. The proposed PCWS prototypes were implemented for real-life driving situations using Simulink MATLAB. The systems ware calibrated to be effective. This means that the system corresponds with actual driver behaviour. The research presented in this dissertation provides the solutions for the development of a PCWS for passing maneuvers. This study is based on driving simulations and the parameters were calibrated using field data. Experimental data is necessary to produce a PCWS that can be implemented in real driving conditions. In order for this system to prevent driver errors, the safe passing thresholds and relative speed were determined in this study.

\subsection{Scope and Objectives}

The scope of this research is the safety issue of head-on collisions on rural two-lane highways resulting from drivers attempting to pass impeding vehicles without sufficient information regarding the relative position and speed of the opposing vehicle.

The primary objectives of this research are:

1. To develop an experimental design that corresponds to driver behaviour on two-lane highways using the STISIM driving simulator and field studies. 
2. To estimate passing parameters using linear regression models that consider driver behaviour and study the factors that affect the decision to pass an impeding vehicle.

3. To develop a passing sight distance model that includes driver behaviour parameters.

4. To conduct reliability analysis of the proposed passing sight distance model and compare the results with current standards.

5. To develop the necessary algorithms for the passing collision warning system that assists drivers in the decision making of passing safely.

6. To develop simulation scenarios using Simulink MATLAB to implement real-life driving situations in order to examine the proposed passing warning system and evaluate the reliability of the system under different conditions.

The proposed warning system is only applicable for straight alignments. In addition, this dissertation does not cover circuit designs for the system or offer a warning system as a commercial product.

\subsection{Dissertation Methodology and Organization}

The research methodology and organization of this dissertation are presented in Figure 1.1. The content of each chapter is outlined below:

Chapter 1 presents research background, statement of the problem, scope and objectives, and research methodology and dissertation organization.

Chapter 2 presents a literature review which covers framework components such as a human factor study, and the development of in-vehicle collision warning algorithms. This chapter also identifies the limitations of existing passing maneuver studies and the development of passing models.

Chapter 3 includes the experimental design using a driving simulator for different scenarios and data collection. Also, it involves the description of the field data conducted in different contraries. The linear regression models for passing parameters are presented, including initial time, passing time and average acceleration rate. 
Chapter 4 presents the modeling of passing sight distance including driver behaviour and PSD parameters.

Chapter 5 presents a reliability-based PSD model using the First-Order Second-Moments method and a Monte Carlo Simulation. The reliability analysis and Monte Carlo simulation were used to evaluate the performance of the proposed PSD model. Current PSD standards were also evaluated and compared with the proposed models.

Chapter 6 presents the framework for an In-Vehicle Passing Warning Collision System, including the development of a passing collision warning algorithm (logic) and the integration of the developed passing model with the proposed passing collision warning algorithms.

Chapter 7 presents the implementation of the Simulink model for both passing with and without PCWS models. Application examples and the validation results for the proposed algorithm are also presented.

Chapter 8 summarizes the research contributions and presents concluding remarks about the experimental and analytical study. Finally, recommendations for future study are presented.

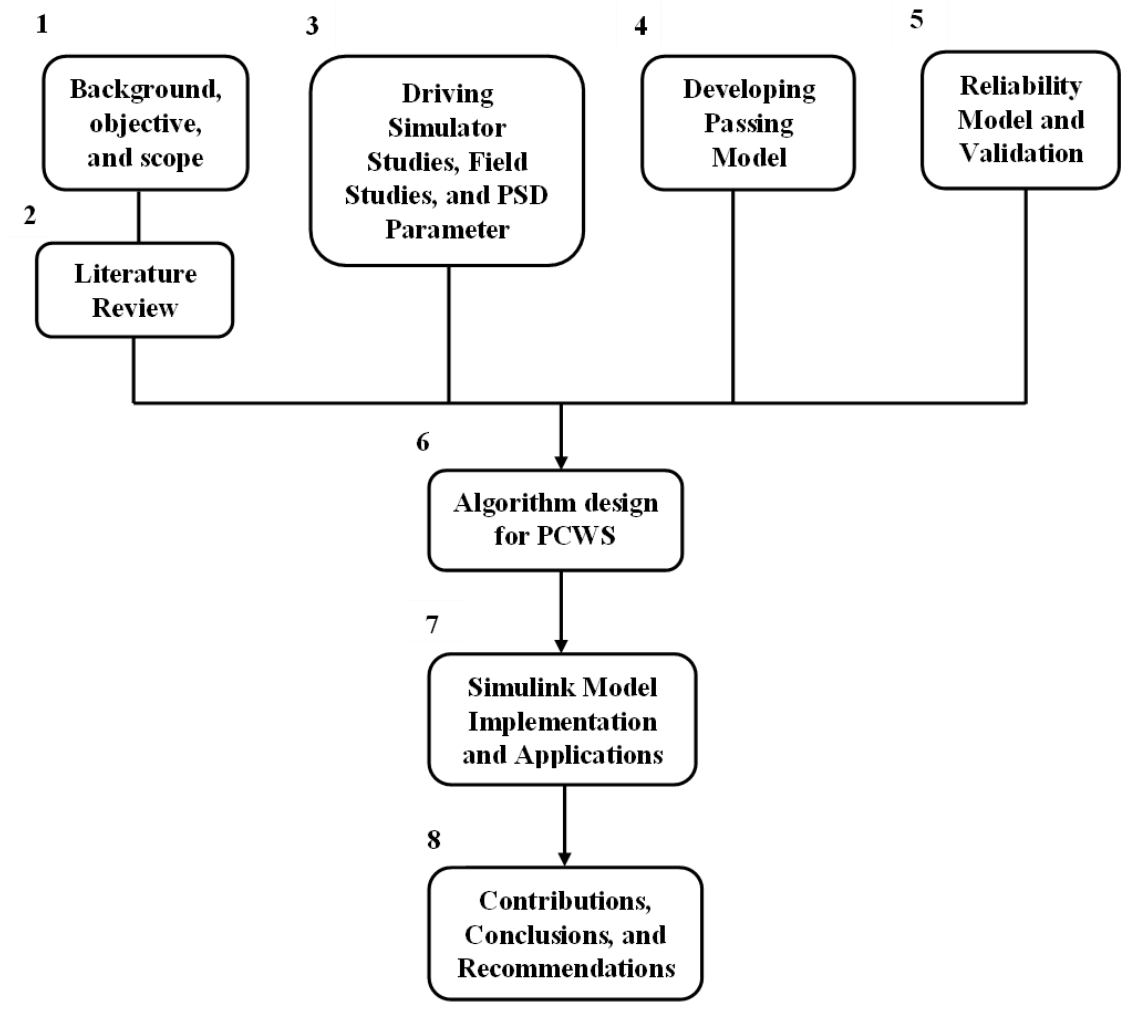

Figure 1. 1: Research methodology flow chart (the number above the box is chapter numbers) 


\section{CHAPTER 2: LITERATURE REVIEW}

This chapter focuses on the analysis of human factors during passing maneuvers and the causes of head-on collisions on two-lane highways. This chapter also describes existing collision warning systems and the human factors that should be taken into account when developing the algorithms for passing collision warning systems. A review of existing passing sight distance models, passing gap acceptance models and driving simulator techniques is also presented.

\subsection{Human Factors and Collision Avoidance Systems}

Current advances in computer, sensor, and digital processing technologies have led to the development of affordable Collision Avoidance Systems (CAS) which can assist drivers in risky situations. CASs are divided into three categories (see Figure 2.1) based on the mechanism of the intervention. The first category includes advisory systems used in situations that do not require any urgent collision avoidance action. The second category includes warning systems that are used in pending collision situations that require action from the driver in order to avoid a collision. The third category includes the automatic control intervention systems (e.g., automatic soft braking, automatic steering and emergency braking) that involve collision situations in which the driver's intervention alone may be insufficient to avoid the collision (Mehmood, 2010).

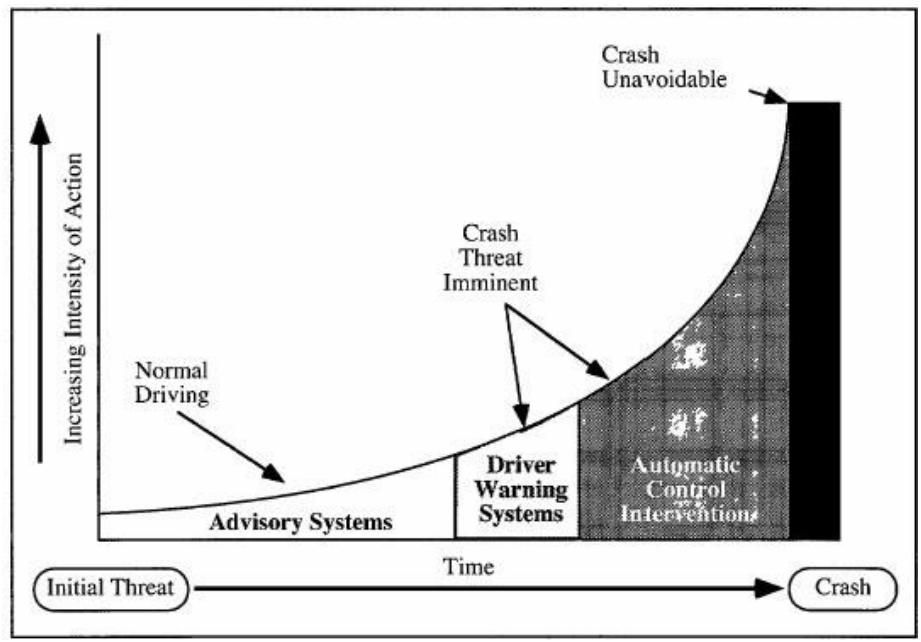

Figure 2.1: Crash Avoidance System Categories (Burgett, 1994) 
Driver errors account for up to $93 \%$ of all traffic accidents (Treat et al., 1977). The different categories of CAS are designed to tackle different types of errors. For example, driver recognition errors may be prevented by an in-vehicle advisory system that simply shows the presence of a potential hazard with proximal-traffic situations or with a traffic control advisory display. Warning systems may also help drivers with decision-making and may prevent decision-making errors (Dabbour, 2009; Taylor, 2005). Inconsistent actions made by the drivers can be addressed by automatic control intervention systems. For example, collisions that are caused by inexperienced drivers can be reduced with fully automatic control systems.

Campbell et al. (1998) emphasized the importance of human factor research in the development of In-vehicle Collision Warning Systems (ICWS). The relationship between the availability of human factors and the ICWS can be used during the warning system design process. Specifically, while warning systems offer great benefits, their efficacy depends on driver acceptance of the new in-vehicle technology, and the ability of the ICWS to integrate the information with the driving tasks and capabilities.

In-vehicle collision warning systems work by making use of sensors that are installed on the front bumper of passenger vehicles to scan the road ahead for vehicles and obstacles. Once a vehicle or obstacle is detected, the warning system determines whether or not there is a risk of collision. If there is any risk of a collision, the system warns the driver or takes the necessary steps to automatically brake. The sensor system can measure the clearance distance, the relative speed, and acceleration of the vehicle ahead through a coordinated system that uses a radio in order to transmit the vehicle speed with acceleration data (Isermann et al., 2012).

Researchers are beginning to consider several combinations of these types of technologies (sensor fusions) in order to overcome certain disadvantages (Granet et al., 2003; Smith, 2000). These systems measure the distance between the two vehicles, to a few centimeters, using the time for the signal to travel towards the vehicle ahead of it and bounce back (Granet et al., 2003). Conversely, the velocity of the vehicle ahead is determined through the measurement of the Doppler Effect along with the radar beam frequency that echoes back. The difference between the 
signals that are transmitted and received provides a measurement of how much slower or faster the vehicle ahead of it is travelling (ENG, 2001). A small digital camera watches the road ahead, continuously processing incoming information in order to track the lane markings. Certain examples are present on vehicles such as the Volvo, the BMW, the Subaru, the Honda and the Mitsubishi (ENG, 2001). Each type of vehicle has different features and functions. The nucleus of the system is the collision avoidance algorithm which receives inputs from the sensor suite, processes them and provides the necessary driver-vehicle warning response.

Designs for passing collision warning algorithms should consider many factors, including:

1) Situational and driver behaviour factors, including the driver's reaction time;

2) The spacing between the passing, impeding, and opposing vehicles;

3) The speed of the passing, impeding, and opposing vehicles; and

4) The acceleration/deceleration rates of the opposing and passing vehicles.

\subsection{Collision Warning Systems}

Collision warning systems can be categorized as kinematics-based or perceptual-based. Kinematics-based collision warning systems use the principal laws of motion and then assume driver reaction times to activate the warnings. These systems generate the warnings when the subject vehicle is within the specified minimum distance. Perceptual-based systems activate the warnings using assumed driver reaction times along with the time-to-collision (TTC) tolerance (Nilsson et al., 1991). The warning algorithm is an important component of these systems. An insufficiently designed algorithm may initiate the warning too early or too late, affecting the reliability of the algorithms (Dabbour, 2009; Mehmood, 2010).

Some researchers have attempted to develop warning systems for intersections. The vehiclemounted collision avoidance system was created by the Calspan Corporation (Pierowicz et al., 2000). This system makes use of an in-vehicle positioning system along with two $77 \mathrm{GHz}$ (later replaced with $24 \mathrm{GHz}$ ) radar sensors with rotating antennae to identify the speed of the 
approaching vehicles (using the Doppler Effect) and warn the driver of any potential conflict. The INTERSAFE research project proposed an intersection collision warning system that uses technologies such as video cameras, laser scanners, GPS, and digital mapping (Fuerstenberg and Chen, 2007; Fuerstenberg and Roessler, 2008).

In this system, video cameras capture lane markings while the laser scanners measure both the distance and speed of vehicles in the oncoming lane. In addition, sophisticated digital mapping is used to find any issues between the vehicles. If there is any incompatibility between the paths of the vehicle with the warning system and other vehicles on the road, the system activates the warning. A probabilistic model for the behaviour of all vehicles was used in order to determine the behaviour of the drivers in the vehicles detected by the system (Dabbour and Easa, 2014). The majority of the existing collision warning systems were developed to deal with rear-end collisions (Vorad, 2009). These systems use a radar-based or laser-based (LIDAR) sensor. As technology continues to improve, so does the accuracy and complexity of the algorithms that are used to notify drivers as well as automatic vehicle responses.

The majority of collision warning systems are developed by research institutes, car companies, and government agencies. The algorithms are classified based on whether they use a timeheadway, time-to-collision, or other underlying kinematic constraints. Time-headway algorithms offer a simplistic approach that is indirectly influenced by relative velocity. They are designed to be consistent with the current recommendations for safe driving. Time-to-collision algorithms predict the contact time and are sensitive to relative velocity. Algorithms that are based on kinematic constraints have significantly higher accuracy when calculating braking time based on an assumed reaction time and the vehicle's deceleration response. Smith (2000) and ENG (2001) produced newer generations of the adaptive cruise-control system. They work by determining the distance and velocity of the vehicle ahead using small onboard sensor systems (ENG, 2001; Granet et al., 2003). These systems use different ultrasonic, radar, electromagnetic or optical techniques.

In 1999, the Chinese Academy of Sciences' Intelligent Control and the Systems Engineering Centre created the Intelligent Vehicle Platform Project. This was supported by a project known as 
the Vehicular Embedded Computing Platform Project, Robotics and by the Xi'an Jiaotong University Institute for Artificial Intelligence. The project uses intelligent driver-assistance and creates safety warning systems for passenger vehicles, especially GPS with vision-based systems (Zheng et al., 2004). These systems offer real time information regarding the road, the vehicle, and the surroundings for a better and safer ride. The system architecture has three layers: the sensory layer, the decision-making layer and the human-interface layer (Zheng et al., 2004). The system notifies drivers of possible hazardous situations based on the vehicle's current position, velocity and orientation along with the road conditions and the surrounding environment.

Dabbour and Easa (2014) developed a collision warning system to assist right-turning drivers at rural intersections. The system used a radar sensor in order to measure the location, speed, and acceleration of the approaching vehicle on the major road. The algorithm of the system is based on acceleration profiles established using experimental data collected by using a GPS data logger device. This device was used to record the position and speed of different right-turning vehicles at 1s intervals.

Passing collisions (head-on) on two-lane highways occur when a vehicle attempts to pass a slower moving vehicle by travelling in the left lane. These collisions occur when the driver of the passing vehicle is distracted or does not appropriately assess the situation. A passing collision warning system (PCWS) can help drivers avoid passing collisions by reducing the chance of human errors. This research presents the framework and design algorithm for a passing collision warning system that assists unprotected passing drivers on two-lane highways. The system uses a radar sensor in the passing vehicle to detect opposing vehicles travelling in the left lane and calculates their relative positions and speeds to estimate the time to collision and compare it with the time required for the passing vehicle to clear the path. The model determines the relative locations and speeds of opposing vehicles at four sequential time intervals. The "safe pass" signal can assist the passing driver to prepare for a safe passing maneuver during the overtaking process. 


\subsection{Existing Passing Sight Distance Models}

Passing Sight Distance (PSD) is used to ensure that passing vehicles have a realistic estimate of their distance from opposing vehicles in order to minimize the possibility of collisions (Harwood and Glennon, 1989). According to El Khoury (2005), the PSD design criteria provide standards for the marking of passing and no-passing zones. These criteria are outlined in the Green Book, A Policy on the Geometric Design of Highways and Streets (AASHTO) (2004). The operational criteria are stated in the FHWA Manual on Uniform Traffic Devices for Streets and Highways (MUTCD) (2003) which has remained unchanged for over seven decades. The aforementioned two sources (AASHTO and MUTCD) are very inconsistent and suggest different minimum PSDs in similar conditions. In 2005, the NCHRP began conducting research to find consistent PSD standards for highway design and operations nationwide. The new standards should be incorporated into the future editions of both the AASHTO and MUTCD manuals (El Khoury, 2005; El Khoury and Hobeika, 2007).

Some models assume a uniform passing speed while occupying the left lane, despite the identification of an acceleration stage before the vehicle enters the left lane (AASHTO, 2004). This model proposes an average acceleration rate of $0.62 \mathrm{~m} / \mathrm{s}^{2}$. Other models describe the trajectories of passing vehicles using more complex kinematic equations (AASHTO, 2011; Glennon, 1988; Hassan et al., 1996; MUTCD (FHWA, 2009)). These models generally suggest the existence of a critical point (point A in Figure 2.2). Once the driver reaches this point it is safer to complete the passing maneuver than to abort it. This is because the time and distance requirements are lower for the completion. According to these models, the acceleration rate of the passing vehicle is constant until the critical point is reached. After the critical point, the speed remains constant and equal to the design speed. There are also alternative formulations including the uniform acceleration models (Rocci, 1998), uniform acceleration until a particular target speed is reached (Wang \& Cartmell, 1998), or models based on an inconstant acceleration that decreases linearly with increases in speed (Lieberman, 1982). 
In order to account for this uncertainty in passing maneuvers, some researchers have used reliability analysis or simulation techniques. These statistical tools make it possible to account for any variability in the input parameters and to obtain a probabilistic formulation for PSD. Sparks et al. (1993) used the Glennon and Liebermann models and incorporated the statistical distributions of the input parameters. Hanley and Forkenbrock (2005) conducted a simulation using previous PSD models while incorporating random distributions of the input parameters. El Khoury and Hobeika (2012) suggested the evaluation of the risk level in the Glennon PSD model using a Monte Carlo simulation. El Bassiouni and Sayed (2010) developed a reliability model using driving simulator data to compare with the AASHTO PSD model (2004). However, the assumptions of the model were not verified.

Driving simulator data has been used by other researchers in order to analyze the acceleration of passing vehicles. Jenkins and Rilett (2004) created a distribution of the time passing drivers spend accelerating using a sample of 96 passing maneuvers. The results revealed that the average acceleration time was $13.3 \mathrm{~s}$ and the average passing time was $20 \mathrm{~s}$ (double the time obtained using field data). The acceleration capability was uniform for all of the simulation vehicles. The acceleration rates of different passenger vehicles during an experiment with controlled conditions were collected by Rakha et al. (2004). The results were used to determine the relationship between acceleration rates and speed. The acceleration starting point was $0 \mathrm{~km} / \mathrm{h}$. The results are not directly applicable to passing maneuvers since acceleration rates change based on the starting speed of the maneuver and driver reactions during risky situations.

Harwood et al. (2010) and Polus et al. (2000) conducted field studies recording passing maneuvers in order to calibrate the parameters of the AASHTO (2001) model using experimental data. Unfortunately, the assumptions of the models were not verified. For example, the acceleration rate was uniform until the design speed was reached. Other researches (Carlson et al., 2006; Hegeman, 2008) have made use of instrumented vehicles in order to observe passing maneuvers on two-lane rural roads. In their work, Carlson et al. (2006) provided a description of the speed evolution for passing vehicles. The initial acceleration stage was followed by a second stage in which the acceleration actually decreased (after being abreast with the impeding vehicle). The acceleration 
model was not calibrated and the distance to the impeding vehicle was obtained from video data. In addition, the instant speed at the beginning of the test and the beginning of the passing maneuver were not measured. The following sections present the current standards from the AASHTO, MUTCD and Hassan et al. (1996) PSD models, which are recommended by AASHTO (2011). A comparison of passing sight distance models is also presented in Figure 2.3.

\subsubsection{AASHTO Model}

When designing two-lane highways, the minimum passing sight distance incorporates certain assumptions about driver behaviour. The following assumptions were made by AASHTO (2004):

1) The impeding vehicle travels at a constant speed during the passing maneuver.

2) The passing vehicle travels at a reduced speed and trails behind the impeding vehicle when entering the passing section, known as a delayed pass.

3) Once the passing section is reached, passing drivers require a short period of time to perceive that the passing section is clear and initiate acceleration.

4) Passing is done using a delayed start and a hurried return when in the opposing traffic lane. Passing vehicles accelerate during the maneuver, and the average speed while occupying the left lane is $16 \mathrm{~km} / \mathrm{h}$ higher than the speed of the impeding vehicle.

5) Once the passing vehicle returns to the right lane, there is an appropriate clearance length between the passing vehicle and any opposing vehicle in the other lane.

AASHTO (2004) developed the following model for the calculation of PSD based on field studies conducted prior to 1958 :

$$
\begin{aligned}
& P S D=d_{1}+d_{2}+d_{3}+d_{4} \\
& d_{1}=0.278 t_{1}\left(v-m+\frac{a t_{1}}{2}\right) \\
& d_{2}=0.278 v t_{2}
\end{aligned}
$$

where $d_{1}=$ distance travelled by the passing vehicle during the perception-reaction times and while accelerating towards the encroachment point along the left lane (the time elapsed $=t_{1}, \mathrm{~s}$ ); $d_{2}=$ distance travelled by the passing vehicle as it occupies the left lane (the time elapsed $=t_{2}, \mathrm{~s}$ ); $d_{3}=$ 
clearance distance between the passing vehicle and opposing vehicle at the end of the pass; $d_{4}=$ distance travelled from the opposing vehicle within two-thirds of the time a passing vehicle will occupy the left lane $=2 / 3 d_{2}$ (the time elapsed $\left.=t_{4}=2 / 3 t_{2}, \mathrm{~s}\right) ; v=$ average speed of the passing vehicle $(\mathrm{km} / \mathrm{h}) ; \mathrm{a}=$ average acceleration $(\mathrm{km} / \mathrm{h} / \mathrm{s})$; and $\mathrm{m}=$ speed difference between the passing and impeding vehicles $(\mathrm{km} / \mathrm{h})$.

Four PSD components are shown in Figure 2.2. This model considers the average speeds that are used to compute the design value for PSD. These speeds differ from the design speeds used for highways. The time required for the driver to abort the pass if a vehicle appears in the opposing lane is time $t_{1}+(1 / 3) t_{2}$.

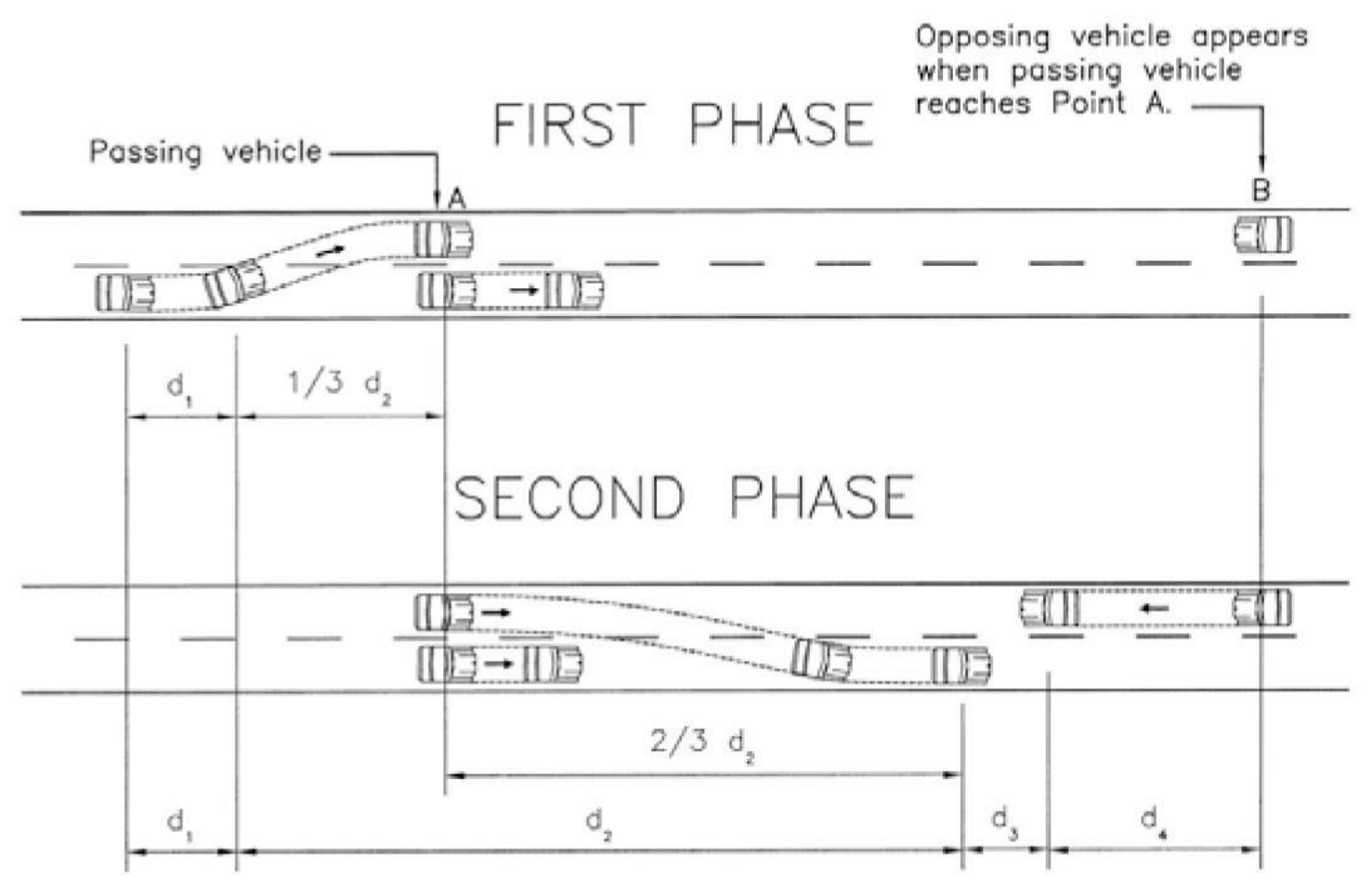

Figure 2. 2: AASHTO modeling for the passing maneuver (AASHTO, 2004)

Using data obtained in previous field studies with design speeds of $80 \mathrm{~km} / \mathrm{h}$, the AASHTO (2004) model presumes that the initial passing time $\left(t_{1}\right)$ varies between 3.6 to $4.5 \mathrm{~s}$ and that the time the passing vehicle occupies the left lane $\left(t_{2}\right)$ varies between 9.3 to $11.3 \mathrm{~s}$ within a speed range of 50 to $100 \mathrm{~km} / \mathrm{h}$. In this model, the clearance distance $\left(d_{3}\right)$ can be estimated based on the speed for a 
range of 30 to $90 \mathrm{~m}$. The distance traveled from an opposing vehicle $\left(d_{4}\right)$ is estimated to be twothirds of the distance that is traveled from the passing vehicle within the left lane. Conventionally, the distance for $d_{2}$ and for $d_{4}$ need to be re-calculated, however, this model takes into account that full clearance distance will not be needed as the passing vehicle may abort pass and return to the right lane early in the passing maneuver if they see a vehicle in the opposing lane.

According to AASHTO (2004), the critical position occurs when the passing vehicle is abreast to the impeding vehicle. The time required for the driver to reach the critical position, calculated from the moment they begin to cross the centerline toward the left lane, is one third of the time required to complete the passing maneuver $\left(1 / 3 \mathrm{~d}_{2}\right)$. Farah (2013) used data from a driving simulator to calculate the critical position and found that it was $41.7 \%$ of $\mathrm{d}_{2}$. This ratio is higher than the one proposed by AASHTO, but almost identical to the results obtained by Harwood et al. (2008) who obtained $41 \%$. These results have implications for the calculation of $\mathrm{d}_{4}$, which ASSHTO defines as the distance that the opposing vehicle travels in two-thirds of the distance the passing vehicle occupies the left lane. In other words, it is the distance that the opposing vehicle travels, from the time the passing vehicle is abreast to the impeding vehicle until the pass is completed.

Based on the AASHTO assumption, the $\mathrm{d} 4$ value can be calculated as $2 / 3 \mathrm{t}_{2} *$ of the speed of the opposing vehicle. Using driving simulation experiments, Farah (2009) concluded that the $\mathrm{d}_{4}$ value should be calculated from the time the vehicle reaches the critical point to the time the pass is completed. Farah (2009) also concluded that AASHTO miscalculated the distance travelled by the opposing vehicle during the passing maneuver. These results suggest the need for further examination to define the parameter $\left(\mathrm{d}_{4}\right)$ since it has serious safety implications (Farah, 2013).

The AASHTO (2004) PSD design values range between 200 and $815 \mathrm{~m}$ and correspond to design speeds between 30 and $130 \mathrm{~km} / \mathrm{h}$. The PSD criteria can be measured using the driver eye height and object height equal to $1.08 \mathrm{~m}$. The AASHTO criterion is also used within highway design to determine whether a certain highway project contains enough PSD length to ensure an adequate level of service along a completed highway. The AASHTO PSD criteria will not be used for the marking of both the passing and the no-passing zones (NCHRP, 2005). 


\subsubsection{MUTCD Design Values for PSD}

Inconsistencies arise when comparing the PSD values used for pavement marking presented within the Canadian and American versions for Manual on Uniform Traffic Control Devices (MUTCD) and those provided in the design guides (AASHTO, 2004; TAC, 2007). The MUTCD criteria were used for the marking of passing and no-passing zones along two-lane highways (FHWA, 2009). The passing zones are not directly marked. Instead, the warrants of the no-passing zones were established using MUTCD, with passing zones allocated to areas where no-passing zones were not warranted. MUTCD provides no-passing zone criteria that are based on data collected for off-peak 85th-percentile speeds instead of design speeds (El Khoury and Hobeika, 2007).

According to NCHRP (2005), the MUTCD PSD criterion is significantly lower than the criterion presented in the AASHTO (2004) PSD designs. For instance, at speed of $100 \mathrm{~km} / \mathrm{h}$, the AASHO and MUTCD PSD criteria equal $670 \mathrm{~m}$ and $320 \mathrm{~m}$, respectively. Minimum passing lengths are also taken into consideration for the marking of passing and no passing zones along two-lane highways. The AASHTO (2004) does not address passing zone lengths. A minimum passing zone length of $122 \mathrm{~m}$ (400 ft.) is indirectly set by MUTCD and two no-passing zones will come within $122 \mathrm{~m}$ of the no-passing stripe that needs to be continued.

According to Hassan et al. (1996), discrepancies arose while comparing the PSD values of the pavement markings presented in the Canadian and American versions of the MUTCD and other design guides (AASHTO, 2004; TAC, 2007). When comparing the PSD values with the pavement markings for the MUTCD model and the AASHTO (2004) guidelines, the MUTCD values were smaller. Harwood and Glennon (1976, 1989) explained that the rationale for selecting the

minimum sight distance requirements is different from that used for MUTCD values. It should be noted that the MUTCD PSD values are similar to the AASHTO (1940) Guideline.

\subsubsection{Hassan, Easa and Abd El Halim Model}

Hassan et al. (1996) developed a revised model of passing maneuver mechanisms. According to the discussion above, the progression of a passing maneuver is as follows: 
- Both the impeding and opposing vehicles travel at constant speeds of $v-m$ and $v$, respectively, for the entire maneuver.

- At the beginning of the pass, the passing vehicle is trailing the impeding vehicle with a travelling speed of $v-m$.

- The passing vehicle accelerates at a constant rate, $a$, towards a speed of $v$, while shifting towards the left lane. The sight distance needed is small and corresponds with the sight distance needed to safely abort the pass.

- Once the passing maneuver builds up, the sight distance required for the passing vehicle to abort the pass increases while the distance required to complete the pass decreases.

Second, if it is not safe to complete the maneuver, it is aborted as follows:

- If the driver of the passing vehicle chooses to abort a pass, a minimum headway of, $h_{1}$, must be maintained between the front bumper of the passing vehicle and the rear bumper of the impeding vehicle. A minimum headway of, $h$, needs to be maintained between the front bumper of the passing vehicle and the front bumper of the opposing vehicle.

- When aborting the pass, the driver in the passing vehicle considers perception-reaction time, $P R T$, before using the brakes. The speed profiles of the passing vehicles remine constant and are not influenced when aborting the pass within the perception-reaction time.

- Thus, vehicles keep decelerating at a constant rate, $d$, once they are in the right lane.

Lastly, at a particular point (the critical distance), the sight distance required to abort the pass is equal to the sight distance required to complete it. Sight distance along this point is called the critical sight distance, with the following factors in notice.

- When reaching a critical position, passing vehicles have already accelerated towards the design speed $v$.

- When passing critical positions, the passing vehicles can safely complete the pass. Towards the end of a completed pass, a minimum headway of, $h_{o}$ must be maintained between the front bumper of the passing and opposing vehicles. A minimum headway of $h_{1}$ must be maintained between the rear bumper of the passing vehicle and the front bumper of the impeding vehicle. 


\subsubsection{Comparison of Passing Sight Distance Models}

Passing Sight Distance (PSD) is an important safety feature in the geometric design of highways. PSD is defined as the minimum sight distance required to safely pass an impeding vehicle when there is an opposing vehicle in the left lane. PSD design is influenced by the AASHTO (AASHTO, 2004) and MUTCD (FHWA, 2003) manuals, along with a few other models such as those proposed by Glennon (1988) and Hassan et al. (1996). The model proposed by Glennon (1988) assumes that the passing driver's front bumper is abreast with the front bumper of the impeding vehicle when completing the passing maneuver if a critical position has not been reached. Hassan et al. (1996) assumed that the passing driver is more likely to complete the passing maneuver when the front bumpers of the passing and impeding vehicles draw even (NCHRP, 2008). When compared with the existing model, the model proposed by AASHTO (2004) uses a more conservative approach.

Table 2. 1: Comparison of the PSD Values (m) from Various PSD Models

\begin{tabular}{lccccccccc}
\hline & \multicolumn{2}{c}{ Speed $(\mathrm{km} / \mathrm{h})$} & & & & & & \\
\cline { 2 - 9 } Model & 40 & 50 & 60 & 70 & 80 & 90 & 100 & 110 & 120 \\
\hline AASHTO (2011) & 140 & 160 & 180 & 210 & 245 & 280 & 320 & 355 & 395 \\
and MUTCD (2003) & & & & & & & & & \\
AASHTO (2004) & 266 & 341 & 407 & 482 & 538 & 613 & 670 & 727 & 774 \\
TAC (2007) & 290 & 350 & 410 & 490 & 550 & 610 & 680 & 730 & 800 \\
Glennon (1988) & - & - & - & 229 & 253 & 277 & 318 & 347 & - \\
Hassan et al. (1996) & - & 144 & 198 & 256 & 297 & 355 & 489 & 656 & 796 \\
Highest PSD value & 290 & 350 & 410 & 490 & 550 & 613 & 680 & 730 & 800 \\
Lowest PSD value & 140 & 160 & 180 & 210 & 245 & 277 & 318 & 347 & 395 \\
\hline
\end{tabular}

Table 2.1 provides a comparison of the PSD values from various PSD models. As we can see in this table, the PSD value proposed by AASHTO (2004) at speeds ranging between $40 \mathrm{~km} / \mathrm{h}$ and $120 \mathrm{~km} / \mathrm{h}$ is larger than the PSD value proposed by the AASHTO (2011), MUTCD, Glennon (1988), and Hassan et al. (1996) models. TAC (2007) uses the AASHTO (2004) model (with rounded values of PSD) resulting in higher PSD values. On the other hand, AASHTO (2011) uses the PSD values proposed by the MUTCD, resulting in smaller PSD values. PSD design depends 
on several parameters including the length, speed and deceleration rate of the passing, impeding and opposing vehicles. These parameters vary significantly depending on driver behaviour and the road conditions. PSD design criteria should be represented by random variables with sufficient probability density functions. In order to counter the inherent variability of these parameters, these variables were replaced with single values in the current PSD design. The result is a single-value PSD design standard (El Khoury and Hobeika, 2007).

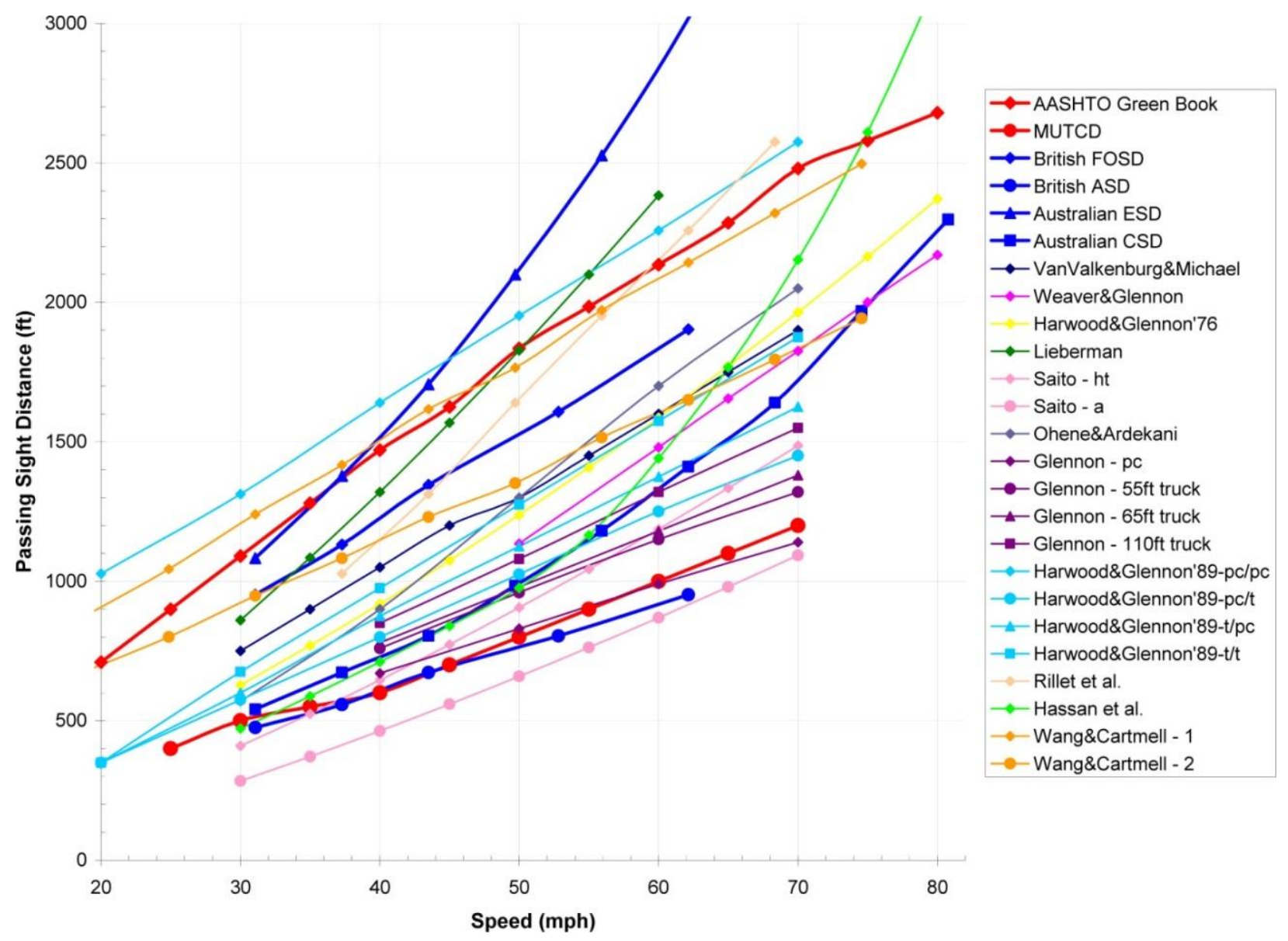

Figure 2. 3: Comparison of the PSD Values from Various PSD Models (NCHRP, 2005)

The PSD values obtained from the PSD models reviewed in a previous section of this dissertation are compared in Figure 2.3. Figure 2.3 shows that the PSD models presented in the previous section provide PSD values that range between those provided in the MUTCD and AASHTO values, and a few PSD values smaller than the MUTCD values or larger than the AASHTO values. Furthermore, NCHRP (2005) and AASTHO (2011) concluded that the PSD models that were 
developed by Glennon (1988) and Hassan et al. (1996) are the best and the most appropriate to present a rationale for passing and no-passing zones on two-lane highways. AASTHO (2011) also stated that new PSD models should consider driver behaviour.

\subsection{Passing Gaps While Overtaking}

Research on overtaking (head-on) accidents is rare, even though these accidents are common and usually fairly serious. The majority of the research within the literature regarding two-lane highways involves issues such as the required sight distance (AASHTO, 2004; Brown et al., 2000; Glennon, 1988; Polus et al., 2000), the influence of the speed of both the passing and impeding vehicles on the number of passing maneuvers (Bar-Gera and Shinar, 2005), overtaking (head-on) accidents (Clarke et al., 1998), the impact of impatience on the critical gap (Pollatschek and Polus, 2005), or the classification of passing maneuvers and overtaking frequency (Hegeman, 2004; Jenkins and Rilett, 2005). Some studies have also discussed driver perception of required passing gaps (Farber and Silver, 1967; Gordon and Mast, 1968; Jones and Heimstra, 1966).

For obvious practical reasons, the research that has been done has infrequently considered real passing maneuvers on two-lane highways, or real head-on accidents (Clarke et al., 1999). Jones and Heimstra (1966) studied the ability to estimate (as closely as possible) the last safe passing moment when another vehicle is approaching in the opposing lane. Nearly 50 percent of the drivers underestimated the last safe passing moment. In addition, there was considerable variation between subjects in their ability to make the required clearance time estimates.

\section{Drivers Can Judge the Distance Required to Overtake}

Gordon and Mast (1968) studied how accurately drivers are able to judge the required distance needed to overtake and pass a vehicle on rural two-lane highways by comparing driver estimates with actual overtaking distances. The following conclusions were drawn from the results: (1) Drivers were unable to accurately estimate passing distances; (2) Estimation errors increased with speed; (3) A greater distance was required when the speed of the lead car increased and (4) Vehicular differences affected the passing distance more than driver variance. 
Glennon (1988) points out that the PSD requirements proposed in the AASHTO (1984) model ignore the possibility that a driver may abort the passing maneuver, leading to overestimates of required passing sight distance. The authors developed a more suitable model that considers the trade-offs between completed and aborted passing maneuvers. Hassan et al. (1996) also pointed out this flaw in the AASHTO (1984) model. The authors developed an analytical model to determine the minimum PSD requirements based on the concept of critical sight distance and considering the kinematic interaction between the passing, impeding, and opposing vehicles. The results of the revised model by Hassan et al. (1996) were compared with field data and the results of the comparison revealed that the revised model provided more accurate simulations than the previous models which were either too liberal or too conservative.

Polus et al. (2000) observed passing maneuvers on rural two-lane highways and analyzed the required sight distance. The authors collected data for approximately 1500 passing maneuvers by videotaping six tangent highway sections. The authors developed a model for the passing process and passing sight distance. In this model, the speed of the impeding vehicle is related to the required passing distance. In definition, this model is similar to the original model used by AASHTO (1994). Jenkins and Rilett (2005) analyzed data collected in a driving simulator during a passing experiment and found that:

(a) The speed increase $\left(\Delta V_{p 1}\right)$ of the passing vehicle during the initiation of the passing maneuver is smaller when there is a greater speed difference $(m)$ between the passing and impeding vehicles at the moment of the initial acceleration.

(b) The speed reduction $\left(\Delta V_{p 2}\right)$ of the passing vehicle during the second portion of the passing maneuver is larger when there is a greater time to collision (TTC) with the opposing vehicle at the moment when the passing vehicle returns to the right lane.

Based on these results, the authors developed a behavioural approach to the classification of passing maneuvers on the basis of a computable assessment of passing conditions and driver behaviour. They concluded that the initiation of a passing maneuver can be identified based on acceleration behaviour, and the end of a passing maneuver can be identified based on deceleration behaviour. Liu and Herman (1996) developed an analytic model involving vehicle and road 
characteristics for passing maneuvers on two-lane highways. The authors found that the required passing sight distance in order to complete or abort a passing maneuver increases along with increases in the speed of the impeding vehicle.

Bar-Gera and Shinar (2005) evaluated the speed differential threshold, at which drivers decide to pass an impeding vehicle. The authors found that drivers have a tendency to pass vehicles that are travelling ahead of them, even if these vehicles are travelling faster than their average speed. This tendency to pass the impeding vehicle is also related to driver speed variability. Hanley and Forkenbrock (2005) indicated that the speed differential between the passing and impeding vehicles decreases when there is a decrease in the time the passing vehicle travels in the left lane during the maneuver.

Gattis et al. (1997) and Romana (1999) studied passing activity on two-lane highways and observed that passing time increased as the gap between the passing and impeding vehicles decreased below three seconds. A review of the literature revealed that there is a lack of mathematical models of gap-acceptance on two-lane highways. Moreover, there are no models that consider the personal characteristics of the driver and their driving style. These research gaps stem from the difficulties involved in observing real life passing maneuvers (Farah, 2009). Despite these difficulties, these areas need to be explored in future research.

\subsection{Passing Maneuver Criteria}

The current highway geometric design guide (AASHTO, 2011) follows the methodology from the MUTCD Model (FHWA, 2003) which provides short PSD values that reduce the safety margin due to the passing situation. Prior to 2004, the AASHTO model provided large PSD values, as illustrated in Figure 2.3. Adequate PSD must be provided, wherever possible, along two-lane highways so that the passing driver can see a sufficient distance ahead, clear of traffic, to overtake a slower vehicle traveling in the same direction (the grey-coloured vehicle in Figure 2.4) without colliding with a third vehicle traveling in the opposite direction (the dark-coloured vehicle in 
Figure 2.4). Lane marking and signage are usually used to inform drivers, on two-lane highways, when adequate PSD is available and passing is allowed.

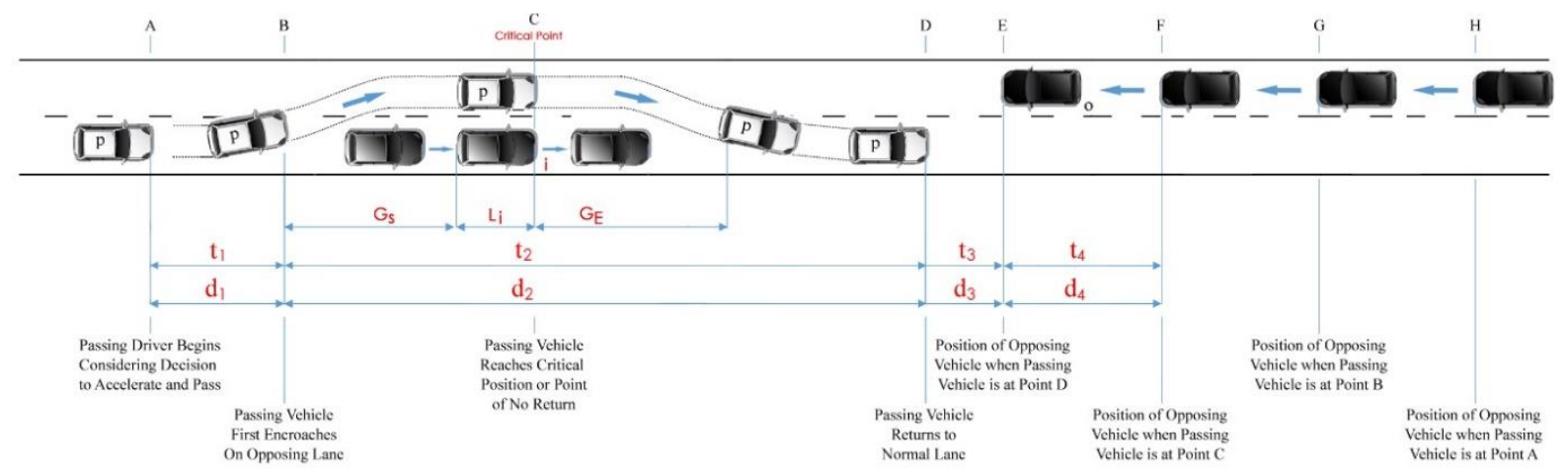

Figure 2. 4: Components of the passing sight distance criteria in different countries (Harwood et al., 1998)

There are several models used to compute the minimum required PSD, either for design purposes or to identify no-passing zones where drivers are informed, through lane markings and signage, that passing is not allowed due to insufficient PSD. Previous geometric design guide versions (e.g. AASHTO 2004) provided a model for PSD computation that allowed the passing driver to perceive the traffic conditions, react to them by deciding whether or not to pass, perform the passing maneuver by driving in the opposing traffic lane, and return to the original lane, while maintaining safe distances between all vehicles.

Previous research studies have found that the above criteria for PSD result in two-lane highways that are generally safe for passing maneuvers (FHWA, 1994; Harwood et al., 2007). Other research studies have found that the AASHTO (2004) criteria are too conservative (Carlson et al. 2006; Harwood et al., 2010; Llorca and García, 2011). Given the rapid improvements in vehicle acceleration/deceleration capabilities and the changes in driver attitudes, if the above criteria are too conservative, some drivers may attempt to pass in non-passing zones, which could be hazardous for those drivers as well as other road users around them (Llorca and García, 2011). Less conservative PSD may be needed to make no-passing zones on two-lane highways more realistic for drivers so that they are more likely to adhere to the passing regulations within those no-passing zones. 
Glennon (1988) developed a model in which he assumed that the critical position of the passing driver occurs when the PSD required to complete the passing maneuver is equal to the sight distance required to abort the passing maneuver and return to the right lane, behind the vehicle being passed, if the driver finds it unsafe to complete the passing maneuver. Hassan et al. (1996) proposed another model in which they assumed that the critical position occurs when the passing sight distances, to complete or abort the passing maneuver, are equal to each other or when the passing vehicle and the vehicle being passed are abreast, whichever occurs first. The criteria can be calculated using a large number of different PSD models. PSD design methods were developed by AASHTO (2004), MUTCD (FHWA, 2003), and the models developed by Glennon (1988), Hassan et al. (1996), Jenkins (2004) and El Khoury and Hobeika (2007), and El-Bassiouni and Sayed (2010).

The PSD definition differs between the Glennon, Hassan et al. and the AASHTO model as follows: (1) In the AASHTO model, PSD is calculated from the moment the passing vehicle begins the perception reaction time to the moment it returns to the right lane with a safe clearance distance. The beginning and ending of PSD, from point A to F, is based on the distance shown in Figure 2.4; (2) Glennon and Hassan et al. only consider part of sight distance that is needed from a critical position towards the end of the passing zone, instead of the distance involving the perception reaction time considered by certain authors as conservative. The beginning and ending of PSD, from point $\mathrm{C}$ to $\mathrm{F}$, is based on the distance shown in Figure 2.4. The PSD values proposed by Glennon and Hassan et al. are therefore lower.

There are clear differences between the geometric design and marking criteria used in different countries. These criteria are not compatible in all analyzed cases, including AASHTO for geometric design (2004) and MUTCD for marking (FHWA, 2003). A small number of the PSD models were based on the results of field studies. More recent extensive field data were obtained by Polus et al. (2000) and Harwood et al. (2007). These authors recorded video from an external fixed position of passing zones. Only one camera was used for each passing zone. The camera measured distance, times, and recorded traffic data. 
Carlson et al. (2006) used a different methodology. They captured video data from moving vehicles in the traffic flow and found that these moving vehicles drove at slower speeds than the impeding vehicles. Data from the Carlson et al. study were then combined with data obtained in the Harwood et al. study (Harwood et al., 2010). There is a discrepancy between the results obtained by Polus et al. (2000) and Harwood et al. (2010). Polus et al. recommended the use of the AASHTO PSD values (or higher values) if the passing vehicles were considered heavy. Conversely, Harwood et al. considered the PSD valued of the AASHTO model to be too conservative due to the existence of a critical position and recommended the use of the MUTCD criteria (Llorca and García, 2011).

AASHTO (2011) recommended that PSD models representing minimum passing sight distances on two-lane highways should integrate certain assumptions concerning driver behaviour. Actual passing vehicle driver behaviour during passing maneuvers differs widely. In order to accommodate these differences in driver behaviour, the recommended design criteria for passing sight distance should include the behaviour.

The purpose of this study was to develop a PSD model that reflects current driver behaviour during passing maneuvers. Passing parameters including the initial time, passing time, and acceleration were developed using driving simulator and field observations. The start and finish of PSD from point $\mathrm{A}$ to $\mathrm{F}$ is based on the distance shown in Figure 2.4, which is consistent with the results of studies conducted by AASHTO prior to 2004. This figure is the review of the international PSD criteria based on the paper by Harwood et al. (1998).

\subsection{Vehicle Acceleration Profile}

Since vehicles usually start a passing maneuver from a resting state, it is not realistic to assume a constant acceleration rate for the vehicle acceleration profile (Mousa, 2002; Perco et al., 2012; Rakha et al., 2004; Wang et al., 2004). Instead, an acceleration profile should be created for each individual case. In this study, the linear decreasing acceleration model was used in order to create the acceleration profiles. This method has been used in several other studies (e.g. Dabbour and 
Easa, 2014; Drew, 1968; Long, 2000; Rao and Madugula, 1986; Wang et al., 2004). According to this model, the acceleration rate can be computed using the following equation:

$a c c=\frac{\partial v}{\partial t}=\alpha-\beta v \pm G g$

where acc represents the acceleration rate for a particular speed $v\left(\mathrm{~m} / \mathrm{s}^{2}\right) ; v$ represents the speed $(\mathrm{m} / \mathrm{s}) ; a$ represents the acceleration rate at the initiation of acceleration $\left(\mathrm{m} / \mathrm{s}^{2}\right) ; \beta$ represents the rate of decrease in acceleration with increases in the speed; $G$ represents the grade $(\mathrm{m} / \mathrm{m})$; and $g$ represents gravity (approximately $9.81 \mathrm{~m} / \mathrm{s}^{2}$ ). Based on the equation above, speed can be calculated as:

$v=\left(\frac{\alpha \pm G g}{\beta}\right)-\left(\left(\frac{\alpha \pm G g}{\beta}\right)-v_{0}\right) e^{-\beta t}$

where $t$ represents the time that has elapsed from the start of acceleration (s) and $v_{0}$ represents the initial speed of the vehicle $(\mathrm{m} / \mathrm{s})$. The distance traversed by the passing vehicle at any time is obtained using the following formula:

$d=t\left(\frac{\alpha \pm G g}{\beta}\right)-\left(\left(\frac{\alpha \pm G g}{\beta}\right)-v_{0}\right)\left(\frac{1-e^{-\beta t}}{\beta}\right)$

Many different values have been suggested for the $\alpha$ and $\beta$ parameters in the equations above. For the average passenger car, the parameter $\alpha$ ranged between $2.02 \mathrm{~m} / \mathrm{s}^{2}$ (Bonneson, 1992) and 2.94 $\mathrm{m} / \mathrm{s}^{2}$ (ITE, 2009) and the parameter $\beta$ ranged between $0.0409 \mathrm{~m} / \mathrm{s}^{2}$ (ITE, 2009) and $0.1326 \mathrm{~m} / \mathrm{s}^{2}$ (Bonneson, 1992). It is important to note that these values represent the maximum capacity of the vehicle. Since the majority of drivers only apply the maximum acceleration power in emergency situations, these values cannot be used for road design purposes (Long, 2000; Wang et al., 2004). 


\subsection{Driving Simulators}

Although simulators have been used since the early 1900s, driving simulators only began to appear in primitive form in the 1970s. The distinction between different simulators can be made according to their level (Kaptein et al, 1996):

1) Low-level: typically consist of a PC or graphic work station, a single monitor, and a simple cap with control.

2) Mid-level: contain advanced imaging systems, a large projection display monitor, a realistic cap, and a simple motion base.

3) High-level: contain a near 360-degree field of view and a wide-range moving base.

There are many possible applications for driving simulators, including human factor research, driver education, medical research, training and assessment, and vehicle design evaluation. When it comes to research concerning traffic behaviour, there are many advantages to the use of driving simulators (Kaptein et al, 1996):

Driving simulators allow researchers to test the effect of new road designs that would be too expensive to build just for research purposes;

1) Driving simulators allow researchers to investigate dangerous situations without any risk;

2) Drivers can be repeatedly challenged with events that may rarely occur in reality;

3) In some countries, field tests may be difficult because of liability problems;

4) Driving simulators allow for optimal experimental control; and

5) Driving simulators allow researchers to investigate the effects of nonexistent road elements.

In spite of these advantages, there is one major disadvantage to using driving simulators: in a driving simulation the driving task is never completely realistic. Researchers must therefore question whether or not a driving simulation is sufficient for the particular area of investigation before using this method in their research study. Because the driver simulator participants rarely need all obtainable information to perform the task, it is generally unnecessary that the information in the driving simulator be identical to what would be available in a real vehicle (Flexman and Stark, 1987). In some experiments, expert drivers may provide better performance in completing 
the simulation task. Recent technological progress has allowed for the development of comparatively low-cost, laboratory-based driving simulators. These simulators provide a safe and economical way to test skills in adverse road conditions (Rizzo et al., 2001). These driving simulators are now widely used to study driver behaviours internationally (Blana, 1996).

Many studies have concluded that driving simulators can provide accurate observations of driver behaviour and functions (Alicandri, 1994; Desmond and Matthews, 1997; Ellingrod et al., 1997; Fraser et al., 1994; Van der Winsum, 1996; Van der Winsum and Brouwer, 1997). Farah (2009) used the STISIM driving simulator (by Systems Technology Inc.) to study driver behaviour on two-lane highways. STISIM is a personal computer-based driving simulator. The fixed-base driving simulator projected a $60^{\circ}$ horizontal $\times 40^{\circ}$ vertical display of a simulated driving scene onto a wall $3.5 \mathrm{~m}$ in front of the driver using a NEC VT670 projector.

An important component of this proposed system is the inclusion of human factors for the driver of the passing vehicle. This includes the perception-reaction time of the signal time triggering the system when the vehicle begins to accelerate. The driver simulation lab at Ryerson University's Department of Civil Engineering was used in order to collect experimental data used to regulate the required models. The throttle, steering wheel, and brakes of the experimental car (illustrated in Figure 2.5) are connected to the driving simulator system to determine the driver's response to different scenarios generated from a computer that uses a wall projector. The driving simulator uses an STISIM simulation system that was developed by Systems Technology Inc (STISIM, 2009). This system uses both event and setup files to operate the simulation, allowing vehicle dynamics and driving scenarios to be modified and created using the Scenario Definition Language, or SDL (Allen et al. 2004).

Driving simulators are used for vehicle design, driver training and safety research. They are also used for the assessment of different human factor areas such as pavement markings (Horberry et al. 2006), perception of traffic signs (Dutta et al. 2004), acceptance behaviour (Alexander et al. 2002), passing maneuvers (Jenkins, 2004; Jenkins and Rilett, 2005), crash avoidance maneuvers (Smith et al.2002), driving distraction as a result of the use of mobile phones, (Rakauskas et al. 
2004) and human behaviour in very high risk situations (Yan et al., 2008). There are many advantages to the use of driving simulators. These include experimental control, efficiency, ease of data collection and safety (Nilsson, 1993).

The scenario definition language (SDL) is used to simplify the creation of experimental designs since users are not required to program visual databases with this language. This simulation system uses STISIM software and PC-compatible hardware components to produce visual and auditory displays related to driving. These real-time driving scenarios are projected onto a screen situated in front of the driver (Figure 2.6).

Driving simulators can identify highway design issues and explain the relationship between drivers and the environment surrounding the roadway (Yan et al., 2008). The assessment of the validity of driving simulators involves both physical and behavioural validation (Jamson, 1999). Physical validity involves the degree to which the simulator and visual system can accurately reproduce the vehicle that is being simulated. The U.S. National Advanced Driving Simulator (NADS), the most sophisticated simulator currently in use, requires highly detailed and accurate vehicle dynamic simulation to determine the movements of the simulated vehicle responding to control and disturbance inputs. Many types of vehicle dynamic models within NADS have been authorized at an absolute validity level, such as the Ford Taurus, the Jeep Cherokee, the Chevrolet Malibu, and a tractor-semitrailer (Salaani and Heydinger, 2000).

Behavioural validation refers to the ability of a simulator to induce a similar driver response than real life situations (Jamson, 1999). According to Blaauw (1982), there are two kinds of behavioural validity: 1) absolute validity, which means that the numerical values connecting the two systems are similar; and 2) relative validity, which means that the differences that are found between the experimental conditions are similar in direction, with similar or identical magnitude in both systems. Many validation reports related to driving speed behaviours have been conducted in order to evaluate whether or not drivers show similar speed performance in driving simulators and real-world scenarios. The University of Central Florida conducted a study to evaluate whether a fix-based driving simulator would offer a true driving experience (Kiefer et al., 1999). The results 
revealed that drivers behaved similarly on the road at many of the locations; however, the results also revealed that drivers had a tendency to drive slower in the simulator than in the field (lower mean speed).

Speed validation studies were conducted by Godley et al. (2002) to compare the speed measurements of an instrumented vehicle and driving simulator. The study involved two separate experiments. The first experiment involved roadways with transverse rumble strips in three different sites, while the second experiment involved roadways with three equal control sites and no rumble strips. The results revealed that drivers reacted to the rumble strips in similar ways in relation to their deceleration patterns along a control road for both the instrumented vehicle and driving simulator, indicating relative validity. A similar validation study was conducted by Tornros (1998) to evaluate driving behaviours (speed and lateral positioning) within a simulated road tunnel. The results revealed that behavioural validity was not satisfactory.

In regards to the choice of speed where relative validity has been achieved (in terms of speed and lateral position), it can be concluded that realistic results are obtainable with driving simulators (Kaptein et at., 1996). The Interuniversity Research Centre for Road Safety (CRISS) simulator speed validation studies paid close attention to the effectiveness of temporary traffic signs along the highway (Bella, 2007). The speed measurements were conducted in both the field and driving simulator experiments in transitional areas, activity areas, termination areas and advance warning areas. The results revealed that the speed differences between real situations and the driving simulator were not significant, indicating the absolute validity of the driving simulator.

McAvoy et al. (2007) evaluated the effectiveness of temporary traffic control units within a work zone at night in order to determine the validity of driving simulators. The spot speeds were taken at three different locations of a freeway work zone. The results of statistical tests revealed that the simulator study was able to replicate the mean travel speed of the field study at night in freeway work zone conditions, indicating absolute validity and relative validity. Dabbour (2009) and Mehmood (2010) evaluated driver behaviour and developed a warning system using STISIM driving simulator data. The warning algorithm is an important component of these systems. An 
insufficiently designed algorithm may initiate the warning too early or too late, affecting the reliability of the algorithms.

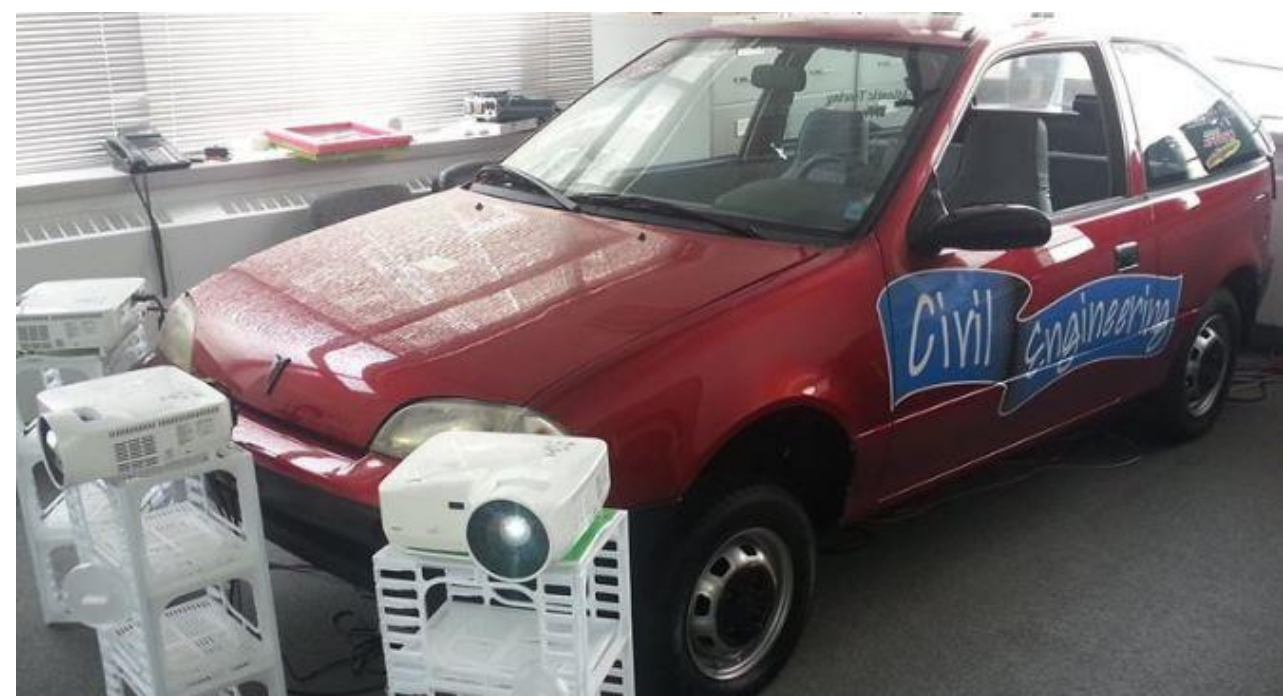

Figure 2. 5: The experimental car used for simulation at Ryerson University

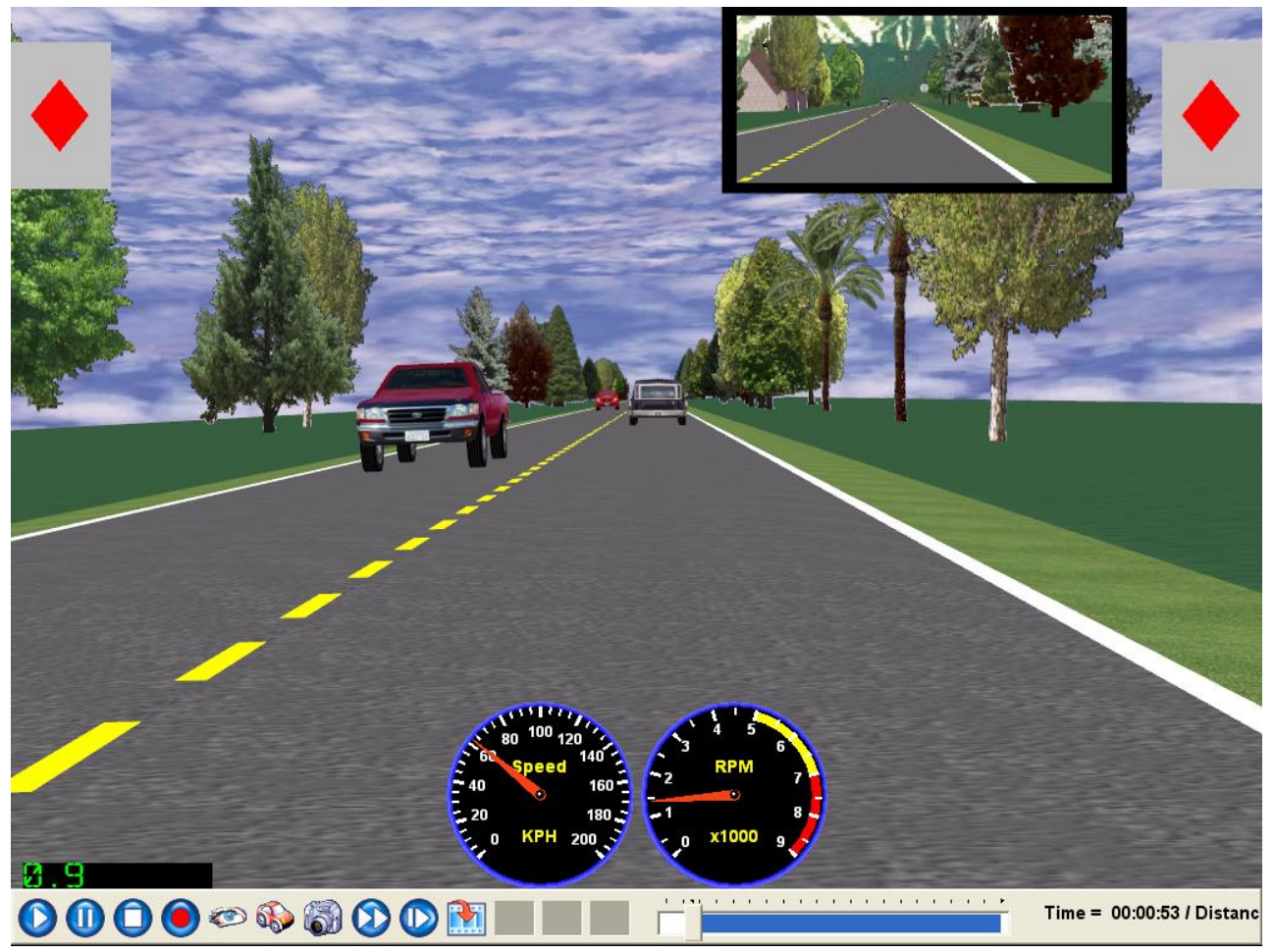

Figure 2. 6: Screen shot from the STISIM driving simulator 


\subsection{Summary}

The literature review presented several issues related to this study. First, a review of human factors, describing the ways in which humans can affect accidents, the sources of head-on collisions on two-lane highways, and the ways accidents related to human factors can be minimized. Second, a review of collision warning systems, highlighting the fact that there is currently no commercially available passing collision warning system to assist passing vehicles on two-lane highways. Third, a review of previously developed passing sight distance models, highlighting the fact that very few of the PDS models for rural two-lane highways have taken driver characteristics into account. The different analytical models needed to calculate the necessary passing sight distance for safe and comfortable passing along two-lane highways were also reviewed, revealing that these models contain inappropriate assumptions, resulting in PSD values that are either shorter or longer than required.

Fourth, a review previous studies on passing gaps was conducted. Fifth, a review of vehicle acceleration profiles was conducted. Lastly, a review of previous studies using driving simulators was conducted and driving simulators were introduced. The STISIM driving simulator system (by Systems Technology Inc.) was used for this study. The literature review revealed that there is a limited amount of research related to driver behaviour and few of these studies are based on actual observations on real highways or laboratory experiments. In this study, intolerance was considered based on real-time driving performance using a driving simulator. Many studies have concluded that driving simulators can provide accurate observations of driver behaviours and functions, confirming their value in driving research. 


\section{CHAPTER 3: EXPERIMENTAL DESIGN AND STATISTICAL ANALYSIS}

This chapter presents the experimental design, data collection, and some preliminary data analysis for driving simulator and field data. A driving simulator was used to collect data for this study. The experiments involved 63 participate with different age and gender. The field study data were collected on actual highways using the in-vehicle video camera and GPS data logger. The data were used to develop regression models for the passing parameters based on human factors. The field data collection process is described. A comparison of the passing parameters estimated using the driving simulator data and the field data is presented in this chapter. The driving simulator data will be used to develop the proposed PSD model in Chapter 4 and the field data will be used in the development of reliability model in Chapter 5.

\subsection{Driving Simulation Experiments}

\subsubsection{Experimental Program}

In the driving simulator experiment, drivers were instructed to drive as they normally would in real driving situations. The participants included seventy drivers (male and female between the ages of 18 and 70) who completed a questionnaire (see Appendix B). In this study, the most important characteristic considered was the effect of human behaviour on PSD. Changes in reaction time, acceleration/deceleration time, and speed variations according to the gender, age, driving experience, average weekly driving hours, and driving scenario are all factors that impact the effect of human behaviour on PSD.

The dependent variables are the time and distance traveled during the passing maneuver. The experiments tested drivers as they followed an impeding vehicle along a simulated rural two-lane highway and either accelerated or decelerated to complete or abort the pass. The test drivers were to choose an acceptable gap within the opposing traffic in order to complete the passing maneuver. Prior to the start of the experiment, the participants provided information such as their age, gender, 
driving experience, and driving frequency and were provided a consent form and instructions for the experiment. Copies of the consent forms and driver information sheets were signed by the drivers before the driving simulation (see Appendix A). After filling out the questionnaire, the participants were invited to take part in a decision making experiment involving a driving simulator.

\subsubsection{Simulation Scenarios}

Four simulation scenarios were used in this study. The first simulation scenario involved a 10.5 $\mathrm{km}$ long segment of a rural two-lane highway containing a combination of straight alignments and gentle horizontal and vertical curves. The lane width was 3.75 meters and the shoulder was 1.5 meters. The roadway geometry was a precise representation of the surveyed road geometry of a rural two-lane highway in Canada. The road markings and data obtained using the GPS data logger device and in-vehicle camera were consistent with the AASHTO guidelines. Roadside objects and road signs were modelled as $3 \mathrm{D}$ objects and placed in the simulation scenario at the appropriate locations. The simulated road could only be driven from north to south (point A to F).

The roadway contained a range of prominent landmarks (e.g. overtaking lanes, directional signs, houses, shops, and farms) to facilitate the identification of their surroundings as participants became familiar with the roadways during their sessions (see Figure 3.1). This simulation scenario started at point $\mathrm{A}$. The distance between point $\mathrm{A}$ and $\mathrm{C}$ was $4.5 \mathrm{~km}$ and the speed limit was 70 $\mathrm{km} / \mathrm{h}$. The driver was required to stop at the red-light signal at the intersection at point $\mathrm{C}$. The distance between point $\mathrm{C}$ and $\mathrm{E}$ was $4 \mathrm{~km}$ and the speed limit was $80 \mathrm{~km} / \mathrm{h}$. The driver was required to stop at the red-light signal at the intersection at point $\mathrm{E}$. The distance between point $\mathrm{E}$ and $\mathrm{F}$ was $2 \mathrm{~km}$ and the speed limit was $90 \mathrm{~km} / \mathrm{h}$.

The scenario took place during the day in good weather conditions with good visibility. The impeding vehicles were traveling in the right lane at a speed of $V d-m$, while the opposing vehicles were traveling in the left lane close to the design speed. The speed of the passing vehicles depends on the driver and available passing gaps. The distance headway between the opposing and passing 
vehicles was selected for natural driving conditions. The second simulation scenario involved a $10.5 \mathrm{~km}$ long segment of a rural two-lane highway. The roadway geometry and traffic conditions were similar to those in the first scenario; however, this scenario included warning messages.

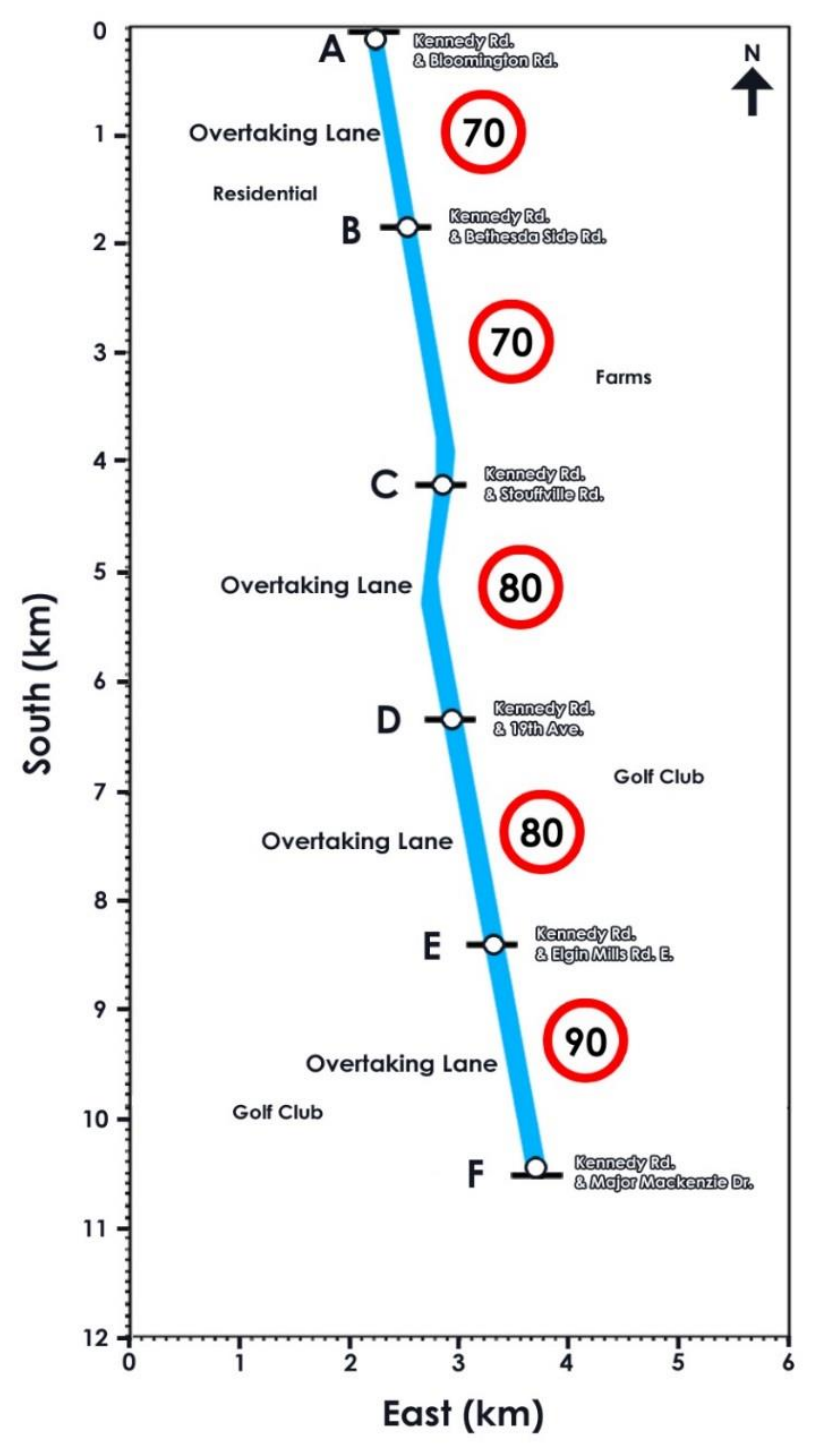

Figure 3. 1: Map of the simulated road

The third simulation scenario involved an $11.5 \mathrm{~km}$ long segment of a rural two-lane highway with different roadway geometry and traffic conditions than the first and second scenarios. This simulated road could only be driven from east to west, passing through the many intersections (see Figure 3.2). This scenario began with a speed limit of $90 \mathrm{~km} / \mathrm{h}$ on a $2.13 \mathrm{~km}$ long segment of a 
rural two-lane highway. A vertical curve began at the $0.0 \mathrm{~km}$ station with grade of $2 \%$ and ended at the $1.75 \mathrm{~km}$ station. At the $2.13 \mathrm{~km}$ station, the speed limit changed to $80 \mathrm{~km} / \mathrm{h}$ and at station 2.4 a right horizontal curve with a radius of $300 \mathrm{~m}$ began. At the $3.2 \mathrm{~km}$ station, the speed limit changed to $70 \mathrm{~km} / \mathrm{h}$ and there was heavy traffic in the opposing lane and no passing zone until the $3.4 \mathrm{~km}$ station.

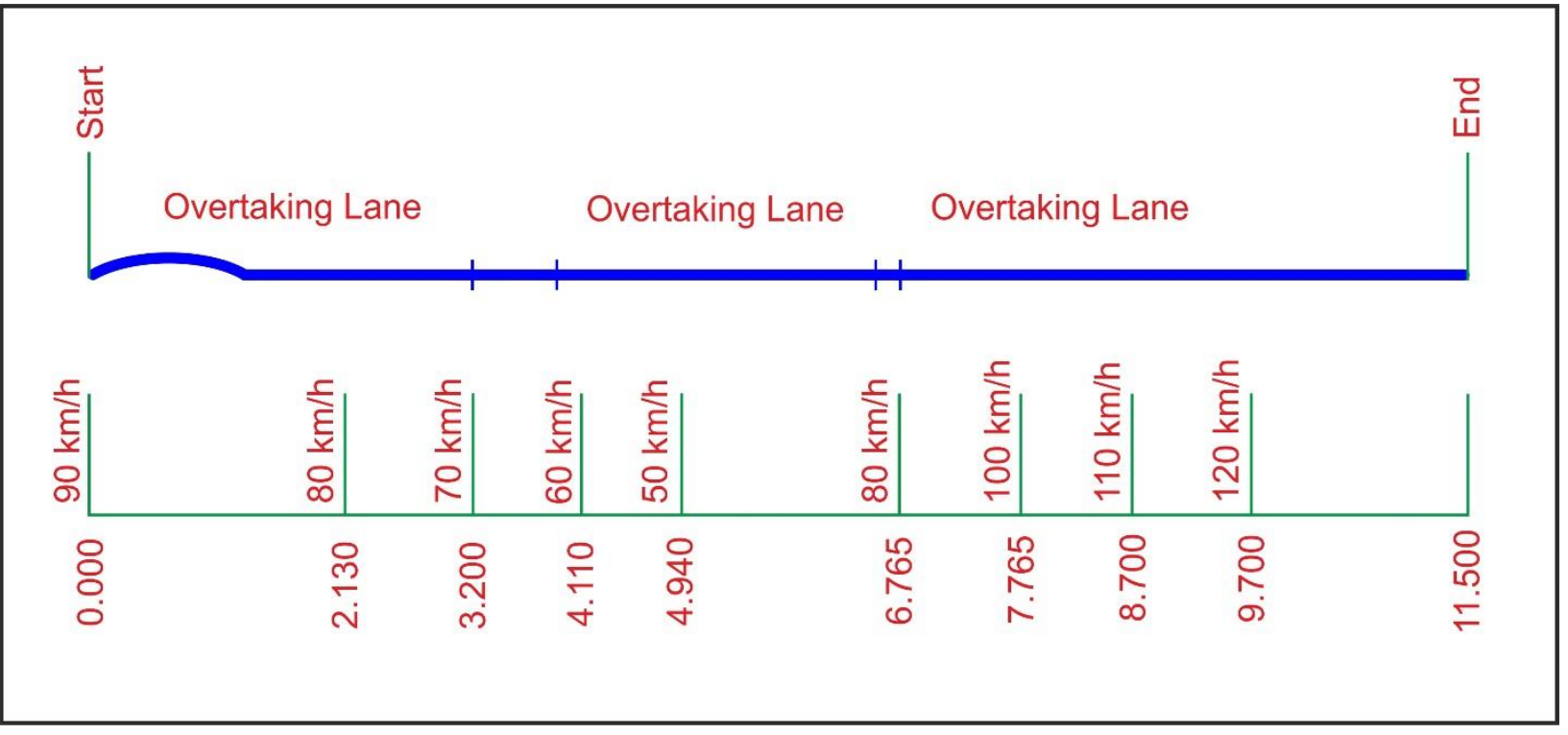

Figure 3. 2: Profile of the simulated road

At the $3.4 \mathrm{~km}$ station, the opposing traffic slowed down and passing was allowed. At the $4.11 \mathrm{~km}$ station, the speed limit changed to $60 \mathrm{~km} / \mathrm{h}$. At the $4.94 \mathrm{~km}$ station, which passes through the village, the speed limit changed to $50 \mathrm{~km} / \mathrm{h}$. At the $6.765 \mathrm{~km}$ station, the speed limit changed to $80 \mathrm{~km} / \mathrm{h}$. A right horizontal curve with a radius of $300 \mathrm{~m}$ began at the $7.225 \mathrm{~km}$ station. A vertical curve with a grade of $2 \%$ and curve length of $400 \mathrm{~m}$ began at the $7.350 \mathrm{~km}$ station. At the 7.765 $\mathrm{km}$ station, the speed limit changed to $100 \mathrm{~km} / \mathrm{h}$. A right horizontal curve with a radius of $300 \mathrm{~m}$ was introduced at the $8.225 \mathrm{~km}$ station. At the $8.7 \mathrm{~km}$ station, the speed limit changed to $110 \mathrm{~km} / \mathrm{h}$. At the $9.7 \mathrm{~km}$ station, the speed limit changed to $120 \mathrm{~km} / \mathrm{h}$. Each side of the road contained a range of prominent landmarks (e.g. overtaking lanes, directional signs, houses, shops, and farms) to facilitate the recognition of their surroundings as participants became familiar with the roads during their sessions (see Figure 3.2). 
One of these landmarks, the $400 \mathrm{~m}$ tunnel, was included to evaluate the effects of perceptual speed regulation. Previous research has shown that drivers tend to decrease their vehicle speed when entering a tunnel, presumably due to an increase in the optical flow rate and an inflation of perceived speed (Denton, 1980; Manser and Hancock, 2007; Törnros, 1998). Perceptual speed regulation of this type is the basis for numerous speed management treatments known as perceptual countermeasures (Godley et al., 2002; Retting et al., 2000). Speed reduction in response to the tunnel was included in the driving simulation experiment in order to assess driver reactions (Samuel et al., 2011). The fourth driving simulation scenario involved an $11.5 \mathrm{~km}$ long segment of a rural two-lane highway. The roadway geometry and traffic conditions were similar to those in the first scenario; however, this scenario included warning messages.

Using the simulated road sections described above, scenarios were created to be presented across 4 experimental sessions (as shown in Table 3.1). The primary difference between the majority of the scenarios was the geometric design and traffic placement on the roads. A representative mixture of vehicles was placed in the opposing lane of each simulation scenario (250 vehicles per hour). Once the participant was ready to begin, the simulation scenario was started. Two $10.5 \mathrm{~km}$ and $11.5 \mathrm{~km}$ scenarios were completed with a short (3-5 min) break in between (see Table 3.1 for experiment structure). During the break, the participants exited the driving simulator car for a drink of water and a stretch or a short chat with the experimenter. Appendix C and D presents the scenarios provided to the different participants.

Table 3. 1: Method Used to Set the Scenario Order

\begin{tabular}{ccc}
\hline Scenario Participant & Warning message & Impeding vehicle \\
\hline 1 & No & Passenger car \\
2 & Yes & Passenger car \\
3 & No & Passenger car \\
4 & Yes & Passenger car \\
\hline
\end{tabular}

\subsubsection{Simulation Data Summary}

The traffic flow rates ranged from 100 to 250 vehicles/hr. Sites with low flow rates were selected because sites with higher flow rates had limited passing maneuvers, according to research 
conducted by Harwood et al. (2010). According to Dabbour (2009), in regards to sample selection, the sample should be a proportionally representative sample of the population of licensed drivers in Canada in regards to gender and age distribution. Dorofeev and Grant (2006) and Moser and Kalton (1971) found this approach is a successful method for sample size selection. These 63 participants were randomly selected from the population (with proper age group and gender).

Table 3. 2: Summary of Driving Parameters from STISIM (Design Speed $80 \mathrm{~km} / \mathrm{h}$ )

\begin{tabular}{lcccccc}
\hline Sample & \multicolumn{3}{c}{ No-Warning } & \multicolumn{3}{c}{ Warning } \\
\hline Variables & Mean & SD & COV & Mean & SD & COV \\
\hline Passing speed, Vp $(\mathrm{m} / \mathrm{s})$ & 23.784 & 4.061 & 0.171 & 24.539 & 4.191 & 0.171 \\
Speed difference, $\mathrm{m}(\mathrm{m} / \mathrm{s})$ & 4.288 & 0.406 & 0.095 & 4.213 & 0.419 & 0.099 \\
Average acceleration, $\mathrm{a}\left(\mathrm{m} / \mathrm{s}^{2}\right)$ & 0.766 & 0.557 & 0.727 & 0.693 & 0.935 & 1.349 \\
Average deceleration, dcc $\left(\mathrm{m} / \mathrm{s}^{2}\right)$ & 0.383 & 1.385 & 3.616 & 0.011 & 0.906 & 82.364 \\
Time initial maneuve, $\mathrm{t}_{1}(\mathrm{~s})$ & 1.982 & 1.238 & 0.625 & 1.845 & 1.084 & 0.588 \\
Time occupation of left lane, t2(s) & 6.093 & 2.483 & 0.408 & 5.485 & 1.924 & 0.351 \\
Time start gap, Gs $(\mathrm{s})$ & 3.038 & 1.485 & 0.489 & 2.633 & 1.278 & 0.485 \\
Time end gap, Ge $(\mathrm{s})$ & 2.322 & 1.630 & 0.702 & 2.073 & 1.122 & 0.541 \\
Passing time gap, Gp $(\mathrm{s})$ & 5.360 & 2.281 & 0.426 & 4.706 & 1.832 & 0.389 \\
Time to collision, TTC $(\mathrm{s})$ & 3.917 & 3.220 & 0.822 & 4.075 & 2.919 & 0.716 \\
Passing Time, PT $(\mathrm{s})$ & 15.451 & 5.130 & 0.332 & 14.578 & 4.637 & 0.318 \\
Distance start gap, Gs $(\mathrm{m})$ & 70.439 & 31.673 & 0.450 & 61.890 & 29.352 & 0.474 \\
Distance end gap, Ge $(\mathrm{m})$ & 57.76 & 35.93 & 0.622 & 52.419 & 27.084 & 0.517 \\
Passing distance gap, Gp $(\mathrm{m})$ & 128.165 & 49.382 & 0.385 & 114.308 & 42.139 & 0.369 \\
Distance traveled during Initial & 42.037 & 24.189 & 0.575 & 39.698 & 21.319 & 0.537 \\
maneuver, $\mathrm{d}_{1}(\mathrm{~m})$ & & & & & & \\
Distance traveled during & 150.000 & 52.152 & 0.348 & 138.930 & 46.874 & 0.337 \\
occupation of left lane, $\mathrm{d}_{2}(\mathrm{~m})$ & 87.543 & 66.032 & 0.754 & 99.401 & 68.200 & 0.686 \\
Clearance distance, $\mathrm{d}_{3}(\mathrm{~m})$ & & & & & & \\
Opposing vehicle distance & 79.561 & 39.178 & 0.492 & 77.041 & 33.963 & 0.441 \\
traveled, d $(\mathrm{m})$ & & & & & & \\
Total distance, $\mathrm{d}_{1}+\mathrm{d}_{2}+\mathrm{d}_{3}+\mathrm{d}_{4}$ & 359.141 & 97.312 & 0.271 & 355.070 & 104.625 & 0.295 \\
(m) & & & & & &
\end{tabular}

The sample was randomly selected from each group of passing drivers and included 34 males and 29 females between the ages of 18 and 64 years. The mean age was 27.19 years with a standard deviation of 11.10 years. The total number of passing maneuvers observed from scenarios 1 and 3 (no warning scenarios) at all passing zones was 169. The total number of passing maneuvers observed from scenarios 2 and 4 (warning scenarios) at all passing zones was 172. The driving 
simulator experiments recorded some accidents, which were then laminated from the collected data. From the original data of TTC, it appeared that there might be extreme outliers. According to Cimbala (2011), these outliers are from a few passing maneuver. Outliers of the data points that are statistically inconsistent within the rest of the data set. It should be noted that some "questionable" data points end up in the outlier's boundaries, but other data points do not. Questionable data points must not be discarded without the proper statistical justification. The results are shown in Table 3.2 and 3.3.

Table 3.3 illustrates that providing an audible warning signal to drivers resulted in improved performance. For example, passing speed increased by $3.17 \%$ when the warning signal was provided. TTC increased by $4.03 \%$ when the warning signal was provided. The total passing distance was also reduced by $1.13 \%$. These results indicate that the warning systems are beneficial and that they provide the driver with a certain level of comfort. This extra level of comfort is illustrated by the improved values in Table 3.3.

Table 3. 3: Comparison of Driving Parameters for Scenarios With and Without Audible Warnings (Design Speed 80 km/h)

\begin{tabular}{lccc}
\hline Variables & No-Warning & Warning & Different \% \\
\hline Passing speed, $\mathrm{Vp}(\mathrm{m} / \mathrm{s})$ & 23.78 & 24.54 & -3.17 \\
Speed difference, $\mathrm{m}(\mathrm{m} / \mathrm{s})$ & 4.29 & 4.21 & 1.75 \\
Average acceleration, $\mathrm{a}\left(\mathrm{m} / \mathrm{s}^{2}\right)$ & 0.77 & 0.69 & 9.53 \\
Time initial maneuver, $\mathrm{t}_{1}(\mathrm{~s})$ & 1.98 & 1.85 & 6.91 \\
Time occupation of left lane, $\mathrm{t}_{2}(\mathrm{~s})$ & 6.09 & 5.49 & 9.98 \\
Passing time gap, GT $(\mathrm{s})$ & 5.36 & 4.71 & 12.20 \\
Time to collision, TTC $(\mathrm{s})$ & 3.92 & 4.08 & -4.03 \\
Passing Time, PT $(\mathrm{s})$ & 15.45 & 14.58 & 5.65 \\
Distance traveled during Initial & 42.04 & 39.70 & 5.56 \\
maneuver, $\mathrm{d}_{1}(\mathrm{~m})$ & & & \\
Distance traveled during occupation of & 150.00 & 138.93 & 7.38 \\
left lane, $\mathrm{d}_{2}(\mathrm{~m})$ & 87.54 & 99.40 & -13.55 \\
Clearance distance, $\mathrm{d}_{3}(\mathrm{~m})$ & 79.56 & 77.04 & 3.17 \\
Opposing vehicle distance traveled, & 359.14 & 355.07 & 1.13 \\
$\mathrm{~d}_{4}(\mathrm{~m})$ & & & \\
Total distance, $\mathrm{d}_{1}+\mathrm{d}_{2}+\mathrm{d}_{3}+\mathrm{d}_{4}(\mathrm{~m})$ & & & \\
\hline
\end{tabular}




\subsubsection{Estimation of Passing Parameters}

Models for the passing parameters $\left(\mathrm{t}_{1}, \mathrm{t}_{2}\right.$, acc, etc) using the driving simulator are presented in Tables 3.4 and 3.5. These regression models were developed based on the original data using SAS (2015). It should be noted that the average weekly driving hours parameter was excluded from the models since it did not yield a good relationship.

Table 3. 4: Results for Passing Parameters using Driving Simulations (Design Speed 80 km/h)

\begin{tabular}{|c|c|c|c|c|c|c|c|c|}
\hline \multirow{2}{*}{ Variables } & \multicolumn{4}{|c|}{ No Warning Models } & \multicolumn{4}{|c|}{ Warning Models } \\
\hline & Coeff. & Std. error & t-value & p- & Coeff. & Std. error & t-value & p- \\
\hline \multicolumn{9}{|c|}{ Initial Passing Time (t1):Linear Regression Model } \\
\hline Constant & 2.8574 & 1.25860 & 2.27 & 0.0245 & 3.6076 & 0.61878 & 5.83 & $<.0001$ \\
\hline Gender & 0.5920 & 0.29391 & 2.01 & 0.0456 & 0.1625 & 0.16869 & 0.96 & 0.3367 \\
\hline Age (year) & 0.0555 & 0.04603 & 1.21 & 0.2298 & 0.0083 & 0.02135 & 0.39 & 0.6975 \\
\hline Exp (year) & -0.0883 & 0.05243 & -1.68 & 0.0941 & -0.0125 & 0.02694 & -0.46 & 0.6431 \\
\hline Passing speed, $\mathrm{Vp}(\mathrm{m} / \mathrm{sec})$ & -0.0841 & 0.03095 & -2.72 & 0.0073 & -0.0786 & 0.01852 & -4.24 & $<.0001$ \\
\hline Model (RMSE, F-value, $\mathrm{P}$ & $>\mathrm{F})$ & 1.54379 & 3.37 & 0.0111 & & 1.07411 & 4.58 & 0.0015 \\
\hline \multicolumn{9}{|c|}{ Passing Time (t2):Linear Regression Model } \\
\hline Constant & 10.2831 & 2.01011 & 5.12 & $<.0001$ & 8.0255 & 1.10264 & 7.28 & $<.0001$ \\
\hline Gender & 1.1642 & 0.46941 & 2.48 & 0.0141 & 0.5832 & 0.30060 & 1.94 & 0.0537 \\
\hline Age (year) & 0.1103 & 0.07351 & 1.50 & 0.1354 & 0.0044 & 0.03805 & 0.12 & 0.9074 \\
\hline Exp (year) & -0.1868 & 0.08374 & -2.23 & 0.0271 & -0.0565 & 0.04801 & -1.18 & 0.2406 \\
\hline Passing speed, $\mathrm{Vp}(\mathrm{m} / \mathrm{sec})$ & -0.2674 & 0.04943 & -5.41 & $<.0001$ & -0.1105 & 0.03301 & -3.35 & 0.0010 \\
\hline Model (RMSE, F-value, $\mathrm{P}$ & $>$ F) & 2.46559 & 10.47 & $<.0001$ & & 1.91401 & 4.69 & 0.0012 \\
\hline \multicolumn{9}{|c|}{ Acceleration Rate (acc):Linear Regression Model } \\
\hline Constant & 0.9154 & 0.44933 & 2.04 & 0.0432 & 2.1337 & 0.49194 & 4.34 & $<.0001$ \\
\hline Gender & 0.0846 & 0.10493 & 0.81 & 0.4213 & 0.1144 & 0.13411 & 0.85 & 0.3949 \\
\hline Age (year) & -0.0255 & 0.01643 & -1.55 & 0.1231 & -0.0279 & 0.01697 & -1.64 & 0.1017 \\
\hline Exp (year) & 0.0242 & 0.01872 & 1.29 & 0.1985 & 0.0287 & 0.02142 & 1.34 & 0.1821 \\
\hline Passing speed, $\mathrm{Vp}(\mathrm{m} / \mathrm{sec})$ & 0.0105 & 0.01105 & 0.95 & 0.3436 & -0.0398 & 0.01473 & -2.70 & 0.0074 \\
\hline Model (RMSE, F-value, $\mathrm{P}$ & $>$ F) & 0.55115 & 1.79 & 0.1328 & & 0.85393 & 2.63 & 0.0353 \\
\hline \multicolumn{9}{|c|}{ Deceleration Rate (dec):Linear Regression Model } \\
\hline Constant & -1.7586 & 1.13025 & -1.56 & 0.1217 & 0.2856 & 0.50138 & 0.57 & 0.5695 \\
\hline Gender & 0.0719 & 0.26419 & 0.27 & 0.7857 & -0.1908 & 0.13655 & -1.40 & 0.1638 \\
\hline Age (year) & -0.0328 & 0.04171 & -0.79 & 0.4330 & -0.0344 & 0.01696 & -2.03 & 0.0439 \\
\hline Exp (year) & -0.0105 & 0.04746 & -0.22 & 0.8258 & 0.0438 & 0.02133 & 2.05 & 0.0413 \\
\hline Passing speed, $\mathrm{Vp}(\mathrm{m} / \mathrm{sec})$ & 0.0858 & 0.02776 & 3.09 & 0.0024 & 0.0317 & 0.01469 & 2.15 & 0.0324 \\
\hline Relative distance, $\mathrm{df}(\mathrm{m})$ & 0.0010 & 0.00159 & 0.64 & 0.5227 & -0.0018 & 0.00072 & -2.54 & 0.0118 \\
\hline \multicolumn{2}{|c|}{ Model (RMSE, F-value, Pr>F) } & 1.38412 & 4.73 & 0.0005 & & 0.84974 & 3.09 & 0.0103 \\
\hline
\end{tabular}


Table 3. 5: Results for Passing Parameters using Driving Simulations (Design Speed 80 km/h)

\begin{tabular}{|c|c|c|c|c|c|c|c|c|}
\hline \multirow{2}{*}{ Variables } & \multicolumn{2}{|c|}{ No Warning Models } & \multicolumn{6}{|c|}{ Warning Models } \\
\hline & Coeff. & Std. error & t-value & p-value & Coeff. & Std. & t-value & p-value \\
\hline \multicolumn{9}{|c|}{ Starting Gap Time (Gs): Linear Regression Model } \\
\hline Constant & -1.0085 & 1.30928 & -0.77 & 0.4422 & 0.0072 & 1.10434 & 0.01 & 0.9948 \\
\hline Gender & 0.1184 & 0.26494 & -0.45 & 0.6556 & 0.4898 & 0.20739 & 2.36 & 0.0191 \\
\hline Age (year) & 0.0168 & 0.04149 & 0.40 & 0.6861 & 0.0238 & 0.02625 & 0.91 & 0.3653 \\
\hline Exp (year) & -0.0603 & 0.04726 & -1.28 & 0.2039 & -0.0652 & 0.03313 & -1.97 & 0.0503 \\
\hline $\begin{array}{l}\text { Speed difference, } \\
\mathrm{m}(\mathrm{m} / \mathrm{sec})\end{array}$ & 0.9611 & 0.27899 & 3.44 & 0.0007 & 0.5155 & 0.22773 & 2.26 & 0.0247 \\
\hline Model (RMSE, F-value & $\operatorname{Pr}>\mathrm{F})$ & 1.39158 & 6.70 & $<.0001$ & & 1.32052 & 3.78 & 0.0055 \\
\hline \multicolumn{9}{|c|}{ Ending Gap Time (Ge): Linear Regression Model } \\
\hline Constant & 1.6757 & 1.0107 & 1.66 & 0.0993 & 1.7137 & 0.4355 & 3.94 & 0.0001 \\
\hline Gender & 0.8445 & 0.3348 & 2.52 & 0.0126 & -0.1324 & 0.1613 & -0.82 & 0.4127 \\
\hline Age (year) & 0.0571 & 0.0519 & 1.10 & 0.2734 & -0.0214 & 0.0203 & -1.06 & 0.2912 \\
\hline Exp (year) & -0.0899 & 0.0595 & -2.95 & 0.0036 & 0.0119 & 0.0255 & 0.47 & 0.6392 \\
\hline $\begin{array}{l}\text { Relative distance, } \mathrm{df} \\
\text { (m) }\end{array}$ & -0.0060 & 0.0020 & -2.95 & 0.0036 & 0.0054 & 0.0009 & 6.29 & $<.0001$ \\
\hline Model (RMSE, F-value & $\operatorname{Pr}>F)$ & 1.7729 & 4.15 & 0.0032 & & 1.0149 & 11.73 & $<.0001$ \\
\hline \multicolumn{9}{|c|}{ Total Gap Time (GT): Linear Regression Model } \\
\hline Constant & 10.686 & 1.8739 & 5.70 & $<.0001$ & 7.2824 & 1.0428 & 6.98 & $<.0001$ \\
\hline Gender & 0.9783 & 0.4376 & 2.24 & 0.0267 & 0.6572 & 0.2843 & 2.31 & 0.0218 \\
\hline Age (year) & 0.0047 & 0.0685 & 0.07 & 0.9457 & -0.0109 & 0.0359 & -0.30 & 0.7626 \\
\hline Exp (year) & -0.0808 & 0.0781 & -1.03 & 0.3022 & -0.0464 & 0.0454 & -1.02 & 0.3085 \\
\hline $\begin{array}{l}\text { Passing speed, } \\
\mathrm{Vp}(\mathrm{m} / \mathrm{sec})\end{array}$ & -0.2303 & 0.0461 & -5.00 & $<.0001$ & -0.0983 & 0.0312 & -3.15 & 0.0019 \\
\hline Model (RMSE, F-value & $\operatorname{Pr}>F)$ & 2.2985 & 8.49 & $<.0001$ & & 1.8102 & 5.38 & 0.0004 \\
\hline \multicolumn{9}{|c|}{ Time to Collision (TTC): Linear Regression Model } \\
\hline Constant & -0.2758 & 0.6705 & -0.41 & 0.6813 & -1.6783 & 0.6609 & -2.54 & 0.0119 \\
\hline Gender & -0.8144 & 0.2221 & -3.67 & 0.0003 & -0.2319 & 0.2448 & -0.95 & 0.3445 \\
\hline Age (year) & -0.0085 & 0.0344 & -0.25 & 0.8056 & 0.0192 & 0.0307 & 0.63 & 0.5326 \\
\hline Exp (year) & 0.0431 & 0.0395 & 1.09 & 0.2767 & -0.0099 & 0.0387 & -0.26 & 0.7978 \\
\hline $\begin{array}{l}\text { Relative distance, } \mathrm{df} \\
\text { (m) }\end{array}$ & 0.0427 & 0.0014 & 31.53 & $<.0001$ & 0.0305 & 0.0013 & 23.38 & $<.0001$ \\
\hline $\begin{array}{l}\text { Model (MSE, F- } \\
\text { value, } \mathrm{Pr}>\mathrm{F} \text { ) }\end{array}$ & & 1.1760 & 268.85 & $<.0001$ & & 1.5403 & 143.64 & $<.0001$ \\
\hline R-Square & & 0.86768 & & & & 0.7389 & & \\
\hline
\end{tabular}

Two models were developed for each passing parameter, one using the no warning simulation and the other using the warning simulation. For the initial passing time $\left(\mathrm{t}_{1}\right)$, the no warning models 
yielded larger values than the warning models. This indicates that the driver requires a longer time to initiate the passing maneuver when there is no warning.

For the no warning models, the estimates were significant to the $10 \%$ level for all the model variables excluding age, which came in at $\sim 20 \%$ level of significance (P-value). For the warning models, gender, age, and experience, all came in at more than $30 \%$ level of significance, indicating a worst fit. The parameter estimates from the no warning models were also much higher compared to the warning models, indicating that the no warning models better capture the effect of the variables of interest. The same trend could be seen for passing time $\left(\mathrm{t}_{2}\right)$. For example, the age variable was significant to the $15 \%$ level in the no warning model, and highly insignificant at the $9 \%$ level for the warning model.

\subsection{Field Data Collection and Analysis}

This section describes the experimental field data collected using HD (High Definition) Dual Camera Car DVRs (Digital Video Recorders) and a Global Positioning System (GPS) data logger device installed on-board the passing, impeding, and opposing vehicles that records the instantaneous position (latitude, longitude, and altitude) and speed of the vehicles at 1s intervals. The GPS data logger used in this study (Holux RCV-3000) measures speed with a precision level of $0.1 \mathrm{~m} / \mathrm{s}(0.36 \mathrm{~km} / \mathrm{h})($ Holux, 2014). Since this system is normally applied to passing zones on two-lane highways with speed limits of $80 \mathrm{~km} / \mathrm{h}$, the relative error is expected to be insignificant. The analysis included a total of 105 passing maneuvers ( $t_{1}$ and $t_{2}$ ) obtained from 25 different drivers and vehicles that were randomly selected from various countries. This field data was then loaded onto a computer. The sample was randomly selected from each group of passing drivers and included 17 male and 8 female drivers between the ages of 20 and 63 years old. The mean age was 34 years with a standard deviation of 13 years. Appendix E provides a summary of the field data.

No specific instructions were given to the drivers about passing or not passing. The only instructions were that they drive normally and to pass when there is an opportunity. The individual 
drivers were unaware that there were two other drivers (with equipped vehicles) on the road in order to ensure that there was no impact on their behaviour. The impeding driver was instructed to slow down to produce possible passing maneuvers. The information about driver characteristics was collected using a questionnaire completed by each participant before the study began.

When analyzing the field data, the assumption was that the passing vehicle moved at a constant speed during the perception and reaction times before applying the gas pedal and accelerating. The passing vehicle then continued to accelerate at a constant rate (a) until it reached the maximum speed which is at the highest speed point. Once the passing vehicle decelerated at a constant rate (d), it returned to the left lane. In their respective PSD models, Glennon (1988) and Hassan et al. (1996) assumed that the driver's perception reaction time (PRT) prior to beginning a pass is equal to $1 \mathrm{~s}$. In addition, the minimum time headway (h) between the passing and impeding vehicles at the end of a completed passing maneuver is $1 \mathrm{~s}$ and the minimum time headway (ho) between the passing and opposing vehicles at the end of a completed passing maneuver is $1 \mathrm{~s}$. However, the ho values were found to be $2 \mathrm{~s}$ based on the results of current driving simulator studies.

The starting time, $t_{1}$, is defined as the time from the moment a passing vehicle decides to pass and moves the vehicle to cross the centre line towards the left lane (s). The starting gap time, Gs(t), is defined as the time from the moment the passing vehicle begins to cross the centre line towards the left lane until it reaches the critical point ( $\mathrm{s}$ ). Passing time, $t_{2}$, is defined as the time from the moment a passing vehicle begins to cross the centre line towards the left lane and travels in the left lane, to the moment it crosses the centre line and returns to the right lane (s). TTC is defined as the time between the opposing and passing vehicles when the passing vehicle completes the pass and drives back to the right lane (s), as shown in Figure 2.4. The time $\left(t_{4}\right)$ can be calculated as follows: $t_{4}=t_{o}=t_{2}-G_{s}=$ the opposing vehicle time (s). The time $\left(t_{o}\right)$ is calculated based on the AASHTO and TAC assumptions (Harwood et al., 1998).

In this study, the data for Gs ( $\mathrm{t}), t_{2}$ and TTc are recorded using a Smartphone by pressing "Start" and "Lap" when analyzing the video camera for passing vehicles that crossed the centre line towards the left lane, reached the critical point, and then travelled in the left lane. This information 
was used to determine the starting gap time, end gap time, and time to collision. The passing vehicle speed $\left(V_{p}\right)$, impeding vehicle speed $\left(V_{i}\right)$, and opposing vehicle speed $\left(V_{o}\right)$ were recorded using the GPS data logger installed on-board the passing, impeding, and opposing vehicles. The GPS data logger used in this study (Holux RCV-3000) measures speed with a precision level of $0.1 \mathrm{~m} / \mathrm{s}(0.36 \mathrm{~km} / \mathrm{h})$ (Holux Technology Inc., 2014). Since this system is normally applied to passing zones on two lane highways with speed limits of $80 \mathrm{~km} / \mathrm{h}$, the relative error is expected to be insignificant.

\subsubsection{Data Collection Process}

In this research study, the most important characteristic considered was the effect of human behaviour on PSD. Changes in reaction time, acceleration/deceleration time, and variations in speed according to the gender, age, experience, and driving scenario are all factors that affect human behaviour in regards to PSD. The dependent variables are the time and distance travelled within the left lane during the passing maneuver. The experiments were conducted by test drivers as they followed the impeding vehicle along a two-lane rural road and then performed either an acceleration/deceleration to complete or abort the pass. The test drivers chose an acceptable gap within the opposing traffic in order to complete or abort the passing maneuver.

The experimental scenarios were developed using random test drivers driving in passenger vehicles (passing, impeding and opposing vehicles) along a two-lane highway. The measurement tools included a GPS data logger and HD in-vehicle video cameras ( 2 devices on board of each passing, impeding and opposing vehicle). The GPS data logger measured the coordinates, distance and speed of the vehicles. Field data were collected at six passing zones on a two-lane highway at four sites in Mecca, Saudi Arabia, Abu Dhabi and Dubai, UAE and Muscat, Oman. The length of the passing zones ranged from $300 \mathrm{~m}$ to $1200 \mathrm{~m}$. The lane width for each direction was between $3.5 \mathrm{~m}$ and $4 \mathrm{~m}$. All data were collected during off-peak periods on roads with proper pavement conditions and optimal weather conditions. The traffic flow rates ranged from 100 to 250 vehicles/hr. Sites with low flow rates were selected because sites with higher flow rates had limited passing maneuvers, according to research conducted by Harwood et al. (2010). 
Table 3. 6: Passing Maneuver Parameters for the Field Study for the Mean, Standard Deviation and Coefficient of Variation (Design Speed $80 \mathrm{~km} / \mathrm{h}$ )

\begin{tabular}{lccc}
\hline Variables & Mean & Standard Deviation & COV \\
\hline$V_{p}(\mathrm{~m} / \mathrm{s})$ & 20.1 & 2.4 & 0.12 \\
$V_{i}(\mathrm{~m} / \mathrm{s})$ & 16.4 & 1.9 & 0.12 \\
$V_{o}(\mathrm{~m} / \mathrm{s})$ & 17.2 & 4.9 & 0.29 \\
$\mathrm{~m}(\mathrm{~m} / \mathrm{s})$ & 3.7 & 1.6 & 0.44 \\
$\mathrm{Lp}(\mathrm{m})$ & 5.8 & 0.006 & 0.001 \\
$\mathrm{Li}(\mathrm{m})$ & 5.8 & 0.006 & 0.001 \\
$\mathrm{~h}(\mathrm{~s})$ & 1.0 & 0.001 & 0.001 \\
$\mathrm{Acc}\left(\mathrm{m} / \mathrm{s}^{2}\right)$ & 0.61 & 0.30 & 0.49 \\
$\mathrm{Dec}\left(\mathrm{m} / / \mathrm{s}^{2}\right)$ & 0.27 & 0.30 & 1.12 \\
$\mathrm{t}_{1}(\mathrm{~s})$ & 3.6 & 0.6 & 0.18 \\
$\mathrm{t}_{2}(\mathrm{~s})$ & 9.6 & 2.5 & 0.26 \\
$\mathrm{Gs}(\mathrm{s})$ & 4.9 & 1.8 & 0.36 \\
$\mathrm{Ge}(\mathrm{s})$ & 3.2 & 1.0 & 0.32 \\
$\mathrm{TTC}(\mathrm{s})$ & 6.1 & 4.7 & 0.76 \\
$\mathrm{~d}_{1}(\mathrm{~m})$ & 62.5 & 16.8 & 0.27 \\
$\mathrm{~d}_{2}(\mathrm{~m})$ & 200.8 & 50.1 & 0.25 \\
$\mathrm{~d}_{3}(\mathrm{~m})$ & 36.6 & 11.9 & 0.33 \\
$\mathrm{~d}_{4}(\mathrm{~m})$ & 97.1 & 85.1 & 0.88 \\
$\mathrm{~d}(\mathrm{~m})$ & 396.9 & 106.9 & 0.27 \\
\hline
\end{tabular}

The speed limit for the sites was $80 \mathrm{~km} / \mathrm{hr}$. The sample was randomly selected from each group of passing drivers and included both male and female drivers of all ages. The total number of passing maneuvers observed at all passing zones was 105. The sample included 17 male and 8 female drivers between the ages of 20 and 63 years. The mean age was 34 years with a standard deviation of 13 years. Table 3.6 shows the results of the field data collected for all passing maneuvers.

The travel time and speed for each vehicle was recorded at $1 \mathrm{~s}$ time intervals using HD in-vehicle video cameras and GPS data loggers with an error rate below $1 \mathrm{~km} / \mathrm{hr}$. Table 3.6 shows the field data. When analyzing the passing maneuver parameters using the AT RISK software (Palisade Corporation, 2016), the passing vehicle speed, $V_{p}=23.5 \mathrm{~m} / \mathrm{s}$, suggested by AASHTO (2004), is 
consistent with the speed of the observed field data (95th percentile). The coefficient of correlation between $m$ and speed, $\rho_{m v}$, is 0.691 . The positive sign for this coefficient is logical because $m$ is expected to increase as the passing vehicle speed increases. A comparison of the elements of the PSD of the AASHTO model and current field studies are presented in Table 3.7 collected for various passing maneuvers.

Table 3. 7: Comparison of the Elements of the PSD Model (Design Speed $80 \mathrm{~km} / \mathrm{h}$ )

\begin{tabular}{lcc}
\hline Variables & AASHTO (2004) & Field Studies \\
\hline Passing speed, $\mathrm{Vp}(\mathrm{m} / \mathrm{s})$ & 23.5 & 20.1 \\
Speed difference, $\mathrm{m}(\mathrm{m} / \mathrm{s})$ & 4.2 & 3.7 \\
Average acceleration, a $\left(\mathrm{m} / \mathrm{s}^{2}\right)$ & 0.7 & 0.6 \\
Initial time, $\mathrm{t}_{1}(\mathrm{~s})$ & 4.3 & 3.6 \\
Time occupation of left lane, $\mathrm{t}_{2}(\mathrm{~s})$ & 10.7 & 9.6 \\
Distance traveled during Initial maneuver, $\mathrm{d}_{1}(\mathrm{~m})$ & 89.0 & 62.5 \\
Distance traveled during occupation of left lane, $\mathrm{d}_{2}(\mathrm{~m})$ & 251.0 & 200.8 \\
Clearance distance, $\mathrm{d}_{3}(\mathrm{~m})$ & 75.0 & 36.6 \\
Opposing vehicle distance traveled, $\mathrm{d}_{4}(\mathrm{~m})$ & 168.0 & 97.1 \\
Total distance $(\mathrm{m}), \mathrm{d}_{1}+\mathrm{d}_{2}+\mathrm{d}_{3}+\mathrm{d}_{4}$ & 583.0 & 396.9 \\
\hline
\end{tabular}

\subsubsection{Variability of PSD Parameters}

The observed field data for the parameters of various passing maneuvers are presented in Table 3.6. The table shows the mean $(\mu)$, standard deviation (SD), and the summary of the statistical measures for all 105 completed passing maneuvers. The passing maneuver parameters are consistent with those obtained in previous research conducted by AASHTO (2004) and Jenkins and Rilett (2005). When analyzing the passing maneuver parameters using the AT RISK software (Palisade Corporation, 2016), the distribution is generated for the goodness-of-fit statistics of ChiSquare and Kolmogorov-Smirnov. Each distribution generates new values for the statistic and the distributions of these values are displayed. For each distribution specified, the program tries to find a set of parameters that best fit the observed data (Palisade Corporation, 2016). 
The data for the speed of the passing $\left(V_{p}\right)$, impeding $\left(V_{i}\right)$ and opposing $\left(V_{o}\right)$ vehicles, as well as the time of initial maneuver $\left(t_{1}\right)$ followed a normal distribution shape, as shown in Figure 3.3. The data for the speed differential $(\mathrm{m})$, time the passing vehicle travels in the left lane $\left(t_{2}\right)$, average acceleration (a), start gap time $\left(G_{s}\right)$ and the end gap time $\left(G_{e}\right)$ followed a lognormal distribution shape. Meanwhile, the data for the time to collision (TTC) followed a Weibull distribution shape, as shown in Figure 3.4. The Weibull distribution parameters for TTC use the following equations:

$$
\begin{aligned}
& \mu_{x}=\alpha i \Gamma\left(1+\frac{1}{\beta i}\right) \\
& \sigma_{x}^{2}=\alpha i^{2} \Gamma\left(1+\frac{2}{\beta i}\right)-\left[\alpha i \Gamma\left(1+\frac{1}{\beta i}\right)\right]^{2}
\end{aligned}
$$

where $\mu_{x}=$ mean, $\sigma_{x}^{2}=$ standard deviation, $\Gamma=$ gamma function, $\alpha i=$ alpha and $\beta \mathrm{i}=$ beta. MATLAB was used to obtain the parameters $\alpha i=1.674$ and $\beta i=6.0788$. A summary of the statistical measures of the passing maneuver parameters is shown in Table 3.8.

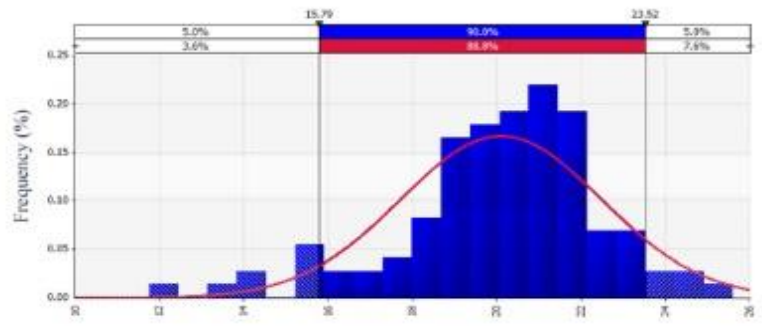

(a)

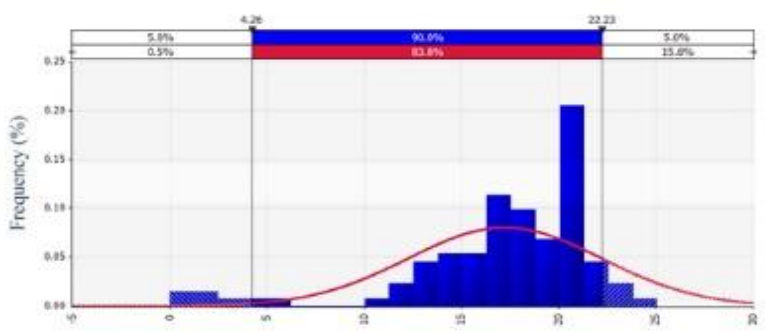

(c)

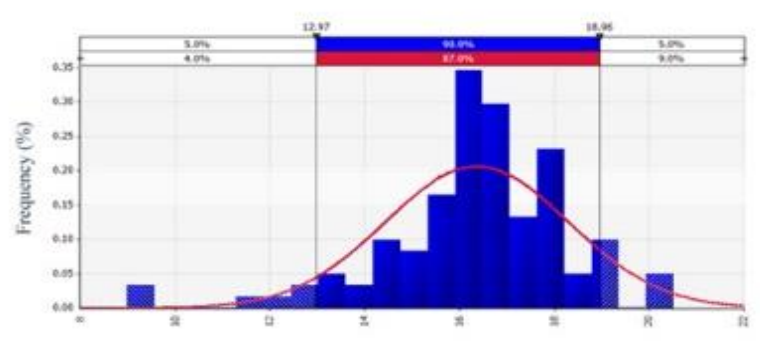

(b)

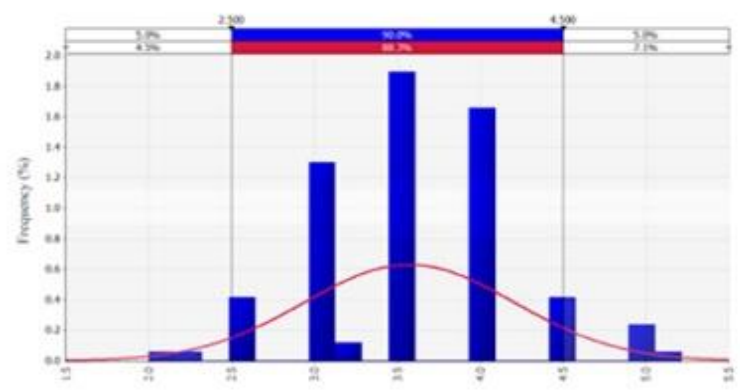

(d)

Figure 3. 3: Frequency Distributions of Observed Passing Maneuver Field Data: (a) Passing Vehicle Speed m/s; (b) Impeding Vehicle Speed m/s, (c) Opposing Vehicle Speed m/s, and (d) the Time of Initial Maneuver sec. 


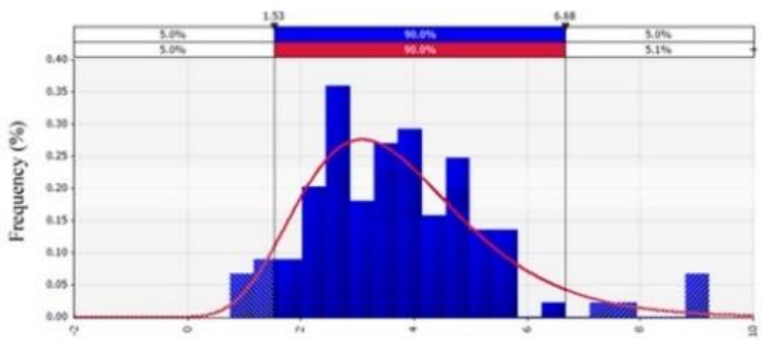

(a)

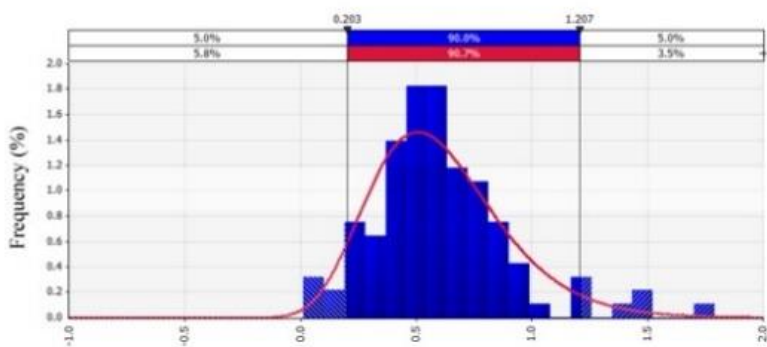

(c)

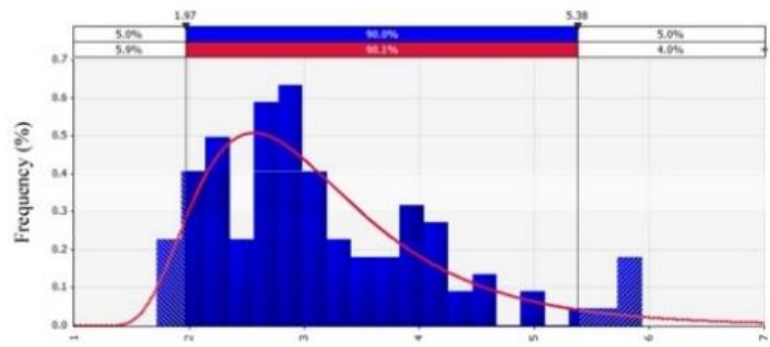

(e)

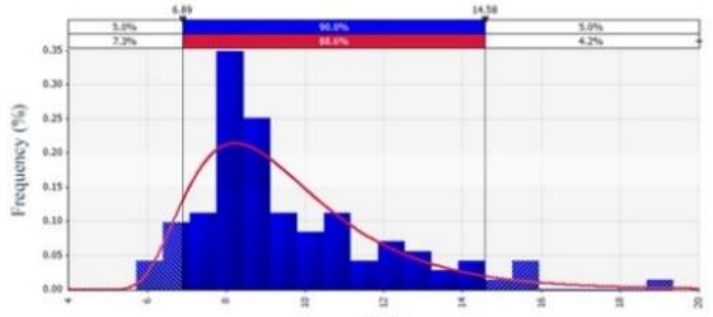

(b)

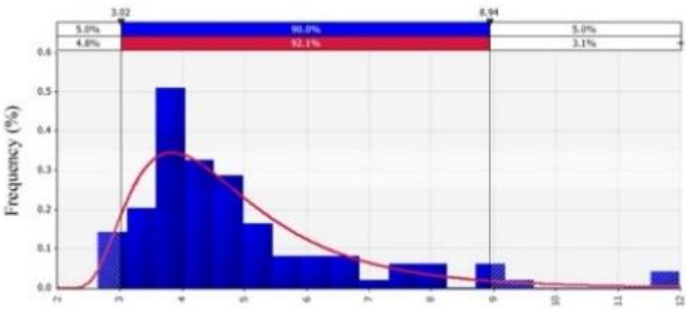

(d)

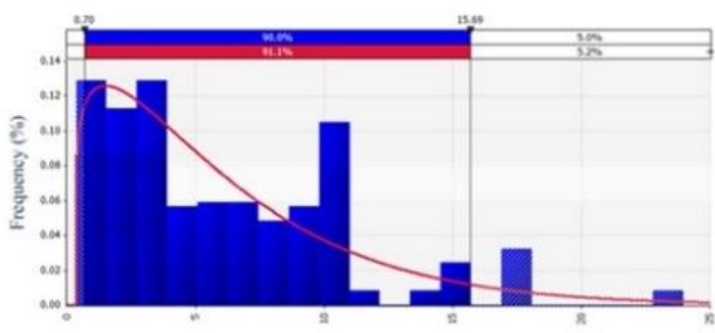

(f)

Figure 3. 4: Frequency Distributions of Observed Passing Maneuver Field Data: (a) Speed Differential $\mathrm{m} / \mathrm{s}$; (b) Time Passing Vehicle Travels in the Left Lane sec; (c) Average Acceleration m/s²; (d) Start Gap Time sec; (e) End Gap Time sec; and (f) Time to Collision sec.

The coefficient of correlation between TTC and speed reduction, $\rho_{t v}$, is 0.236 . The positive sign for this coefficient is logical because the TTC time is expected to increase as the passing vehicle speed decreases. Information regarding the mean $(\mu)$, standard deviation $(\sigma)$, probability distribution of the $V_{p}, V_{i}, V_{o}, m, a, t_{1}, t_{2}, G_{s}, G_{e}$, and TTC are needed for the Simulink models. Results for the statistical significance (95\% confidence interval) involving the mean for the passing maneuver parameters can be seen in Table 3.8. 
Table 3. 8: Passing Maneuver Parameters for the Field Study and Results of Statistical Significance for Passing Maneuvers (Design Speed $80 \mathrm{~km} / \mathrm{h}$ )

\begin{tabular}{lcccccccccc}
\hline Variables & Dist. & Mean & SD & DF & t-value & P-value & Chi-Sq & K-S & $\begin{array}{c}\text { 95th } \\
\text { \% }\end{array}$ & $\begin{array}{c}\text { 99th } \\
\text { \% }\end{array}$ \\
\hline $\mathrm{Vp}(\mathrm{m} / \mathrm{s})$ & Normal & 20.10 & 2.39 & 484 & 20.10 & 0.16 & 13.29 & 0.10 & 23.52 & 24.79 \\
$\mathrm{Vi}(\mathrm{m} / \mathrm{s})$ & Normal & 16.37 & 1.94 & 440 & 16.37 & 0.03 & 18.31 & 0.12 & 18.96 & 20.33 \\
$\mathrm{Vo}(\mathrm{m} / \mathrm{s})$ & Normal & 17.23 & 4.98 & 638 & 17.23 & 0.00 & 40.49 & 0.15 & 22.23 & 23.39 \\
$\mathrm{~m}(\mathrm{~m} / \mathrm{s})$ & Normal & 3.73 & 1.64 & 405 & 3.40 & 0.21 & 12.14 & 0.09 & 6.68 & 9.21 \\
$\mathrm{acc}\left(\mathrm{m} / \mathrm{s}^{2}\right)$ & Normal & 0.61 & 0.30 & 49 & 0.61 & 0.09 & 15.57 & 0.12 & 1.21 & 1.52 \\
$\mathrm{dec}\left(\mathrm{m} / \mathrm{s}^{2}\right)$ & Normal & 0.27 & 0.30 & 51 & -0.27 & 0.00 & 26.77 & 0.12 & 0.09 & 0.23 \\
$\mathrm{t}_{1}(\mathrm{~s})$ & Normal & 3.57 & 0.63 & 205 & 3.57 & 0.00 & 183.00 & 0.15 & 4.50 & 5.00 \\
$\mathrm{t}_{2}(\mathrm{~s})$ & Lognorm & 9.60 & 2.45 & 457 & 4.99 & 0.21 & 11.69 & 0.09 & 14.58 & 15.75 \\
$\mathrm{Gs}(\mathrm{s})$ & Lognorm & 4.90 & 1.78 & 368 & 2.83 & 0.01 & 20.83 & 0.12 & 8.94 & 11.91 \\
$\mathrm{Ge}(\mathrm{s})$ & Lognorm & 3.16 & 1.00 & 278 & 2.06 & 0.18 & 12.14 & 0.05 & 5.38 & 5.86 \\
$\mathrm{TTC}(\mathrm{s})$ & Weibull & 6.11 & 4.66 & 581 & - & 0.00 & 19.68 & 0.67 & 15.69 & 17.54 \\
\hline
\end{tabular}

DF: degree of freedom; Dist: Distribution; Chi-Sq: Chi-Square Statistic; K-S: Kolmogorov-Smirnov statistic; acc: Acceleration; dec: Deceleration; TTc alpha: 1.1674; TTc beta: 6.0788 .

\subsubsection{Comparison of Field and Driving Simulator Results}

The primary goal of this research study was to gain an understanding of the decision to accept or reject an available passing gap for different road designs and conditions. Detailed trajectory and driver demographic characteristic data was collected. The trajectory data included the speed, position, and acceleration of the passing vehicle as well as all other vehicles at a resolution of 0.1 s. This raw data was then used to calculate other variables of interest, such as relative speed and distance between vehicles. Available passing gaps were defined as the time gaps between the opposing vehicle and the passing vehicle at the time that the impeding vehicle encounters the passing vehicle. A total of 525 gaps were observed, and 105 passing maneuvers were completed. The following factors were included in the experimental design: (1) Passing gap time in the opposing lane(s), mean of $18.4 \mathrm{~s}$, minimum of $10.4 \mathrm{~s}$, and maximum of $27.7 \mathrm{~s}$, (2) Age, mean of 34.4 years, minimum of 20 years, maximum of 63 years, and (3) Experience, mean of 12.5 years, minimum of 1 year, maximum if 34 years. 
The gap acceptance analysis involved the characterization of each passing opportunity (the accepted and rejected passing gaps). Only passenger vehicles were considered in the analysis (for both impeding and passing vehicles). The following variables were taken into consideration: a) passing gap time (s): gaps between the opposing vehicle and the passing vehicle at the time that the impeding vehicle encounters the passing vehicle; b) acceptance: accepted or rejected gap; c) the visibility of opposing vehicles: opposing traffic is always visible in the simulator because there is unlimited sight distance and long gaps are discarded by the truncated negative exponential gap distribution. The field observations included both sight distance-limited cases (opposing vehicles were not seen) and opposing vehicle-limited cases (opposing vehicles were seen). Only the opposing-vehicle limited cases were included in the analysis in order to ensure that the two databases were valid for comparison; d) age and experience of the passing driver: collected in the field study; e) waiting time (s) from the time the passing vehicle began following the impeding vehicle; and f) impeding vehicle speed (m/s) (Llorca \& Farah, 2016).

Table 3.9 provides a summary of the field data (based on this study) and driving simulator (based on Farah, 2013) data for passenger cars and a comparison of the driver parameters for both studies. A comparison of the results from both of the data collection methods was also conducted, as well as a detailed analysis of passing performance. The number of observations may differ for each variable as a result of the different data collection methods used (i.e. age and experience can only be observed for the instrumented vehicle and not the static method).

There were slight differences in the gender distributions (32\% and $31 \%$ female for the field data and the driving simulator data, respectively). The age of the passing drivers was slightly higher for the field data (mean of 34.4 years for the field data compared to a mean of 33 years for the driving simulator data). There were no significant differences between the field and driving simulator distributions for gender and age. Table 3.9 compares the passing time gap (GT) for the impeding passenger car vehicle type. The passing time was slightly different but significantly higher for the field data. The speed of the passing (Vp) and impeding vehicles (Vi) differ in both studies. There were significantly lower speeds in the field study compared to the driving simulator study. Table 3.9 revealed significant differences in the distributions for the average speed difference $(\mathrm{m})$ 
between the passing and impeding vehicles. The average speed difference $(\mathrm{m})$ in the field study was significantly lower than the average speed difference in the driving simulator study.

Table 3. 9: Comparison between the Databases of the Field and Driving Simulator Studies (Design Speed $80 \mathrm{~km} / \mathrm{h}$ )

\begin{tabular}{|c|c|c|c|c|c|c|c|c|}
\hline \multirow{2}{*}{$\begin{array}{l}\text { Sample } \\
\text { Variable }\end{array}$} & \multicolumn{4}{|c|}{ Field data } & \multicolumn{4}{|c|}{$\begin{array}{l}\text { Driving Simulator data } \\
\text { (Farah, 2013) }\end{array}$} \\
\hline & Mean & SD & Min & Max & Mean & SD & Min & Max \\
\hline Passing time gap, GT (s) & 8.06 & 2.33 & 4.76 & 17.72 & 7.10 & 2.20 & 2.80 & 19.40 \\
\hline $\begin{array}{l}\text { Passing distance gap, GT } \\
\text { (m) }\end{array}$ & 161.01 & 45.81 & 80.04 & 324.05 & 175.50 & 56.30 & 68.50 & 403.00 \\
\hline Passing speed, $\mathrm{Vp}(\mathrm{km} / \mathrm{h})$ & 72.36 & 8.61 & 42.31 & 92.20 & 75.60 & 21.20 & 40.70 & 145.40 \\
\hline Following distance, $\mathrm{d} 12(\mathrm{~m})$ & 52.49 & 17.09 & 30.75 & 126.56 & 13.50 & 10.20 & 1.40 & 83.00 \\
\hline Impeding speed, Vi $(\mathrm{km} / \mathrm{h})$ & 58.91 & 6.97 & 32.33 & 73.89 & 60.50 & - & 38.50 & 61.50 \\
\hline Speed difference, $\mathrm{m}(\mathrm{km} / \mathrm{h})$ & 13.44 & 5.89 & 2.71 & 33.22 & 15.10 & 13.30 & 2.20 & 83.90 \\
\hline Relative distance, D (m) & 451.25 & 109.45 & 256.50 & 809.50 & 480.40 & 203.60 & 3.20 & 1006.70 \\
\hline $\begin{array}{l}\text { Relative speed }(\mathrm{Vp}-\mathrm{Vo}) \text {, } \\
(\mathrm{km} / \mathrm{h})\end{array}$ & 10.32 & 19.14 & -35.39 & 81.44 & 0.30 & 8.20 & $\begin{array}{c}- \\
17.90\end{array}$ & 23.90 \\
\hline Time start gap, Gs (s) & 4.90 & 1.78 & 2.65 & 11.99 & 1.60 & 1.30 & 0.20 & 11.10 \\
\hline Time end gap, Ge (s) & 3.16 & 1.00 & 1.72 & 5.94 & 5.50 & - & 2.60 & 8.30 \\
\hline Time to collision, TTC (s) & 6.11 & 4.66 & 0.36 & 23.98 & 3.90 & 4.10 & 0.06 & 25.70 \\
\hline
\end{tabular}

The initial relative distance between the passing and opposing vehicles $(D)$ was significantly higher with longer passing distances for the driving simulator data. The relative speed between the passing and opposing vehicles $(\mathrm{Vp}-\mathrm{Vo})$ was significantly higher for the field data. The time start gap (Gs) was significantly higher for the field data (Gs was on average 4.9 s). The time end gap (Ge) was significantly lower for the field data (Ge was on average $4.9 \mathrm{~s}$ ). The value of Ge was not presented in Farah (2013) and calculated in this study. Lastly, Table 3.9 shows the differences in the safety margin or time to collision (TTC). This table reveals that the differences in the safety margin were significantly higher for the field data (TTC average of $6.11 \mathrm{~s}$ ).

\subsection{Estimation of Passing Parameters}

Linear regression models were developed based on the field data using SAS software (SAS, 2015 ) for the initial time $\left(t_{1}\right)$, passing time $\left(t_{2}\right)$, average acceleration (acc) rate, average 
deceleration rate $(\mathrm{dec})$, starting gap time $\left(G_{s}\right)$, ending gap time $\left(G_{e}\right)$, total gap $\left(G_{T}\right)$, time to collision (TTC), speed increase $\left(\Delta V_{P 1}\right)$ and speed reduction $\left(\Delta V_{P 2}\right)$.

\subsubsection{Initial Passing Time $\left(t_{1}\right)$}

Regression analysis was performed to model $t_{\mathbf{1}}$ (see Figure 3.3) for normal driving conditions. The independent variables were the drivers' gender, age, driving experience, average weekly driving hours, and the speed of the passing vehicle. The repeated measures ANOVA revealed many significant variables which affect $t_{\mathbf{1}}$ during different passing maneuvers. Several variable combinations were verified to develop models for $t_{1}$ in kinematic conditions. The linear model was developed as follows:

$t_{1}=4.4409+0.0552$ Gender +0.0164 Age -0.0233 Exp -0.0179 Awh $-0.0358 v_{p}$

where $t_{1}=$ initial passing time $(\mathrm{s})$, Age $=$ passing vehicle driver age (years), Gender $=$ passing vehicle driver gender ( 0 for males and 1 for females), Exp = passing vehicle driver driving experience (years), Awh $=$ passing vehicle driver weekly driving hours (hours), and $v p=$ passing vehicle speed $(\mathrm{m} / \mathrm{s})$. The results revealed that, at a 95\% confidence level, the passing vehicle speed before reaching the critical point $\left(V_{p}\right)$ explained a suitable amount of the passing vehicle's speed decrease $(F=1.91)$. The estimated slope of the linear regression line was considerably significant $(\mathrm{t}=-1.31$, $\mathrm{p}$-value $=0.1939)$. The model Root MSE was 0.5886, the F-value was 4.3, and the $\operatorname{Pr}>$ F was $<0.0001$.

These results are an indication that increases in the initial passing time during the passing maneuver are linearly related to $V_{p}$ at the moment of initial acceleration. To ensure the acceptable performance of the proposed model, the model must consider the initial time of the passing driver in the passing maneuver, which is the time required by the driver to initiate the passing maneuver. The mean of the initial time was $3.572 \mathrm{~s}$ and the standard deviation was $0.634 \mathrm{~s} .95 \%$ of the observations were less than $4.5 \mathrm{~s}$. The second value $(3.6 \mathrm{~s})$ can therefore be used for design purposes. 


\subsubsection{Passing Time $\left(t_{2}\right)$}

Regression analysis was performed to model $t_{2}$ (see Figure 3.4) for normal driving conditions. The independent variables were the drivers' gender, age, driving experience, average weekly driving hours, and the speed of the passing vehicle. The repeated measures ANOVA revealed many significant variables which affect $t_{2}$ during different passing maneuvers. Several variable combinations were verified to develop models for $t_{2}$ in kinematic conditions. The linear model was developed as follows:

$$
t_{2}=8.968+3.515 \text { Gender }+0.223 \text { Age-0.303 Exp-0.166 Awh-0.111 } v_{p}
$$

where $t_{2}=$ passing vehicle time when occupying the left lane $(\mathrm{s}), V_{p}=$ passing vehicle speed $(\mathrm{m} / \mathrm{s})$. The results revealed that, at a $95 \%$ confidence level, the passing vehicle speed $\left(V_{p}\right)$ explained a suitable amount of the difference in the speed decrease $(F=1.60)$. The estimated slope of the linear regression line was considerably significant $(\mathrm{t}=-1.26$, $\mathrm{p}$-value $=0.2091)$. The model Root MSE was 1.8867, the F-value was 15.33, and $\mathrm{Pr}>\mathrm{F}$ was $<0.0001$. These results are an indication that increases in the passing time during the passing maneuver are linearly related to $V_{p}$ at the moment of initial acceleration. To ensure the acceptable performance of the proposed model, the model must consider the time the passing vehicle driver travels in the left lane, which is the time required by the driver to safely pass the slow moving vehicle. The mean of the initial time was $9.597 \mathrm{~s}$ and the standard deviation value was 2.452 s. $95 \%$ of the observations were less than $14.58 \mathrm{~s}$. The second value $(9.6 \mathrm{~s})$ can therefore be used for design purposes.

\subsubsection{Acceleration Rate (acc)}

Regression analysis was performed to model acc for normal driving conditions. The independent variables were the drivers' gender, age, driving experience and average weekly driving hours. For the second model, passing vehicle speed was added. The repeated measures ANOVA revealed many significant variables which affect acc during different passing maneuvers. Several variable 
combinations were verified in order to develop models for acc in kinematic conditions. The linear model was developed as follows:

$$
\mathrm{acc}=0.6789-0.0885 \text { Gender }-0.0015 \text { Age }+0.0009 \operatorname{Exp}+0.0001 \mathrm{Awh}+0.0014 \mathrm{Vp}
$$

where acc $=$ passing vehicle acceleration rate $\left(\mathrm{m} / \mathrm{s}^{2}\right)$. The results revealed that, at a $95 \%$ significance level, the passing vehicle speed, until it reaches the maximum speed $(V p)$, explained a suitable amount of the passing vehicle speed increase $(F=0.01)$. The estimated slope of the linear regression line was considerably significant $(\mathrm{t}=0.09$, $\mathrm{p}$-value $=0.9285)$. The model Root MSE is 0.3059; F-value is 0.36; and $\operatorname{Pr}>\mathrm{F}$ is <.0001. These results indicate that increases in the passing vehicle acceleration rate during the passing maneuver are linearly related to the drivers' gender, age, driving experience and average weekly driving hours at the moment of initial acceleration. These results are also an indication that increases in the passing vehicle acceleration rate during the passing maneuver are linearly related to $V p$ at the moment of initial acceleration.

\subsubsection{Deceleration Rate $(\mathrm{dec})$}

Regression analysis was performed to model dec for normal driving conditions. The independent variables were the drivers' gender, age, driving experience and average weekly driving hours. For the second model, the passing vehicle speed and the distance between the passing and opposing vehicles were added. The repeated measures ANOVA revealed many significant variables which affect dec during different passing maneuvers. Several variable combinations were verified in order to develop models for dec in kinematic conditions. The linear model was developed as follows:

$\operatorname{dec}=-1.0909+03490$ Gender +0.0068 Age -0.0111 Exp -0.0018 Awh +0.0204 Vp + $0.0004 d f(3.6)$ 
where $\operatorname{dec}=$ passing vehicle deceleration rate $\left(\mathrm{m} / \mathrm{s}^{2}\right)$. The results revealed that, at a $95 \%$ significance level, the passing vehicle speed, after it reaches the maximum speed $(V p)$, explained a suitable amount of the speed increase of the passing vehicle $(\mathrm{F}=8.31)$ and the increase in the distance between the passing and opposing vehicles $(d f)(\mathrm{F}=5.39)$. The estimated slope of the linear regression line was considerably significant for $V p(\mathrm{t}=2.11$, $\mathrm{p}$-value $=0.0376)$ and for $d f(\mathrm{t}$ $=1.63$, $\mathrm{p}$-value $=0.1067)$. The model Root MSE is 0.255485; F-value is 8.27; and $\operatorname{Pr}>\mathrm{F}$ is <.0001. These results are an indication that a decrease in the passing vehicle deceleration rate during the passing maneuver is linearly related to $V p$ and $d f$ at the moment of initial deceleration.

\subsubsection{Starting Gap Time $\left(G_{s}\right)$}

Regression analysis was performed to model $G_{s}$ for normal driving conditions. The independent variables were driver gender, age, driving experience, average weekly driving hours, and speed difference. The repeated measures ANOVA revealed many significant variables which affect $G_{s}$ during different passing maneuvers. Several combinations of variables were verified to develop models for $G_{s}$ in kinematic conditions. The linear model was developed as follows:

$G_{s}=2.646+1.964$ Gender +0.213 Age -0.244 Exp -0.117 Awh $-0.245 m$

where $G_{s}=$ starting gap time (s), Gender = passing vehicle driver gender ( 0 for males and 1 for females), $A g e=$ passing vehicle driver age (years), $\operatorname{Exp}=$ passing driver driving experience (years), $A w h=$ passing vehicle driver weekly driving hours (hours), and $m=$ speed difference $(\mathrm{m} / \mathrm{s})$. The results indicated that, at a 95\% significance level, the speed difference $(\mathrm{m})$ explained a suitable amount of the difference in the speed increase $(\mathrm{F}=5.42)$. The estimated slope of the linear regression line was considerably significant $(\mathrm{t}=-2.33$, $\mathrm{p}$-value $=0.0220)$. The model Root MSE is 1.4633; F-value is 10.86; and $\mathrm{Pr}>\mathrm{F}$ is <.0001. These results are an indication that the increase in starting gap time during the passing maneuver is linearly related to $m$ at the moment of starting initial acceleration. 


\subsubsection{Ending Gap Time (Ge)}

Regression analysis was performed to model $G_{e}$ for normal driving conditions. The independent variables were driver gender, age, driving experience, average weekly driving hours, and distance headway. The repeated measures ANOVA revealed many significant variables which affect $G_{e}$ during different passing maneuvers. Several combinations of variables were verified to develop models for $G_{e}$ in kinematic conditions. The linear model was developed as follows:

$G_{e}=2.324+1.003$ Gender +0.033 Age $-0.049 E x p-0.054$ Awh $+0.003 d f$

where $G_{e}=$ ending gap time (s) and $d f=$ the distance headway between the passing and opposing vehicles when the passing vehicle reached the critical point $(\mathrm{m})$. The results indicated that, at a 95\% significance level, the $d f$ value explained a suitable amount of the difference in the distance increase $(\mathrm{F}=22.28)$. The estimated slope of the linear regression line was considerably significant $(\mathrm{t}=4.72$, $\mathrm{p}$-value $=<.0001)$. The model Root MSE is 0.7689; F-value is 15.39; and $\mathrm{Pr}>\mathrm{F}$ is <.0001. These results are an indication that the increase in ending gap time during the passing maneuver is linearly related to $d f$ at the moment of starting initial deceleration.

\subsubsection{Total Gap Time $\left(G_{T}\right)$}

Regression analysis was performed to model $G_{T}$ for normal driving conditions. The independent variables were driver gender, age, driving experience, average weekly driving hours, and passing vehicle speed. The repeated measures ANOVA revealed many significant variables which affect $G_{T}$ during different passing maneuvers. Several combinations of variables were verified to develop models for $G_{T}$ in kinematic conditions. The linear model was developed as follows:

$G_{T}=7.845+3.323$ Gender +0.212 Age -0.285 Exp -0.156 Awh -0.128 Vp

where $G_{T}=$ total gap time (s) and $V p=$ the passing vehicle speed during the passing maneuver $(\mathrm{m} / \mathrm{s})$. The results indicated that, at a $95 \%$ significance level, the $V p$ value explained a suitable amount of the passing vehicle speed decrease $(\mathrm{F}=0.23)$. The estimated slope of the linear 
regression line was considerably significant $(\mathrm{t}=-1.52$, $\mathrm{p}$-value $=0.1327)$. The model Root MSE is 1.8195; F-value is 14.43; and $\mathrm{Pr}>\mathrm{F}$ is <.0001. These results are an indication that the increase in total gap time during the passing maneuver is linearly related to $V p$ at the moment of starting the initial crossing of the left lane.

\subsubsection{Time to Collision (TTC)}

Regression analysis was performed to model the TTC for normal driving conditions. The independent variables were driver gender, age, driving experience, average weekly driving hours, and opposing vehicle speed. The repeated measures ANOVA revealed many significant variables which affect $V o$ during different passing maneuvers. Several combinations of variables were verified to develop models for TTC in kinematic conditions. The linear model was developed as follows:

$\mathrm{TTC}=15.751+0.235$ Gender -0.125 Age +0.062 Exp +0.109 Awh -0.482 Vo

where TTC $=$ time to collision $(\mathrm{s})$ and $V o=$ the opposing vehicle speed $(\mathrm{m} / \mathrm{s})$. The results indicated that, at a 95\% significance level, the $V o$ value explained a suitable amount of the opposing vehicle speed decrease $(F=35.15)$. The estimated slope of the linear regression line was considerably significant $(\mathrm{t}=-5.92, \mathrm{p}$-value $=<0.0001)$. The model Root MSE is 3.9841; F-value is 8.70; and $\operatorname{Pr}$ $>\mathrm{F}$ is <.0001. These results are an indication that the increase in the time to collision is linearly related to $V o$ at the moment the passing vehicle returns to the right lane.

\subsubsection{Speed Increase $\left(\Delta V_{P 1}\right)$}

Speed Increase, $\Delta V_{P 1}$, is calculated from the moment the driver of the passing vehicle begins to accelerate to the moment the driver of the passing vehicle begins to decelerate. It is expected that the value for speed increase will be smaller when the speed difference $(m)$ is greater at early acceleration, as found in previous research conducted by Jenkins and Rilett (2005). In order to examine this, the linear regression analysis was conducted using regression ANOVA as follows: 
$\Delta V_{P 1}=8.528+0.630$ Gender -0.096 Age +0.021 Exp +0.017 Awh $+0.219 m$

The results indicated that, at a 95\% significance level, the speed difference $(m)$ explained a suitable amount of the difference in the speed increase $(\mathrm{F}=0.97)$. At a $95 \%$ significance level, the estimated slope of the linear regression line was considerably significant $(t=0.98, p$-value $=0.3272)$. The Root MSE is 3.0941, indicating a satisfactory explanation of the result. These results are an indication that the increase in speed of the passing vehicle during the passing maneuver is linearly related to $m$ at the moment of initial acceleration.

\subsubsection{Speed Reduction $\left(\Delta V_{P 2}\right)$}

Speed Reduction, $\Delta V_{P 2}$, is calculated from the moment the driver of the passing vehicle begins to decelerate. It is estimated that the speed reduction of a passing vehicle will be greater when the time to collision (TTC) is smaller, as found in previous research conducted by Jenkins and Rilett (2005). In order to examine this, a linear regression analysis was conducted using a regression ANOVA as follows:

$\Delta V_{P 2}=-2.219+2.552$ Gender -0.049 Age +0.022 Exp +0.034 Awh -0.177 TTC (3.12)

The results indicated that, at a 95\% significance level, the time to collision (TTC) explained a suitable amount of the speed decrease ( $\mathrm{F}=11.67)$. At a 95\% significance level, the estimated slope of the linear regression line was significant $(\mathrm{t}=-3.42$, $\mathrm{p}$-value $=0.0009)$. The Root MSE is 2.3943, indicating a satisfactory explanation of the result. These results indicate that the decrease in speed of the passing vehicle during the passing maneuver is linearly related to TTC at the moment of initial deceleration. 


\subsection{Verification and Discussion}

\subsubsection{Passing Parameters}

There is a reasonable explanation for choosing the parameters illustrated in the regression models. For the $t_{1}, t_{2}, G s, G e$, and GT models, a positive sign for the gender parameter indicates that female drivers take a longer time than male drivers under similar conditions. A positive sign for the age parameter indicates that time will increase with age. A negative sign for the driver experience and average weekly driver hour parameters indicates that drivers with high experience and average weekly hours take less time than drivers with less experience and less weekly hours under similar conditions, which is consistent with previous research conducted by Mehmood and Easa (2009). For the TTC model, a negative sign for $V o$ is logical because an increase in time to collision is expected as the speed of the opposing vehicle decreases, which is consistent with previous research conducted by Jenkins and Rilett (2005).

Passing maneuvers are complicated and drivers must make a number of decisions that are based on the prevailing passing conditions. The driver chooses the size gap within the opposing traffic, the distance to follow behind the impeding vehicle, and the distance he/she should leave in front of the impeding vehicle when returning to the right lane. The driver also chooses when he/she begins to accelerate, the rate at which he/she accelerates, when he/she begin to decelerate, and the rate at which he/she decelerates. The primary motivation for passing maneuvers is the desire to maintain a particular travelling speed. A passing driver will overtake an impeding vehicle by travelling at a higher speed within the opposing traffic lane. If there are no opposing vehicles in the opposing lane, the passing driver may choose to continue passing the impeding vehicle at a constant speed or accelerate to minimize the time spent in the left lane. If there are opposing vehicles in the left lane, the driver must slow down and follow the impeding vehicle until they have the opportunity to pass. Before the completion of the passing maneuver, the passing driver may choose to decelerate to a desired travel speed. 
Data for many passing maneuvers were examined in order to identify the moment when drivers accelerate or decelerate during passing maneuvers. The acceleration began once the passing vehicle moved towards the left lane. The deceleration began before the passing vehicle moved back into the right lane. These results are consistent with those obtained in previous research conducted by Jenkins (2004). Acceleration duration was calculated as a time interval from the time acceleration began to the time deceleration began.

A frequency distribution of passing vehicle speed $\left(V_{p}\right)$ duration for passing maneuvers is provided in Figure 3.3.a. The distribution was normal with a mean of $20.1 \mathrm{~m} / \mathrm{s}$ and a standard deviation of $2.4 \mathrm{~m} / \mathrm{s}$. All of the results were obtained using the Kolmogorov-Smirnov test $(\mathrm{Z}=0.10)$. A frequency distribution of the time of initial passing maneuver $\left(t_{1}\right)$ duration is provided in Figure 3.3.d. The time of initial maneuver duration distribution was normal with a mean of $3.6 s$ and a standard deviation of $0.6 \mathrm{~s}$. All of the results were obtained using the Kolmogorov-Smirnov test $(Z=0.15)$.

A PDF of the time passing vehicles travel in the left lane $\left(t_{2}\right)$ during passing maneuvers is provided in Figure 3.4.b. The distribution was lognormal with a mean of $9.6 s$ and a standard deviation of $2.5 \mathrm{~s}$. All of the results were obtained using the Kolmogorov-Smirnov test $(Z=0.09)$. A frequency distribution of the average acceleration ( $a c c$ ) duration for passing maneuvers is provided in Figure 3.4.c. The distribution was normal with a mean of $0.61 \mathrm{~m} / \mathrm{s}^{2}$ and a standard deviation of 0.30 $\mathrm{m} / \mathrm{s}^{2}$. All of the results were obtained using the Kolmogorov-Smirnov test $(\mathrm{Z}=0.12)$. The distributions reveal the variability in passing vehicle speed, the time of initial maneuver, the time that the passing vehicle travels in the left lane, and the average acceleration of drivers during passing maneuvers.

\subsubsection{Passing Gap Comparison}

The following data were based on a design speed of $80 \mathrm{~km} / \mathrm{h}$. For the field studies, a total of 525 gaps were observed and 105 passing maneuvers were completed. The following factors were included in the experimental design: (1) Passing gap time in the opposing lane (s), mean of $18.4 \mathrm{~s}$, 
minimum of 10.4 s, maximum of 27.7 s, (2) Age, mean of 34.4 years, minimum of 20 years, maximum of 63 years, and (3) Experience, mean of 12.5 years, minimum of 1 year, maximum of 34 years.

For the driving simulator studies (No-Warning), a total of 825 gaps were observed and 169 passing maneuvers were completed. The following factors were included in the experimental design: (1) Passing gap time in the opposing lane (s), mean of $15.654 \mathrm{~s}$, minimum of $5.813 \mathrm{~s}$, maximum of $38.34 \mathrm{~s}$, (2) Age, mean of 24.67 years, minimum of 18 years, maximum of 59 years, and (3) Experience, mean of 6.65 years, minimum of 0 year, maximum of 30 years.

Table 3.10 provides a comparison of the parameters for both the field study and the driving simulator study (No-Warning). It can be seen that the mean values for the parameters are higher for the field data compared to the simulator (no warning) data. This trend further affirms the fact that in simulations people drive more aggressively because there is no risk of injury or liability.

Table 3. 10: Comparison Between the Databases for the Field Study and Driving Simulator Study (Design Speed $80 \mathrm{~km} / \mathrm{h}$ )

\begin{tabular}{lcccccccc}
\hline Sample & \multicolumn{3}{c}{ Field Data } & \multicolumn{4}{c}{ Simulator Data - No-Warning } \\
\hline Variable & Mean & SD & Min & Max & Mean & SD & Min & Max \\
\hline Passing time gap, Gp (s) & 8.06 & 2.33 & 4.76 & 17.72 & 5.36 & 2.28 & 2.13 & 14.60 \\
Passing distance gap, Gp (m) & 161.01 & 45.81 & 80.04 & 324.05 & 128.17 & 49.38 & 37.00 & 312.00 \\
Passing speed, Vp (km/h) & 72.36 & 8.61 & 42.31 & 92.20 & 85.62 & 14.62 & 46.45 & 160.22 \\
Following distance, d12 (m) & 52.49 & 17.09 & 30.75 & 126.56 & 70.44 & 31.67 & 20.00 & 188.00 \\
Impeding speed, Vi (km/h) & 58.91 & 6.97 & 32.33 & 73.89 & 70.19 & 13.16 & 60.00 & 80.00 \\
Speed difference, m (km/h) & 13.44 & 5.89 & 2.71 & 33.22 & 15.44 & 1.46 & 7.98 & 19.35 \\
Relative distance, D (m) & 451.25 & 109.45 & 256.50 & 809.50 & 429.58 & 111.18 & 236.00 & 684.00 \\
Relative speed (Vp-Vo), & 10.32 & 19.14 & -35.39 & 81.44 & 5.62 & 14.62 & -33.55 & 80.22 \\
(km/h) & 4.90 & 1.78 & 2.65 & 11.99 & 3.04 & 1.49 & 0.54 & 9.02 \\
Time start gap, Gs (s) & 3.16 & 1.00 & 1.72 & 5.94 & 2.32 & 1.63 & 0.29 & 10.61 \\
Time end gap, Ge (s) & 6.11 & 4.66 & 0.36 & 23.98 & 3.92 & 3.22 & 0.06 & 15.55 \\
Time to collision, TTC (s) & & & & & & &
\end{tabular}

Table 3.11 provides a comparison of the parameters for both the warning and no warning driving simulator studies. For the warning driving simulator studies, a total of 860 gaps were observed and 172 passing maneuvers were completed. The following factors were included in the experimental 
design: (1) Passing gap time in the opposing lane (s), mean of $14.58 \mathrm{~s}$, minimum of $6.73 \mathrm{~s}$, maximum of $28.11 \mathrm{~s}$, (2) Age, mean of 25.75 years, minimum of 18 years, maximum of 64 years, and (3) Experience, mean of 6.64 years, minimum of 0 year, maximum of 30 years. A comparison of the results from both of the data collection methods was also conducted, as well as a detailed analysis of passing performance and gap-acceptance decisions.

Table 3. 11: Comparison of Passing Gap Parameters between the No-Warning and Warning Simulator Databases (Design Speed $80 \mathrm{~km} / \mathrm{h}$ )

\begin{tabular}{lcccccccc}
\hline Sample & \multicolumn{3}{c}{ No-Warning } & \multicolumn{4}{c}{ Warning } \\
\hline Variable & Mean & SD & Min & Max & Mean & SD & Min & Max \\
\hline Passing time gap, Gp (s) & 5.36 & 2.28 & 2.13 & 14.60 & 4.71 & 1.83 & 1.17 & 13.55 \\
$\begin{array}{l}\text { Passing distance gap, Gp } \\
\text { (m) }\end{array}$ & 128.17 & 49.38 & 37.00 & 312.00 & 114.31 & 42.14 & 20.00 & 324.00 \\
Passing speed, Vp (km/h) & 85.62 & 14.62 & 46.45 & 160.22 & 88.34 & 15.09 & 44.01 & 138.10 \\
Following distance, d12 & 70.44 & 31.67 & 20.00 & 188.00 & 61.89 & 29.35 & 10.00 & 217.00 \\
(m) & & & & & & & & \\
Impeding speed, Vi (km/h) & 70.19 & 13.16 & 60.00 & 80.00 & 73.17 & 13.58 & 60.00 & 80.00 \\
Speed difference, m (km/h) & 15.44 & 1.46 & 7.98 & 19.35 & 15.17 & 1.51 & 10.19 & 19.60 \\
Relative distance (C.P.), df & 167.10 & 86.51 & 29.00 & 418.00 & 176.44 & 85.72 & 20.00 & 420.00 \\
(m) & & & & & & & & \\
Relative speed (Vp-Vo), & 5.62 & 14.62 & -33.55 & 80.22 & 8.34 & 15.09 & -36.00 & 58.10 \\
(km/h) & 3.04 & 1.49 & 0.54 & 9.02 & 2.63 & 1.28 & 0.52 & 9.55 \\
Time start gap, Gs (s) & 2.32 & 1.63 & 0.29 & 10.61 & 2.07 & 1.12 & 0.52 & 9.38 \\
Time end gap, Ge (s) & 3.92 & 3.22 & 0.06 & 15.55 & 4.08 & 2.92 & 0.51 & 12.39 \\
Time to collision, TTC (s) & & & & & & & &
\end{tabular}

The number of observations may differ for each variable as a result of the different data collection methods used (i.e. age and experience can only be observed for the instrumented vehicle and not the static method). The mean values for all parameters show more aggressive behaviour in the presence of a warning system. This may be due to the fact that the drivers trusted the commands of the warning system and initiated the passing maneuver even in conditions they would not have if no audible signal was provided. Tables 3.12, 3.13, and 3.14 provide a comparison of the parameters for both the no-warning and warning driving simulator studies based on design speeds of $70 \mathrm{~km} / \mathrm{h}, 80 \mathrm{~km} / \mathrm{h}$, and $90 \mathrm{~km} / \mathrm{h}$, respectively. These tables illustrate that providing an audible warning signal to drivers resulted in improved performance. For a design speed of $70 \mathrm{~km} / \mathrm{h}$, passing speed increased by $6.26 \%$ when the warning signal was provided. The total passing distance was 
also reduced by $\sim 0.33 \%$. For a design speed of $80 \mathrm{~km} / \mathrm{h}$, passing speed increased by $3.17 \%$ when the warning signal was provided. The total passing distance was also reduced by $\sim 1.13 \%$.

Table 3. 12: Comparison of Passing Parameters between the No-Warning and Warning Simulator Databases (Design Speed $70 \mathrm{~km} / \mathrm{h}$ )

\begin{tabular}{lccc}
\hline Variables & No-Warning & Warning & Different \% \\
\hline Passing speed, $\mathrm{Vp}(\mathrm{m} / \mathrm{s})$ & 22.67 & 24.09 & -6.26 \\
Speed difference, $\mathrm{m}(\mathrm{m} / \mathrm{s})$ & 4.40 & 4.26 & 3.23 \\
Average acceleration, $\mathrm{a}\left(\mathrm{m} / \mathrm{s}^{2}\right)$ & 0.94 & 1.14 & -21.28 \\
Time initial maneuve, $\mathrm{t}_{1}(\mathrm{~s})$ & 1.89 & 1.72 & 8.99 \\
Time occupation of left lane, $\mathrm{t}_{2}(\mathrm{~s})$ & 5.38 & 4.99 & 7.25 \\
Distance traveled during Initial maneuver, $\mathrm{d}_{1}(\mathrm{~m})$ & 37.67 & 34.41 & 8.65 \\
Distance traveled during occupation of left lane, & 125.44 & 124.59 & 0.68 \\
$\mathrm{~d}_{2}(\mathrm{~m})$ & 51.22 & 56.36 & -10.04 \\
Clearance distance, $\mathrm{d}_{3}(\mathrm{~m})$ & 67.53 & 65.58 & 2.89 \\
Opposing vehicle distance traveled, $\mathrm{d}_{4}(\mathrm{~m})$ & 281.86 & 280.94 & 0.33 \\
Total distance, $\mathrm{d}_{1}+\mathrm{d}_{2}+\mathrm{d}_{3}+\mathrm{d}_{4}(\mathrm{~m})$ & & & \\
\hline
\end{tabular}

For a design speed of $90 \mathrm{~km} / \mathrm{h}$, passing speed increased by $7.25 \%$ when the warning signal was provided. The total passing distance was also reduced by $\sim 10.15 \%$. These results indicate that the warning systems are beneficial and that they provide the driver with a certain level of comfort. This extra level of comfort is illustrated by the improved values in Tables 3.12, 3.13, and 3.14.

Table 3. 13: Comparison of Passing Parameters between the No-Warning and Warning Simulator Databases (Design Speed 80 km/h)

\begin{tabular}{lccc}
\hline Variables & No-Warning & Warning & Different \% \\
\hline Passing speed, $\mathrm{Vp}(\mathrm{m} / \mathrm{s})$ & 23.78 & 24.54 & -3.17 \\
Speed difference, $\mathrm{m}(\mathrm{m} / \mathrm{s})$ & 4.29 & 4.21 & 1.75 \\
Average acceleration, $\mathrm{a}\left(\mathrm{m} / \mathrm{s}^{2}\right)$ & 0.77 & 0.69 & 9.53 \\
Time initial maneuve, $\mathrm{t}_{1}(\mathrm{~s})$ & 1.98 & 1.85 & 6.91 \\
Time occupation of left lane, $\mathrm{t}_{2}(\mathrm{~s})$ & 6.09 & 5.49 & 9.98 \\
Distance traveled during Initial maneuver, $\mathrm{d}_{1}(\mathrm{~m})$ & 42.04 & 39.70 & 5.56 \\
Distance traveled during occupation of left lane, & 150.00 & 138.93 & 7.38 \\
$\mathrm{~d}_{2}(\mathrm{~m})$ & 87.54 & 99.40 & -13.55 \\
Clearance distance, $\mathrm{d}_{3}(\mathrm{~m})$ & 79.56 & 77.04 & 3.17 \\
Opposing vehicle distance traveled, $\mathrm{d}_{4}(\mathrm{~m})$ & 359.14 & 355.07 & 1.13 \\
Total distance, $\mathrm{d}_{1}+\mathrm{d}_{2}+\mathrm{d}_{3}+\mathrm{d}_{4}(\mathrm{~m})$ & & & \\
\hline
\end{tabular}


Table 3. 14: Comparison of Passing Parameters between the No-Warning and Warning Simulator Databases (Design Speed $90 \mathrm{~km} / \mathrm{h}$ )

\begin{tabular}{lccc}
\hline Variables & No-Warning & Warning & Different \% \\
\hline Passing speed, $\mathrm{Vp}(\mathrm{m} / \mathrm{s})$ & 24.14 & 25.89 & -7.25 \\
Speed difference, $\mathrm{m}(\mathrm{m} / \mathrm{s})$ & 4.25 & 4.08 & 4.12 \\
Average acceleration, $\mathrm{a}\left(\mathrm{m} / \mathrm{s}^{2}\right)$ & 0.97 & 0.78 & 19.59 \\
Time initial maneuve, $\mathrm{t}_{1}(\mathrm{~s})$ & 2.05 & 2.00 & 2.44 \\
Time occupation of left lane, $\mathrm{t}_{2}(\mathrm{~s})$ & 6.33 & 5.74 & 9.32 \\
Distance traveled during Initial maneuver, $\mathrm{d}_{1}(\mathrm{~m})$ & 44.34 & 46.56 & -5.01 \\
Distance traveled during occupation of left lane, & 157.90 & 149.87 & 5.09 \\
$\mathrm{~d}_{2}(\mathrm{~m})$ & 119.66 & 84.76 & 29.17 \\
Clearance distance, $\mathrm{d}_{3}(\mathrm{~m})$ & 79.73 & 79.69 & 0.05 \\
Opposing vehicle distance traveled, $\mathrm{d}_{4}(\mathrm{~m})$ & 401.63 & 360.88 & 10.15 \\
Total distance, $\mathrm{d}_{1}+\mathrm{d}_{2}+\mathrm{d}_{3}+\mathrm{d}_{4}(\mathrm{~m})$ & & & \\
\hline
\end{tabular}

\subsection{Chapter Summary}

This chapter presented methodology for the analysis of passing maneuvers using a driving simulator and data collected using field data. This study investigated the effect of driver behaviour on passing maneuvers and presented regression models for initial time, passing time, acceleration rate, starting gap, ending gap, and time to collision, which are necessary elements of passing maneuvers. The driver factors included gender, age, driving experience, and average weekly driving hours. Different scenarios were used to capture the impact of factors related to the various vehicles involved and different driver characteristics. The driving simulator and field data estimations of passing parameters will be used to develop and validate the passing sight distance model in Chapter 4. These data will be applied to a Simulink simulation model which will be discussed in Chapter 7 under the implementation phase of this dissertation. 


\section{CHAPTER 4: DEVELOPMENT OF PSD MODEL}

This chapter covers the first part of the design phase. i.e. using driving simulator data to develop the proposed PSD model. The PSD model assumptions and model structure are described, followed by model validation and a comparison using the data obtained from the field study. This chapter describes the proposed PSD model, which will be used in the development of an in-vehicle warning system (discussed in detail in Chapter 6). The proposed PSD model reflects the driver behaviour in passing maneuvers as was observed in the driving simulator study. A comparison between existing PSD models and the proposed model as well as a discussion of the variability of key parameters is then presented, followed by a chapter summary.

\subsection{PSD Model Assumptions}

The following are some assumptions made by previous authors in order to formulate and solve the equations required to establish minimum PSD's:

1. The impeding vehicle travels at a constant speed of $v-m$, which is less than the design speed of vd;

2. The opposing vehicle travels at a design speed of $v_{d}$;

3. At the beginning of a pass, the passing vehicle trails the impeding vehicle while travelling at a speed of $v-m$;

4. Then, the passing vehicle accelerates at constant rate, a, to the design speed $v_{d}$, at or prior to the critical position, then continues at the design speed unless the passing maneuver is aborted;

5. Once the pass builds up, the sight distance required for the passing vehicle to abort the pass will increase and the sight distance required to complete the pass will decrease;

6. A two second time headway occurs between the passing and opposing vehicles at the end of the pass. 


\subsection{Model Structure}

The components of the PSD criteria for the model developed in this study are illustrated in Figure 3.3. The PSD calculations used in the model developed in this study are similar to those used in the AASHTO model (Equation (2.1)). $d_{1}$, and $d_{2}$ are similar to those used in the AASHTO model, as shown below, however, $d_{3}$ and $d_{4}$ are developed as follows:

$$
\begin{aligned}
& d_{1}=t_{1}\left(v_{p}-m+\frac{a t_{1}}{2}\right) \\
& d_{2}=v_{p} t_{2} \\
& d_{3}=h\left(v_{p}+v_{o}\right) \\
& d_{4}=t_{o} v_{o}
\end{aligned}
$$

where $v_{p}$ and $v_{o}=$ passing and opposing vehicle speed during the passing maneuver $(\mathrm{m} / \mathrm{s})$, respectively; $t_{1}=$ time that the passing vehicle traveled during the perception-reaction times and acceleration towards crossing the left lane $(\mathrm{s}) ; t_{2}=$ time that the passing vehicle occupied the left lane $(\mathrm{s}) ; h=$ time headway at the end of the pass $(\mathrm{s}) ; a=$ average acceleration $\left(\mathrm{m} / \mathrm{s}^{2}\right), t_{o}=t_{2}-$ $G_{S}=\left(\frac{1}{2}\right) t_{2}=$ the opposing vehicle time (s). $t_{o}$ is calculated based on the driving simulator data and follows the AASHTO (2004) and TAC (2007) assumptions, as described in previous research conducted by Harwood et al. (1998). Based on the trajectories of the vehicles, $d_{4}$ is calculated from the time the passing vehicle moves from the critical point to return to the right lane, which is consistent with the research conducted by Farah (2013).

According to Glennon (1988) and Hassan et al. (1996), the head-on-clearance time $(h)$ is the time between the passing and opposing vehicles at the end time headway. AASHTO (2001) considered values in excess of $3 \mathrm{~s}$ starting from speeds over $64 \mathrm{~km} / \mathrm{h}$. Polus et al. (2000) found values of headon clearance ranging from 1.5 to $2.5 \mathrm{~s}$. El Khoury (2005) measured this parameter from the simulation for both completed and aborted passing maneuvers. The head-on clearance values influenced the risk index of every run of the simulation. Passing maneuvers with a final clearance time value under $2 \mathrm{~s}$ are considered risky. The author selected an average clearance time value of 
$2 \mathrm{~s}$. The value of $h$ is $2 \mathrm{~s}$ based on the driving simulator data, which is consistent with previous research conducted by El Khoury (2005) and El Khoury and Hobeika (2007). As previously explained, the passing and opposing vehicle speeds are considered in order to determine the passing maneuver on a two-lane highway. The proposed PSD is computed using the following equation:

$$
P S D=t_{1}\left(v_{d}-m+\frac{a t_{1}}{2}\right)+t_{2} v_{d}+h\left(2 v_{d}\right)+\left(\frac{1}{2}\right) t_{2} v_{d}
$$

where $P S D=$ passing sight distance $(\mathrm{m})$; and $v_{d}=$ design speed $(\mathrm{m} / \mathrm{s})$. The differential speed, $\mathrm{m}$, for a design speed of $80 \mathrm{~km} / \mathrm{h}$ was a constant value of $4.167 \mathrm{~m} / \mathrm{s}(15 \mathrm{~km} / \mathrm{h})$ based on the AASHTO design guide. Conversely, based on the field studies, the values for $\mathrm{m}$ were calculated by Glennon (1988), Harwood and Glennon (1989), Hassan et al. (1996), and El Khoury and Hobeika (2007) as shown in the following equation:

$$
m=24-\frac{v_{d}}{10}
$$

where $\mathrm{m}=$ speed differential $(\mathrm{km} / \mathrm{h})$, and $v_{d}=$ design speed $(\mathrm{km} / \mathrm{h})$. The proposed PSD model uses the driving simulator data based on design speeds of $70 \mathrm{~km} / \mathrm{h}, 80 \mathrm{~km} / \mathrm{h}$, and $90 \mathrm{~km} / \mathrm{h}$ for the safety margin with respect to the minimum PSD calculation. In order to verify the accuracy of this hypothesis, the safety margin for the proposed PSD calculation was compared to the field data. In addition, the safety margin for the proposed PSD was compared to the AASHTO (2011), AASHTO (2004), TAC (2007), MUTCD (2003), Glennon (1988), and Hassan et al. (1996) models. This comparison shows the superior mean value of the proposed model; however, it is important to note that the AASHTO (2011) model provides a more liberal estimate while the AASHTO (2004) model provides a more conservative estimate compared to the other PSD models. Additionally, AASHTO (2011) claims that the AASHTO (2004) model is more conservative and that PSD estimates should follow the MUTCD (2003) model. However, AASHTO (2011) did not include any formula to calculate PSD and more research is recommended to develop a new PSD model. 


\subsection{Model Validation and Comparison}

In order to test the validity of different models, the models presented in this study were compared with the PSD requirements from the models developed by AASHTO (2011), AASHTO (2004), TAC (2007), MUTCD (2003), Glennon (1988), and Hassan et al. (1996). In the AASHTO (2004) study, different passing vehicle speeds were used to measure the distance travelled by the passing vehicle from the initial passing maneuver point until it reached the right lane, and the time that elapsed while travelling this distance. The current driving simulator data were used to determine the required PSD for each passing vehicle speed using the following assumptions:

1) The opposing vehicle is travelling at the same speed as the passing vehicle, which is equal to the design speed, $v_{d}$.

2) The speed differential, m, was calculated using Equation (4.6) based on the Glennon (1988), Hassan et al. (1996), and El Khoury and Hobeika (2007) assumptions.

3) The minimum time headway, h, between the passing and opposing vehicles at the end of the pass is $2 \mathrm{~s}$, based on the results of current driving simulator studies and the El Khoury and Hobeika, (2007) assumptions.

4) The clearance distance between the passing and opposing vehicles at the end of the pass was $2 v_{d} h$ instead of the constant distance for each speed which is assumed by the AASHTO model.

5) The distance travelled by the opposing vehicle was $\left(\frac{1}{2}\right) t_{2} v_{d}$, based on the results of current driving simulator studies instead of the distance $\left(\frac{2}{3}\right) t_{2} v$ which is assumed by the AASHTO model.

6) The acceleration rate values were calculated according to the values provided by the driving simulator studies for initial acceleration rates during a passing maneuver (Table 4.1).

7) $t_{1}$ and $t_{2}$ were calculated according to the values provided by driving simulator studies for initial time rates and passing time (Table 4.1). 
8) The comparison of PSD Values $(m)$ between estimated PSD model (Equation (4.5)) and observed driving simulator data for design speeds of $70 \mathrm{~km} / \mathrm{h}, 80 \mathrm{~km} / \mathrm{h}$, and $90 \mathrm{~km} / \mathrm{h}$ are presented in Tables 4.2, 4.3, and 4.4, respectively.

9) The comparison of PSD Values $(m)$ from various PSD models and the model presented in this chapter is shown in Table 4.5.

The estimation of difference $(\%)$ is a measure of how effectively the proposed PSD model estimates the passing parameters and passing sight distance. The difference was calculated using the following equation:

Difference $\%=\frac{\text { Estimated-Observed }}{\text { Observed }} \times 100$

Table 4. 1: Elements of the Safe PSD Model

\begin{tabular}{lccc}
\hline & \multicolumn{3}{c}{ Speed Range $(\mathrm{km} / \mathrm{h})$} \\
\cline { 2 - 4 } Component of PSD & $70-79$ & $80-89$ & $90-99$ \\
\hline Passing speed $(\mathrm{km} / \mathrm{h})$ & 70 & 80 & 90 \\
Speed difference $(\mathrm{km} / \mathrm{h})$ & 17 & 16 & 15 \\
Initial maneuver: & & & \\
$\mathrm{a}=$ average acceleration $(\mathrm{km} / \mathrm{h} / \mathrm{s})$ & 3.400 & 3.500 & 3.500 \\
$\mathrm{t}_{1}=$ time $(\mathrm{s})$ & 1.88 & 1.982 & 2.054 \\
$\mathrm{~d}_{1}=$ distance traveled $(\mathrm{m})$ & 29.37 & 37.17 & 44.88 \\
Occupation of left lane: & & & \\
$\mathrm{t}_{2}=$ time $(\mathrm{s})$ & 5.426 & 6.093 & 6.33 \\
$\mathrm{~d}_{2}=$ distance traveled $(\mathrm{m})$ & 105.59 & 135.51 & 158.38 \\
Clearance length: & & & \\
$\mathrm{h}=$ time headway $(\mathrm{s})$ & 2 & 2 & 2 \\
$\mathrm{~d}_{3}=$ distance traveled $(\mathrm{m})$ & 77.84 & 88.96 & 100.08 \\
Opposing vehicle: & & & \\
$\mathrm{d}_{4}=$ distance traveled $(\mathrm{m})$ & 52.79 & 67.75 & 79.19 \\
Total distance $(\mathrm{m}), \mathrm{d}_{1}+\mathrm{d}_{2}+\mathrm{d}_{3}+\mathrm{d}_{4}$ & 265.60 & 329.40 & 382.52 \\
\hline
\end{tabular}

The proposed model provides PSD requirements which closely resemble the results obtained from the field data, ensuring safe and comfortable passing maneuvers. Interestingly, the safety margin and PSD requirements for a comfortable passing maneuver obtained using the PSD model 
developed in this study increase once the design speed increases, and therefore, the degree of possible hazards resulting from human errors or a shift in the model's assumptions increases. For example, changing the model's assumptions causes a higher perception-reaction time because of any type of accident. This safety margin can overcome these hazards.

Table 4. 2: Comparison between Estimated PSD Model and Observed Driving Simulator Data (Design Speed $70 \mathrm{~km} / \mathrm{h}$ )

\begin{tabular}{lccc}
\hline Variables & Estimated & Observed & Different $\%$ \\
\hline Design Speed, $\mathrm{V}_{\mathrm{d}}(\mathrm{km} / \mathrm{h})$ & 70.00 & 70.00 & 0.00 \\
Impeding vehicle $\mathrm{speed}, \mathrm{V}_{\mathrm{i}}(\mathrm{km} / \mathrm{h})$ & 53.00 & 54.16 & -2.14 \\
Speed difference, $\mathrm{m}(\mathrm{km} / \mathrm{h})$ & 17.00 & 15.84 & 7.32 \\
Average acceleration, $\mathrm{a}(\mathrm{km} / \mathrm{h} / \mathrm{s})$ & 3.40 & 3.40 & 0.00 \\
Initial maneuver time, $\mathrm{t}_{1}(\mathrm{~s})$ & 1.89 & 1.89 & 0.00 \\
Passing time, $\mathrm{t}_{2}(\mathrm{sec})$ & 5.38 & 5.38 & 0.00 \\
Time headway, $\mathrm{h}(\mathrm{sec})$ & 2.00 & 2.00 & 0.00 \\
Distance for initial maneuver, $\mathrm{d}_{1}(\mathrm{~m})$ & 30.88 & 37.67 & -18.01 \\
Distance occupation of left lane, $\mathrm{d}_{2}(\mathrm{~m})$ & 104.69 & 125.44 & -16.54 \\
Clearance distance, $\mathrm{d}_{3}(\mathrm{~m})$ & 77.84 & 51.22 & 51.97 \\
distance of opposing vehicle, $\mathrm{d}_{4}(\mathrm{~m})$ & 52.35 & 67.53 & -22.48 \\
Total distance $(\mathrm{m}), \mathrm{d}_{1}+\mathrm{d}_{2}+\mathrm{d}_{3}+\mathrm{d}_{4}$ & 265.77 & 281.86 & -5.71 \\
\hline
\end{tabular}

Table 4. 3: Comparison between Estimated PSD Model and Observed Driving Simulator Data (Design Speed $80 \mathrm{~km} / \mathrm{h}$ )

\begin{tabular}{lccc}
\hline Variables & Estimated & Observed & Different $\%$ \\
\hline Design Speed, $\mathrm{V}_{\mathrm{d}}(\mathrm{km} / \mathrm{h})$ & 80.00 & 80.00 & 0.00 \\
Impeding vehicle speed, $\mathrm{V}_{\mathrm{i}}(\mathrm{km} / \mathrm{h})$ & 64.00 & 64.56 & -0.87 \\
Speed difference, $\mathrm{m}(\mathrm{km} / \mathrm{h})$ & 16.00 & 15.44 & 3.63 \\
Average acceleration, a $(\mathrm{km} / \mathrm{h} / \mathrm{s})$ & 3.40 & 3.40 & 0.00 \\
Initial maneuver time, $\mathrm{t}_{1}(\mathrm{~s})$ & 1.98 & 1.98 & 0.00 \\
Passing time, $\mathrm{t}_{2}(\mathrm{~s})$ & 6.09 & 6.09 & 0.00 \\
Time headway, $\mathrm{h}(\mathrm{s})$ & 2.00 & 2.00 & 0.00 \\
Distance for initial maneuver, $\mathrm{d}_{1}(\mathrm{~m})$ & 37.12 & 42.04 & -11.70 \\
Distance occupation of left lane, $\mathrm{d}_{2}(\mathrm{~m})$ & 135.51 & 150.00 & -9.66 \\
Clearance distance, $\mathrm{d}_{3}(\mathrm{~m})$ & 88.96 & 87.54 & 1.62 \\
distance of opposing vehicle, $\mathrm{d}_{4}(\mathrm{~m})$ & 67.75 & 79.56 & -14.84 \\
Total distance, $\mathrm{d}_{1}+\mathrm{d}_{2}+\mathrm{d}_{3}+\mathrm{d}_{4}$ & 329.34 & 359.14 & -8.30 \\
\hline
\end{tabular}


Table 4. 4: Comparison between Estimated PSD Model and Observed Driving Simulator Data (Design Speed $90 \mathrm{~km} / \mathrm{h}$ )

\begin{tabular}{lccc}
\hline Variables & Estimated & Observed & Different $\%$ \\
\hline Design Speed, $\mathrm{V}_{\mathrm{d}}(\mathrm{km} / \mathrm{h})$ & 90.000 & 90.000 & 0.000 \\
Impeding vehicle $\mathrm{speed}, \mathrm{V}_{\mathrm{i}}(\mathrm{km} / \mathrm{h})$ & 75.000 & 74.690 & 0.415 \\
Speed difference, $\mathrm{m}(\mathrm{km} / \mathrm{h})$ & 15.000 & 15.310 & -2.025 \\
Average acceleration, a $(\mathrm{km} / \mathrm{h} / \mathrm{s})$ & 3.500 & 3.500 & 0.000 \\
Initial maneuver time, $\mathrm{t}_{1}(\mathrm{~s})$ & 2.054 & 2.054 & 0.000 \\
Passing time, $\mathrm{t}_{2}(\mathrm{~s})$ & 6.33 & 6.33 & 0.000 \\
Time headway, $\mathrm{h}(\mathrm{s})$ & 2.000 & 2.000 & 0.000 \\
Distance for initial maneuver, $\mathrm{d}_{1}(\mathrm{~m})$ & 44.878 & 44.340 & 1.214 \\
Distance occupation of left lane, $\mathrm{d}_{2}(\mathrm{~m})$ & 158.377 & 157.900 & 0.302 \\
Clearance distance, $\mathrm{d}_{3}(\mathrm{~m})$ & 100.080 & 119.660 & -16.363 \\
distance of opposing vehicle, $\mathrm{d}_{4}(\mathrm{~m})$ & 79.188 & 79.730 & -0.679 \\
Total distance, $\mathrm{d}_{1}+\mathrm{d}_{2}+\mathrm{d}_{3}+\mathrm{d}_{4}$ & 382.523 & 401.630 & -4.757 \\
\hline
\end{tabular}

\subsection{Comparison with Existing Models}

PSD model values for acceleration rate, time $t_{1}$, and $t_{2}$ obtained from the current driving simulator studies for design speeds of $70 \mathrm{~km} / \mathrm{h}, 80 \mathrm{~km} / \mathrm{h}$, and $90 \mathrm{~km} / \mathrm{h}$ are presented in Table 4.1. Figure 4.1 and Table 4.5 show that the PSD requirements from Glennon's model are similar to those from the MUTCD model, indicating a short passing sight distance. The Hassan et al. model also provided a short passing sight distance because it considers the critical point as the starting point. Conversely, the PSD requirements from the AASHTO (2004) and TAC (2007) models are longer than those required for a safe and comfortable maneuver, indicating that the model is too conservative.

The PSD model developed in this study was compared with the existing design and marking standards. The model parameters selected have a constant minimum headway of 2 s. Figure 4.1 and Table 4.5 present the PSD requirements for a passenger car passing another passenger car, according to the PSD model developed in this study. The figure and table both show the PSD requirements recommended in the AASHTO (2011), AASHTO (2004) and TAC (2007) design standards and the MUTCD (2003) marking standards. This study assumed that the passing vehicle 
begins acceleration before crossing the centreline to and continues to accelerate until reaching the critical point.

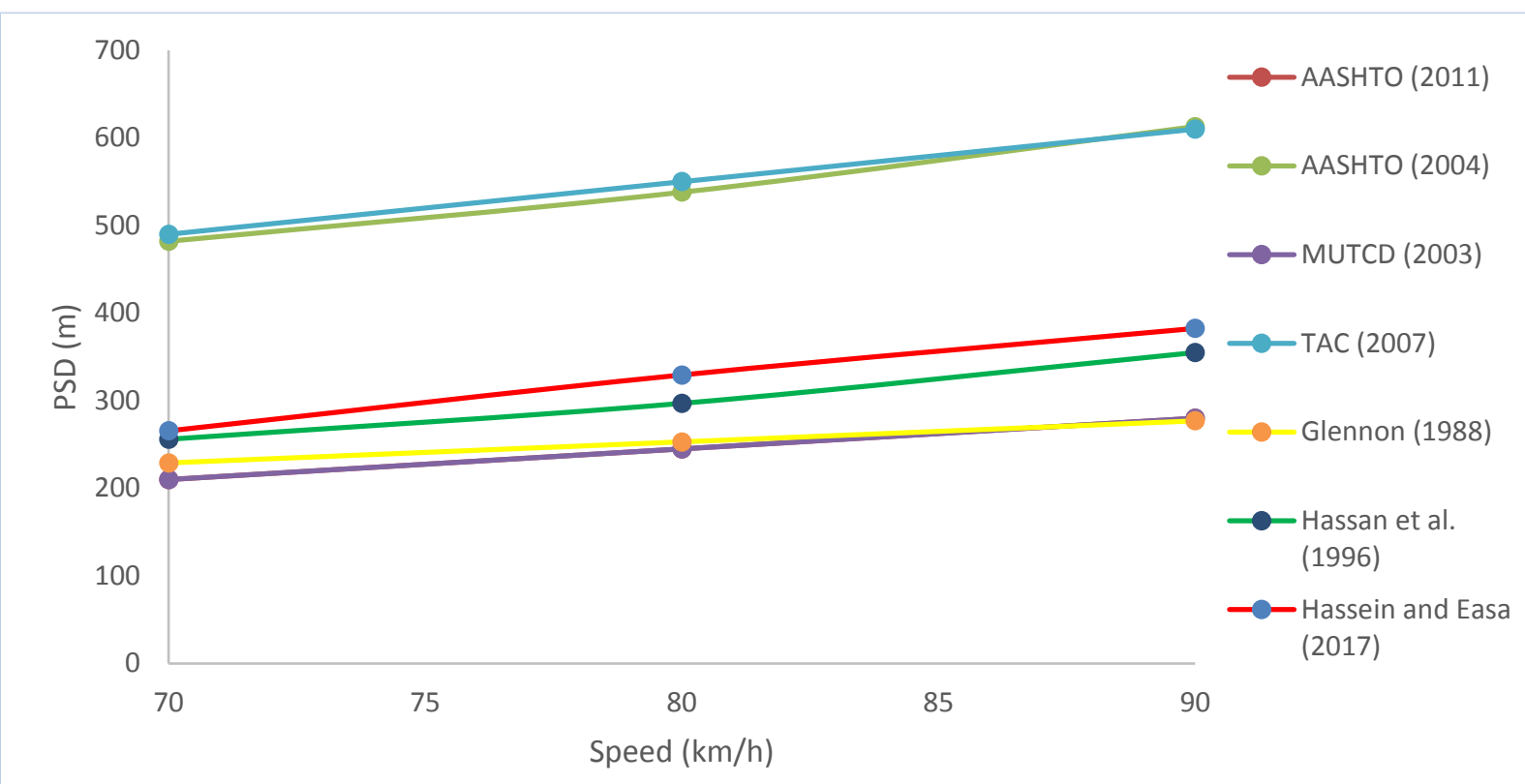

Figure 4. 1: Comparison of PSD Values (m) from Various PSD Models

Table 4. 5: Comparison of PSD Values (m) from Various PSD Models

\begin{tabular}{llcc}
\hline \multirow{2}{*}{ Model } & \multicolumn{3}{c}{ Speed $(\mathrm{km} / \mathrm{h})$} \\
\cline { 2 - 4 } Speed $(\mathrm{km} / \mathrm{h})$ & 70 & 80 & 90 \\
\hline AASHTO (2011) & 210 & 245 & 280 \\
AASHTO (2004) & 482 & 538 & 613 \\
MUTCD (2003) & 210 & 245 & 280 \\
TAC (2007) & 490 & 550 & 610 \\
Glennon (1988) & 229 & 253 & 277 \\
Hassan et al. (1996) & 256 & 297 & 355 \\
Hassein and Easa (2017) & 266 & 329 & 383 \\
Highest PSD value & 490 & 550 & 613 \\
Lowest PSD value & 210 & 245 & 277 \\
\hline
\end{tabular}


The results revealed that there is a great difference between the AASHTO (2004) and AASHTO (2011) standards in regards to PSD requirements for safe and economic road designs. Conversely, following the AASHTO (2011) and MUTCD standards would cause issues for passing passenger cars as the design speed is higher than $70 \mathrm{~km} / \mathrm{h}$ due to the small PSD values. Clearly, the AASHTO (2011) and MUTCD marking standards require major revisions in order to account for traffic usage for any specific highway to ensure safety and comfort for all passing maneuvers.

Table 4.5 compares the proposed PSD model with the AASHTO (2011), AASHTO (2004), TAC (2007), MUTCD (2003), Glennon (1988), and Hassan et al. (1996) models for design speeds of 70 $\mathrm{km} / \mathrm{h}, 80 \mathrm{~km} / \mathrm{h}$, and $90 \mathrm{~km} / \mathrm{h}$. The comparison shows an improved proposed model, however, the AASHTO (2004) model is more conservative when compared to the other PSD models. It can also be observed that the proposed model values lie between the lowest and highest values reported by the various other models. The results reveal that the proposed PSD model is slightly more conservative and provides a larger safety margin compared to the most recent standard, AASTHO (2011). The AASHTO (2011) and MUTCD models were developed based on the 85th percentile of field data in 1940. The proposed model provides a general formula that can be applied to different design speeds. The PSD values of the proposed model were approximately $20 \%$ higher than those obtained using the AASTHO (2011) model. Furthermore, the proposed model results are very close to the Glennon (1988) and Hassan et al. (1996) models, which are recommended by $\operatorname{AASHTO}(2011)$.

\subsection{Validation of the Proposed PSD Model}

PSD parameters values obtained from the field data as well as the simulation data for a design speed of $80 \mathrm{~km} / \mathrm{h}$ are presented in Table 4.6.The passing parameters based on current field data indicate an average acceleration rate, $a$, of $2.45(\mathrm{~km} / \mathrm{h} / \mathrm{s})$, initial maneuver time, $t_{1}$ of $3.6(\mathrm{~s})$, passing time, $t_{2}$ of $9.6(\mathrm{~s})$, and time headway, $h$ of $1(\mathrm{~s})$. The PSD values from the proposed model are $9 \%$ higher than the PSD values from the field studies. This can be explained by the random driving behaviour that occurs on the field compared to a more controlled environment. The results 
also show that the higher PSD of the proposed model provides the driver with an increased sense of safety and ease when completing the passing maneuver.

Table 4. 6: Comparison between the Estimated PSD Model and the Observed Field Data (Design Speed $80 \mathrm{~km} / \mathrm{h})^{\mathrm{a}}$

\begin{tabular}{lccc}
\hline Variables & Estimated & Observed & Different \% \\
\hline Impeding vehicle speed, $\mathrm{V}_{\mathrm{i}}(\mathrm{km} / \mathrm{h})$ & 64.00 & 66.68 & -4.02 \\
Speed difference, $\mathrm{m}(\mathrm{km} / \mathrm{h})$ & 16.00 & 13.32 & 20.12 \\
Distance for initial maneuver, $\mathrm{d}_{1}(\mathrm{~m})$ & 68.46 & 62.50 & 9.54 \\
Distance occupation of left lane, $\mathrm{d}_{2}(\mathrm{~m})$ & 213.50 & 200.80 & 6.33 \\
Clearance distance, $\mathrm{d}_{3}(\mathrm{~m})$ & 44.48 & 36.60 & 21.53 \\
distance of opposing vehicle, $\mathrm{d}_{4}(\mathrm{~m})$ & 106.75 & 97.41 & 9.59 \\
Total distance $(\mathrm{m}), \mathrm{d}_{1}+\mathrm{d}_{2}+\mathrm{d}_{3}+\mathrm{d}_{4}$ & 433.20 & 397.31 & 9.03 \\
\hline a Average acceleration, a $(\mathrm{km} / \mathrm{h} / \mathrm{s})=2.45 ;$ Initial maneuver & & \\
time, $\mathrm{t}_{1}(\mathrm{sec})=3.6 ;$ Passing time, $\mathrm{t}_{2}(\mathrm{~s})=9.6 ;$ Time headway, $\mathrm{h}$ & & \\
$(\mathrm{s})=1$. & &
\end{tabular}

\subsection{Chapter Summary}

This chapter presented a discussion of model parameters and a proposed PSD model. A PSD model was developed using the driving simulator data and validated using field data. The new model provided a safety margin for passing maneuvers which increases with increases in design speed, thus overcoming variations in any of the parameters within the design value. The assumptions used in the proposed model were tested to ensure the simplicity of the model without affecting accuracy. The results revealed that the MUTCD marking standard is in need of major revisions, such as the inclusion of existing traffic characteristics and passing vehicle driving behaviour on each highway.

The analysis conducted in this study revealed that the calculated PSD for design and critical PSD for marking are very complex in regards to the assumptions made about the behaviour of passing vehicles. The proposed model introduced in this study clearly defines the conditions and the acceleration behaviour of passing vehicles. The passing vehicle can continue to accelerate through the critical point and the gaps between the passing and the impeding vehicles are determined in terms of the speed of the impeding vehicle. 
The proposed PSD model produces a longer minimum passing sight distances for marking than the current solutions provided by AASHTO (2011) and MUTCD. In this model, the total passing sight distance for the design of highways is calculated using a passenger vehicle that passes a similar vehicle, which is consistent with the assumption used by AASHTO (2004). The PSD values obtained using the proposed PSD model are lower than the values obtained using the AASHTO (2004) design guidelines. For example, at design speeds of $80 \mathrm{~km} / \mathrm{h}$, the proposed PSD model suggests a total passing sight distance of $330 \mathrm{~m}$ based on the current driving simulator data while the AASHTO (2011) model suggests a total passing sight distance of $240 \mathrm{~m}$. The AASHTO (2004) model suggests a total passing sight distance of $540 \mathrm{~m}$. 


\section{CHAPTER 5: RELIABILITY MODEL}

The minimum distance required for a safe passing maneuver is determined by several random variables. Reliability analysis is frequently used in highway design and considers the mean and standard deviation for each random variable in the probability distribution. In this chapter, the limitations of the current design are addressed and a new reliability-based geometric design which takes into account the random variability of several design parameters was developed in order to calculate PSD.

The reliability model described in this chapter was developed for the model described in Chapter 4. This reliability model is based on the First-Order Second-Moment (FOSM) and Monte Carlo Simulation (MCS) methods used for PSD calculation. In order to evaluate the validity of the proposed model, the results of the study were compared with the American Association of State Highway and Transportation Officials (AASHTO) and the Manual on Uniform Traffic Control Devices for Streets and Highways (MUTCD) models. The analysis and PSD distribution are based on a design speed of $80 \mathrm{~km} / \mathrm{h}$. The results of the reliability index and MCS model show safety improvements. Using the reliability-based design method, transportation engineers can adjust PSD in order to minimize the probability of failure for the reliability index $\beta$.

\subsection{Reliability Modeling}

This research study proposes a reliability model based on the First-Order Second-Moment (FOSM) method and Monte Carlo simulation model that takes into account the variability of the parameters used in the development of PSD models. The following section describes the procedures and analyses required in order to obtain probability distributions for PSD. The reliability model is a powerful tool for analyzing complex systems (Easa, 1994; Easa, 2000; Easa and Cheng, 2013). The data used to establish the PSD distribution was obtained from field experiments conducted in different countries. An application example and a sensitivity analysis for various random variables are also presented in this chapter. 
Reliability modeling accounts for parameter variability by using the mean and standard deviation in a closed-form estimation method. Both the mean and standard deviation of the PSD used in the proposed model were compared with the AASHTO and MUTCD values for evaluation purposes. The FOSM method has been used in many applications to compute the reliability index and provide the probability of failure. The safety margin, $M(P S D)$ based on Navin (1990), is obtained using the following equation:

$$
M(P S D)=E\left[P S D_{S}\right]-E\left[P S D_{D}\right]
$$

where $\mathrm{E}\left(P S D_{S}\right)$ is the expected value of supply $P S D(S)$ and $\mathrm{E}\left(P S D_{D}\right)$ is the expected value of demand PSD $(D)$. Both $S$ (supply) and $D$ (demand) are random variables, therefore, $G(X)$ is also a random variable. The expression $G(X)=S-D$ is called a performance function or limit state function. In highway geometric design, supply refers to the provision of safe and comfortable driving conditions (e.g., length and availability of sight distance). Demand refers to the accommodation requirements of drivers or vehicles in order to provide a safe and comfortable design (e.g., stopping and passing sight distance). Supply and demand are often uncertain and tend to overlap. The non-compliance probability is the probability that occurs when $G(X)$ is negative (i.e., $P_{n c}=P[G(X)<0]$ ) and the safety index is:

$$
\beta(P S D)=\frac{E\left[P S D_{S}\right]-E\left[P S D_{D}\right]}{\sqrt{\operatorname{Var}\left(P S D_{S}\right)+\operatorname{Var}\left(P S D_{D}\right)}}
$$

The expected values, along with the reliability index, become functions of the basic PSD design parameters $\left(v_{d}, \mathrm{~m}, \mathrm{a}, t_{1}, t_{2}\right.$, and $\left.h\right)$.

\subsubsection{Reliability Theory}

Reliability is defined as $R=\operatorname{Pr}[G(X) \geq 0]=\operatorname{Pr}[S \geq D]$. The probability of failure is defined as $P_{f}=\operatorname{Pr}[G(X)<0]$ (Figure 5.1). $G(X)$ is the performance function. 


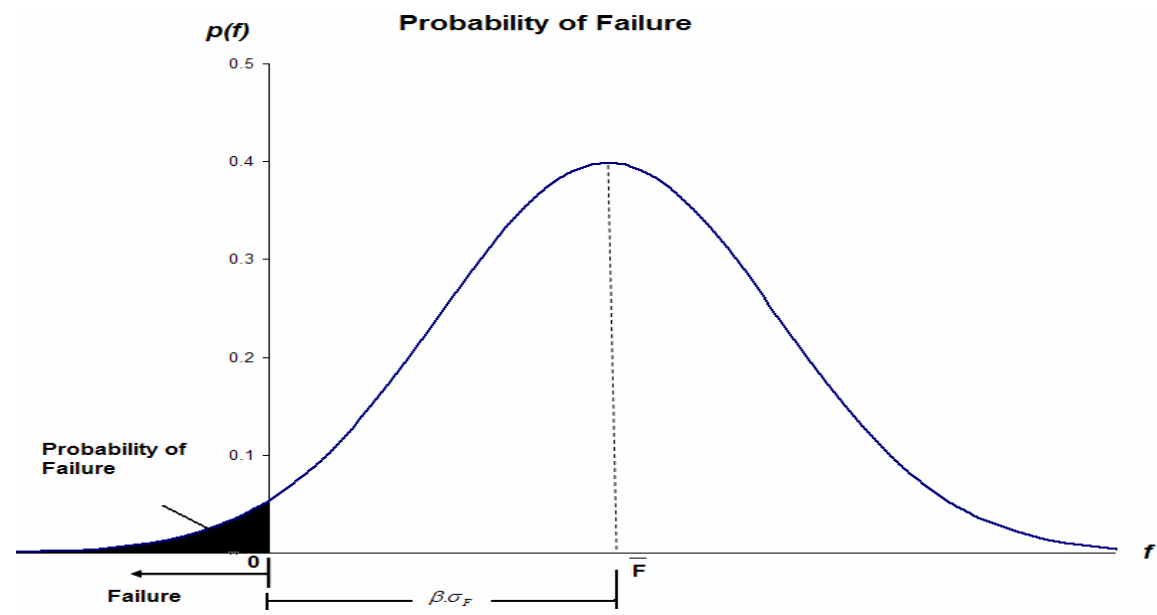

Figure 5. 1: The probability of failure

The FOSM method, based on the Hasofer-Lind (1974) method, was used as the reliability method in this study. This method works in standard normal space (Figure 5.2) using the following equations:

$$
\begin{aligned}
& G=\left(\mu_{R}-\mu_{S}\right)+\sigma_{R} Z_{1}-\sigma_{S} Z_{2} \\
& \tilde{G}=\frac{\left(\mu_{R}-\mu_{S}\right)}{\sqrt{\sigma_{R}^{2}+\sigma_{S}^{2}}}+\frac{\sigma_{R}}{\sqrt{\sigma_{R}^{2}+\sigma_{S}^{2}}} Z_{1}-\frac{\sigma_{S}}{\sqrt{\sigma_{R}^{2}+\sigma_{S}^{2}}} Z_{2}
\end{aligned}
$$

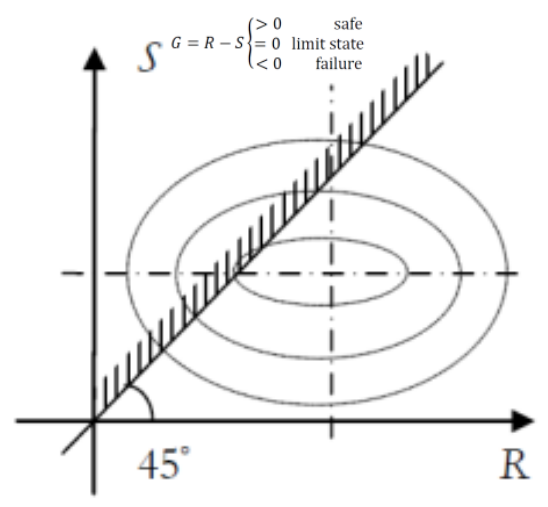

(a) Original space

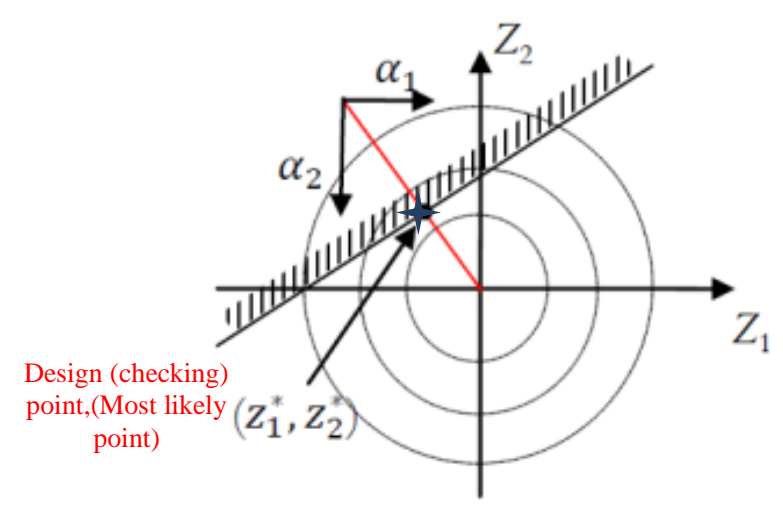

(b) Standard space

Figure 5. 2: Original space and standard space (Haldar and Mahadevan, 2000) 
For the geometrical interpretation of beta, the minimum distance between the origin and the limit state function (once the performance function equals 0 ) is the standard normal space (Figure 5.2). $z_{i}^{*}=-a_{i} b, b=-z^{* \mathrm{~T}} \boldsymbol{a}$. The information included in the general sensitivity factors is usually found within the physical model (performance function) and uncertainty (variance).

$$
\begin{aligned}
\alpha_{i} & =\frac{\partial g /\left(\partial z_{i}\right)}{\sqrt{\sum_{j=1}^{n}\left(\partial g /\left(\partial z_{i}\right)\right)^{2}}}=\frac{\partial g /\left(\partial z_{i}\right)}{l} \\
\frac{\partial g}{\partial z_{i}} & =\frac{\partial G}{\partial x_{i}} \frac{\partial x}{\partial z_{i}}=\frac{\partial G}{\partial x_{i}} \sigma_{i}
\end{aligned}
$$

The calculation of the H-L index for the Nonlinear-Performance Function is done using the following steps: (1) Optimization problem: Minimize $\beta=\left(z^{T} z\right)^{1 / 2}$ subject to $g(z)=0$, and (2) Iterative Procedures (Taylor expansion at the design point): Standardization: transforms the performance function $G(X)$ within the original space towards the performance function $g(z)$ within the standard normal space by $Z_{i}=\left(x_{i}-\mu_{i}\right) / \sigma_{i}$, chooses an initial design point $Z^{(1)}$, calculates $\beta=\left(z^{T} z\right)^{1 / 2}$, calculates direction cosines, calculates $g(z) z^{(m+1)}=-a^{(m)}\left[\beta^{(m)}+\right.$ $\left.\frac{g\left(z^{(m)}\right)}{l}\right]$, and updates the design point.

\subsubsection{Reliability of PSD}

There are a few reliability models to consider when looking at passing maneuvers. El Khoury and Hobeika $(2007 ; 2012)$ proposed a probabilistic method to evaluate the risk index of the AASHTO (2004) and MUTCD (FHWA, 2003) PSD designs and marking standards. These researchers used a deterministic model (Glennon, 1988) but included probability distributions for each input variable. The model was used for a single case within a Monte Carlo simulation to evaluate the risk level for each PSD value. El-Bassiouni and Sayed (2010) also evaluated the risk index of the AASHTO passing maneuver design standards. The validity of the PSD models above may be limited since they only considered probabilistic distributions that were reported in the literature or were obtained through driving simulation experiments for the input parameters (Llorca et al., 2014). The reliability model proposed in this study was developed based on the new PSD model that was presented earlier in Chapter 4. 
MATLAB software was used to generate random variables with probability density functions that were chosen with different parameters based on the proposed formula. When completing the pass, the required input parameters are: $v_{d}=$ the passing vehicle speed $(\mathrm{m} / \mathrm{s}), m=$ the differential speed between the passing and impeding vehicles $(\mathrm{m} / \mathrm{s}), a=$ average acceleration $\left(\mathrm{m} / \mathrm{s}^{2}\right), t_{1}=$ time that the passing vehicle travelled during the perception-reaction times and acceleration before crossing the left lane (s), $t_{2}=$ time that the passing vehicle occupied the left lane (s), and $\mathrm{h}=$ time headway at the end of passing (s). The PSD demand from the driver is directly proportional to $v_{d}, m, a, t_{1}$, $t_{2}$, and $h$. The input variable is therefore a random quantity based on a normal distribution with a mean of $(\mu)$ and variance of $\left(\sigma^{2}\right)$ for each parameter. Since the mean and standard deviation quantities are random variables, the probability density functions can be generated and used in the reliability analysis of $P S D$. The next task is to simplify the PSD as shown in Equation (5.7), according to the proposed PSD model in Equation (4.5) that was developed and described in Chapter 4. The derivations of design equations for PSD distribution are shown in Equations (5.8) $-(5.13)$.

$$
P S D=t_{1}\left(v_{d}-m+\frac{a t_{1}}{2}\right)+\left(\frac{3}{2}\right) t_{2} v_{d}+2 h v_{d}
$$

The partial derivatives for the $P S D$ functions are:

$$
\begin{aligned}
& \frac{\partial P S D}{\partial V_{d}}=t_{1}+\frac{3}{2}\left(t_{2}\right)+2 h \\
& \frac{\partial P S D}{\partial m}=-t_{1} \\
& \frac{\partial P S D}{\partial a}=\frac{t_{1}^{2}}{2} \\
& \frac{\partial P S D}{\partial t_{1}}=v_{d}-m+a t_{1} \\
& \frac{\partial P S D}{\partial t_{2}}=\frac{3}{2}\left(v_{d}\right) \\
& \frac{\partial P S D}{\partial h}=2 v_{d}
\end{aligned}
$$

The reliability analysis application procedure is as follows: 
Step 1, the appropriate performance function $G(X)$ is $g=P S D$ and can be obtained from Equation (5.7).

Step 2, standardization: $Z_{1}=\frac{V_{d-\mu_{V_{d}}}}{\sigma_{V_{d}}} ; Z_{2}=\frac{m-\mu_{m}}{\sigma_{m}} ; Z_{3}=\frac{a-\mu_{a}}{\sigma_{a}} ; Z_{4}=\frac{t_{1-\mu_{t_{1}}}}{\sigma_{t_{1}}} ; Z_{5}=$ $\frac{t_{2-\mu_{2}}}{\sigma_{t_{2}}} ;$ and $Z_{6}=\frac{h-\mu_{h}}{\sigma_{h}}$.

The developed performance function is shown in Equation (5.14). After standardization, initialization: choose $\mathbf{z}^{(\mathbf{0})}=(\mathbf{0}, \mathbf{0}) \cdot \boldsymbol{\beta}^{(\mathbf{0})}=\left(\sqrt{\mathbf{z}^{\boldsymbol{T}} \mathbf{z}}\right)^{(\mathbf{0})}=\mathbf{0}$. Then, direction cosines (sensitivity factors): $\frac{\partial g}{\partial z_{1}}, \frac{\partial g}{\partial z_{2}}, \frac{\partial g}{\partial z_{3}}, \frac{\partial g}{\partial z_{4}}, \frac{\partial g}{\partial z_{5}}, \frac{\partial g}{\partial z_{6}}$. After that, evaluating at $z^{(0)}$, we have $\frac{\partial g}{\partial z_{1}}, \frac{\partial g}{\partial z_{2}}, \frac{\partial g}{\partial z_{3}}, \frac{\partial g}{\partial z_{4}}, \frac{\partial g}{\partial z_{5}}$, $\frac{\partial g}{\partial z_{6}}$, and $l$. The last step, calculating $\alpha_{1}, \alpha_{2}, \alpha_{3}, \alpha_{4}, \alpha_{5}$, and $\alpha_{6}$. Calculating the performance function $g$ and updating the design point. With every loop, it is necessary to go back to step 1 and start over (until Beta is minimized)

$$
\begin{aligned}
& g=-\left[\left(\sigma_{t_{1}} Z_{4}+\mu_{t_{1}}\right) *\left(\left(\sigma_{V_{d}} Z_{1}+\mu_{V_{d}}\right)-\left(\sigma_{m} Z_{2}+\mu_{m}\right)+\left(\frac{1}{2}\right) *\left(\sigma_{a} Z_{3}+\mu_{a}\right) *\left(\sigma_{t_{1}} Z_{4}+\mu_{t_{1}}\right)\right)+\right. \\
& \left.\left(\frac{3}{2}\right)\left(\sigma_{t_{2}} Z_{5}+\mu_{t_{2}}\right) *\left(\sigma_{V_{d}} Z_{1}+\mu_{V_{d}}\right)+\left(2 *\left(\sigma_{V_{d}} Z_{1}+\mu_{V_{d}}\right) *\left(\sigma_{h} Z_{6}+\mu_{h}\right)\right)+g_{0}\right]
\end{aligned}
$$

\subsection{Monte-Carlo Simulation}

The Monte Carlo Simulation creates random numbers that are then used to generate random variables based on the probability distributions of those variables. The Monte Carlo Simulation is a powerful technique capable of analyzing a complex engineering system and was therefore used in this study. The simulation was conducted using MATLAB software which can be used to perform random sampling with the PDFs selected for alternative parameters based on the developed formulas. In this study, the Monte Carlo Simulation used the parameter distributions based on Table 3.8 that generates random numbers. Six random variable numbers $\left(V_{d}, m, a, t_{1}\right.$, $t_{2}$, and $h$ ) were generated to determine the passing maneuver on a two-lane highway. After creating a sufficient number of random variables, PSD was computed using question (5.7). 


\subsection{Application of Reliability Analysis to PSD}

\subsubsection{Input Parameters}

The proposed model was developed in order to obtain PSD distributions. MATLAB software was used to perform random sampling with probability density functions that were chosen with different parameters based on the developed formula. The PSD reliability method requires the mean and standard deviation of various random variables. The mean and standard deviation of the random variables were obtained from the results of the field studies (see Chapter 3). The input parameters used were: the passing vehicle's speed $\left(V_{d}\right)$, differential speed $(m)$, average acceleration (a), the time that the passing vehicle travelled during the perception-reaction times and the acceleration before crossing the left lane $\left(t_{1}\right)$, time that the passing vehicle occupied the left lane $\left(t_{2}\right)$, and time headway at the end of passing (h). The input data based on design speed $80 \mathrm{~km} / \mathrm{h}$ are shown in Table 5.1. The mean and standard deviation for the input variables are: $V_{d} \sim N\left(20.099,2.393^{2}\right), m \sim N\left(3.734,1.636^{2}\right), a \sim N\left(0.606,0.301^{2}\right), t_{1} \sim N\left(3.572,0.634^{2}\right)$, $t_{2} \sim N\left(9.597,2.452^{2}\right)$, and $\mathrm{h} \sim N\left(1,0.001^{2}\right)$.

Table 5. 1: Input data for the analysis of PSD reliability

\begin{tabular}{ccc}
\hline Parameters & Mean & SD \\
\hline$V_{d}(\mathrm{~m} / \mathrm{s})$ & 20.099 & 2.393 \\
$m(\mathrm{~m} / \mathrm{s})$ & 3.734 & 1.636 \\
$a\left(\mathrm{~m} / \mathrm{s}^{2}\right)$ & 0.606 & 0.301 \\
$t_{1}(\mathrm{~s})$ & 3.572 & 0.634 \\
$t_{2}(\mathrm{~s})$ & 9.597 & 2.452 \\
$h(\mathrm{~s})$ & 1 & 0.001 \\
\hline
\end{tabular}

\subsubsection{PSD Results}

The following outputs were obtained using the FOSM method. Direction cosines: $\alpha_{1}=$ 0.9797, $\alpha_{2}=-0.0137, \alpha_{3}=0.0045, \alpha_{4}=0.032, \alpha_{5}=0.1973, \alpha_{6}=1.0729 \mathrm{e}-04, \quad V_{d}^{*}=$ $22.986 \mathrm{~m} / \mathrm{s}, m^{*}=3.706 \mathrm{~m} / \mathrm{s}, a^{*}=0.607 \mathrm{~m} / \mathrm{s}^{2} ; t_{1}^{*}=3.597 \mathrm{~s} ; t_{2}^{*}=10.193 \mathrm{~s} ;$ and $h^{*}=1 \mathrm{~s}$. The mean and standard deviation of the expected $P S D_{D}$ are $447.264 \mathrm{~m}$ and 
$33 \mathrm{~m}$, respectively. The mean and standard deviation of the expected $P S D_{S}$ are $501.714 \mathrm{~m}$ and 33 $\mathrm{m}$, respectively, with a 95\% confidence level. The reliability index $\left(\beta_{\mathrm{PSD}}\right)$ is 1.232 , the probability of failure $\left(P_{f}\right)$ is 0.109 , and the reliability $(R)$ is $89.1 \%$. Table 5.2 provides the results for the PSD supply at different confidence levels. This supply value represents the available sight distance as the establishment of safe margins and comfortable driving conditions.

Table 5. 2: Results of the Reliability PSD supply values at different confidence levels

\begin{tabular}{lccccc}
\hline Confidence Level & $\mathbf{8 0 \%}$ & $\mathbf{8 5 \%}$ & $\mathbf{9 0 \%}$ & $\mathbf{9 5 \%}$ & $\mathbf{9 9 \%}$ \\
\hline Beta & 0.84 & 1.04 & 1.29 & 1.65 & 2.33 \\
PSD Supply & 474.98 & 481.58 & 489.83 & 501.71 & 524.15 \\
\hline
\end{tabular}

\subsection{Application of the Monte Carlo Simulation Method}

The following outputs were gathered using the Monte Carlo Simulation method for the data in Table 5.1: $V_{d}^{*}=20.099 \mathrm{~m} / \mathrm{s}, m^{*}=3.731 \mathrm{~m} / \mathrm{s}, a^{*}=0.603 \mathrm{~m} / \mathrm{s}^{2} ; t_{1}^{*}=3.573 \mathrm{~s} ; t_{2}^{*}=9.614 \mathrm{~s} ;$ and $h^{*}=1 \mathrm{~s}$. The mean and standard deviation of the expected $P S D_{D}$ are $392.458 \mathrm{~m}$ and $89.597 \mathrm{~m}$, respectively.

Table 5. 3: Monte Carlo Simulation Results for PSD Design Values

\begin{tabular}{ll}
\hline Variable & Value \\
\hline PSD Minimum (m) & 156.251 \\
PSD Maximum (m) & 973.813 \\
PSD Mean (m) & 392.458 \\
PSD Standard Deviation (m) & 89.597 \\
PSD Demand (m) & 392.458 \\
Design Speed, Vd (m/s) & 20.099 \\
Speed Differential, m (m/s) & 3.731 \\
Average Acceleration, a $\left(\mathrm{m} / \mathrm{s}^{2}\right)$ & 0.603 \\
Initiated Time, $t_{1}(\mathrm{~s})$ & 3.573 \\
Passing Time, $t_{2}(\mathrm{~s})$ & 9.614 \\
Minimum time headway, $\mathrm{h}(\mathrm{s})$ & 1.000 \\
\hline
\end{tabular}


The expected $P S D_{S}$ is $540.294 \mathrm{~m}$ based on a $95 \%$ confidence level. The probability of failure $\left(P_{f}\right)$ is 0.009 , and the reliability $(R)$ is $99 \%$. Table 5.3 presents the results of the Monte Carlo Simulation for the present study and Table 5.4 presents the results of PSD supply at different confidence levels.

Table 5. 4: Results of Monte Carlo Simulation PSD Supply Values at Different Confidence Levels

\begin{tabular}{lccccc}
\hline Confidence Level & $\mathbf{8 0 \%}$ & $\mathbf{8 5 \%}$ & $\mathbf{9 0 \%}$ & $\mathbf{9 5 \%}$ & $\mathbf{9 9 \%}$ \\
\hline Beta & 0.84 & 1.04 & 1.29 & 1.65 & 2.33 \\
PSD Supply & 467.72 & 485.64 & 508.04 & 540.29 & 601.22 \\
\hline
\end{tabular}

\subsection{Comparison to Current PSD Standards}

The PSD distributions of specific road design speeds and preliminary reliability studies for the current design values were examined. Navin (1990) developed a method to calculate the reliability index $\left(\beta_{R} \beta_{R}\right)$, also known as the safety index, for design values with certain distributions. The AASHTO design guideline (AASHTO, 2004), the MUTCD manual (FHWA, 2003), and Glennon (1988) design values were compared to the forecasted PSD distributions, which included calculations of the safety indices. Equation (5.15) was used to calculate the safety index.

$$
\beta_{R}=\frac{\bar{S}-\bar{D}}{\sqrt{\sigma_{S}^{2}+\sigma_{D}^{2}}}
$$

where $S$ represents the supply for the PSD. This represents an actual PSD that is supplied along the road. $D$ is the driver-vehicle demand value and represents the forecasted PSD distributions required by drivers when performing passing maneuvers and $\sigma^{2}$ is the corresponding variance. Like the MUTCD and the AASHTO design guideline, the Glennon model design values are all single constant values with zero variance. Figure 5.3 illustrates the various safety indices obtained with the current PSD design and the proposed model values. The proposed model showed an larger safety index in comparison to the other models. The AASHTO results overestimate the PSD for every speed range. 


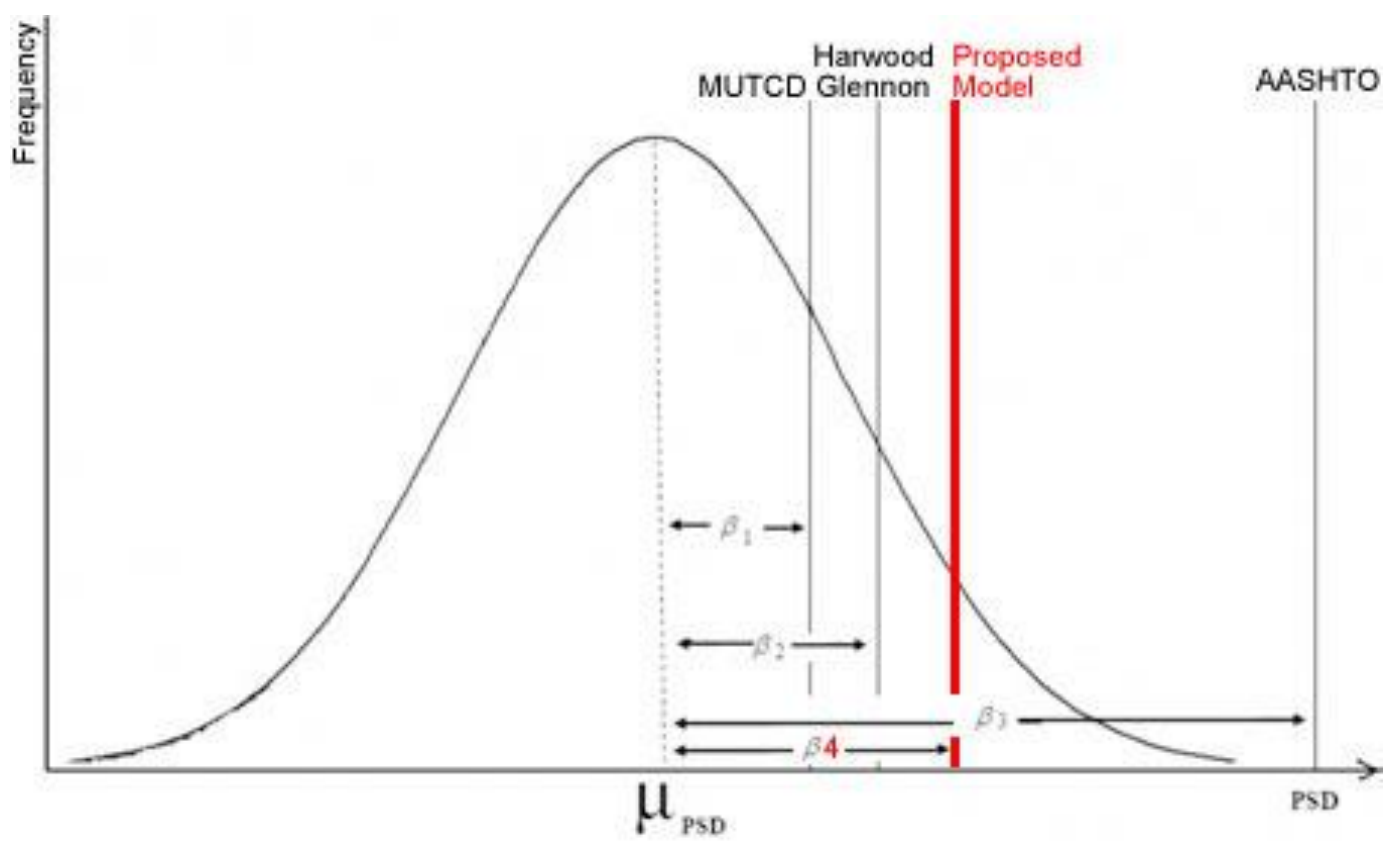

Figure 5. 3: Reliability index of different PSD design values

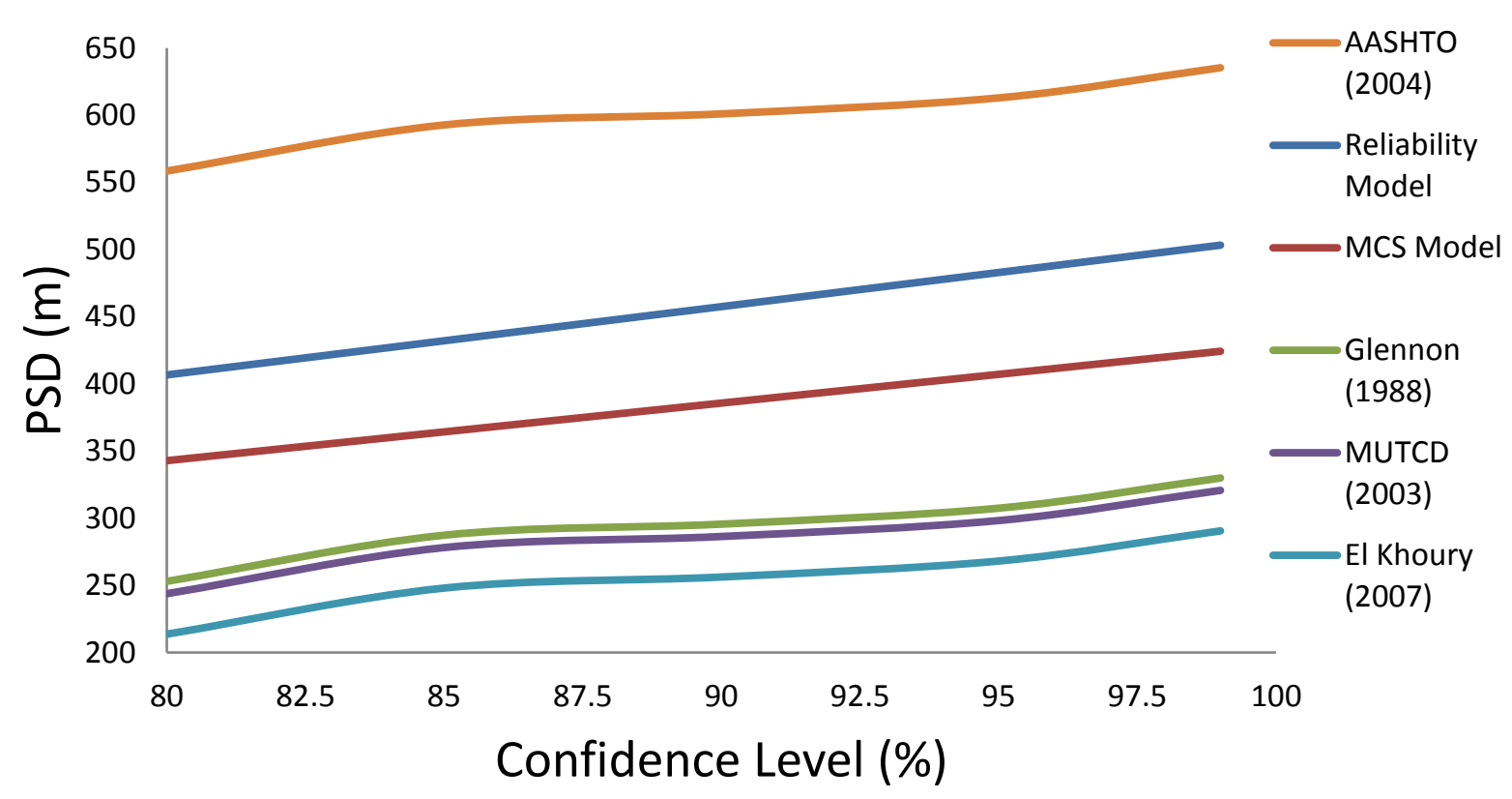

Figure 5. 4: Comparison of PSD models for different confidence levels 


\subsection{Discussion}

The proposed reliability model assumes that the safety margin distribution is normal with respect to the minimum PSD calculation. In order to verify the accuracy of this assumption, the safety margin for the proposed reliability method was compared to the safety margins of the MUTCD, Glennon (1988), AASHTO, and El Khoury and Hobeika (2007) models. In the proposed reliability model, $\left(P_{f}\right)$ equals $6.4 \%$. The data used were obtained from the field experiments. The mean and standard deviation of the safety margin of the $P S D_{D}$ based on the proposed reliability method were $447.264 \mathrm{~m}$ and $33 \mathrm{~m}$, respectively. Figure 5.4 provides a comparison of the PSD models for different confidence levels. As we can see, the estimated $P_{f}$ values show reasonable accuracy.

Table 5. 5: Comparison the Proposed Reliability and Monte Carlo Simulation Models with Different PSD Models

\begin{tabular}{|c|c|c|c|c|}
\hline \multirow[b]{2}{*}{ Element } & \multicolumn{2}{|c|}{ Safety Margin (m) } & \multirow[b]{2}{*}{$\begin{array}{c}\text { Coefficient of } \\
\text { Variation }\end{array}$} & \multirow[b]{2}{*}{ Beta } \\
\hline & Mean & $\begin{array}{l}\text { Standard } \\
\text { Deviation }\end{array}$ & & \\
\hline & Reliability Model & & & \\
\hline AASHTO (2004) & 558.40 & 33.00 & 0.06 & 10.41 \\
\hline AASHTO (2011) and & & & & \\
\hline MUTCD (2003) & 243.80 & 33.00 & 0.14 & 0.87 \\
\hline Glennon (1988) & 253.00 & 33.00 & 0.13 & 1.15 \\
\hline El Khoury (2007) & 211.20 & 33.40 & 0.16 & - \\
\hline \multirow[t]{2}{*}{ Proposed Model } & 447.26 & 33.00 & 0.07 & 1.23 \\
\hline & $\begin{array}{c}\text { Monte-Carlo } \\
\text { Simulation } \\
\end{array}$ & & & \\
\hline El Khoury (2007) & 213.65 & 32.77 & 0.15 & - \\
\hline Proposed Model & 392.46 & 89.59 & 0.23 & - \\
\hline
\end{tabular}

Table 5.5 compares the proposed reliability model with the AASHTO, MUTCD, Glennon (1988), and El Khoury and Hobeika (2007) models for a speed design of $80 \mathrm{~km} / \mathrm{h}$. The proposed model showed a larger mean value, a smaller coefficient of variation, and an improved safety index in comparison to the other models. The AASHTO (2004) model was more conservative. Two observations emerge when using the data in Table 5.6 and comparing the Monte Carlo Simulation model with the reliability model: (1) a $13.96 \%$ decrease in the mean and (2) a $63.17 \%$ increase in 
the standard deviation for PSD (Table 5.6). These results indicate an improved safety margin for the proposed analytical model when compared with the Monte Carlo simulation model.

Table 5. 6: Comparison of Reliability and Monte Carlo Simulation Model Results

\begin{tabular}{|c|c|c|c|c|c|c|}
\hline \multirow[b]{2}{*}{$\begin{array}{c}\text { Design } \\
\text { speed }\end{array}$} & \multicolumn{3}{|c|}{$\operatorname{Mean}(m)$} & \multicolumn{3}{|c|}{ Standard deviation $(\mathrm{m})$} \\
\hline & $\begin{array}{c}\text { Monte- } \\
\text { Carlo }\end{array}$ & Analytical & Dif. $(\%)$ & $\begin{array}{c}\text { Monte- } \\
\text { Carlo }\end{array}$ & Analytical & Dif. (\%) \\
\hline $\begin{array}{c}80 \\
\mathrm{Km} / \mathrm{h}\end{array}$ & 392.46 & 447.26 & 13.96 & 89.59 & 33 & 63.17 \\
\hline
\end{tabular}

\subsection{Summary}

This research study presented geometric highway design procedures that account for variations in the parameters of the PSD formulation. The FOSM method was the reliability method used in the study. The results obtained using the proposed model differed from those obtained by Glennon (1988). The proposed PSD model described the passing maneuver mechanics that are used for the base formulation of the reliability model.

The PSD distribution was then calculated using a design speed of $80 \mathrm{~km} / \mathrm{h}$. The distribution obtained was then used to assess the reliability index of the current PSD standards. The results revealed that the values of the AASHTO (2011), MUTCD, Glennon (1988), and El Khoury (2007) designs were smaller than the PSD of the proposed model. On the other hand, the values of the AASHTO (2004) model were too conservative in relation to the required PSD design values. A Monte Carlo simulation was used to validate the proposed model for a design speed of $80 \mathrm{~km} / \mathrm{h}$. The reliability model was more conservative than the simulation model. 


\section{CHAPTER 6: DEVELOPMENT OF AN IN-VEHICLE PASSING COLLISION WARNING SYSTEM}

This chapter extends the design phase, building upon the material presented in Chapters 4 and 5 of this dissertation and presents the framework and design algorithm for an in-vehicle passing collision warning system that assists drivers while conducting passing maneuvers on two-lane highways. The algorithm presented here for the proposed in-vehicle passing collision warning system will be implemented in a Simulink simulation model (to be presented in Chapter 7).

\subsection{Proposed Collision Warning System}

The proposed in-vehicle passing collision warning system (PCWS) reflects driver behaviour during passing maneuvers. The proposed passing collision warning system is intended to help passing drivers determine a safe passing gap in order to complete the passing maneuver. The system identifies the closest impeding vehicle in the right lane of two-lane highways using a radar sensor, and measures its position and speed. The system also identifies the closest opposing vehicle in the left lane and measures its position and speed at four consecutive time intervals in order to determine its relative distance and speed. The system uses a reading sensor and a processing component with a driver-vehicle interface to determine whether or not a "safe" message needs to be displayed for the driver in the passing vehicle. The system also considers the time required for the driver to detect the warning message and react to it.

The in-vehicle PCWS uses two radar sensors with rotating antennae, which are utilized to identify the speed of opposing vehicles (using the Doppler Effect) and warn the driver of any potential conflicts. The radar sensors use a range of no less than $1000 \mathrm{~m}$ to detect all of the vehicles travelling in the opposite direction which could potentially collide with the passing vehicle. The proposed system uses a radar sensor (such as the Symeo, LPR-1D24 (Symeo, 2016)). The proposed system uses a pair of radar sensors installed on the right and left sides of the front bumper of the passing vehicle within a distance of $0.618 \mathrm{~m}$ from the center. The radar sensors can provide information 
such as the speed, location, and distance of the impeding and opposing vehicles. The radar sensors send a signal at every time interval, $\Delta t$, to scan the left lane for any opposing traffic. The time interval is $0.1 \mathrm{~s}$ based on the $10 \mathrm{~Hz}$ radar sensors used. The closest object detected is recorded at a distance $d$ and azimuth angle $\theta$ where polar coordinates are used with the origin point to correspond with the detector's location.

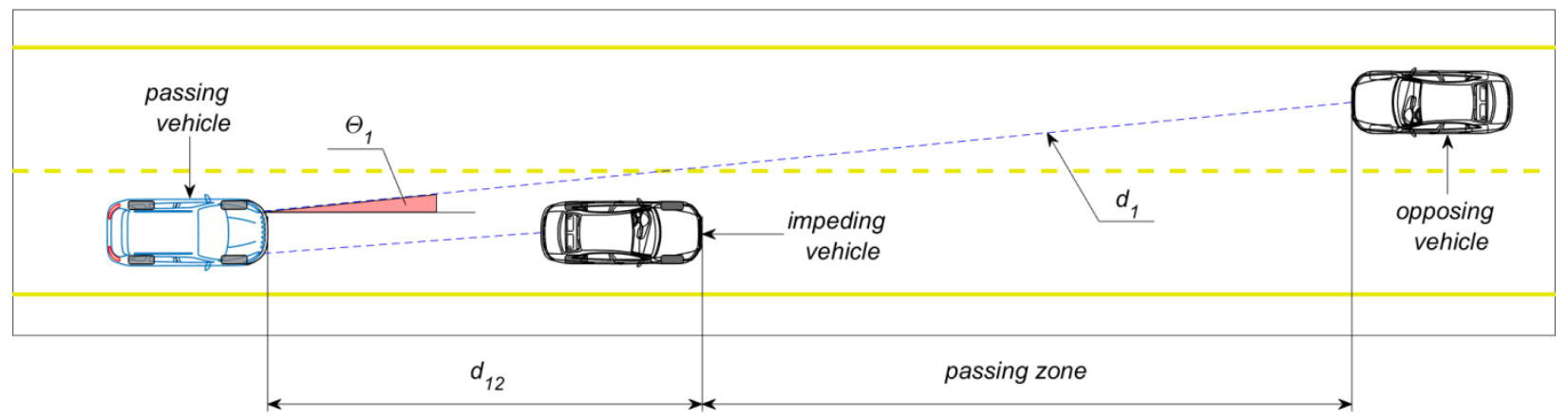

(a) : Calculating the distance and angle at time $\mathrm{T}$

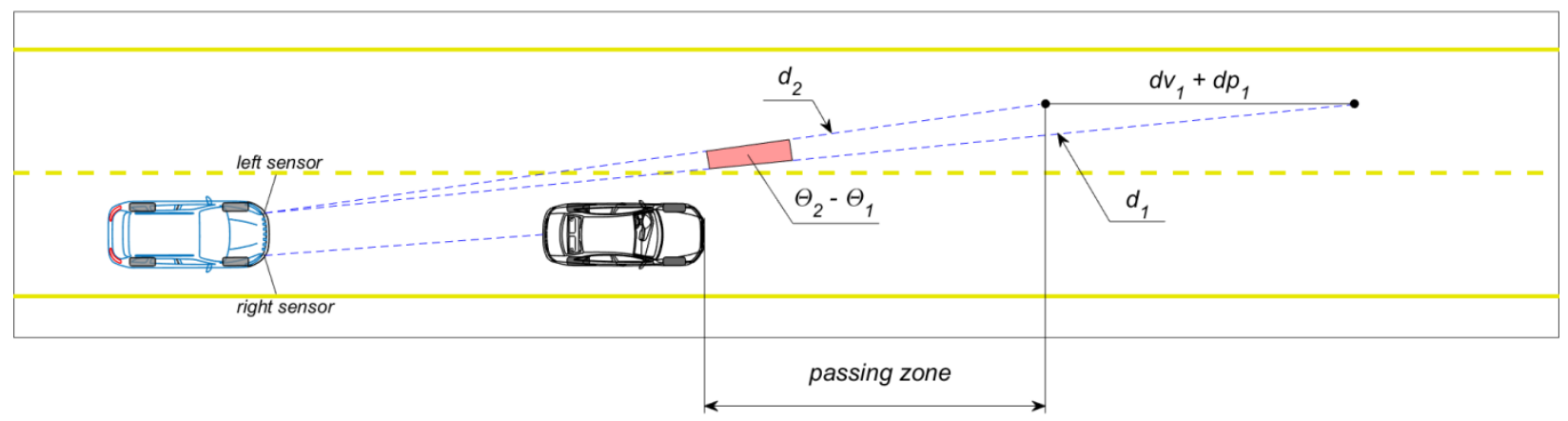

(b) : Calculating the distance traversed by the opposing vehicle

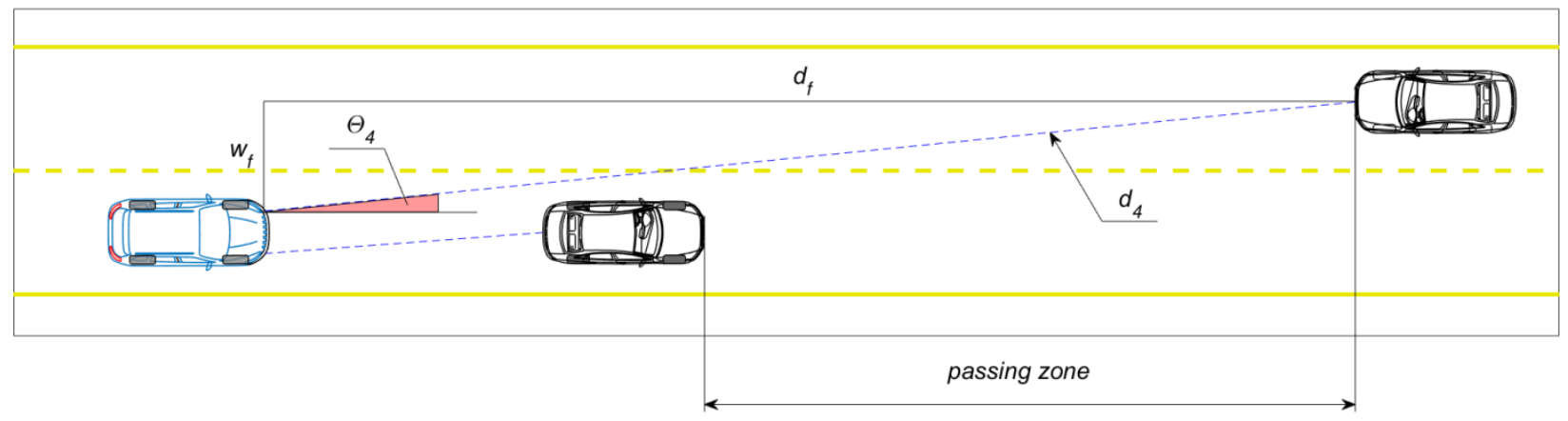

(c) : Calculating the distance at time $\mathrm{T}+3 \mathrm{t}$

Figure 6. 1 Calculating the distance and angle at each time interval 
Figure 6.1 illustrates the detection beam generated by the detector at a particular time interval in order to scan the left lane of two-lane highways. The closest object detected is recorded at distance $\mathrm{d}$ and azimuth angle $\theta$ where polar coordinates are used with the origin point to correspond with the detector's location. The system assumes that the oncoming vehicle is coming from the east and the azimuth angle is measured counter-clockwise from the assumed north meridian located at the detector's location.

\subsection{Algorithm for the Passing Collision Warning System}

The system algorithm then provides an estimation of the distance and time needed for the passing vehicle to accelerate and complete the passing maneuver. The algorithm also considers the time needed for the passing vehicle driver to detect the message displayed by the PCWS and react to it. If the passing maneuver can be completed safely, the "safe" signal will be displayed. If the passing maneuver must be aborted because it is unsafe to complete, a 'not safe' signal will be displayed (see Figure 6.2).

The proposed algorithm uses radar sensors which can be installed in the passing vehicle. The radar sensors can provide information such as the speed, location, and distance of the impeding and opposing vehicles. The radar sensors send a signal at every time interval, $\Delta \mathrm{t}$, to scan the left lane for any oncoming traffic. The detection sensor is used to detect all of the vehicles travelling in the opposite direction that could potentially collide with the passing vehicle. Using a reading sensor and a processing unit with a driver-vehicle interface (DVI) unit, the algorithms follow the procedures illustrated in Figure 6.2 to determine whether or not a "safe" message should be displayed for the driver of the passing vehicle.

The algorithm procedures can be explained as follows:

1. When the detection sensors detect moving objects in the coverage area (opposite traffic lanes), the system automatically displays a warning message for the driver. The message can be auditory, visual, haptic, or a combination of any of these. The message will not deactivate until the algorithm confirms that a safe pass is possible. 
2. The system can estimate the time required for each detected vehicle, $t_{\text {opposing }}$, to reach the conflict point using methodology that is presented later in this section.

3. The system can also estimate the time required for the passing vehicle, $t_{\text {passing }}$, to complete the passing maneuver.

4. If the time required for the opposing vehicle to reach the conflict point, $t_{\text {opposing }}$, is longer than the time required to complete the passing maneuver, $t_{\text {passing, }}$ plus the time considered as the safety margin, a "safe" message is displayed and the passing vehicle can then begin the passing maneuver. If the time required for the opposing vehicle to reach the conflict point, $t_{\text {opposing }}$, is longer than the time required to complete the passing maneuver, $t_{\text {passing }}$, but there is insufficient time as a safety margin, a "not safe" message is displayed. The system repeats the algorithm above until the criterion described in the previous steps are met (for example, a proper gap is determined).

The algorithm is capable of recognizing multiple opposing vehicles and the procedures outlined above are followed for each passing vehicle; the "safe" signal will not be displayed until the passing maneuver is clear for all opposing vehicles. Figure 6.2 shows the flow chart for the passing collision warning algorithm. The second part of the PCWS system is based on the trigonometric functions relating to detection sensor readings. Based on the initial part of the model, the range and azimuth angles for the opposing vehicles are calculated at four by 0.1 second intervals $(T$; $T+\Delta t ; T+2 \Delta t ; T+3 \Delta t$ ) where $T$ represents the start time and $\Delta t$ represents the time interval for the detection sensors, as illustrated in Figure 6.1. The range and azimuth angle are included in the PCWS system and calculated from the initial part of the model.

The input data for the Passing Collision Warning System (PCWS) includes the following information: (1) gender, age, driving experience and average weekly driving hours for the driver of the passing vehicle; (2) the number of lanes; and (3) lane width. The PCWS calculates the offset distance $\left(w_{f}\right)$, azimuth angle $(a z)$, the angle of the detection sensor $\left(d_{s}\right)$, and the distance between the passing and opposing vehicles $\left(d_{f}\right)$ at 0.1 second intervals. Based on the driver input data and the detection sensor notification, the PCWS determines the conflict point used to calculate the time 
needed for the passing vehicle to clear the path of the opposing vehicle, $t_{\text {passing }}$, and the time needed for the opposing vehicle to reach the conflict point, $t_{\text {opposing }}$.

The results of the PCWS system include the following: (1) Perception-Reaction Time and initial acceleration $\left(t_{1}\right)$ is based on: gender, age, driving experience, average weekly driving hours and passing vehicle speed; (2) the time to complete the pass $\left(t_{2}\right)$ is based on: gender, age, driving experience, average weekly driving hours, passing vehicle speed, and $d f$; (3) the distance and the speed of the opposing vehicles in 0.1 second intervals; (4) the range and azimuth angle of the opposing vehicles at 0.1 second intervals; (5) the time needed for the passing vehicle to clear the path of the opposing vehicles $\left(t_{\text {passing }}\right)$; (6) the time needed for the opposing vehicles to reach the conflict point $\left(t_{\text {opposing }}\right)$; $(7)$ the safety margin involving the opposing vehicles, which is defined as the difference between the time needed for the opposing vehicles to reach the conflict point, $t_{\text {opposing }}$, and the time needed for the passing vehicle in order to clear the path of the opposing vehicles, $t_{\text {passing }}$; $(8)$ the safety message provided for the passing vehicle (safe or not safe) and (9) the final decision that is determined by the system of whether or not to continue displaying the passing warning signal. Figure 6.2 is a flow chart for the passing collision warning algorithm.

The second part of the PCWS system is based on the trigonometric functions relating to detection sensor readings. Based on the initial part of the model, the range and azimuth angles for the opposing vehicles are calculated at four 0.1 second intervals $(T ; T+t ; T+2 t ; T+3 t)$ where $T$ equals the start time and $t$ equals the particular time interval of the detection sensors, as shown in Figure 6.1. The range and azimuth angle are included in the PCWS system and are calculated from the initial part of the model.

The PCWS system determines the conflict point used to calculate the time needed for the opposing vehicle to reach the conflict point, $t_{\text {opposing }}$, and the time needed for the passing vehicle to clear the path of the opposing vehicle, $t_{\text {passing. }}$. If an opposing vehicle is determined to have no risk of conflict with the passing vehicle, the PCWS system removes the vehicle from the calculations and provides it with a 'safe' label. This is repeated for each opposing vehicle. Lastly, the PCWS system 
provides a final decision that is based on the labels that are attached to the opposing vehicles (safe or unsafe).

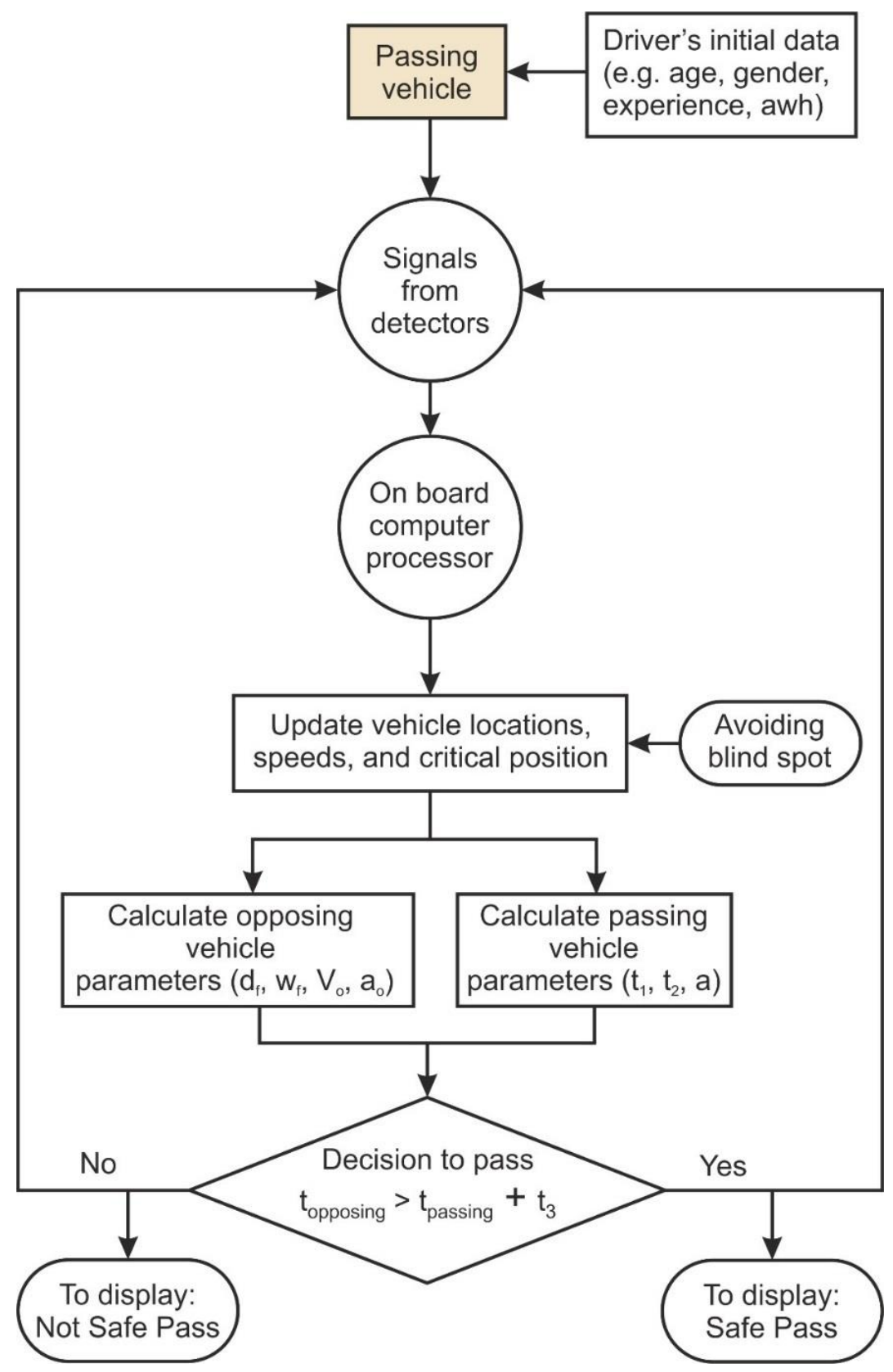

Figure 6. 2: Flow chart for the passing collision warning algorithm 


\subsection{Determining the Location of the Opposing Vehicle}

Figure 6.2 presents schematic illustrations depicting the methodology that is used to calculate the

time needed for the opposing vehicle to reach the conflict point, $t_{\text {opposing }}$. The procedure is shown below:

1. A detection radar signal is created, from one of the two sensors, at time $T$ to scan all of the traffic lanes. If no object is detected in the opposing lane (left lane), a "safe" signal is displayed for the driver. Therefore, the closest object detected, the opposing vehicle, is recorded at distance $d_{l}$ with the azimuth angle $\theta_{1}$ (registered from the face plane in the vehicle). Polar coordinates are then used with an origin point corresponding with the location of the detection sensor, illustrated in Figure 6.1.a.

2. A second radar signal is created at time $T+\Delta t$, as $\Delta t$ becomes the time interval of the detection sensor, with the new location for opposing vehicle being recorded at distance $d_{2}$ with the azimuth angle $\theta_{2}$ being the similar above polar coordinates used, illustrated in Figure 6.1.b.

3. If $d_{2}$ is less than $d_{1}$ (considering the passing vehicle displacement of passing vehicle $d p_{1}$ only) (no change in the detected object speed), the algorithms conclude that the object does not move. A 'safe' message is then displayed for the driver (unless other objects are detected with the two detection sensors). It is important to note that the generation of "safe" signals is based on the assumption that a passing-zone can be effectively designed for the passing sight distance provided by the developed PSD model based on Equation (4.5), (see Chapter 4, Table 4.1) for a design speed of $80 \mathrm{~km} / \mathrm{h}(\mathrm{PSD}=330 \mathrm{~m})$.

4. If $d_{2}$ is higher than $d_{l}$, the algorithm concludes that the object is moving away from the passing vehicle and a "safe" message can be displayed for the driver (if another object isn't detected with the two detection sensors).

5. If $d_{2}$ is lower than $d_{l}$, the distance crossed by the opposing vehicle in the first time interval, $d v_{1}$, can be calculated using the following formula (as highlighted in Figure 6.3):

$$
d v_{1}=\sqrt{d_{1}^{2}+d_{2}^{2}-2 d_{1} \cdot d_{2} \cos \left(\theta_{1}-\theta_{2}\right)}-d p_{1}
$$




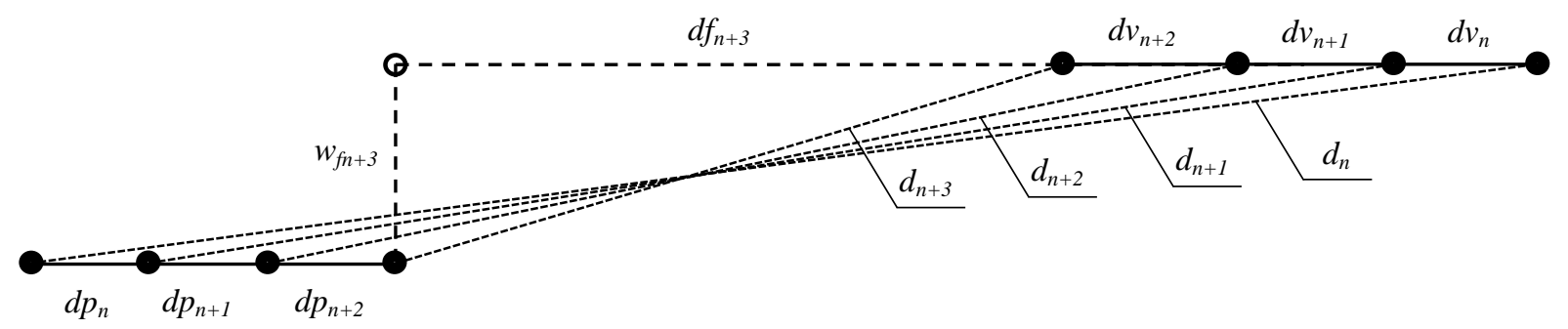

Figure 6. 3: Schematic opposing vehicle locations at different time instances

6. A third radar signal is sent at time $T+2 \Delta t$ and the distance, $d_{3}$, and azimuth angle, $\theta_{3}$, of vehicle $\mathrm{A}$ is recorded. The distance crossed by the opposing vehicle in the second time interval, $d v_{2}$, can be calculated using the following equation:

$$
d v_{2}=\sqrt{d_{2}^{2}+d_{3}^{2}-2 d_{2} \cdot d_{3} \cos \left(\theta_{2}-\theta_{3}\right)}-d p_{2}
$$

7. A fourth radar signal is created at time $T+3 t$ and the new location for vehicle $\mathrm{A}$ is recorded at . distance $d_{4}$ with azimuth angle, $\theta_{4}$. The distance that is crossed by the vehicle in the third time interval, $d v_{3}$, can be calculated using the following equation:

$$
d v_{3}=\sqrt{d_{3}^{2}+d_{4}^{2}-2 d_{3} \cdot d_{4} \cos \left(\theta_{3}-\theta_{4}\right)}-d p_{3}
$$

8. The speed, $v_{T+3 \Delta t}$, is calculated by solving the formula of first derivatives based on general formulas from numerical derivatives by 4 points (whereas $d v_{1}, d v_{2}$ and $d v_{3}$ are all calculated by solving Equations (6.1), (6.2) and (6.3), respectively):

$$
V_{T+3 \cdot \Delta t}=\frac{\frac{1}{3} \cdot d v_{1}-\frac{7}{6} \cdot d v_{2}+\frac{11}{6} \cdot d v_{3}}{\Delta t}
$$

which is the speed of the opposing vehicle after three time intervals, $v_{\text {opp }}$. 
9. The side offset involving the opposing vehicle and the passing vehicle, $w_{f}$, are calculated using the following equation for each $n$-state (the mean value is used to reduce the probability of reading errors):

$$
w_{f}=s_{l}+\frac{1}{3} \sum_{n=1}^{3} \frac{d_{n} \cdot d_{n+1} \cdot \sin \left(\Theta_{n+1}-\Theta_{n}\right)}{d v_{n}+d p_{n}}
$$

where; $s_{l}=$ represents the location of the left radar sensor in the passing vehicle, which equals $0.618(\mathrm{~m})$ from the vehicle longitudinal axis, and $d_{p n}$ is the horizontal displacement of the passing vehicle from point $\mathrm{n}$ to $\mathrm{n}+1$ (see Figure 6.4).

10. The distance from the opposing vehicle (taken at time $\mathrm{T}+3 \Delta \mathrm{t}$ ) and the detector, $d_{f}$, is calculated as follows:

$$
d_{f}=\sqrt{d_{4}^{2}-w_{f}^{2}}
$$

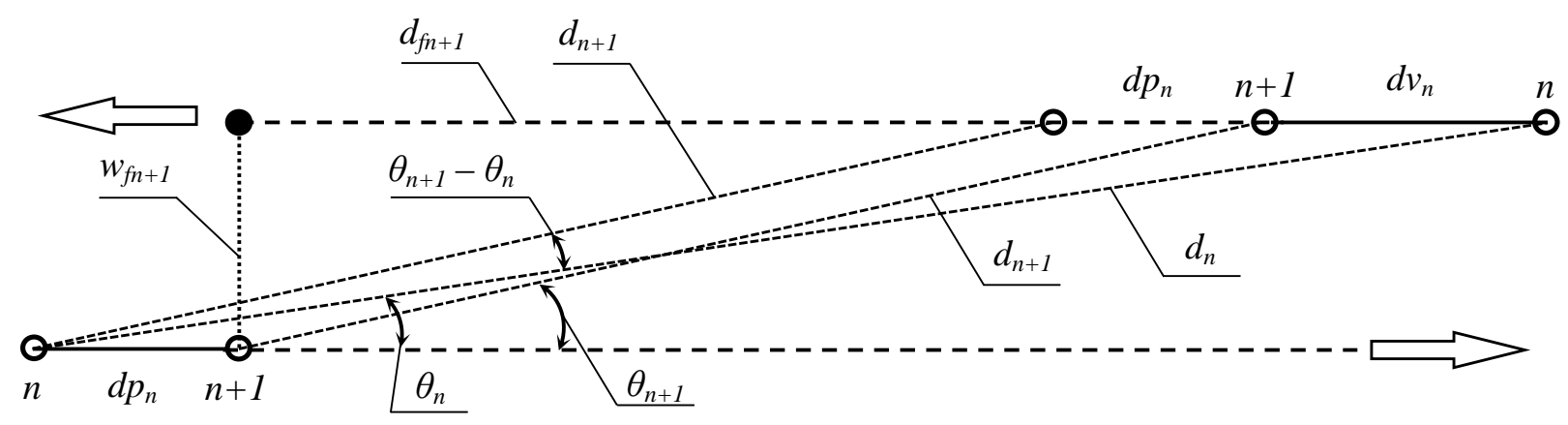

Figure 6. 4: Calculating the distance $d_{f}$ and the offset $w_{f}$

Figure 6.4 illustrates the measured distance of the two adjacent states $n$ and $n+1$. To solve the problem geometrically, the parallel line segment, $d_{n+l}$, is first shifted into the $n$ state. A triangle is then obtained with a base of $d v_{n}+d p_{n}$ and edges of $d_{n+1}, d_{n}$, forming an acute angle $\theta_{n+1}-\theta_{n}$. Calculating value via the passing vehicle device data and knowing the angles of the adjoining measurements, $\theta_{n+1}, \theta_{n}$, one can estimate the value of the opposing vehicle's movements according to the radar's pulse time period $\Delta t$. 
11. Based on the conflict types involving the opposing and passing vehicles (in the opposing lane or traveling in the same lane), opposing time, $t_{\text {opposing. }}$. The time needed for the opposing vehicle to reach the end of its part of the distance to the critical point is calculated using the following formula:

$$
t_{\text {opposing }}=\frac{d_{f}}{\left(v_{o p p}+v_{p}\right)}
$$

where $d_{f}$ can be calculated from (6.6); $v_{p}$ is the speed of the passing vehicle; $v_{o p p}$ is the speed of an opposing vehicle, which is determined using Equation (6.4).

\subsection{Determining the Location of the Passing Vehicle}

The total time needed for the driver of a passing vehicle to complete the pass, $t_{\text {passing }}$, is the sum of the following:

1) The driver's perception-reaction time and initial acceleration $\left(t_{1}\right)$, which is the time needed by the driver to notice the "safe" signal and then take the necessary action (to activate throttle); and

2) The vehicle's travel time $\left(t_{2}\right)$, which is the time needed to accelerate and clear the path for the oncoming vehicle in the opposing lane. This involves the time needed to cross the offset distance involving the passing and opposing vehicles and the length of the passing vehicle itself.

Finally, the total time required for the passing vehicle to complete the pass, $t_{\text {passing }}$, is calculated using the following formula:

$$
t_{\text {passing }}=t_{1}+t_{2}
$$

where $t_{1}=$ initial time, $t_{2}=$ passing time. The sum of $t_{1}$ and $t_{2}$ is the total time for the passing maneuver. Linear regression models for the initiation of the passing time $\left(t_{1}\right)$, and passing time $\left(t_{2}\right)$ were developed based on the field data collected using SAS software (SAS, 2015). The 
development of the passing time parameters was presented in Chapter 3. Figure 6.5 shows the definition of times.

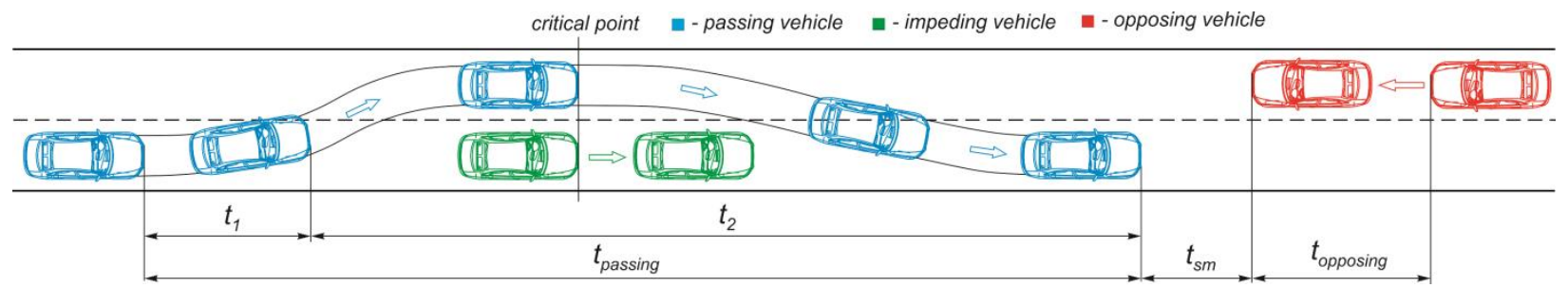

Figure 6. 5: Initial time maneuver

\subsection{Distance Headway Parameter}

The PSD length is specified before assigning the location of the three vehicles. The Pitts carfollowing model can be used to calculate the minimum headway between the passing vehicle and the impeding vehicle (Halati et al., 1997). The minimum distance assumes that the passing vehicle is trying to narrow the distance between the passing and impeding vehicles before initiating a passing maneuver. The following formula was used to calculate the distance headway that is required between the two vehicles:

$$
d_{1-2}=L_{i}+10+k V_{p}+b k\left(V_{i}-V_{p}\right)^{2}
$$

where $d 1-2=$ space headway between the impeding and passing vehicles (from the front bumper to the front bumper), $L i=$ length of the impeding vehicle, and $V i$ and $V p=$ speed of the impeding and passing vehicles, respectively, $b=$ calibration constant that is defined as 0.1 (when $V p>V i$ ) or 0 otherwise, and $k=$ driver sensitivity factor for the passing vehicle. In the Pitts car-following model, the default values for the driver sensitivity factor range between 0.6 and $1.5 \mathrm{~s}$. At lower values, the behaviour becomes more aggressive and the following vehicles maintain smaller distance headway. In this paper, the sensitivity for the passing driver can be captured within the equation through a variable $k$. The values for $k$ are randomly selected from the uniform distribution, similar to the method used by El Khoury and Hobeika (2012). 


\subsection{Blind Spot}

One challenge of this task is the blind spot effect. The blind spot effect is when a passing vehicle's radar cannot detect an opposing vehicle due to obstacles such as an impeding vehicle. In this case, it is impossible to clearly determine the initial visibility conditions of opposing vehicles because the eventual mutual location of three vehicles corresponds to an infinite quantity of variants. This means that the driver of the passing vehicle should move a little to the left to foster a radar beam which will bypass the impeding vehicle and detect an opposing vehicle. Afterwards, a complete pass can be carried out if the warning system displays a safe message. Blind spots are detected as follows. Initially, the coordinates of the intersection point of two lines are determined. One line involves the segment joining a passing vehicle's left sensor point and the midpoint of an opposing vehicle's front bumper. The second line is perpendicular to the longitudinal axis of an impeding vehicle and passes through the outermost point of its rear bumper.

If the point is within the boundaries of the width of the impeding vehicle (Figure 6.6), the signal does not pass and two measurements must be made to slow the vehicle. Moreover, the rapport of passing and slow vehicles, when moving strictly in track, makes the blind spot effect more enhanced. Therefore, the passing driver needs to move the primary steering maneuver in the direction of the separating dash line, after which the intersection point of the two lines is no longer within the boundaries of the width of the impeding vehicle and the sensor of the passing vehicle can detect an opposing vehicle. Then, the algorithm is able to turn on the warning system.

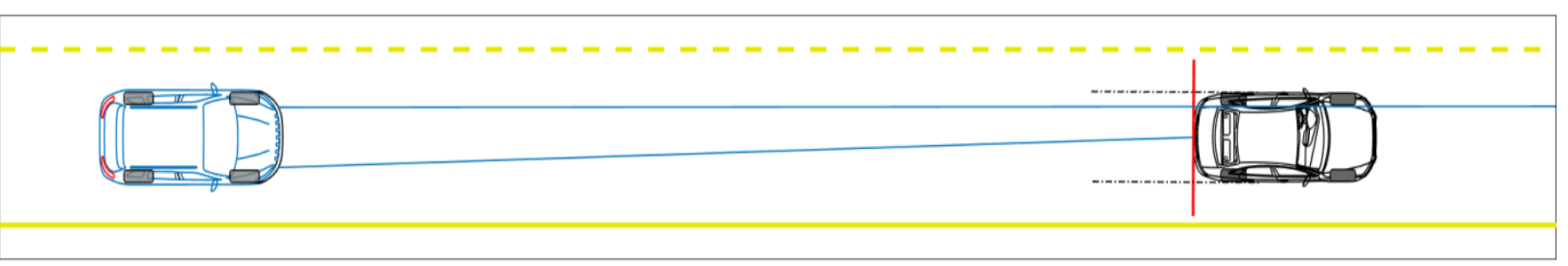

Figure 6. 6: The "blind spot" effect for the left sensor 


\subsection{The Decision-Making Process}

Before the driver makes a decision to pass, the system maintain a minimum distance headway given by Equation (6.9). The last step in the algorithm (see Figure 6.2) compares the time needed for the opposing vehicle to reach a conflict point, $t_{\text {opposing }}$, with the time needed for a passing vehicle to complete the passing maneuver, $t_{\text {passing }}$ (see Figure 6.5). The following condition is used for the initial decision:

$$
t_{\text {opposing }}>t_{\text {passing }}+t_{3}
$$

Where $t_{\text {opposing }}$ can be calculated from Equation (6.7), $t_{\text {passing }}$ can be calculated from Equation (6.8), and $t_{3}$ is the safety margin ( $\mathrm{s}$ ). If the above condition is met for the detected opposing vehicle, a "safe to pass" message is displayed for the driver. If not, a "not safe to pass" message will be displayed until the above condition is met. The subsequent timing of the passing and opposing vehicles will be updated at each time interval during the passing maneuver (see Figure 6.7). The algorithm records these times for subsequent decision-making. The time needed by the passing vehicle to complete the passing maneuver can be calculated using the following formula:

$$
t_{\text {passing }} *=t_{1}+t_{2}-t_{c}
$$

Where $t_{\text {passing }} *$ is the actual passing time during the passing maneuver $(\mathrm{s}), t_{1}=$ initial time $(\mathrm{s}), t_{2}$ is passing time $(\mathrm{s})$, and $t_{C}$ is the current sensor signal processing time (s). The $t_{C}$ value is zero before the initial decision. During $t_{\text {passing }} *$, the data processing continues using the radar sensor and the measurement of the distance between the passing and opposing vehicles is provided. The system continuously monitors overtaking safety until the passing maneuver is complete (see Figure 6.7). The following condition is used for subsequent decisions:

$$
t_{\text {opposing }} *>t_{\text {passing }} *+t_{3}
$$


Where $t_{\text {opposing }} *$ is the opposing vehicle time during the passing maneuver that can be calculated from Equation (6.7), $t_{\text {passing }} *$ can be calculated from Equation (6.11), and $t_{3}$ is the safety margin (s). If the above condition is met for the detected opposing vehicle, a "safe to continue to pass" message is displayed for the driver. If not, a "not safe to continue to pass" message will be displayed until the above condition is met.

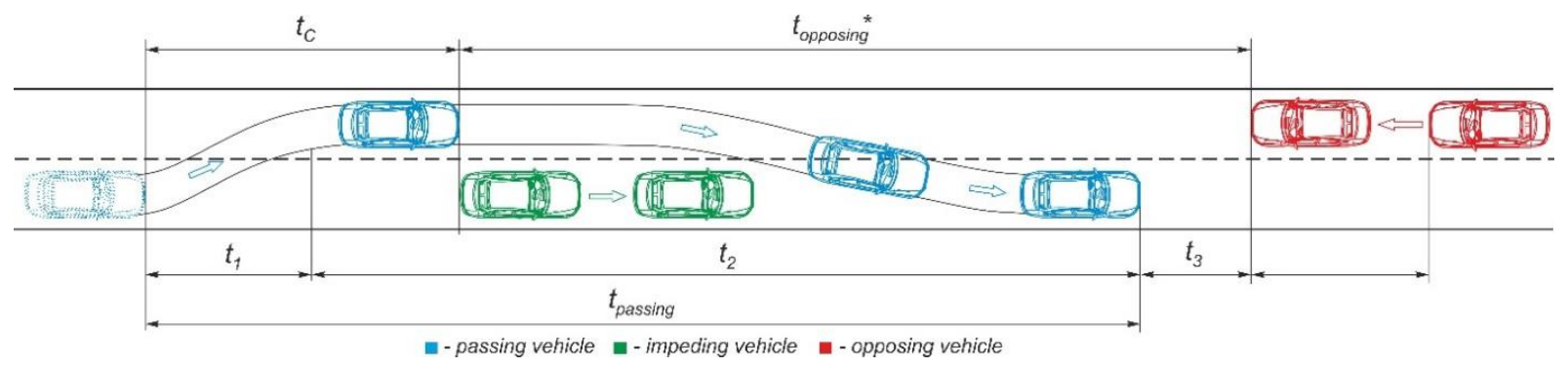

Figure 6. 7: Subsequent time maneuver

\subsection{Alternative Method for Initial Decision}

The initial decision in this case could be based on an available PSD and a required PSD. The available PSD can be calculated using a radar sensor measurement. The required PSD can be calculated using Equation (5.7) based on the reliability model described in chapter 5. In the passing collision warning system design, supply refers to the provision of safe and comfortable driving conditions (e.g., length and availability of passing sight distance that are measured using the radar sensor). Demand refers to the accommodation requirements of drivers or vehicles in order to provide a safe and comfortable maneuver (proposed PSD reliability model using Equation (5.7)). In the initial decision, the proposed warning system checks if the available PSD is larger than the required PSD. If this condition satisfied, the system will display "safe" message. Otherwise, a "not safe" message will be displayed until the above condition is met.

\subsection{Summary}

This chapter presents the framework and algorithm design for a collision warning system intended to help drivers conduct safe passing maneuvers on two-lane highways. This system makes use of 
a detector (radar sensor) to measure the speed and location of the closest opposing vehicle on a two-lane highway at four successive time intervals to discern the distance to the conflict point, as well as the relative distance and speed. The algorithm used in this system calculates the distance and time required for the passing vehicle to accelerate to the point of maximum speed. The algorithm then ascertains whether there is any possible conflict between the opposing and passing vehicles and displays a warning message if a conflict is detected. A vehicle-presence detector (placed in the passing vehicle) is used to activate the system and launch the algorithm. One of the novel contributions of the algorithm presented in this study is that it considers the time required for the driver to notice the warning message displayed by the system and react to it (to start or abort the passing maneuver). 


\section{CHAPTER 7: DEVELOPMENT OF THE SIMULATION ENVIRONMENT AND VALIDATION}

This chapter presents the implementation phase of this dissertation. The passing gap and passing collision warning system models are replicated in a real life environment using Simulink simulation models and various application examples are provided. Two Simulink models were developed: with and without the passing collision warning system. This chapter extends the description of the fundamental aspects of the passing gap acceptance model and the relationship between gap acceptance and the behaviour of the driver of the passing vehicle. The methodology described in this chapter was designed in order to model this behaviour.

\subsection{Simulink-Model Implementation}

The main argument for the use of Simulink simulations is their high level of efficiency. The model structure reflects its communications and the functionality of different elements, it provides the highest rate of model development by using the standard block library, it incorporates powerful tools for flow processing of results and data, it is capable of real-time simulation, and it can integrate the simulation environment with external devices in real time. All of these features make it easier for the elaboration of mechatronic systems such as PCWS.

\subsubsection{Justification of the use of Simulink}

Modern applied science not only involves the development of mathematical descriptions of technical systems and processes, but also the search for the best possible approach to the modelling and implementation of these processes in real engineering systems. Some of the issues with pure mathematical models are that they do not always fully correspond to the principles of digital data processing, and often cannot take into account some technical nuances and modelling errors. The use of Simulink, a powerful imitation environment, allows researchers to simultaneously look at an object, the structure of its constituent systems, and to monitor behaviour and control algorithms 
(Stateflow), summing up the basis for rapid prototyping of mechatronic systems. The numerical simulation in the Simulink/Simscape/Stateflow environment allows for the organization of SIL, PIL, HIL, and MIL tests for virtual models, as well as direct access to compile a code for controller firmware.

The present level of transport process precision modeling involves the integration of the vehicle's dynamics and controlled numerical simulation. Kretschmer at el. (2005) and Ruiz at el. (2007) used the Simulink model to develop a vehicle dynamics control model for safe overtaking maneuvers. At this stage of the research process, the two-dimensional simulation is used to replicate real life traffic maneuvering processes, allowing us to test ideas and develop related models. The development of simulation models clearly defines the goal of PCWS: the parallel forecasting and comparison of the time needed to outrun an impeding vehicle provided its detection, and the time until the hypothetical collision with an opposing vehicle.

The prototyping requires the development of an expanded model, which could sequentially approach the functionality of the real embedded device by means of simulation. This simulation combined with an event-driven model allows for the creation of warning system operation algorithms that are more logical and accurate, providing continuous functioning during overtaking. This study does not cover the effect of vehicle design features due to the complicated nature of the general model.

\subsubsection{Vehicle 2D-Dynamics Model}

Each vehicle used in the general simulation as a block (Figure 7.1.a) is described by the following differential equations:

$$
\left\{\begin{array}{l}
m \cdot \delta_{r} \cdot\left(\frac{d V_{C x}}{d t}-\frac{d \phi}{d t} \cdot V_{C y}\right)=\sum F_{x}^{(e)} \\
m \cdot\left(\frac{d V_{C y}}{d t}+\frac{d \phi}{d t} \cdot V_{C x}\right)=\sum F_{y}^{(e)} \\
I \cdot \frac{d^{2} \phi}{d t^{2}}=\sum M_{Z}
\end{array} .\right.
$$


The system of equations given by Equation (7.1) is represented in the vehicle's local coordinate system via longitudinal, lateral and rotational (around axis OZ) dynamics. $m$ represents the vehicle's mass, I represents the moment of inertia relative to the $\mathrm{OZ}$ axis, VCx and VCy represent the velocities along the axes of the local coordinate system associated with mass center $\mathrm{C}, \delta \mathrm{r}$ represents the coefficient that takes into account the inertia of the transmission's rotating masses, $\phi$ represents the angle of the vehicle's rotation around the $\mathrm{OZ}$ axis, and $\mathrm{F}(\mathrm{e}) \mathrm{x}, \mathrm{F}(\mathrm{e}) \mathrm{y}$, and $\mathrm{Mz}$ represent the generalized external force factors along the $\mathrm{x}$ and $\mathrm{y}$ axes and around $\mathrm{z}$ (respectively). The vehicle control is carried out by changing the magnitude or direction of power factors, that is, traction and the lateral reactions of the tires. The system of Equation (7.2) can be represented by derivatives via matrixes, making it simple and accessible for Simulink implementation without needing any special commercial software.

$$
\left(\begin{array}{c}
\frac{d V_{C x}}{d t} \\
\frac{d V_{C y}}{d t} \\
\frac{d \omega}{d t}
\end{array}\right)=\left(\begin{array}{ccc}
\frac{1}{m \cdot \delta_{r}} & 0 & 0 \\
0 & \frac{1}{m} & 0 \\
0 & 0 & \frac{1}{I}
\end{array}\right) \cdot\left(\begin{array}{l}
\sum F_{x}^{(e)} \\
\sum F_{y}^{(e)} \\
\sum M_{C}
\end{array}\right)+\left(\begin{array}{c}
V_{C y} \\
-V_{C x} \\
0
\end{array}\right) \cdot \frac{d \phi}{d t}
$$

where $\omega=\mathrm{d} \phi / \mathrm{dt}$ yaw rate or rotational velocity.

\subsubsection{Simulink-Model of Vehicle Steerability}

The Simulink model shown in Figure 7.1 was developed based on two-dimensional vehicle dynamics (steerability) in order to replicate different overtaking scenarios on a two-lane highway. The main feature of the proposed single vehicle model is its four-point road contact (as opposed to the bicycle models that are still widely used). The distribution of the vertical forces on the wheels, which is the most influential factor in the tire slip process, is provided including longitudinal and lateral deviations. This distribution takes into account the effect of the inertia's 
pseudo-forces at the vehicle's mass center. The model uses a non-linear tire-road contact and degree of adhesion.

The model allows for the inclusion of various PCSW functioning algorithms and to analyze the overtaking process without a pre-installed warning system. The basis of the model (Figure 7.1.a) are blocks 1, 10,18, which represent the two-dimensional dynamics of a single vehicle, consisting in turn of subsystems and components from standard Simulink libraries. Each block has its own icon and can be individually adjusted for a specific vehicle, setting the geometric, kinematic and physical characteristics. The input and output ports of car blocks are implemented through wireless data blocks. This allows for the organization of separate subsystems of initial data input 29 and results output 30 (graphical representations of solutions). Blocks 2, 11, 20 and 3, 12, 21 are vectors that transmit initial positions (plane location and yaw rotation angle) and velocities (longitudinal, lateral and yaw rate) according to degrees of freedom. Blocks 4, 13, 22 execute the transfer of desired course velocities, which are used for the adjustments of necessary traction forces.

The steering wheel angles are provided through input ports 5, 14, and 23. The kinematic relationship between the steering system and the steering wheel is determined for each vehicle. The rationalization of the steering trapezoid was done to reach Ackerman's angle distribution. The relationship between the steering system and the steering wheel are subsequently detected via steering mechanism parameters. The special polynomials reflect the kinematics of the steering system as a mathematical expression. The steering wheel impact is event-driven and controlled by Stateflow.

The outputs are as follows: blocks 6, 15, and 24 - accelerations (longitudinal and lateral) in the vehicle's local coordinate system; blocks 7, 16, 25 - velocities (longitudinal and lateral); blocks 8, 17, 26 - all absolute displacements relative to the global coordinate system; blocks 9, 18, 27 steering wheel turning angles. Subsystem 28 is the event-driven Stateflow model of the warning system that uses the output parameter data for the analysis of the mutual location of vehicles on a road, and executes a time forecast comparing the critical time value with a current safe margin of time to collision. Switches 31 and 32 allow for the execution of animations or the creation of 
movies when the modeling has been computed. Slider 36 regulates the frequency of animation frames.

(a)
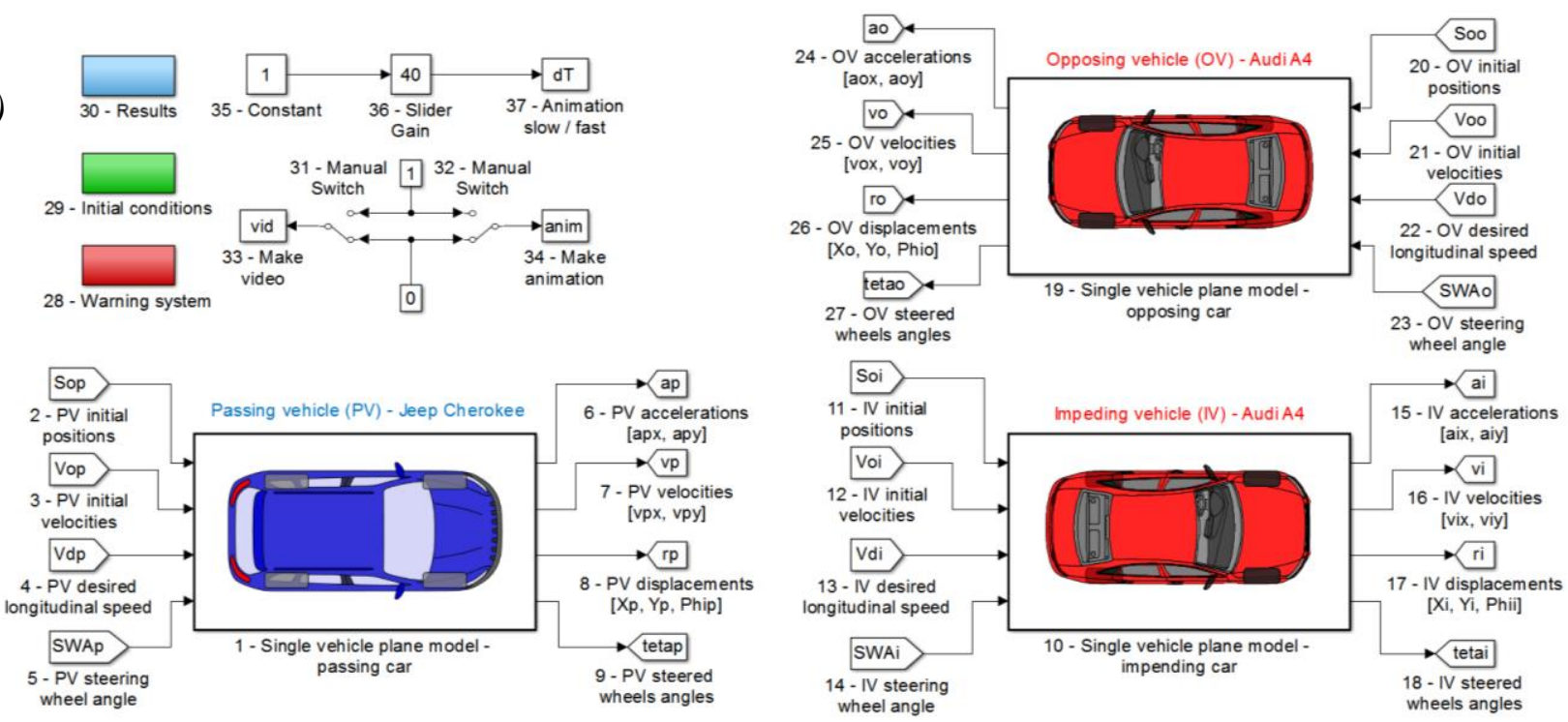

(b)

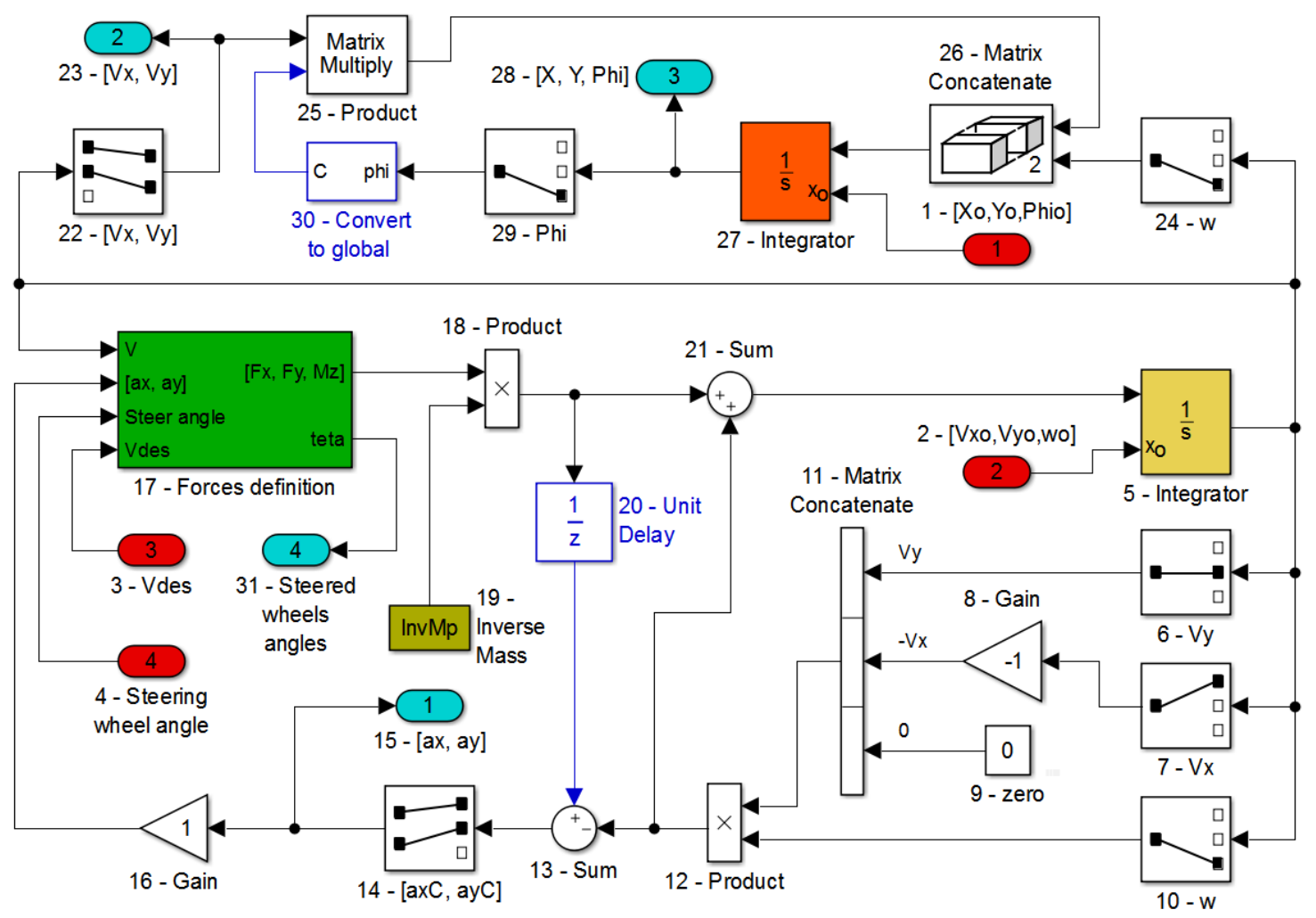

Figure 7. 1: Simulink model for Collision Warning System development: (a) General interface of 3vehicle model, (b) Simulink structure of single vehicle plane model 
The pattern's basis (Figure 7.1.b) consists of first-order continuous type integrators 5 and 27, which coherently integrate a system of 6 equations reduced to Cauchy's form. Block 1 (port 1) sends the vector of the mass center's initial position and the yaw rate $[\mathrm{X} 0, \mathrm{Y} 0, \phi 0]$ to integrator 28 , and block 2 (input port 2) sends the velocity vectors $[\mathrm{Vx} 0, \mathrm{Vy} 0, \omega 0]$ to integrator 5. Block 3 (input port 3 ) holds the desired speed value, which is associated with the vehicle traction mode. Block 4 (port 4) controls the steering wheel control signal. The internal variable includes the steering gear ratio and provides the turning angle distribution of the steering wheel.

The structure aims for a matrix representation of computational operations. The following calculation procedures are the most important. Block 17 allows for the generation of a vector of generalized force factors, taking into account the current kinematics of motion and control factors. Block 19 contains a built-in variable whose value corresponds to the pre-inverted mass matrix that can significantly speed up the computing process. Block 20 eliminates the phenomenon of excess algebraic loop in the structure. Block 30 sends the transition matrix from the vehicle's local coordinate system to the global coordinate system. This block uses the yaw angle as an input and submits a computed matrix to the input port of block 25. The multiplication of the vector of velocities in the local coordinate system and the transition matrix provides the vector of velocities in the global coordinate system as an output from block 25 that will then be integrated by block 27.

Blocks 7, 10, 14, 22, 24, and 29 help with the selection of certain necessary variables. Block 23 is the output vector of velocities (longitudinal and lateral) in the local coordinate system. Block 28 provides the output vector of displacements and yaw rotation in the global coordinate system. Computational procedures are performed almost instantly, making this a promising model for the simulation of traffic situations involving several vehicles. A large number of virtual tests were conducted to demonstrate the quality and accuracy of the model's representation of the maneuvering process of vehicles. Appendix F describes the Simulink library model. The distributions of desired velocities by time correspond to the average experimental values, but are changed each time the model begins according to the random deviations that are generated. The initial vehicle distances comply with the regulations provided in the references. The input data 
from the field studies for Passing Collision Warning Systems (PCWSs) included the following: (1) initial speed; (2) initial distance; (3) detection sensor angle; (4) gender, age, driving experience and average weekly driving hours of the passing vehicle driver; (5) the number of lanes, lane width and delay distance of the highway geometric design.

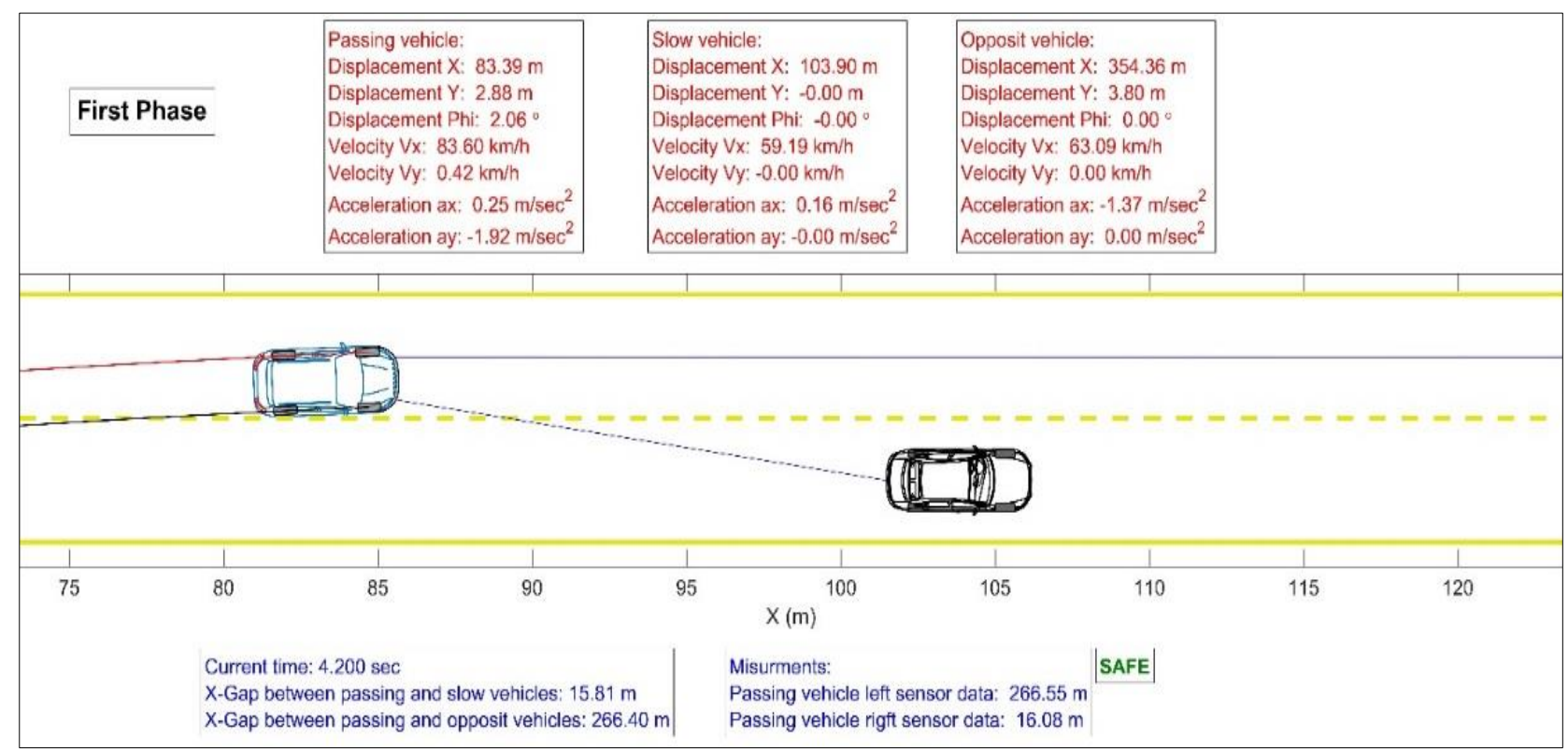

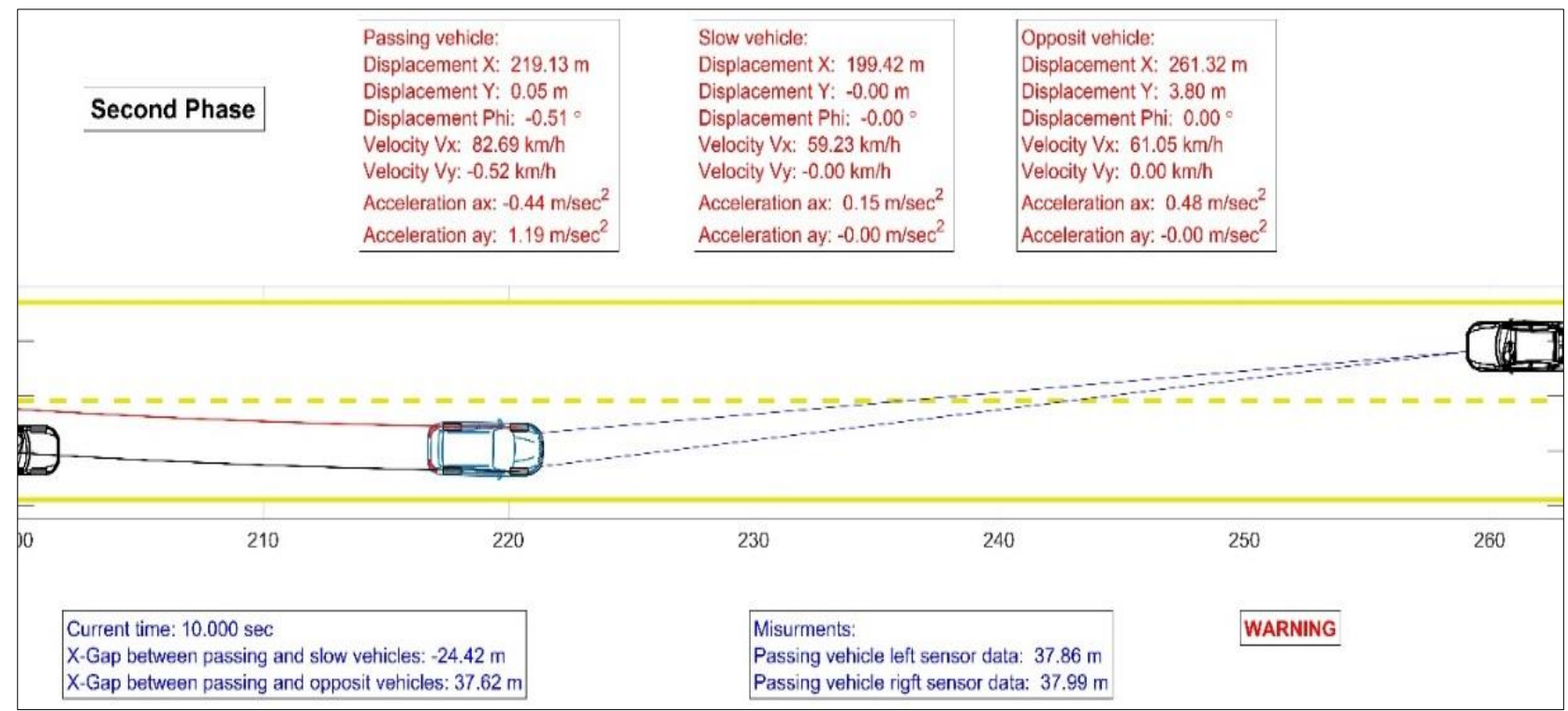

Figure 7. 2: Example of PCWS simulation (Design speed of $80 \mathrm{~km} / \mathrm{h}$ ) 


\subsubsection{Simulink Model Structure}

Computational procedures are performed almost instantly, making this a promising model for the simulation of traffic situations involving several vehicles. A large number of virtual tests were executed and the results revealed that the model is capable of adequately representing the vehicle maneuvering process. The results of passing maneuver trajectories are presented in Figure 7.2.

\subsection{Decision Making Model}

Drivers require a sufficient time gap to ensure that they can safely maneuver past an impeding vehicle on a two-lane highway. Gap availability is an important element of safe passing maneuvers. Time gaps are used to determine passing behaviour based on human factors. The following sections provide detailed information about the formulation and validation of passing decision making. The start gap $\left(\mathrm{G}_{\mathrm{s}}\right)$ and the end gap $\left(\mathrm{G}_{\mathrm{e}}\right)$ are shown in Figure 7.3. $\mathrm{G}_{\mathrm{s}}$ was defined as the point when the passing vehicle's left front wheel touches the center line to the critical point and $\mathrm{G}_{\mathrm{e}}$ was defined as from the critical point to the point when the passing vehicle's rear left wheel touches the center line. These definitions are consistent with those used in other studies (Farah, 2013; Hegeman, 2004; Mahdi, 1991).

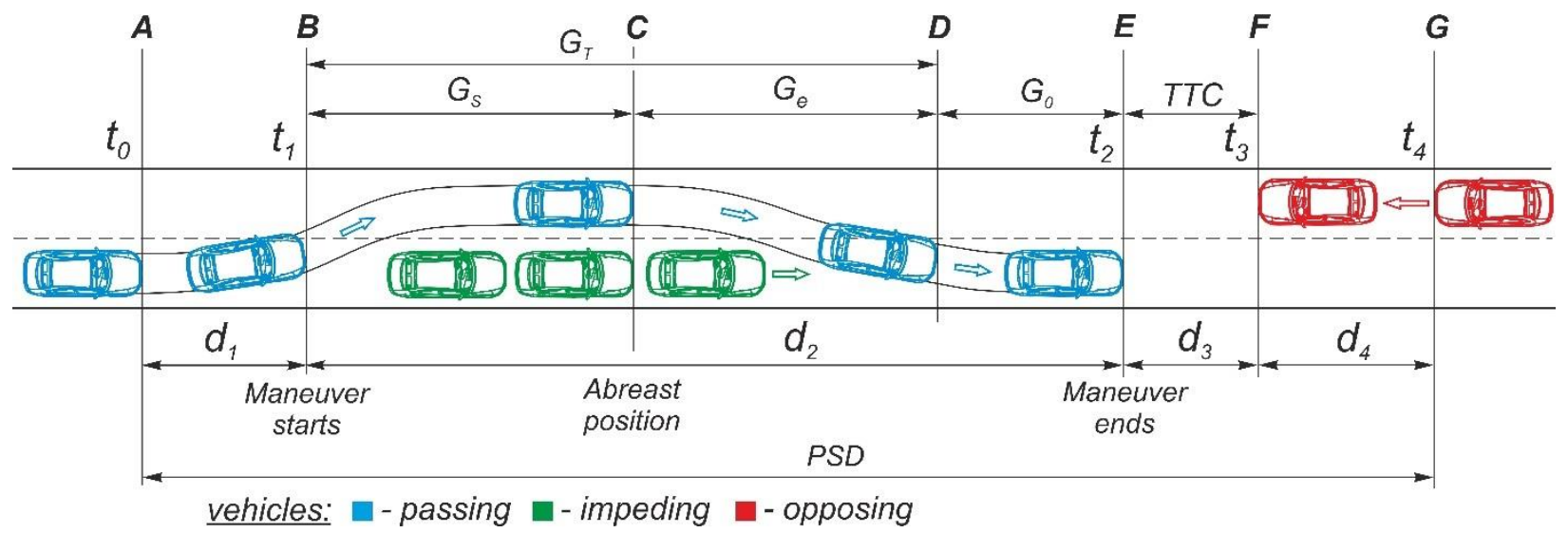

Figure 7. 3: Estimates of the Passing Maneuver 
The simulation model was developed in order to evaluate the behaviour of passing drivers. Field data were used in this Simulink model. The situations encountered by participants are illustrated in Figure 7.4. This study focused on the decision whether to pass an impeding vehicle. In making this choice, the driver of the passing vehicle needs to consider the available passing gaps. These gaps were defined as the time gap between the opposing vehicle and the passing vehicle at the time that the impeding vehicle encounters the passing vehicle (see Figure 7.4).

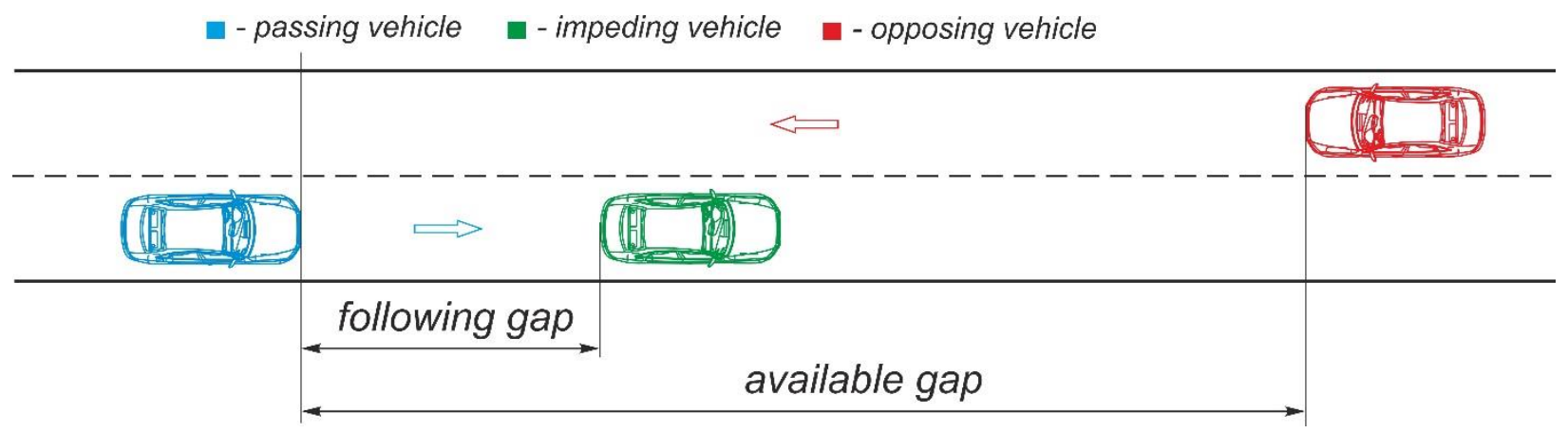

Figure 7. 4: Passing Gap Acceptance Situation

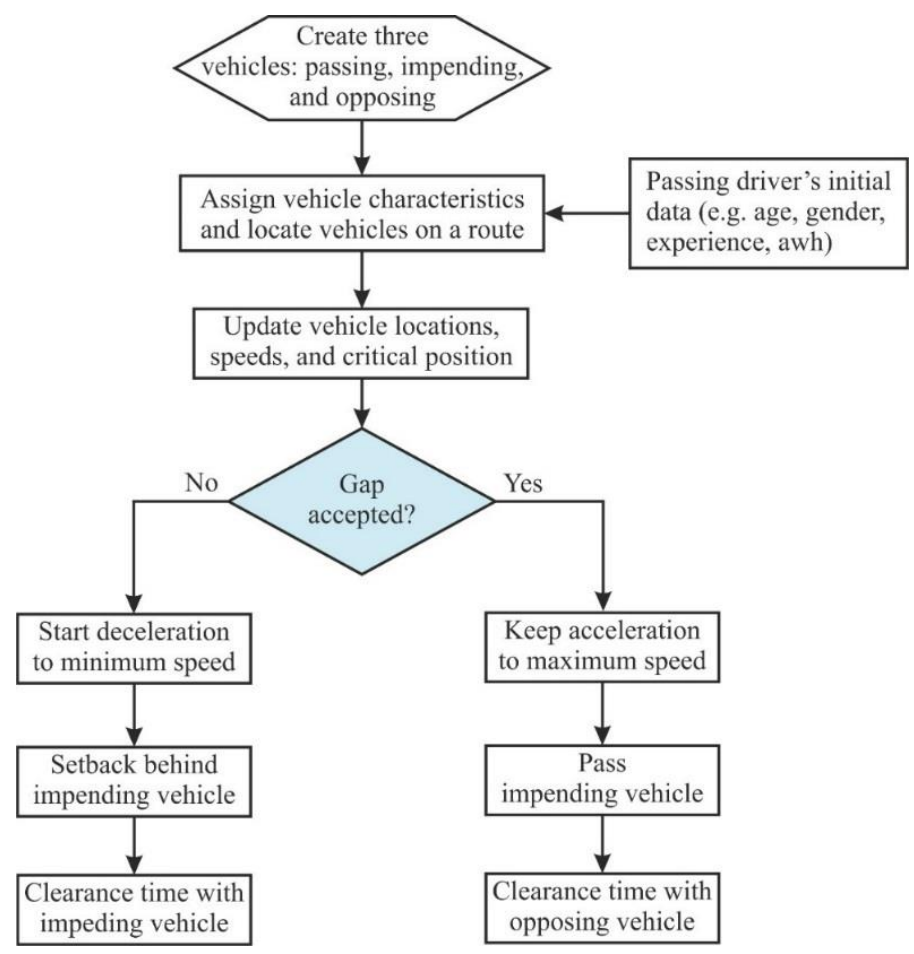

Figure 7. 5: Structure of the Passing Gap Model 
Mathematically, the time gap is calculated by dividing the distance between approaching vehicles by the sum of their speeds. A number of different scenarios were designed to capture the impact of various traffic factors on passing behaviour. The completion of passing maneuvers is modelled by the driver's ability to make the decision of whether to accept or reject an available passing gap. The model structure is illustrated in Figure 7.5. Drivers must first decide whether or not they wish to pass the impeding vehicle. A driver who is interested in passing evaluates the available passing gap and either accepts it and completes the passing maneuver, or rejects it and aborts the passing maneuver. The model for the decision to pass is formulated as follows, based on logic:

$$
\begin{aligned}
D M(i) & =\left\{\begin{array}{lll}
\text { Complete the Pass } & \text { if } \quad P S D_{a v l} \geq P S D_{\text {req }} \\
\text { Abort the Pass } & \text { if } \quad P S D_{a v l}<P S D_{\text {req }}
\end{array}\right. \\
P S D_{a v l} & =D / v_{o} \\
P S D_{r e q} & =t_{1}+G_{s}+G_{e}+G_{o}+T T C
\end{aligned}
$$

where $\mathrm{i}=$ indices for the driver of the passing vehicle; $D M(i)=$ indicator variable with a value of complete the pass if the driver wishes to pass and abort the pass if the driver does not wish to pass; and $P S D_{a v l}=$ available passing time for the driver of the passing vehicle (s); $D=$ initial distance between the passing and opposing vehicles $(\mathrm{m}) ; v_{o}=$ opposing vehicle speed $(\mathrm{m} / \mathrm{s}) ; P S D_{\text {req }}=$ required passing sight distance time $(\mathrm{s}) ; t_{1}=$ initiated time that the passing vehicle travelled during the perception-reaction time and acceleration towards the left lane (s); $G_{\mathrm{s}}=$ starting gap time until the critical point is reached (s); $G_{\mathrm{e}}=$ ending gap time (s); $G_{\mathrm{o}}=$ transition time at the end of the passing maneuver (s); and TTC $=$ time to collision $(\mathrm{s})$.

\subsection{Decision-Making Process}

\subsubsection{Without Warning System}

The chart-model in Figure 7.6.a reflects vehicle handling depending on the drivers desire to pass and a subjective assessment of the road situation. The Stateflow chart software provides the steering wheel angle as the output signal $S$. The decisive maneuver is composed of the four 
simplest combinations, which are executed by state blocks S1, S2, S3, and S4. Therefore, the handling algorithm creates the control signal $\mathrm{S}$, which is changed functionally according to the current state. The PID-controller, which is well known in automation theory, was used to model driving. The PID-controller forms the output handling signal from two input signals, the desired and actual steering angles. The PID function (Simulink function pidst) compensates for the difference between the steering signal input (desired) and the calculated current steering wheel angle.

The actual direction is defined by the current yaw angle phi and the theoretical direction is calculated as a value of the angle deviation, which is a derivative and described via Hermit polynomials on the base length $\mathrm{L}$ (Matlab function tl) from the initial position $\mathrm{x}_{0}$. The chart operates as follows. When the default initial state S0 is accepted, the zero-output signal S is provided. This corresponds to a straight-ahead movement without any action on the steering wheel. When the input variable desire to pass (corresponding to Equation (7.3)) becomes logical 1, the transition to state $\mathrm{S} 1$ is carried out. During the state $\mathrm{S} 1$ execution, the passing vehicle is changing road locations and moving toward the left lane. This state has two possible transitions. For completed passes, transition number 1 from state S1 signifies a switch to state S2 (further rectilinear motion) if the parameter $G \_a c c e p t$, which becomes logical 1 (see section 7.2).

In this case, the side displacement on the base length $\mathbf{L}$ will be completed. For aborted passes, transition number 2 from state S1 to state S3 will be expected if the parameter $G$ _accept equals logical 0 after shifting into the opposing lane. In this case, passage is deemed unsafe and impossible. This means that state $\mathrm{S} 3$ is equivalent to state $\mathrm{S} 1$, but provides a negative sign for signal $\mathrm{S}$ to return the passing vehicle to the right lane. In case of a transition from state $\mathrm{S} 2$ to state $\mathrm{S} 3$, the passing vehicle continues in a straight line until the critical point is reached. After that, state S3 provides the signal for the vehicle to return to the right lane. State S4 subsequently provides the signal for the vehicle to continue in a straight line. 


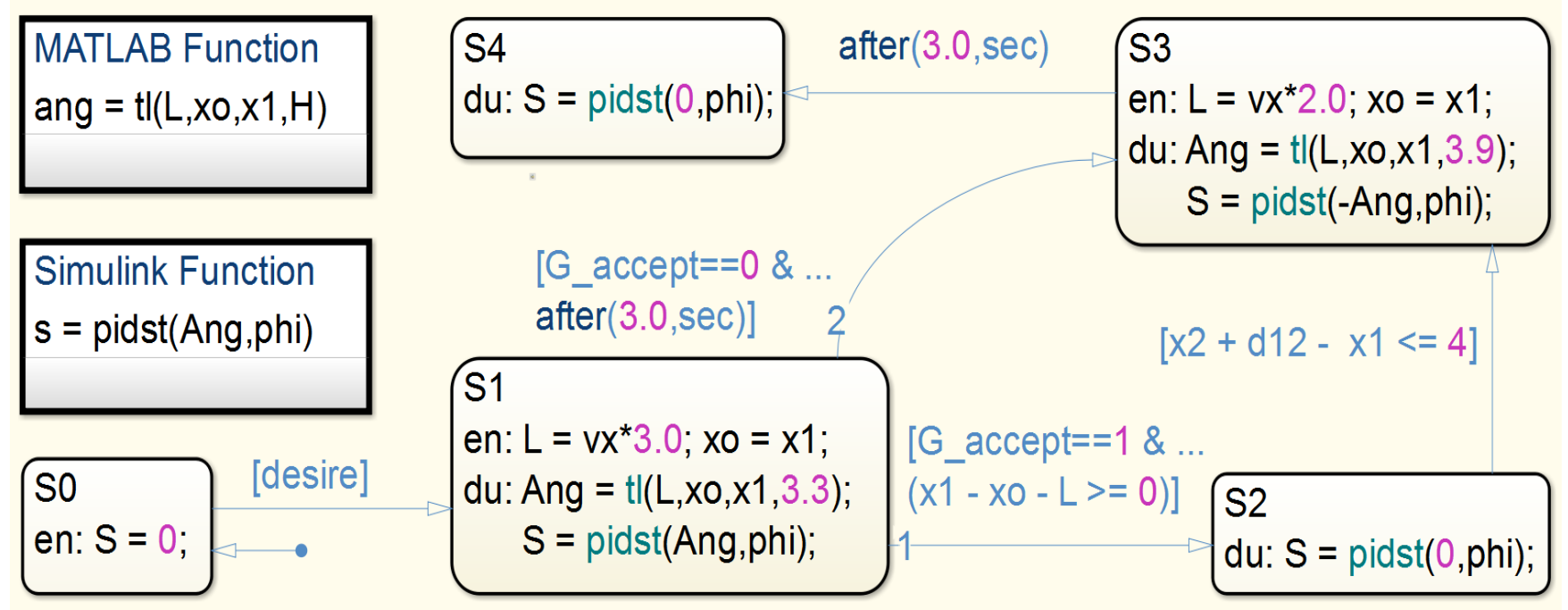

(a) Without Warning Model

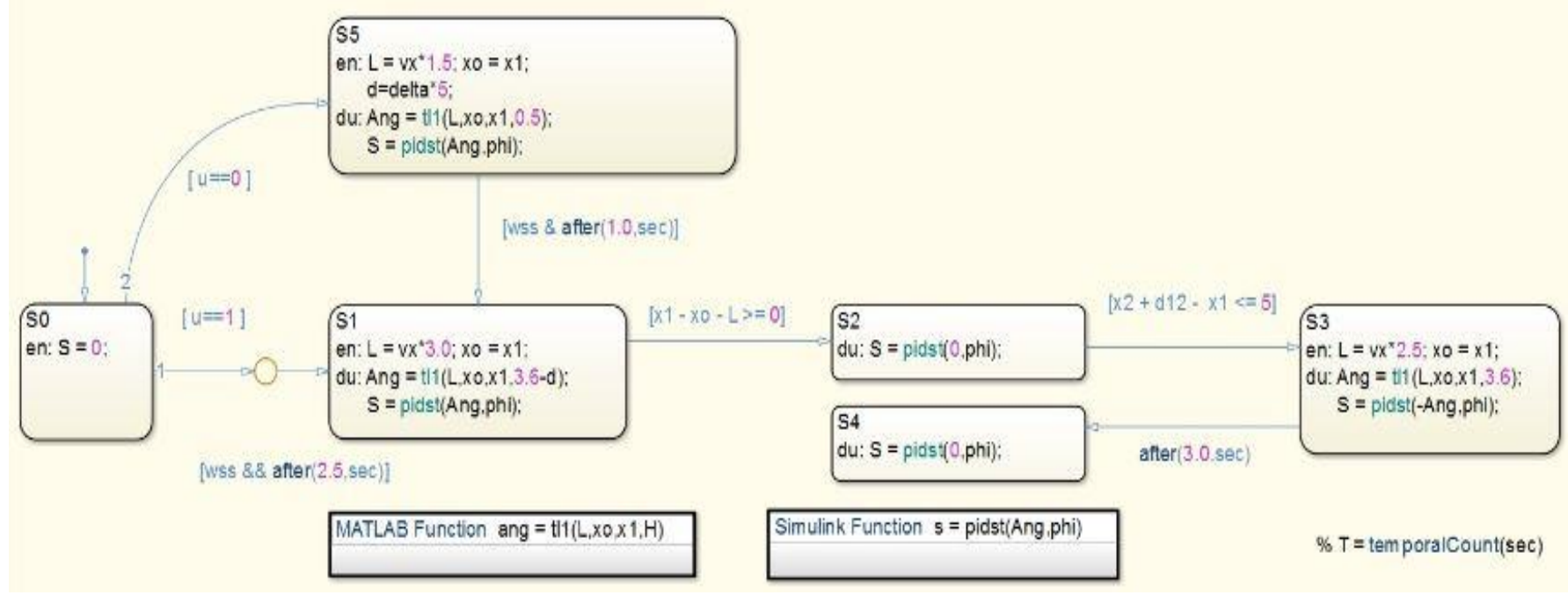

(b) With Warning Model

Figure 7. 6: Decision Making and Steering Control Stateflow:

\subsubsection{With Warning System}

The chart-model in Figure 7.6.b reflects vehicle handling depending on the drivers desire to pass and a subjective assessment of the road situation. The Stateflow chart software provides the steering wheel angle as the output signal $S$. The decisive maneuver is composed of the four simplest combinations, which are executed by state blocks S1, S2, S3, and S4. Therefore, the 
handling algorithm creates the control signal $\mathrm{S}$, which is changed functionally according to the current state. The PID-controller, which is well known in automation theory, was used to model driving. The PID-controller forms the output handling signal from two input signals, the desired and actual steering angles. The PID function (Simulink function pidst) compensates for the difference between the steering signal input (desired) and the calculated current steering wheel angle.

The basic functional idea of this warning system is the preventive forecasting of mutual locations of vehicles moving toward each other. Two radar sensors are used via detectors that are mounted symmetrically on the vehicle's front bumper. These detectors operate using the Doppler effect. This allows the warning system to simultaneously control the position of two vehicles. This chapter does not cover the device simulation and signal processing due to the complicated nature of the general model. The calculation of the distance from the sensor to the opposing vehicle is executed geometrically from the solutions of differential equations.

The StateFlow chart was used for computational procedures and the arrangement of the warning system. A poll of the sensors is provided at time interval $t=0.1 \mathrm{sec}$ and new vehicle route distances are defined after each assessment. Following the first four data acquisition measurements, the finite difference formulas are used to determine the kinematic characteristics of the opposing vehicles. The kinematics of an overtaking vehicle are determined by reading devices that allow for the use of these parameters directly from motion equation solutions. The chart is organized in such a way that creates a delay in the 4 time intervals; the values for the primary data storage require the first four points. Subsequent cycles repeat times at intervals of one-time step. At these time intervals, the new values are calculated for opposing vehicle speed, final distance and estimated time remaining to collision.

\subsection{Application Example for Without Warning Model}

An application example is provided in this section in order to illustrate the methodology for the PSD Required Time Model used for passenger vehicles. Every time the simulation begins, the 
random deviations are generated in the PSD time model parameters which define the originality and uniqueness of traffic situations and correspond to real observations. The input data for the passing vehicle from the field studies included the following: (1) initial speed of 20 (m/s); (2) initial distance of $460(\mathrm{~m})$; (3) initial acceleration rate of the opposing vehicle of $0.68(\mathrm{~m} /)$; (4) gender 0 (male=0), age of 27 (year), driving experience of 10 (years) and average weekly driving hours of 30 (hours) for the passing vehicle driver; and (5) number of lanes of 2, lane width of 3.75 $(\mathrm{m})$, and design speed of $22.22(\mathrm{~m} / \mathrm{s})$, which is equal to $80(\mathrm{~km} / \mathrm{h})$ in highway geometric design.

The following gap distance was $d_{12}=44.4 \mathrm{~m}$ from the front bumper of the passing vehicle to the back bumper of the impeding vehicle. The following outputs were gathered as an example: initial time $t_{l}=3.36 \mathrm{~s}$; starting gap Gs $=1.38 \mathrm{~s}$; ending gap $\mathrm{Ge}=1.92 \mathrm{~s}$; transition time $G_{o}=1 \mathrm{~s}$; time to collision $T T C=7.3 \mathrm{~s}$; speed increases during acceleration $\Delta v_{p l}=7.25 \mathrm{~m} / \mathrm{s} ;$ speed reduction during deceleration $\Delta v_{p 2}=-3.59 \mathrm{~m} / \mathrm{s}$; final distance $d_{f}=271.7 \mathrm{~m}$; passing vehicle speed $v_{p}=21.15 \mathrm{~m} / \mathrm{s}$; impeding vehicle speed $v_{i}=18.42 \mathrm{~m} / \mathrm{s}$; opposing vehicle speed $v_{o}=18.6 \mathrm{~m} / \mathrm{s}$; the required passing time $P T_{r e q}=14.96 \mathrm{sec}$; the available passing time $P T_{a v l}=24.73 \mathrm{sec}$.

Figure 7.7 reflects the kinematic characteristics of a passing vehicle during an overtaking procedure, allowing for a qualitative assessment of the adequacy of the virtual experiment simulation. The first curve represents the longitudinal acceleration of the vehicle's mass center (Figure 7.7.a, blue colour). This curve represents the power unit's ability to realize the traction force depending on the adhesion with a road surface. The results indicate that the passing vehicle accelerates uniformly before transitioning into the opposing lane and shortening the distance to the impeding vehicle. The acceleration remains constant after the passing vehicle enters the opposing lane, corresponding to vehicle velocity increments of the value $\Delta v_{p}$.

The speed increases while the overtaking procedure is being executed and decreases once the critical point is reached. The lateral acceleration (Figure 7.7.a, red colour) best demonstrates the model's ability to represent the vehicle roadability. The absolute value of the lateral acceleration does not exceed $5 \mathrm{~m} / \mathrm{s}^{2}$ during the maneuver. The peak values of the lateral acceleration correspond to moments of motion trajectory curvature changes, when lateral reactions reach the highest values. 
The inertia of model dynamics during the transient process can be seen through the delay of the stabilization mode.

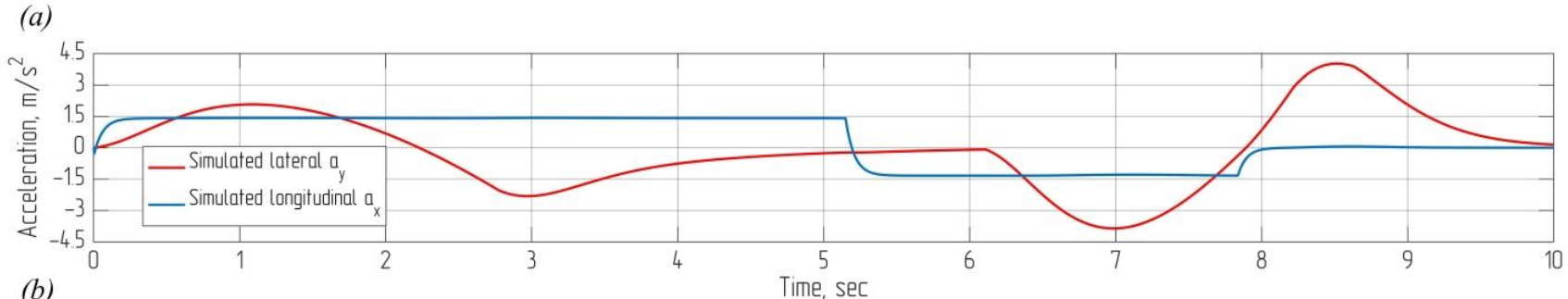

(b)

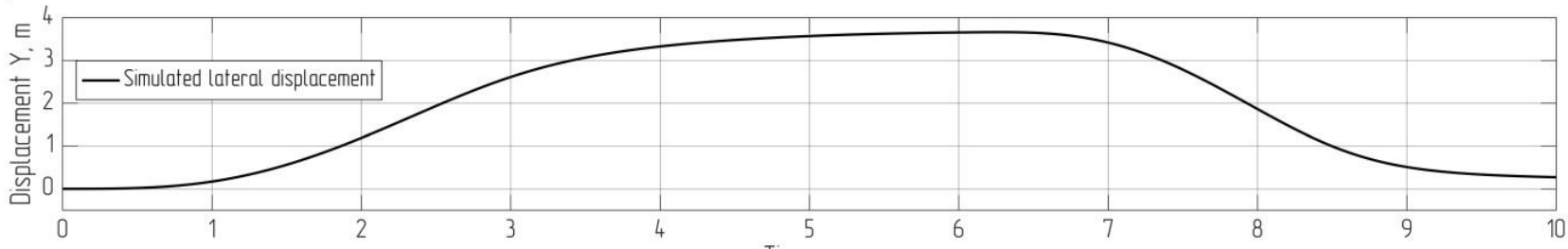

(c)

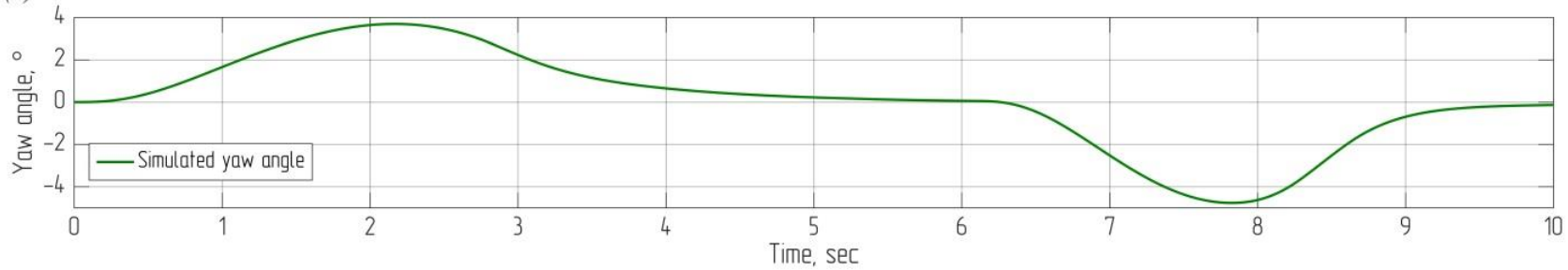

(d)
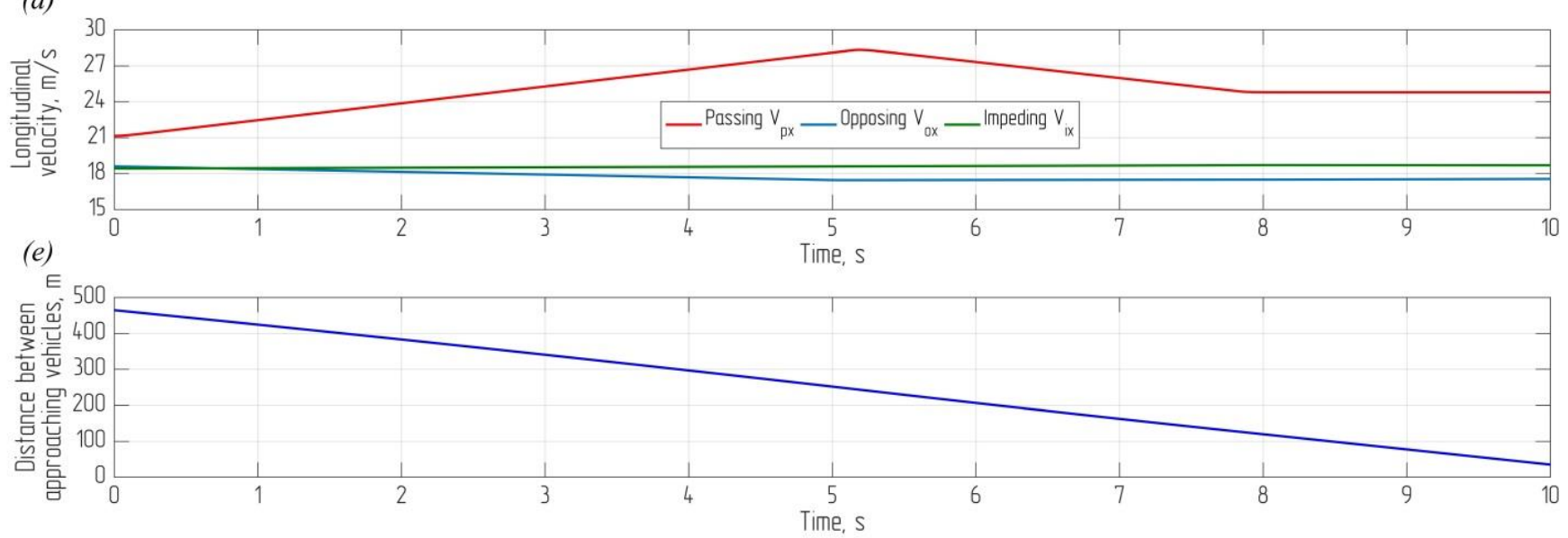

Figure 7. 7: Simulation output data: (a) Passing vehicle acceleration while overtaking, (b) Passing vehicle lateral displacement on two-lane highway, (c) Passing vehicle yaw turning, (d) Longitudinal vehicle velocities, (e) Distance between the passing and opposing vehicles 
The next curve (Figure 7.7.b, magenta color) represents the passing vehicle's displacements on road lanes. Starting offset corresponds to the driver desire to pass (Figure 7.6.a), which correlates with the assessment of required and available time gaps. There is then a transition process to the middle of the oncoming traffic lane which occurs according to the positive logical value of parameter $G \_a c c e p t$ (Figure 7.6.a). Overtaking is done while maintaining a steady position in the oncoming lane, and a sharper movement while completing the process and returning to the original lane. The yaw angle curve (Figure 7.7.c) reflects all transition processes and characterizes the driving stability and steerability of the model. The graphics in Figure 7.7.a, 7.7.b, and 7.7.c are smooth curves with continuous changes in curvature. This implies a steady motion without any jerking of the vehicle, confirming the quality of the model.

Figure 7.7.d illustrates the laws of changes in vehicle velocity during the overtaking process. These speeds are determined by experimentally established average parameters via regression equations with the addition of stochastic components. Figure 7.7.e shows a decrease in the distance between approaching vehicles (from the initial $460 \mathrm{~m}$ ). During the simulation, the movement of the impeding, opposing, and passing vehicles is monitored.

\subsection{Application Example for PCWS Model}

\subsubsection{Detection Data for the First Four States}

An application example is provided in this section to illustrate the methodology utilized in this study for passenger vehicles. The example assumes that the advisory system is using a detector with a frequency of $10 \mathrm{~Hz}$ and $0.1 \mathrm{~m}$ and 0.1 precision levels for the reading distance and azimuth angle, respectively. The first detector was installed on the right side of the front bumper of the passing vehicle. The setback distance (d12) is approximately $32 \mathrm{~m}$ from the front bumper of the passing vehicle to the front bumper of the impeding vehicle.

The second detector was installed on the left side of the front bumper of the passing vehicle and the setback distance (PSD) was approximately $580 \mathrm{~m}$ from the front bumper of the passing vehicle 
to the front bumper of the opposing vehicle. The initial detection measurements for the opposing vehicle were obtained at a distance (d1) of $545 \mathrm{~m}$, a sensor ray angle $(\theta 1)$ of $0.29^{\circ}$, and a speed of approximately $19.5 \mathrm{~m} / \mathrm{s}$. The second detection measurements for the same vehicle were obtained at a distance $(\mathrm{d} 2)$ of $535.5 \mathrm{~m}$, a sensor ray angle $(\theta 2)$ of $0.295^{\circ}$, and a speed of $19.33 \mathrm{~m} / \mathrm{s}$. The third detection measurements for the same vehicle were obtained at a distance (d3) of $525.7 \mathrm{~m}$, a sensor ray angle $(\theta 3)$ of $0.294^{\circ}$, and a speed of $19.17 \mathrm{~m} / \mathrm{s}$. The fourth detection measurements for the same vehicle were obtained at a distance $(\mathrm{d} 4)$ of $515.7 \mathrm{~m}$, a sensor ray angle $(\theta 4)$ of $0.295^{\circ}$, and a speed of $18.98 \mathrm{~m} / \mathrm{s}$. The front distance between the opposing vehicle and the detector (df), calculated using Equation (6.6), was $515 \mathrm{~m}$ and the distance between the impeding vehicle and the conflict point was $273.63 \mathrm{~m}$ (see Figure 7.8).

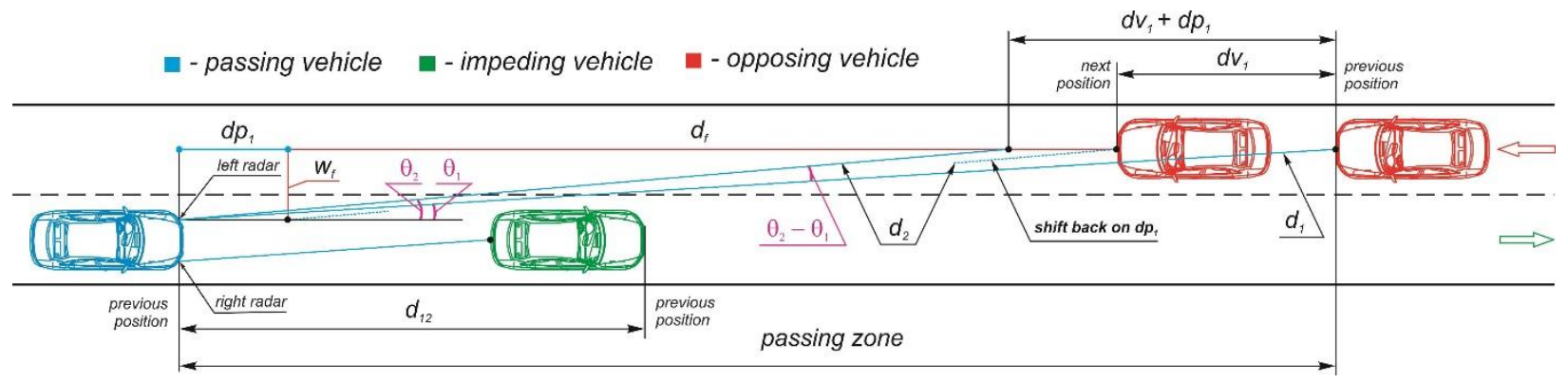

Figure 7. 8: Calculating distance and angle at each time interval

Since the impeding vehicle is traveling at a near-constant speed, the time required for the passing vehicle to overtake the impeding vehicle (tpassing $=\mathrm{t} 1+\mathrm{t} 2-\mathrm{tc}$ ), computed using Equation (6.11), was $10.68 \mathrm{~s}$. The time required for the opposing vehicle to reach the conflict point (topposing), computed using Equation (6.7), was 14.27 s. The difference between topposing and tpassing the $3.59 \mathrm{~s}$ safety margin was larger than the critical $2.0 \mathrm{~s}$ (95\% confidence interval). This safety margin was significantly larger than the measurement error associated with the precision level $(0.1 \mathrm{~s})$. The warning message displayed to the passing driver can therefore be deactivated. For a design speed of $22.22(\mathrm{~m} / \mathrm{s})$, it is important to note that the warning message would not have been deactivated if the opposing vehicle was detected at a shorter distance (less than $330 \mathrm{~m}$ ) from the passing vehicle or if the impeding vehicle was travelling at a higher speed (higher than $22.22 \mathrm{~m} / \mathrm{s}$ ). It is also important to note that the warning message would not have been deactivated if a higher confidence 
level had been used (higher than 99\%) or if the precision levels of the detector were above $0.1 \mathrm{~m}$ and 0.1 when measuring the distance and the angle, respectively.

\subsubsection{Passing Vehicle Overtaking Characteristics and Data Processing}

Figures 7.9.a, 7.9.b, and 7.9.c illustrate the kinematic characteristics of a passing vehicle during the overtaking process, allowing for the qualitative assessment of the adequacy of the virtual experiment simulation. The first curve represents the longitudinal acceleration of the vehicle's mass center (Figure 7.9.a, blue colour). This curve represents the power unit's ability to achieve the traction force depending on the adhesion with the road surface. As can be seen, the passing vehicle accelerates uniformly before transitioning into the opposing lane and shortening the distance to the impeding vehicle. The acceleration is decreased after departure on an opposing vehicle's lane during overtaking. This fact corresponds to vehicle's power plant property of reducing torque while its speed increases. The overtaking is executed at a constant speed value and the speed decreases once the vehicle begins the transition back into its lane. The lateral acceleration (Figure 7.7.a, red colour) best demonstrates the model's ability to represent the vehicle roadability. The absolute value of the lateral acceleration does not exceed $3.3 \mathrm{~m} / \mathrm{s}^{2}$ during the maneuver.

The peak values of the lateral acceleration correspond to moments of motion trajectory curvature changes, when lateral reactions reach the highest values. The inertia of model dynamics during the transient processes can be seen through the delay of the stabilization mode. The next curve (Figure 7.9.b, magenta colour) represents the passing vehicle's displacements on the road lanes. Starting offset corresponds to the left sensor's exit from the blind zone when the radar data processing begins. There is then a transition process to the middle of the oncoming traffic lane. Overtaking is done while maintaining a steady position in the oncoming lane, and a more sharp movement while completing the process and returning to the original lane. The yaw angle curve (Figure 7.9.c, green colour) reflects all transition processes and characterizes the driving stability and steerability of the model. The graphics in Figures 7.9.a, 7.9.b, and 7.9.c are smooth curves with continuous 
changes in curvature. This implies a steady motion without any jerking of the vehicle, confirming the quality of the model.

As illustrated in Figure 7.9.d, during the 1st second of computation time, the effect of the blind spot is compensated via the pre-steer maneuver arrangement (Figure 7.9.c). The following sample time points (Figure 7.9.d) are spent obtaining the first four measurement values illustrated on the graph of the distance to the opposing vehicle. After the information is accumulated, the warning system is ready to begin a forecasting assessment. This can be seen in Figures 7.9.e, 7.9.f, and 7.9.g around the 2nd second. There is good agreement between the impeding vehicle's actual speed (Figure 7.9.e, black colour) and the speed obtained using a numerical estimation (Figure 7.9.e, magenta colour) with some delay.

It is apparent that the sharp change in the movement mode of approaching vehicles has a negative impact on the accuracy of distance estimations. The absolute error, which is mostly positive with an average value below $1 \mathrm{~m} / \mathrm{s}$ (Figure 7.9.f), compensates for the delay, slightly reducing the estimated safety time. At the 12th second, the maneuver is almost complete. This time corresponds to a specified time, $t_{\text {passing. }}$. The warning signal reflects that the remaining distance is not sufficient to stay in the opposing lane. Figure 7.9.g illustrates the numerical data processing and the prediction of the safety margin time.

\subsection{PCWS as a Unified System}

The risk of collision during passing maneuvers is what makes driver behaviour different than in other situations (i.e. free-flow or following situations). Passing is only permitted in zones in which the passing sight distance $(P S D)$ required is smaller than the available sight distance. $P S D$ can be defined as the minimum distance needed to safely complete a passing maneuver when there is a vehicle approaching in the opposing lane. This distance is estimated using the proposed passing maneuver model developed in Chapter 4. This model assumptions regarding passing vehicle acceleration and speed variation were evaluated using field data. 
Once the required PSD has been predicted, a passing collision warning system (PCWS) can be used. These systems may help reduce driver judgement errors during passing maneuvers. The proposed PCWS prototypes have been implemented for real life driving situations using Simulink MATLAB. The systems ware calibrated in order to be effective. This means that the system corresponds to the actual driver behaviour. The study presented in this dissertation provides the solutions for the development of a PCWS for passing maneuvers.

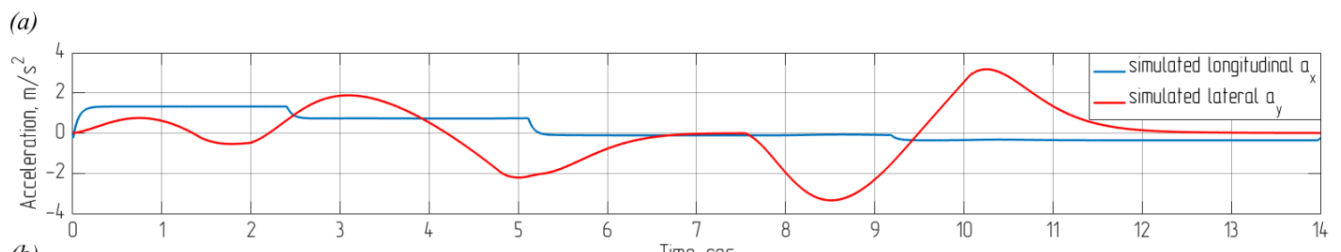

(b)

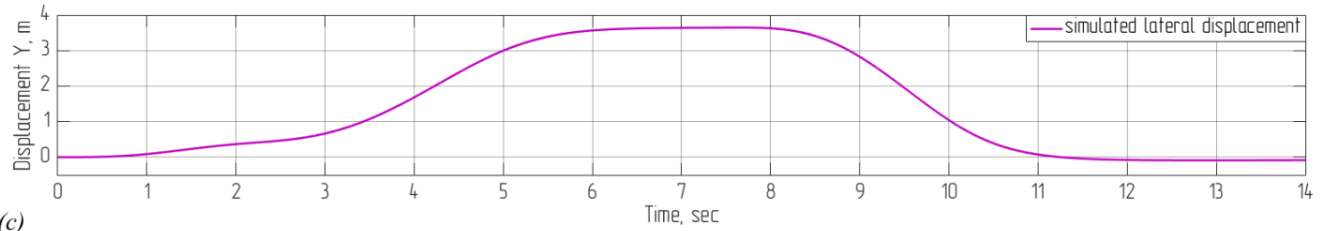

(c)
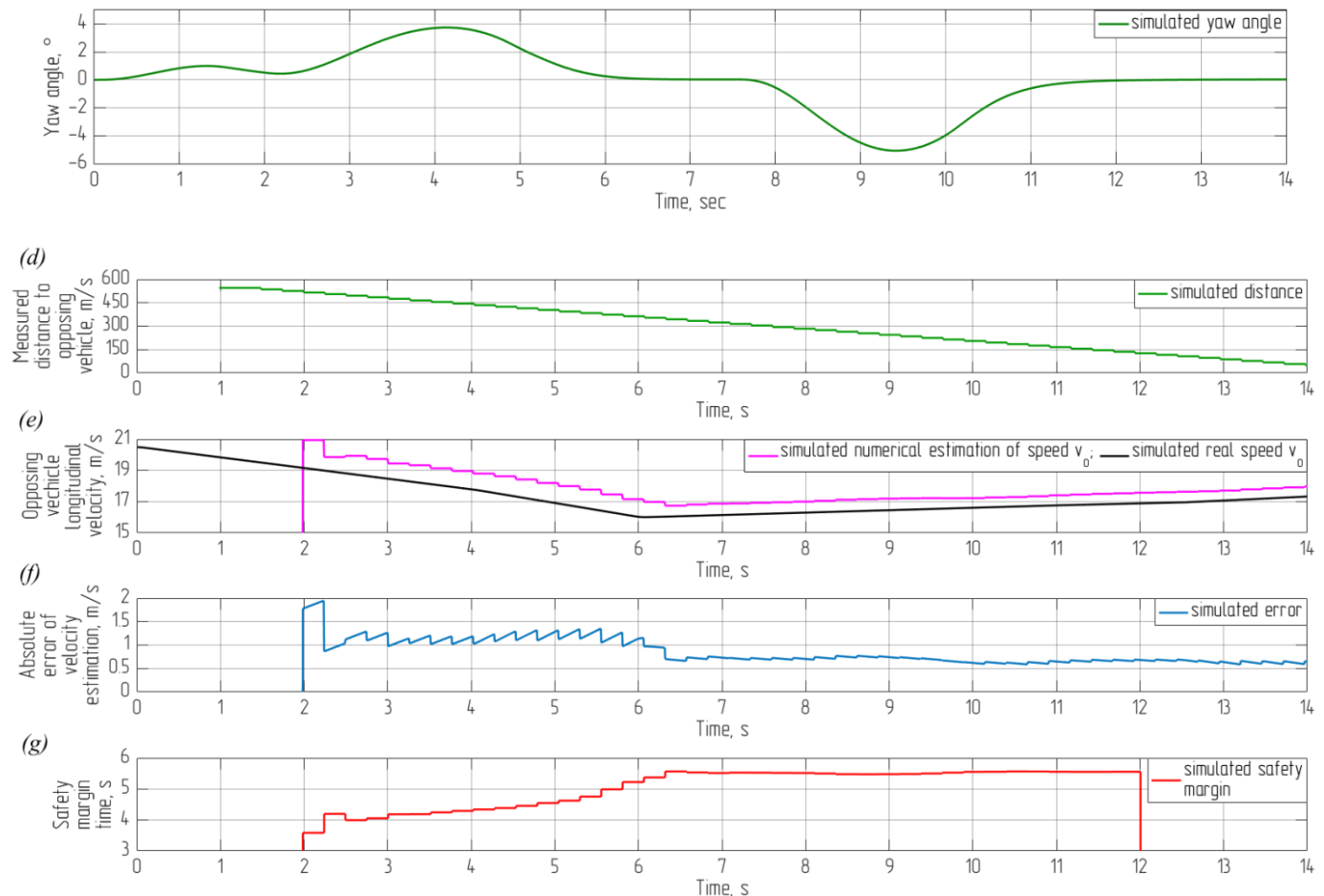

Figure 7. 9: Simulation output data: (a) Passing vehicle acceleration, (b) Passing vehicle lateral displacement on two-lane highway, (c) Passing vehicle yaw turning, (d) Sensor measurements for approaching vehicles, (e) Opposing vehicle velocity, (f) Velocity estimation error for the opposing vehicle, (g) Predicted safety margin time. 


\subsection{Chapter Summary}

Passing decisions were modelled as the decision to accept or reject an available passing gap. The probability of completing a passing maneuver was modelled as the product of the probability of a positive decision for both of these choices. Different scenarios were used to capture the impact of factors related to the various vehicles involved and different driver characteristics. The estimation results revealed that modeling the decision to pass makes a statistically significant contribution to the explanation of passing behaviour. The model incorporates variables that capture the impact of driver characteristics and the attributes of the specific passing gap that are evaluated by the driver.

A Simulink scenario was created to evaluate the performance of the proposed system for different precision measurement levels for the distance and the azimuth angle to ensure acceptable performance under different conditions. There are a number of advantages to traffic modeling using integrated vehicle dynamics simulations. The implementation of Simulink is intended to replicate real-life passing situations. A Simulink simulation model for two-lane highways was presented in this study. The simulation results were validated for a design speed of $80 \mathrm{~km} / \mathrm{h}$. The PCWS system was established for passenger vehicles. 


\section{CHAPTER 8: CONCLUSIONS, CONTRIBUTIONS, AND RECOMMENDATIONS}

\subsection{Research Summary and Conclusions}

The goal of this research project was to find a solution to the safety issue of head-on collisions on rural two-lane highways resulting from unprotected drivers attempting to pass impeding vehicles without sufficient information regarding the relative position and speed of the opposing vehicle. The passing collision warning system (PCWS) framework developed in this study for two-lane highways can help drivers avoid passing collisions by reducing the chance of human errors. The goals of this research were: (1) to conduct a literature review of existing collision warning systems and existing passing sight distance models, (2) to collect passing maneuver data using field studies and driving simulator studies, (3) to develop deterministic and reliability-based models for passing sight distance (PSD) that consider driver characteristics, (4) to develop an in-vehicle passing collision warning system that accounts for driver characteristics, and (5) to implement Simulink to replicate real-life driving situations.

The case studies were based on driving simulation scenarios as well as field studies. The solution proposed for this safety issue was the development of a new Intelligent Transportation System ITS application with two main functions: (1) the detection of the vehicles involved in the passing maneuver, and (2) the display of a message informing the driver if it is safe or unsafe to pass. There were several steps involved in the development of the proposed system, from the development of a conceptual framework, to a well-defined system that includes the design of all subsystem components and functions. The systems performance was then evaluated in order to ensure that it achieved the primary objective of improving road safety. Chapter 1 covered the background, statement of the problem, scope and objectives, and research methodology.

Chapter 2 of this study began with a detailed and comprehensive literature review of human factors, collision warning systems, existing passing sight distance models, vehicle acceleration profiles, passing gap acceptance, and driving simulators. The different passing scenarios used in 
the driving simulator were then carefully analyzed in Chapter 3 in order to identify passing parameters without a warning message. Passing scenarios with a warning message were then developed in order to investigate passing parameters with a warning message. Extensive driving simulator and field data regarding the geometry of the roadway, flow of traffic, and speed distribution by vehicle type was then collected (Chapter 3). This data was then analyzed in order to identify any useful information and parameters which were then introduced into the analysis in the next stage of the study.

The passing sight distance model was developed based on the results obtained in the driving simulator studies and validated using the field studies (Chapter 4). The proposed PSD model evaluation was conducted in Chapter 5 using a reliability model and Monte Carlo simulation. These models, intended to reflect actual conditions, are run using MATLAB. These models verify the accuracy of the proposed passing sight distance model and improve road safety. Chapter 6 covered the structure of the PCWS system, including the identification of system requirements, the description of functional components, and the development of a conceptual design of components such as the radar detector, the control processor, and the warning system.

In order to assess the system functions and the performance of the application, a simulation was conducted (Chapter 7). Simulink was used to write a special software program and a large number of parameters were introduced to reflect reality. This simulation was used for both system cases (without and with a warning message). A comparison of the results indicated that those obtained using the simulation closely resembled the results obtained in the field studies. It is critical that drivers obey the messages displayed by the system. Multiple sensitivity tests were conducted for different scenarios. The input parameters used in the field studies included an in-vehicle video camera and a GPS data logger. The system showed a high degree of performance. There were zero collisions in any of the tests conducted using the warning system.

\subsection{Research Contributions}

The key scientific contributions of this research project are as follows: 
1. The development of passing sight distance (PSD) parameters including initial time, passing time and average acceleration rate using a driving simulator and field studies conducted in different countries which consider driver characteristics. The development and validation of statistical models (initial time, passing time and time to collision) used to estimate the time required for the driver to complete the pass and a passing collision warning system which accounts for the time needed for a driver to perceive the message displayed by the warning system and react to it. This includes the regression models based on field data that are only used in the early development stages of the warning system. These statistical models can be used to increase the accuracy and reliability of any passing collision warning system.

2. The development of a passing sight distance model based on the results of driving simulator studies which include human factors such as driver age, gender, driving experience, and average weekly driving hours. The proposed model was validated using the results of the field studies.

3. The presentation of design procedures that account for variations in all contributing parameters within the PSD formulation. The FOSM method, based on Hasofer-Lind, was used for this reason. The results of the proposed PSD model differ from those obtained using the Glennon (1988) and Hassan at el. (1996) models. The PSD formula used to describe the mechanics of passing maneuvers was used as the base for the formulation of the reliability model. The calculated distribution was used to assess the reliability indices of current PSD standards. The results indicate that the mean design values of the AASHTO (2011), MUTCD, Glennon's and Hassan at el. models are smaller than the proposed PSD model, while the AASHTO (2004) and TAC (2007) values overestimate PSD requirements.

4. The understanding of driver behaviour as well as the human factors that impact the decision to pass a slow moving vehicle on rural two-lane highways is enhanced by modelling the different passing behaviour parameters. These models have the potential to improve traffic and safety, and traffic simulation models.

5. The elimination of unnecessary warnings and an increase in the reliability of the warning system by reducing driver nuisance, for example, the no warning message will be displayed 
when the vehicle detected is not travelling in the opposing lane, or the opposing vehicle is a sufficient distance away (there is no risk of a collision).

6. The development of an algorithm to display warning messages to the driver if required. The design of algorithms to calculate the time required by the opposing vehicle to reach the passing vehicle and a comparison with the time required by the passing vehicle to clear the path. These algorithms consider the position and speed of the opposing vehicles. These algorithms also consider the time required by the driver of the passing vehicle to perceive the message displayed by the warning system and react to it, increasing the accuracy of calculations involving the time required by the passing vehicle to complete the passing maneuver. Lastly, these algorithms consider the variation among drivers in the selection of the desired acceleration rate during the passing maneuver. These algorithms can be used to increase the accuracy and reliability of any passing collision warning system.

7. The development of a passing collision warning system prototype for drivers on straight two-lane highways to prevent passing collisions and improve road safety. The Simulink implementation was used to replicate real-life passing maneuvers. The verification and validation of the developed collision warning system was done using a simulation environment to test the proposed warning system in real life conditions. The passing maneuver parameters were selected from a distribution curve based on data collected in this study. The results indicate that the proposed warning system functions successfully.

\subsection{Limitations and Future Research}

This study examined a new area related to traffic safety, which has opened the door for further research and analysis, as well as a new ITS application that can be upgraded for more sophisticated functions and technologies. The proposed application was successful in drawing a conceptual framework of the various system functions and detailed information regarding the design of each component. The simulation successfully explained the primary parameters and the sequence of events that lead to head-on collisions. Further research must be conducted in order to fill some of the knowledge gaps in this area of study and provide a complete picture. The following four areas are of particular interest: 
1. Data Collection: This study did not examine the differences between driver characteristics in the driving simulation study and field data as well as the differences in environments and driver's culture in each study. More intensive field surveys over a larger area may be required. This could be done once the system is installed in order to collect data, before and after the system is activated, over a long period of time.

2. Human Factor Studies: There are still many questions that need to be addressed in regards to human factors and their impact on passing maneuvers.

3. Efficiency of the system: The research needs to be extended to cover the effect of horizontal and vertical alignments on the passing collision warning system as well as side effects (e.g., wind, drag) in order to increase the efficiency of the system.

4. Commercial products: The investigation was limited and did not cover circuit designs for the system or offer a warning system as a commercial product. More research and development is needed to achieve these goals that are beyond the scope of this research and can be reached using multi-disciplinary approaches, such as: mechanical and electrical engineering. 


\title{
Appendix A: Copies of Consent Agreement and Driver Information Sheet
}

\author{
CONSENT AGREEMENT: DRIVER PASSING VEHICLE BEHAVIOUR
}

\section{Investigators}

Udai Hassein and Dr. Said Easa, from the Civil Engineering Department at Ryerson University, are conducting this research study. The results of this study will contribute to Udai Hassein's Ph.D thesis and publications.

\section{Purpose of Study}

The purpose of this experiment is to measure the response times and acceleration rates for different drivers during passing maneuvers on two-lane highways. This is part of the research project to develop a passing sight distance model to improve road safety based on the driving simulator data. This particular passing behavior, which will be described from a specific acceleration and deceleration behavior, can be used for modifying the criteria, thus improving the guidance that was given for passing drivers and the safety for the passing areas. The study involves using different age groups such as young drivers from 18 to 24 years old, middle age drivers from 25 to 50 years old and senior drivers over 50 years old. The study will focus on both genders, male and female.

\section{Description of Study and Your Participation}

If you volunteer to participate in this study, you will be asked to do the following things:

1. You will be asked to drive a simulator and complete a questionnaire. The simulator consists of a non-moving car that is connected to a computer system to simulate the movement of an actual passenger car. The simulation scenario is presented on a large screen via a projector connected to the computer. The system works like a video game where you, the driver, are not moving and the scene shown on the screen is moving according to your actions (braking or pressing on the gas pedal). The driving simulator is located on the 4th floor of the Monetary Times building in the Road Safety lab (at 341 Church street).

2. You will be asked to complete a questionnaire asking you about your driving experience. This will take approximately 2-5 minutes.

3. A driving simulator and questionnaire form will be used to perform the experiments. You will be asked to drive by using the driving simulator (by pressing on the gas and brake pedals). You will test a total of 4 scenarios. Potential risks could include dizziness from the visual simulation of the road (same effects from video games) or fatigue. In the case that you feel dizzy or tired, you will be asked to stop the experiment. Any necessary medical attention will be provided if needed. 
4. The simulation includes 2 groups of scenarios, with each group including 2 scenarios (total of 4 scenarios), with each group including several passing scenarios.

5. Each scenario takes approximately 12 minutes to be completed.

6. The total time to complete all scenarios (including set-up times) is approximately 60 minutes.

7. You will have full control over the simulation vehicle (steering, throttle and brake).

8. Please try to react to the simulation screen as natural as possible (as if you were driving an actual vehicle).

9. There will be approximately 100 participants that will take part in this research.

10. During the driving simulator experiment, participating drivers are required to drive along a system of two-lane highways.

11. Participating drivers will estimate the available passing sight distance based on their driving experience and complete the passing maneuver only when they decide if it is safe to pass. 12. Please feel free to ask any questions before the start of the experiment.

\section{Potential Risks and Discomforts}

Potential risks of harm involved in this study are minimal.

In the case that you feel dizzy or tired, you will be asked to stop the experiment. Any necessary medical attention will be provided if needed. You will be given a one minute break between each scenario you complete. If at any time you feel the need to take a longer break, you may do so. If at any time during the experiment you feel discomfort and would like to stop participating in the study, you may do so.

You will be instructed to adhere to all traffic laws and regulations, including the provision that you can pass only if passing is allowed as indicated by the centreline lane marking on their side of travel. You are strongly asked to react promptly once it is safe to pass without compromising your own safety or the safety of other road users.

\section{Potential Benefits to Participants and/or to Society}

The potential benefits that participants may expect from this research include improving road safety on a two lane highway. This particular passing behavior, can be used for modifying the criteria, thus improving the guidance that was given for passing drivers and the safety for the passing areas. This research study may also assist in enhancing road design.

I cannot guarantee, however, that you will receive any benefits from participating in this study.

\section{Confidentiality}

Your confidentiality will be maintained since each participant will have a number associated to his/her name. Once you drive the simulator, the data (from the driving simulator) will be recorded and saved to your corresponding number in a folder on a USB (Total Control software records this data in a text file). Once all participants have participated in the study, I will use the data to conduct my analysis. 


\section{Voluntary Participation and Withdrawal}

Participation in this study is voluntary. You can choose whether to be in this study or not. If you volunteer to be in this study, you may withdraw at any time without consequences of any kind. If you choose to withdraw from this study you may also choose to withdraw your data from the study. If you feel uncomfortable with an aspect of the study or certain questions on the questionnaire you do not have to complete that part of the study. Your choice of whether or not to participate will not influence your future relations with Ryerson University, Udai Hassein or Dr. Said Easa.

If you are not driving the simulator as you would normally drive a vehicle and you are causing accidents on purpose and driving off the road on purpose, I will ask you to terminate your participation in this research study without regard to your consent.

\section{Questions About The Study}

If you have any questions about the research now, please ask. If you have questions later about the research, you may contact us.

\section{Signature of Research Participant/Legal Representative}

Your signature below indicates that you have read the information in this agreement and have had a chance to ask any questions you have about the study "Analyzing Passing Sight Distance Behavior Based on Driving Simulator" as described herein. Your questions have been answered to your satisfaction, and you agree to participate in this study. You have been given a copy of this form.

Name of Participant (please print)

Signature of Participant

Date 


\section{Appendix B: Questionnaire Form for Test Driver}

\section{Analysis of Driver Behavior of Passing on Two-Lane Highways Using Driving Simulator}

Thanks for your agreement to complete the questionnaire form. You will need approximately 3 minutes to fill in the whole questionnaire. Your participation is on a volunteering basis and all of the information will be completely confidential and they will not be given to any third party under any circumstances. You can skip any question you are not interested to answer, also you can quit at any time. By participating in this study and by reliable filling of the questionnaire you are assisting the researchers to improve and promote the research in road safety.

1. Gender: ( ) Male ( ) Female

2. Year of birth:

3. Years of driving experience:

4. Average weekly driving hours:

5. Type of your driving license: 


\section{Appendix C: Simulation Scenarios 1 \& 2 for Passing Situation}

STISIM Drive is a driving simulator developed by Systems Technology Inc that allows drivers to control all aspects of driving, including speed and steering. A real vehicle (including a steering wheel as well as gas and brake pedals) has been integrated into the simulator. A roadway view is projected onto the wall ahead of the driver using a projector. Together, the arrangement and projection provide a real-world driving experience. The following are the basic components of the STISIM Drive simulator: a graphics environment, driver controls, scenario definition language (SDL), and SITSIM Drive software.

The graphics environment includes the graphic card in the computer that generates the images, the image display system, and the graphic models that are used so that the images can be displayed. The driver controls (such as the maximum speed, lateral vehicle position, sound effects, etc.) use the configuration file for the STISIM Drive software that is installed on the desktop computer. The SDL is used to program the event file, which then displays the various events and roadway features for the driver. The event files define the necessary output variables, which are collected in the output file. The details of the event files are described below.

\section{METRIC}

$-1 \quad$ Scenario-1

-1 2 Lanes Highway-- Passing Sight Distance

$-1 \quad$ kennedy Road and Bloomington Road

$-1 \quad$ by: Udai

-1 Starting the Intersection of kennedy Road and Bloomington Road

-1 Driving on Kennedy Road to south diection

-1 , Specify roadway widths and cross-slope

-1 Starting the road of 4-lane Arterial Road

0 , ROAD , 3.7, 4, 2, 2, 0.15, 0.85, .7, .12, .16, 37, -2, -2, -4, 1.83, -4, 1.83, 0, 1.52, 0, 1.52, 0, 0, 0 , 
-1 Speed limit $=70(\mathrm{~km} / \mathrm{h})=19.44444(\mathrm{~m} / \mathrm{sec})$

-1 Control Vehicle for Intersection 01

$120, \mathrm{CV}, 19,0$

$82, \mathrm{CV}, 0,0$

$83, \mathrm{BRK}, 45,1,40$

123, BRK, 70, 2, 0

-1 intersection 01 (distance $100 \mathrm{~m}$ from start), full intersection, left turn only allowed, non signalised

$10, \mathrm{I}, 0,90,1,2,2$

10, SIGN, 13, 80, 0, 1, 0, 0

10, SL, $-90,6,4,10,0,-30,3,1,0$

-1 no-passing zone from $250 \mathrm{~m}$ to $750 \mathrm{~m}$

150, SIGN, 100, 100, C:ISTISIM\DatalSigns \Sp70Mph.3ds, 0, 0, 0

150, LS, 80, 100

250, SIGN, 100, 100,C:ISTISIM\DatalEuroSigns\No_Passing.3ds

-1 Two-lane Rural Road with passing zone (solid line on both sides)

200, ROAD, 3.7, 2, 1, 2, 0.15, 0.85, .7, .12, .16, 0, -2, -2, 0, 0, 0, 0, -8, 1.52, -8, 1.52, 0, 0, 0 ,

C:ISTISIM\DatalTextures\Grass08.Jpg, 25, C:ISTISIM\DatalTextures\Dirt03.Jpg, 12,

C:ISTISIM\DatalTextures\Grass08.Jpg, 25

-1 , Add some vertical curvature to the scenario

250, VC, 150, 0.01

$550, \mathrm{VC}, 150,-0.01$

600, VC, 170, -0.03

940, VC, 170, 0.03

-1 Two-lane Rural Road with passing zone (dash line on Right side)

750, ROAD, 3.7, 2, 1, 3, 0.15, 0.85, .7, .12, .16, 0, -2, -2, 0, 0, 0, 0, -8, 1.52, -8, 1.52, 0, 0, 0 , C:ISTISIM\DatalTextures\Grass08.Jpg, 25, C:ISTISIM\Data\Textures\Dirt03.Jpg, 12, 
C:ISTISIM\DatalTextures\Grass08.Jpg, 25

-1 Two-lane Rural Road with passing zone (dash line on both sides)

950, ROAD, 3.7, 2, 1, 1, 0.15, 0.85, .7, .12, .16, 0, -2, -2, 0, 0, 0, 0, -8, 1.52, -8, 1.52, 0, 0, 0 ,

C:ISTISIM\DatalTextures\Grass08.Jpg, 25, C:ISTISIM\DatalTextures\Dirt03.Jpg, 12,

C:ISTISIM\DatalTextures\Grass08.Jpg, 25

-1 Two-lane Rural Road with passing zone (dash line on left side)

1950, ROAD, 3.7, 2, 1, 4, 0.15, 0.85, .7, .12, .16, 0, -2, -2, 0, 0, 0, 0, -8, 1.52, -8, 1.52, 0, 0, 0 ,

C:ISTISIM\DatalTextures\Grass08.Jpg, 25, C:ISTISIM\DatalTextures\Dirt03.Jpg, 12,

C:ISTISIM\DatalTextures\Grass08.Jpg, 25

-1 intersection 02 (distance $2100 \mathrm{~m}$ from start,Bethesda Side Road), full intersection, left turn only allowed, non signalised

1760, I, 0, 340, 3, 0, 0

1760, SIGN, 13, 280, 0, 1, 0, 0

-1 Two-lane Rural Road with passing zone (solid line on both sides)

2050, ROAD, 3.7, 2, 1, 2, 0.15, 0.85, .7, .12,.16, 0, -2, -2, 0, 0, 0, 0, -8, 1.52, -8, 1.52, 0, 0, 0 ,

C:ISTISIM\DatalTextures\Grass08.Jpg, 25, C:ISTISIM\DatalTextures\Dirt03.Jpg, 12,

C:ISTISIM\DatalTextures|Grass08.Jpg, 25

-1 , Add some vertical curvature to the scenario

2600, VC, 75, 0.02

$2750, \mathrm{VC}, 75,-0.02$

-1 Two-lane Rural Road with passing zone (dash line on left side)

2850, ROAD, 3.7, 2, 1, 4, 0.15, 0.85, .7, .12, .16, 0, -2, -2, 0, 0, 0, 0, -8, 1.52, -8, 1.52, 0, 0, 0 ,

C:ISTISIM\DatalTextures\Grass08.Jpg, 25, C:ISTISIM\DatalTextures\Dirt03.Jpg, 12,

C:ISTISIM\DatalTextures\Grass08.Jpg, 25

-1 , Adding horizontal curve to the left side of the roadway

3000, C, 300, 30, 190, 30, -.0025, 1, 4 
-1 Two-lane Rural Road with passing zone (solid line on both side)

3250, ROAD, 3.7, 2, 1, 2, 0.15, 0.85, .7, .12, .16, 0, -2, -2, 0, 0, 0, 0, -8, 1.52, -8, 1.52, 0, 0, 0 ,

C:ISTISIM\DatalTextures\Grass08.Jpg, 25, C:ISTISIM\DatalTextures\Dirt03.Jpg, 12,

C:ISTISIM\DatalTextures\Grass08.Jpg, 25

-1 , Adding horizontal curve to the roadway

$3350, \mathrm{C}, 300,30,190,30, .0025,1,4$

-1 Changing the road to 4-lane Arterial Road

3900, ROAD, 3.7, 4, 2, 2, 0.15, 0.85, .7, .12, .16, 37, -2, -2, -4, 1.83, -4, 1.83, 0, 1.52, 0, 1.52, 0, 0, 0,

-1 intersection 03 (distance 4200 m from start),Stouffville Rd., 4 way; straight only

4060, I, 0, 140, 1, 4, 4

4060, SIGN, 13, 80, 0, 1, 0, 0

4060, SL, -140, 6, 4, 10, 0, -30, 3, 1, 0

-1 Speed limit $=80(\mathrm{~km} / \mathrm{h})=22.22222(\mathrm{~m} / \mathrm{sec})$

-1 no-passing zone from $4500 \mathrm{~m}$ to $5600 \mathrm{~m}$

-1 4400, SIGN, 100, 100,C:ISTISIM\DatalEuroSigns\No_Passing.3ds

-1 4500, SIGN, 100, 100, C:ISTISIM\DatalEuroSigns\EuroSpeed_090.LMM, 0, 0, 0

4500, LS, 80, 100

-1 Two-lane Rural Road with passing zone (solid line on both sides)

4500, ROAD, 3.7, 2, 1, 2, 0.15, 0.85, .7, .12, .16, 0, -2, -2, 0, 0, 0, 0, -8, 1.52, -8, 1.52, 0, 0, 0 ,

C:ISTISIM\DatalTextures\Grass08.Jpg, 25, C:ISTISIM\DatalTextures\Dirt03.Jpg, 12,

C:ISTISIM|DatalTextureslGrass08.Jpg, 25

-1 , Add some vertical curvature to the scenario

4750, VC, 75, -0.01

4900, VC, 75, 0.01

-1, Adding horizontal curve to the left side of the roadway

4900, C, 300, 30, 190, 30, -.0025, 1, 4 
-1 , Adding vertical curve to the roadway

$5600, \mathrm{VC}, 170,0.01$

5940, VC, 170, - 0.01

-1 Two-lane Rural Road with passing zone (dash line on Right side)

5600, ROAD, 3.7, 2, 1, 3, 0.15, 0.85, .7, .12, .16, 0, -2, -2, 0, 0, 0, 0, -8, 1.52, -8, 1.52, 0, 0, 0 ,

C:\STISIM \Data\Textures\Grass08.Jpg, 25, C:\STISIM\DatalTextures\Dirt03.Jpg, 12 ,

C:ISTISIM\DatalTextures\Grass08.Jpg, 25

-1 Two-lane Rural Road with passing zone (dash line on both sides)

6000, ROAD, 3.7, 2, 1, 1, 0.15, 0.85, .7, .12, .16, 0, -2, -2, 0, 0, 0, 0, -8, 1.52, -8, 1.52, 0, 0, 0 ,

C:ISTISIM\Data\Textures\Grass08.Jpg, 25, C:ISTISIM\Data\Textures\Dirt03.Jpg, 12,

C:ISTISIM|DatalTextureslGrass08.Jpg, 25

-1 Two-lane Rural Road with passing zone (dash line on left side)

6200, ROAD, 3.7, 2, 1, 4, 0.15, 0.85, .7, .12, .16, 0, -2, -2, 0, 0, 0, 0, -8, 1.52, -8, 1.52, 0, 0, 0 ,

C:ISTISIM \Data\Textures\Grass08.Jpg, 25, C:ISTISIM\DatalTextures\Dirt03.Jpg, 12,

C:ISTISIM\DatalTextures\Grass08.Jpg, 25

-1 Two-lane Rural Road with passing zone (solid line on both sides)

6300, ROAD, 3.7, 2, 1, 2, 0.15, 0.85, .7, .12, .16, 0, -2, -2, 0, 0, 0, 0, -8, 1.52, -8, 1.52, 0, 0, 0 ,

C:ISTISIM\DatalTextures\Grass08.Jpg, 25, C:ISTISIM\DatalTextures\Dirt03.Jpg, 12,

C:ISTISIM\DatalTextures\Grass08.Jpg, 25

-1 intersection 04 (distance $6400 \mathrm{~m}$ from start, 19 th Ave.), full intersection, left turn only allowed, non signalised

6060, I, 0, 340, 3, 0, 0

6060, SIGN, 13, 280, 0, 1, 0, 0

-1 Two-lane Rural Road with passing zone (dash line on Right side)

6500, ROAD, 3.7, 2, 1, 3, 0.15, 0.85, .7, .12,.16, 0, -2, -2, 0, 0, 0, 0, -8, 1.52, -8, 1.52, 0, 0, 0 ,

C:ISTISIM\DatalTextures\Grass08.Jpg, 25, C:ISTISIM\DatalTextures\Dirt03.Jpg, 12, 
C:ISTISIM\DatalTextures\Grass08.Jpg, 25

-1 Two-lane Rural Road with passing zone (dash line on left side)

6800, ROAD, 3.7, 2, 1, 4, 0.15, 0.85, .7, .12, .16, 0, -2, -2, 0, 0, 0, 0, -8, 1.52, -8, 1.52, 0, 0, 0 ,

C:ISTISIM\DatalTextures\Grass08.Jpg, 25, C:ISTISIM\DatalTextures\Dirt03.Jpg, 12,

C:ISTISIM\DatalTextures\Grass08.Jpg, 25

-1 , Adding vertical curve to the roadway

6800, VC, 170, 0.02

7140, VC, $170,-0.02$

-1 Two-lane Rural Road with no-passing zone (solid line on both sides)

7100, ROAD, 3.7, 2, 1, 2, 0.15, 0.85, .7, .12, .16, 0, -2, -2, 0, 0, 0, 0, -8, 1.52, -8, 1.52, 0, 0, 0 , C:ISTISIM \DatalTextures\Grass08.Jpg, 25, C:ISTISIM\DatalTextures\Dirt03.Jpg, 12,

C:ISTISIM\DatalTextures|Grass08.Jpg, 25

-1 Two-lane Rural Road with passing zone (dash line on Right side)

7200, ROAD, 3.7, 2, 1, 3, 0.15, 0.85, .7, .12, .16, 0, -2, -2, 0, 0, 0, 0, -8, 1.52, -8, 1.52, 0, 0, 0 ,

C:ISTISIM \Data\Textures\Grass08.Jpg, 25, C:ISTISIM\DatalTextures\Dirt03.Jpg, 12,

C:ISTISIM\DatalTextures\Grass08.Jpg, 25

-1 Two-lane Rural Road with no-passing zone (solid line on both sides)

7550, ROAD, 3.7, 2, 1, 2, 0.15, 0.85, .7, .12, .16, 0, -2, -2, 0, 0, 0, 0, -8, 1.52, -8, 1.52, 0, 0, 0 , C:ISTISIM\DatalTextures\Grass08.Jpg, 25, C:ISTISIM\DatalTextures\Dirt03.Jpg, 12, C:ISTISIM\DatalTextures\Grass08.Jpg, 25

-1 Two-lane Rural Road with passing zone (dash line on Right side)

7650, ROAD , 3.7, 2, 1, 3, 0.15, 0.85, .7, .12, .16, 0, -2, -2, 0, 0, 0, 0, -8, 1.52, -8, 1.52, 0, 0, 0, C:ISTISIM\DatalTextures\Grass08.Jpg, 25, C:ISTISIM\DatalTextures\Dirt03.Jpg, 12, C:ISTISIM\DatalTextures|Grass08.Jpg, 25

-1 Two-lane Rural Road with no-passing zone (solid line on both sides)

7800, ROAD , 3.7, 2, 1, 2, 0.15, 0.85, .7, .12, .16, 0, -2, -2, 0, 0, 0, 0, -8, 1.52, -8, 1.52, 0, 0, 0, 
C:ISTISIM\Data\Textures\Grass08.Jpg, 25, C:\STISIM\Data\Textures\Dirt03.Jpg, 12,

C:ISTISIM\DatalTextures\Grass08.Jpg, 25

-1 Changing the road to 4-lane Arterial Road

8300, ROAD, 3.7, 4, 2, 2, 0.15, 0.85, .7, .12, .16, 37, -2, -2, -4, 1.83, -4, 1.83, 0, 1.52, 0, 1.52, 0, 0, 0,

-1 intersection 05 (distance 8500 m from start, Elgin Mills Rd.), full intersection, left turn only allowed, non signalised

$8360, \mathrm{I}, 0,140,1,2,2$

8360, SIGN, 13, 80, 0, 1, 0, 0

8360, SL, -140, 6, 4, 10, 0, -30, 3, 1, 0

-1 Speed limit $=90(\mathrm{~km} / \mathrm{h})=25(\mathrm{~m} / \mathrm{sec})$

-1 passing zone from $8800 \mathrm{~m}$ to $10200 \mathrm{~m}$

-1 8600, SIGN, 100, 100,C:ISTISIM\DatalEuroSigns\No_Passing.3ds

-1 8600, SIGN, 100, 100, C:ISTISIM\DatalEuroSigns\EuroSpeed_090.LMM, 0, 0, 0

8600, LS, 90, 100

-1 Two-lane Rural Road with no-passing zone (solid line on both sides)

8700, ROAD , 3.7, 2, 1, 2, 0.15, 0.85, .7, .12, .16, 0, -2, -2, 0, 0, 0, 0, -8, 1.52, -8, 1.52, 0, 0, 0 , C:ISTISIM $\backslash$ DatalTextures\Grass08.Jpg, 25, C:ISTISIM $\backslash$ DatalTextures\Dirt03.Jpg, 12,

C:ISTISIM\DatalTextures\Grass08.Jpg, 25

-1 Two-lane Rural Road with passing zone (dash line on both sides)

8800, ROAD , 3.7, 2, 1, 1, 0.15, 0.85, .7, .12, .16, 0, -2, -2, 0, 0, 0, 0, -8, 1.52, -8, 1.52, 0, 0, 0 ,

C:ISTISIM $\backslash$ DatalTextures\Grass08.Jpg, 25, C:ISTISIM\DatalTextures\Dirt03.Jpg, 12,

C:ISTISIM\DatalTextures\Grass08.Jpg, 25

-1 Two-lane Rural Road with no-passing zone (solid line on both sides)

10200, ROAD, 3.7, 2, 1, 2, 0.15, 0.85, .7, .12, .16, 0, -2, -2, 0, 0, 0, 0, -8, 1.52, -8, 1.52, 0, 0, 0 ,

C:ISTISIM\DatalTextures\Grass08.Jpg, 25, C:ISTISIM\DatalTextures\Dirt03.Jpg, 12,

C:ISTISIM\DatalTextures\Grass08.Jpg, 25 
-1 Changing the road to 4-lane Arterial Road

10300, ROAD, 3.7, 4, 2, 2, 0.15, 0.85, .7, .12, .16, 37, -2, -2, -4, 1.83, -4, 1.83, 0, 1.52, 0, 1.52, 0, 0, 0,

-1 intersection 06 (distance $10500 \mathrm{~m}$ from start, Bloomington Rd.), full intersection, left turn only allowed, non signalised

10360, I, 0, 140, 1, 2, 2

10360, SIGN, 13, 80, 0, 1, 0, 0

10360, SL, $-140,6,4,10,0,-30,3,1,0$

-1 Two-lane Rural Road with passing zone (solid line on both sides)

10700, ROAD, 3.7, 2, 1, 2, 0.15, 0.85, .7, .12, .16, 0, -2, -2, 0, 0, 0, 0, -8, 1.52, -8, 1.52, 0, 0, 0,

C:ISTISIM\DatalTextures\Grass08.Jpg, 25, C:ISTISIM\DatalTextures\Dirt03.Jpg, 12,

C:ISTISIM\DatalTextures\Grass08.Jpg, 25

-1 , Add some divided attention parameters

750, DA, 1,0

1250, DA, 2, 0

1750, DA, 3, 0

5600, DA, 4, 0

6500, DA, 5, 0

7200, DA, 6, 0

8800, DA, 7, 0

9500, DA, 8, 0

-1 start saving dynamic data

-1 Sign PSD1 at $750 \mathrm{~m}$, starting passing zone, speed limit 70(km/h)

600, BSAV, 1, 0.04975, Reaction Time Data for speed limit signPSD1, $1,2,4,6,7,8,12,23,26,35,36,37,38,19$

750, ESAV

750, BSAV, 1, 0.04975, Sign PSD1, 1,2,4,6,7,8,12,23,26,35,36,37,38, 19

1125, ESAV 
-1 Sign PSD2 at $1250 \mathrm{~m}$, starting passing zone, speed limit 70( $\mathrm{km} / \mathrm{h})$

1125, BSAV, 1, 0.04975, Reaction Time Data for speed limit signPSD2, $1,2,4,6,7,8,12,23,26,35,36,37,38,19$

1250, ESAV

1250, BSAV, 1, 0.04975, Sign PSD2, 1,2,4,6,7,8,12,23,26,35,36,37,38, 19

1625, ESAV

-1 Sign PSD3 at $1750 \mathrm{~m}$, starting passing zone, speed limit 70(km/h)

1625, BSAV, 1, 0.04975, Reaction Time Data for speed limit signPSD3, $1,2,4,6,7,8,12,23,26,35,36,37,38,19$

1750, ESAV

1750, BSAV, 1, 0.04975, Sign PSD3, 1,2,4,6,7,8,12,23,26,35,36,37,38,19

2125, ESAV

2125, BSAV, 1, 0.04975, Sign PSD3-2, 1,2,4,6,7,8,12,23,26,35,36,37,38,19

2630, ESAV

-1 Sign PSD4 at $5600 \mathrm{~m}$, starting passing zone, speed limit 80(km/h)

5450, BSAV, 1, 0.04975, Reaction Time Data for speed limit signPSD4, $1,2,4,6,7,8,12,23,26,35,36,37,38,19$

5600, ESAV

5600, BSAV, 1, 0.04975, Sign PSD4, 1,2,4,6,7,8,12,23,26,35,36,37,38, 19

6046, ESAV

6046, BSAV, 1, 0.04975, Sign PSD4-2, 1,2,4,6,7,8,12,23,26,35,36,37,38,19

6350, ESAV

-1 Sign PSD5 at $6500 \mathrm{~m}$, starting passing zone, speed limit 80(km/h)

6350, BSAV, 1, 0.04975, Reaction Time Data for speed limit signPSD5, $1,2,4,6,7,8,12,23,26,35,36,37,38,19$

6500, ESAV

6500, BSAV, 1, 0.04975, Sign PSD5, 1,2,4,6,7,8,12,23,26,35,36,37,38,19 
6946, ESAV

6946, BSAV, 1, 0.04975, Sign PSD5-2, 1,2,4,6,7,8,12,23,26,35,36,37,38,19

7050, ESAV

-1 Sign PSD6 at $7200 \mathrm{~m}$, starting passing zone, speed limit 80(km/h)

7050, BSAV, 1, 0.04975, Reaction Time Data for speed limit signPSD6, $1,2,4,6,7,8,12,23,26,35,36,37,38,19$

7200, ESAV

7200, BSAV, 1, 0.04975, Sign PSD6, 1,2,4,6,7,8,12,23,26,35,36,37,38, 19

7694, ESAV

7694, BSAV, 1, 0.04975, Sign PSD6-2, 1,2,4,6,7,8,12,23,26,35,36,37,38,19

8650, ESAV

-1 Sign PSD7 at $8800 \mathrm{~m}$, starting passing zone, speed limit 90(km/h)

8650, BSAV, 1, 0.04975, Reaction Time Data for speed limit signPSD7, $1,2,4,6,7,8,12,23,26,35,36,37,38,19$

8800, ESAV

8800, BSAV, 1, 0.04975, Sign PSD7, 1,2,4,6,7,8,12,23,26,35,36,37,38, 19

9350, ESAV

-1 Sign PSD8 at $8800 \mathrm{~m}$, starting passing zone, speed limit 90(km/h)

9350, BSAV, 1, 0.04975, Reaction Time Data for speed limit signPSD8, $1,2,4,6,7,8,12,23,26,35,36,37,38,19$

9500, ESAV

9500, BSAV, 1, 0.04975, Sign PSD8, 1,2,4,6,7,8,12,23,26,35,36,37,38,19

10020, ESAV

10020, BSAV, 1, 0.04975, Sign PSD8-2, 1,2,4,6,7,8,12,23,26,35,36,37,38,19

10500, ESAV

750,RMSB,0,First performance block in passing-zone 1, SL 70 km/h 1130,RMSE 
1250,RMSB,0,Second performance block in passing-zone 2, SL $70 \mathrm{~km} / \mathrm{h}$

1630,RMSE

1750,RMSB,0,third performance block in passing-zone 3, SL $70 \mathrm{~km} / \mathrm{h}$

2130,RMSE

5600,RMSB,0,forth performance block in passing-zone 4, SL $80 \mathrm{~km} / \mathrm{h}$

6050,RMSE

6500,RMSB,0,fifth performance block in passing-zone 5, SL $80 \mathrm{~km} / \mathrm{h}$

6950,RMSE

7200,RMSB,0,sixth performance block in passing-zone 6, SL $80 \mathrm{~km} / \mathrm{h}$

7650,RMSE

7650,RMSB,0,sixth-No-pass performance block in passing-zone 6, SL $80 \mathrm{~km} / \mathrm{h}$

8100,RMSE

8800,RMSB,0,seventh performance block in passing-zone 7, SL $90 \mathrm{~km} / \mathrm{h}$

9320,RMSE

9500,RMSB,0,eighth performance block in passing-zone 8, SL $90 \mathrm{~km} / \mathrm{h}$

10020,RMSE

-1 big rig passing wav file.

$\{$ Tags Sound Files $=\mathrm{C}: \backslash$ STISIM $\backslash$ Sound $\backslash\}$

7500, Speed Warnings, 1, 19.33, FllwWarn.Wav, 44, FLLWInstructions.Wav, 30, 10

1250, Speed Warnings, 1, 19.33, LowWarning.Wav, 95.33, HighWarning.Wav, 20, 10

1750, Speed Warnings, 0

-1 Vehicles travelling on the same direction of the driver

$0, \mathrm{~V}, 20,260,1.85,1,26$

-1 Slow Vehicles in the same lane, impeding vehicle speed $=55(\mathrm{~km} / \mathrm{h})$

200, V, 15.27778, 143.84, 1.83, 1, *18 35,

$800, \mathrm{~V}, 16,115.76,1.83,1, * 18 \sim 35$, 
1300, V, 15, 115.76, 1.83, 1, *18 35,

$2000, \mathrm{~V}, 18,220,1.83,1, * 18 \sim 35$,

$3280, \mathrm{~V}, 17,210,1.83,1, * 18 \sim 28$,

$3140, \mathrm{~V}, 19,210,1.83,1, * 18 \sim 35$

-1 Slow Vehicles in the same lane, impeding vehicle speed $=65(\mathrm{~km} / \mathrm{h})$

$4800, \mathrm{~V}, 18,115.76,1.83,1, * 18 \sim 35$,

6100, V, 17.77778, 115.76, 1.83, 1, *18 35,

$6800, \mathrm{~V}, 19,115.76,1.83,1, * 18 \sim 35$,

$7100, \mathrm{~V}, 19,185,1.83,1, * 18 \sim 28$

-1 Slow Vehicles in the same lane, impeding vehicle speed $=75(\mathrm{~km} / \mathrm{h})$

$8000, \mathrm{~V}, 20.83333,260,1.83,1, * 18 \sim 35$,

$8500, \mathrm{~V}, 17,65.76,1.83,1, * 18 \sim 35$,

$9000, \mathrm{~V}, 20,115.76,1.83,1, * 18 \sim 35$,

9800, V, 22.77778, 260, 1.83, 1, *18 35,

-1 Vehicles travelling on the opposing direction of the driver

-1------------EVENT---------PSD-1 slow vehicle to pass

-1 Availble $\mathrm{PSD}=375.41 \mathrm{~m}$ is enough for passing; $\mathrm{Vd}=70 \mathrm{~km} / \mathrm{h}$

$-1 \mathrm{~d} 1+\mathrm{d} 2+\mathrm{d} 3+\mathrm{d} 4=375.41 \mathrm{~m}$

350, PR, C:ISTISIM IPSD_sound $\backslash$ speed_70.wav, 0, 10

750, PR, C:ISTISIM \PSD_sound $\backslash$ safe_pass.wav, 0, 2

150, SIGN, 100, 100, C:ISTISIM\DatalSigns \Sp70Mph.3ds, 0, 0, 0

150, LS, 70, 100

220, A, 19.44444, 311.36, $-1.83, * 30 \sim 34,4,0,48.77, .5$

$-1 \mathrm{~d} 1+\mathrm{d} 2+\mathrm{d} 3+\mathrm{d} 4=375.41 \mathrm{~m}$

650, SIGN, 100, 100,C:ISTISIM\DatalSigns\PassingAllowed.3ds

542.43, A, 19.44444, 207.57, -1.83, *1 35;-8;-9;-16;-17;-3;-5, 4, 0, 48.77, .5 
750, A, 19.44444, 375.41, -1.83, *30 34, 4, 0, 48.77, .5

-1------------EVENT---------PSD-2 slow vehicle to pass

-1 Availble PSD= $375.41 \mathrm{~m}$ is enough for passing; $\mathrm{Vd}=70 \mathrm{~km} / \mathrm{h}$

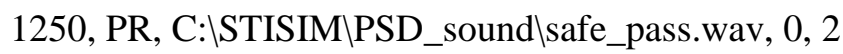

$-1 \mathrm{~d} 1+\mathrm{d} 2+\mathrm{d} 3+\mathrm{d} 4=375.41 \mathrm{~m}$

1150, SIGN, 100, 100,C:ISTISIM\DatalSigns\PassingAllowed.3ds

1042.43, A, 19.44444, 207.57, -1.83, *1 35;-8;-9;-16;-17;-3;-5, 4, 0, 48.77, .5

$1250, \mathrm{~A}, 19.44444,375.41,-1.83, * 30 \sim 34,4,0,48.77, .5$

-1------------EVENT---------PSD-3 slow vehicle to pass

-1 Availble $\mathrm{PSD}=375.41 \mathrm{~m}$ is enough for passing; $\mathrm{Vd}=70 \mathrm{~km} / \mathrm{h}$

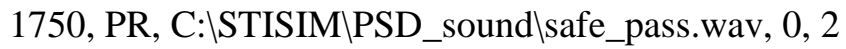

$-1 \mathrm{~d} 1+\mathrm{d} 2+\mathrm{d} 3+\mathrm{d} 4=375.41 \mathrm{~m}$

1650, SIGN, 100, 100,C:ISTISIM\DatalSigns\PassingAllowed.3ds

1542.43, A, 19.44444, 207.57, -1.83, *1 35;-8;-9;-16;-17;-3;-5, 4, 0, 48.77, .5

1750, A, 19.44444, 375.41, -1.83, *1 35;-8;-9;-16;-17;-3;-5, 4, 0, 48.77, .5

-1 Conflict traffic (opposite direction)

2417.32, A, 22, 311.36, -1.83, *30 34, 4, 0, 48.77, .5

2156.64, A, 19.444, 356.64, -1.83, *1 35;-8;-9;-16;-17;-3;-5, 4, 0, 48.77, .5

2356.64, A, 19.444, 304.8, -1.85, *18 35

2569, A, 19.444, 311.36, $-1.85, * 18 \sim 35$

2629, A, 19.444, 311.36, $-1.85, * 18 \sim 35$

2359, A, 19.444, 513, $-1.85, * 18 \sim 35$

2360, A, 19.444, 604, -1.85, *18 35

2710, A, 19.444, 311.36, -1.83, *1 35;-8;-9;-16;-17;-3;-5, 4, 0, 48.77, .5

2870, A, 19.444, 365.76, -1.83, *1 35;-8;-9;-16;-17;-3;-5, 4, 0, 48.77, .5

3000, A, 19.444, 311.36, -1.83, *30 34, 4, 0, 48.77, .5 
3245, A, 19.444, 220, -1.85, *18 35

$3325, \mathrm{~A}, 19.444,220,-1.85, * 18 \sim 35$

$3335, \mathrm{~A}, 19,555,-1.85, * 18 \sim 35$

$3645, \mathrm{~A}, 19.5,262,-1.85, * 18 \sim 35$

$3725, \mathrm{~A}, 19.5,262,-1.85, * 18 \sim 35$

$3820, \mathrm{~A}, 19,422,-1.85, * 18 \sim 35$

3864.1, A, 19.44444, 261.44, -1.83, *30 34, 4, 0, 48.77, .5

-1 Conflict traffic (opposite direction)

4494, A, 19, 366.74, -1.83, *1 35;-8;-9;-16;-17;-3;-5, 4, 0, 48.77, .5

5044, A, 22, 366.74, -1.85, *18 35

5094, A, 21, 366.74, $-1.85, * 18 \sim 35$

5139, A, $21,366.74,-1.85, * 18 \sim 35$

-1------------EVENT---------PSD-4 slow vehicle to pass

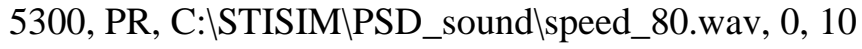

5600, PR, C:ISTISIMIPSD_soundlsafe_pass.wav, 0, 2

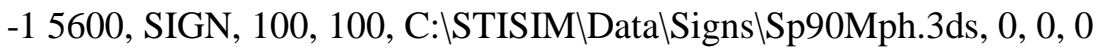

5600, LS, 80, 100

-1 Availble $\mathrm{PSD}=446.18 \mathrm{~m}$ is enough for passing; $\mathrm{Vd}=80 \mathrm{~km} / \mathrm{h}$

-1 Start passing zone from $5600 \mathrm{~m}$

$-1 \mathrm{~d} 1+\mathrm{d} 2+\mathrm{d} 3+\mathrm{d} 4=446.18 \mathrm{~m}$

5500, SIGN, 100, 100,C:ISTISIM\DatalSigns\PassingAllowed.3ds

$5354.47, \mathrm{~A}, 22,245.53,-1.83, * 30 \sim 34,4,0,48.77, .5$

5600, A, 22, 446.18, -1.83, *1 35;-8;-9;-16;-17;-3;-5, 4, 0, 48.77, .5

$5944, \mathrm{~A}, 21,220,-1.85, * 18 \sim 35$

-1------------EVENT---------PSD-5 slow vehicle to pass

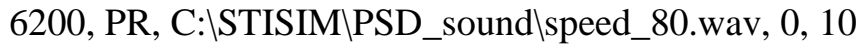




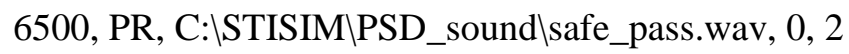

-1 Start passing zone from $6500 \mathrm{~m}$

-1 Conflict traffic (opposite direction)

$6120, \mathrm{~A}, 22,245.53,-1.85, * 18 \sim 35$

$6170, \mathrm{~A}, 21,245.53,-1.85, * 18 \sim 35$

-1 Availble $\mathrm{PSD}=446.18 \mathrm{~m}$ is enough for passing; $\mathrm{Vd}=80 \mathrm{~km} / \mathrm{h}$

6400, SIGN, 100, 100,C:ISTISIM\DatalSigns\PassingAllowed.3ds

6254.47, A, 22, 245.53, -1.83, *1 35;-8;-9;-16;-17;-3;-5, 4, 0, 48.77, .5

6500, A, 22, 446.18, -1.83, *1 35;-8;-9;-16;-17;-3;-5, 4, 0, 48.77, .5

-1------------EVENT---------PSD-6 slow vehicle to pass

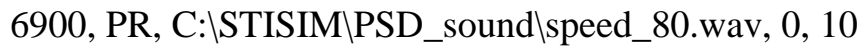

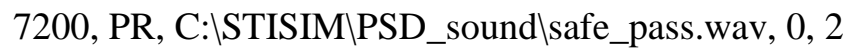

-1 Start passing zone from $7200 \mathrm{~m}$

7100, SIGN, 100, 100,C:ISTISIM\DatalSigns\PassingAllowed.3ds

-1 Conflict traffic (opposite direction)

-1 Availble $\mathrm{PSD}=446.18 \mathrm{~m}$ is enough for passing; $\mathrm{Vd}=80 \mathrm{~km} / \mathrm{h}$

6954.47, A, 21, 245.53, -1.85, *18 35

$7200, \mathrm{~A}, 21,446.18,-1.85, * 18 \sim 35$

-1------------EVENT---------NO-PSD-6A slow vehicle to not pass

7650, PR, C:ISTISIMIPSD_sound\not_safe_pass.wav, 0, 10

-1 No-Passing-Zone

-1 Conflict traffic (opposite direction)

7710, A, 21, 366.74, -1.83, *1 35;-8;-9;-16;-17;-3;-5, 4, 0, 48.77, .5

$7725, \mathrm{~A}, 21,262,-1.85, * 18 \sim 35$

7974, A, 22, 365.76, -1.83, *1 35;-8;-9;-16;-17;-3;-5, 4, 0, 48.77, .5

8304, A, 22, 365.76, -1.83, *1 35;-8;-9;-16;-17;-3;-5, 4, 0, 48.77, .5 
8464.44, A, $22,285.56,-1.83, * 30 \sim 34,4,0,48.77, .5$

-1 Street Sign

-1 3630, SIGN, 100, 2759, C:ISTISIM\DatalSigns\ParkSt.3ds, 0

-1 Street Sign

-1 4630, SIGN, 100, 2759, C:ISTISIM\DatalSigns\RanchSt.3ds, 0

-1-----------EVENT---------PSD-7 slow vehicle to pass

8500, PR, C:ISTISIM \PSD_sound $\backslash$ speed_90.wav, 0, 10

8800, PR, C:ISTISIM \PSD_sound\safe_pass.wav, 0, 2

-1 Start passing zone from $8800 \mathrm{~m}$

8700, SIGN, 100, 100,C:ISTISIM\DatalSigns\PassingAllowed.3ds

-1 Conflict traffic (opposite direction)

-1 Availble $\mathrm{PSD}=520.61 \mathrm{~m}$ is enough for passing; $\mathrm{Vd}=90 \mathrm{~km} / \mathrm{h}$

$8514.44, \mathrm{~A}, 25,285.56,-1.85, * 18 \sim 35$

8800, A, 25, 520.61, -1.83, *1 35;-8;-9;-16;-17;-3;-5, 4, 0, 48.77, .5

9100, A, 25, 285.56, -1.83, *1 35;-8;-9;-16;-17;-3;-5, 4, 0, 48.77, .5

9150, A, 25, 285.56, -1.83, *1 35;-8;-9;-16;-17;-3;-5, 4, 0, 48.77, .5

-1------------EVENT---------PSD-8 slow vehicle to pass

9200, PR, C:ISTISIMIPSD_soundlspeed_90.wav, 0, 10

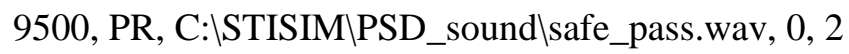

9214.44, A, 25, 285.56, -1.83, *1 35;-8;-9;-16;-17;-3;-5, 4, 0, 48.77, .5

$9500, \mathrm{~A}, 25,520.61,-1.83, * 30 \sim 34,4,0,48.77, .5$

9800, A, 19.44444, 285.56, -1.83, *1 35;-8;-9;-16;-17;-3;-5, 4, 0, 48.77, .5

$9850, \mathrm{~A}, 25,285.56,-1.83, * 30 \sim 34,4,0,48.77, .5$

-1 Trees

140, TREE, 90, $0, * 1 \sim 18,9.45,18.29,0$

375, TREE, $80,0, * 1 \sim 18,9.45,18.29,0$ 
805, TREE, 95, $0, * 1 \sim 18,9.45,18.29,0$ 1275, TREE, $85,0, * 1 \sim 18,9.45,18.29,0$ 1805, TREE, 75, 0, *1 18, 9.45, 18.29, 0 2290, TREE, $150,0, * 1 \sim 18,9.45,18.29,0$ 3365, TREE, $70,0, * 1 \sim 18,9.45,18.29,0$ 3740, TREE, $150,0, * 1 \sim 18,9.45,18.29,0$ 3800, TREE, $70,0, * 1 \sim 18,9.45,18.29,0$ 5170, TREE, 200, $0, * 1 \sim 18,9.45,18.29,0$ 6170, TREE, 200, $0, * 1 \sim 18,9.45,18.29,0$ 7170, TREE, 200, 0, *1 18, 9.45, 18.29, 0 8000, TREE, 200, $0, * 1 \sim 18,9.45,18.29,0$ 8170, TREE, 200, $0, * 1 \sim 18,9.45,18.29,0$ 9170, TREE, 200, $0, * 1 \sim 18,9.45,18.29,0$ 10000, TREE, 200, 0, *1 18, 9.45, 18.29, 0 -1 Buildings 360, BLDG, 250, -14.59, $\mathrm{H}^{*} 2 ; 4 \sim 7 ; 9 ; 13$ 360, BLDG, 320, -14.59, H*2;4 7;9;13 360, BLDG, 220, 14.59, H*2;4 7;9;13 360, BLDG, 300, 14.59, H*2;4 7;9;13 1750, BLDG, 242.02, 18.99, G*1 13 2300, BLDG, 247.02, -18.99, B*1 5;9;13 15 3800, BLDG, 282.02, 18.99, B*1 5;9;13 15 3800, BLDG, 322.02, 18.99, B*1 5;9;13 15 3800, BLDG, 372.02, 18.99, B*1 5;9;13 15 4900, BLDG, 422.02, 18.99, B*1 5;9;13 15 5100, BLDG, 462.02, 18.99, G*1 13 
5200, BLDG, 502.02, 18.99, B*1 5;9;13 15

5500, BLDG, 552.02, 18.99, G*1 13

5600, BLDG, 612.02, 18.99, G*1 13

5900, BLDG, 662.02, 18.99, B*1 5;9;13 15

6000, BLDG, 722.02, 18.99, G*1 13

6800, BLDG, 812.02, 18.99, B*1 5;9;13 15

8200, BLDG, 892.02, 18.99, G*1 13

4750, BLDG, 285.02, -18.99, G*1 13

4750, BLDG, 326.02, -18.99, G*1 13

4900, BLDG, 372.02, -18.99, G*1 13

5400, BLDG, 432.02, -18.99, B*1 5;9;13 15

5900, BLDG, 522.02, -18.99, B4

6000, BLDG, 557.02, -18.99, B*1 5;9;13 15

6100, BLDG, 612.02, -18.99, G*1 13

6800, BLDG, 662.02, -18.99, G*1 13

8200, BLDG, 722.02, -18.99, G*1 13

8515, BLDG, 202.02, 19.99, B*1 5;9;13 15

8515, BLDG, 322.02, 19.99, B*1 5;9;13 15

8515, BLDG, 622.02, 19.99, G*1 13

8515, BLDG, 892.02, 19.99, G*1 13

8515, BLDG, 285.02, -19.99, G*1 13

8515, BLDG, 432.02, -19.99, B*1 5;9;13 15

8515, BLDG, 622.02, -19.99, G*1 13

9015, BLDG, 202.02, 19.99, B*1 5;9;13 15

9015, BLDG, 372.02, 19.99, B*1 5;9;13 15

9015, BLDG, 502.02, 19.99, B*1 5;9;13 15 
9015, BLDG, 662.02, 19.99, B*1 5;9;13 15

9015, BLDG, 892.02, 19.99, G*1 13

9015, BLDG, 206.02, -19.99, G*1 13

9015, BLDG, 372.02, -19.99, G*1 13

9015, BLDG, 557.02, -19.99, B*1 5;9;13 15

9015, BLDG, 722.02, -19.99, G*1 13

9315, BLDG, 202.02, 19.99, B*1 5;9;13 15

9315, BLDG, 322.02, 19.99, B*1 5;9;13 15

9315, BLDG, 552.02, 19.99, G*1 13

9315, BLDG, 722.02, 19.99, G*1 13

9315, BLDG, 206.02, -19.99, G*1 13

9315, BLDG, 326.02, -19.99, G*1 13

9315, BLDG, 557.02, -19.99, B*1 5;9;13 15

9315, BLDG, 722.02, -19.99, G*1 13

9765, BLDG, 202.02, 19.99, B*1 5;9;13 15

9765, BLDG, 242.02, 19.99, G*1 13

9765, BLDG, 282.02, 19.99, B*1 5;9;13 15

9765, BLDG, 322.02, 19.99, B*1 5;9;13 15

9765, BLDG, 372.02, 19.99, B*1 5;9;13 15

9765, BLDG, 422.02, 19.99, B*1 5;9;13 15

9765, BLDG, 502.02, 19.99, B*1 5;9;13 15

9765, BLDG, 552.02, 19.99, G*1 13

9765, BLDG, 662.02, 19.99, B*1 5;9;13 15

9765, BLDG, 722.02, 19.99, G*1 13

9765, BLDG, 812.02, 19.99, B*1 5;9;13 15

9765, BLDG, 892.02, 19.99, G*1 13 
9765, BLDG, 206.02, -19.99, G*1 13

9765, BLDG, 247.02, -19.99, B*1 5;9;13 15

9765, BLDG, 285.02, -19.99, G*1 13

9765, BLDG, 326.02, -19.99, G*1 13

9765, BLDG, 372.02, -19.99, G*1 13

9765, BLDG, 422.02, -19.99, B*1 5;9;13 15

9765, BLDG, 522.02, -19.99, G*1 13

9765, BLDG, 612.02, -19.99, G*1 13

9765, BLDG, 692.02, -19.99, G*1 13

-1 $1 * * * * * * * * * * * * * * * * * * * * * * * * * * * * * * * * * * * * * * * * * *$

-1 PED standing beside the road

0, PED, 1800, 0, 0, -12, L, *1 8

0, PED, 4085, 0, 0, 10, R, *1 8

0, PED, 4088, 0, 0, 13, R, *1 8

0, PED, 4095, 0, 0, 14, R, *1 8

0, PED, 4100, 0, 0, 10, R, *1 8

0, PED, 5700, 0, 0, 10, R, *1 8

0, PED, 5705, 0, 0, 13, R, *1 8

0, PED, 5710, 0, 0, 14, R, *1 8

-1 0, PED, 3645, 0, 0, 9, R, *1 8

-1 0, PED, 3650, 0, 0, 10, R, *1 8

-10, PED, 3655, 0, 0, 13, R, *1 8

-1 0, PED, 3660, 0, 0, 14, R, *1 8

-1 0, PED, 3665, 0, 0, 9, R, *1 8

-1 0, PED, 3670, 0, 0, 10, R, *1 8

-10, PED, 3675, 0, 0, 13, R, *1 8 
0, PED, 5020, 0, 0, -14, L, *1 8

0, PED, 5025, 0, 0, -10, L, *1 8

0, PED, 5035, 0, 0, -13, L, *1 8

0, PED, 5700, 0, 0, -14, L, *1 8

-1 PED crossing the street at intersection 03

0, PED, 4191, 4, 2, 9, R, *1 10;-4;-5

0, PED, 4189, 0, 0, -12, L, *1 10;-4;-5

0, PED, 4192, 4, 2, -13, L, *1 10;-4;-5

10500, ES 


\title{
Appendix D: Simulation Scenarios 3 \& 4 for Passing Situation
}

\author{
METRIC \\ $-1 \quad$ Scenario-2 \\ -1 2 Lanes Highway-- Passing Sight Distance \\ $-1 \quad$ by: Udai \\ -1 , Specify roadway widths and cross-slope \\ -1 Two-lane Rural Road with passing zone \\ 0 , ROAD $, 3.7,2,1,1,0.15,0.85, .7, .12, .16,0,-2,-2,0,0,0,0,-8,1.52,-8,1.52,0,0,0$, \\ C:ISTISIM\DatalTextures\Grass08.Jpg, 25, C:ISTISIM\DatalTextures\Dirt03.Jpg, 12, \\ C:ISTISIM\DatalTextures\Grass08.Jpg, 25 \\ -1 Two-lane Rural Road without passing zone \\ 3200, ROAD , 3.7, 2, 1, 2, 0.15, 0.85, .7, .12, .16, 0, -2, -2, 0, 0, 0, 0, -8, 1.52, -8, 1.52, 0, 0, 0 , \\ C:ISTISIM\DatalTextures\Grass08.Jpg, 25, C:ISTISIM\DatalTextures\Dirt03.Jpg, 12, \\ C:ISTISIM\DatalTextures\Grass08.Jpg, 25 \\ -1 Two-lane Rural Road with passing zone \\ 3900, ROAD, 3.7, 2, 1, 1, 0.15, 0.85, .7, .12, .16, 0, -2, -2, 0, 0, 0, 0, -8, 1.52, -8, 1.52, 0, 0, 0 , \\ C:ISTISIM\DatalTextures\Grass08.Jpg, 25, C:ISTISIM\DatalTextures\Dirt03.Jpg, 12, \\ C:ISTISIM\DatalTextures\Grass08.Jpg, 25 \\ -1, Add some vertical curvature to the scenario \\ $0, \mathrm{VC}, 438,0.02$ \\ 1314, VC, 438, -0.02 \\ 0, SIGN, 100, 60, C:ISTISIM\DatalEuroSigns\EuroSpeed_090.Lmm, 1, 0, 0 \\ 0, LS, 90, 60 \\ -1 passing maneuver and signs
}


-1 , Add some divided attention parameters

600, DA, 1, 0

1250, DA, 2, 0

2240, DA, 3, 0

3900, DA, 4, 0

4410, DA, 5, 0

5240, DA, 6, 0

7065, DA, 7, 0

8065, DA, 8, 0

9000, DA, 9, 0

10000, DA, 10, 0

-1 start saving dynamic data

-1 Sign PSD1 at $600 \mathrm{~m}$, starting passing zone, speed limit 90(km/h)

450, BSAV, 1, 0.04975, Reaction Time Data for speed limit signPSD1, $1,2,4,6,7,8,12,23,26,35,36,37,38,19$

600, ESAV

600, BSAV, 1, 0.04975, Sign PSD1, 1,2,4,6,7,8,12,23,26,35,36,37,38, 19

1100, ESAV

-1 Sign PSD2 at $1250 \mathrm{~m}$, starting passing zone, speed limit 90(km/h)

1100, BSAV, 1, 0.04975, Reaction Time Data for speed limit signPSD2, $1,2,4,6,7,8,12,23,26,35,36,37,38,19$

1250, ESAV

1250, BSAV, 1, 0.04975, Sign PSD2, 1,2,4,6,7,8,12,23,26,35,36,37,38,19

1800, ESAV

-1 Sign NO-PASS1 at $1800 \mathrm{~m}$, starting no-passing zone, speed limit 90(km/h)

1800, BSAV, 1, 0.04975, Reaction Time Data for speed limit sign-NO-PASS1, $1,2,4,6,7,8,12,23,26,35,36,37,38,19$ 
2090, ESAV

-1 Sign PSD3 at $2240 \mathrm{~m}$, starting passing zone, speed limit 80(km/h)

2090, BSAV, 1, 0.04975, Reaction Time Data for speed limit signPSD3, $1,2,4,6,7,8,12,23,26,35,36,37,38,19$

2240, ESAV

2240, BSAV, 1, 0.04975, Sign PSD3, 1,2,4,6,7,8,12,23,26,35,36,37,38, 19

3000, ESAV

-1 Sign NO-PASS2 at $3600 \mathrm{~m}$, starting no-passing zone, speed limit 70(km/h)

3600, BSAV, 1, 0.04975, Reaction Time Data for speed limit sign-NO-PASS2, $1,2,4,6,7,8,12,23,26,35,36,37,38,19$

3750, ESAV

-1 Sign PSD4 at $3900 \mathrm{~m}$, starting passing zone, speed limit 70(km/h)

3750, BSAV, 1, 0.04975, Reaction Time Data for speed limit signPSD4, $1,2,4,6,7,8,12,23,26,35,36,37,38,19$

3900, ESAV

3900, BSAV, 1, 0.04975, Sign PSD4, 1,2,4,6,7,8,12,23,26,35,36,37,38, 19

4260, ESAV

-1 Sign PSD5 at $4410 \mathrm{~m}$, starting passing, speed limit 60(km/h)

4260, BSAV, 1, 0.04975, Reaction Time Data for speed limit signPSD5, $1,2,4,6,7,8,12,23,26,35,36,37,38,19$

4410, ESAV

4410, BSAV, 1, 0.04975, Sign PSD5, 1,2,4,6,7,8,12,23,26,35,36,37,38, 19

5090, ESAV

-1 Sign PSD6 at $5240 \mathrm{~m}$, starting passing, speed limit 50(km/h)

5090, BSAV, 1, 0.04975, Reaction Time Data for speed limit signPSD6, $1,2,4,6,7,8,12,23,26,35,36,37,38,19$

5240, ESAV

5240, BSAV, 1, 0.04975, Sign PSD6, 1,2,4,6,7,8,12,23,26,35,36,37,38, 19 
6000, ESAV

-1 Sign PSD7 at $7065 \mathrm{~m}$, starting passing, speed limit 80(km/h)

6915, BSAV, 1, 0.04975, Reaction Time Data for speed limit signPSD7, $1,2,4,6,7,8,12,23,26,35,36,37,38,19$

7065, ESAV

7065, BSAV, 1, 0.04975, Sign PSD7, 1,2,4,6,7,8,12,23,26,35,36,37,38,19

7915, ESAV

-1 Sign PSD8 at $8065 \mathrm{~m}$, starting passing, speed limit 100(km/h)

7915, BSAV, 1, 0.04975, Reaction Time Data for speed limit signPSD8, $1,2,4,6,7,8,12,23,26,35,36,37,38,19$

8065, ESAV

8065, BSAV, 1, 0.04975, Sign PSD8, 1,2,4,6,7,8,12,23,26,35,36,37,38, 19

8850, ESAV

-1 Sign PSD9 at $9000 \mathrm{~m}$, starting passing, speed limit 110(km/h)

8850, BSAV, 1, 0.04975, Reaction Time Data for speed limit signPSD9, $1,2,4,6,7,8,12,23,26,35,36,37,38,19$

9000, ESAV

9000, BSAV, 1, 0.04975, Sign PSD9, 1,2,4,6,7,8,12,23,26,35,36,37,38, 19

9850, ESAV

-1 Sign PSD10 at 10000 m, starting passing, speed limit 120(km/h)

9850, BSAV, 1, 0.04975, Reaction Time Data for speed limit signPSD10, $1,2,4,6,7,8,12,23,26,35,36,37,38,19$

10000, ESAV

10000, BSAV, 1, 0.04975, Sign PSD10, 1,2,4,6,7,8,12,23,26,35,36,37,38,19

11200, ESAV

600,RMSB,0,First performance block in passing-zone 1, SL $90 \mathrm{~km} / \mathrm{h}$ 1120,RMSE 
1250,RMSB,0,Second performance block in passing-zone 2, SL $90 \mathrm{~km} / \mathrm{h}$ 1770,RMSE

2240,RMSB,0,third performance block in passing-zone 3, SL $80 \mathrm{~km} / \mathrm{h}$ 2700,RMSE

3900,RMSB,0,forth performance block in passing-zone 4, SL $70 \mathrm{~km} / \mathrm{h}$ 4280,RMSE

4410,RMSB,0,fifth performance block in passing-zone 5, SL $60 \mathrm{~km} / \mathrm{h}$ 4720,RMSE

5240,RMSB,0,sixth performance block in passing-zone 6, SL $50 \mathrm{~km} / \mathrm{h}$ 5490,RMSE

7065,RMSB,0,seventh performance block in passing-zone 7, SL $80 \mathrm{~km} / \mathrm{h}$ 7525,RMSE

8065,RMSB,0,eighth performance block in passing-zone 8, SL $100 \mathrm{~km} / \mathrm{h}$ 8665,RMSE

9000,RMSB,0,ninth performance block in passing-zone 9, SL $110 \mathrm{~km} / \mathrm{h}$ 9680,RMSE

10000,RMSB,0,tenth performance block in passing-zone 10, SL $120 \mathrm{~km} / \mathrm{h}$ 10760,RMSE

$\{$ Tags Sound Files $=$ C: $\backslash$ STISIM $\backslash$ Sound $\backslash\}$

400, Speed Warnings, 1, 19.33, FllwWarn.Wav, 44, FLLWInstructions.Wav, 30, 10

600, Speed Warnings, 1, 25, LowWarning.Wav, 95.33, HighWarning.Wav, 20, 10

900, Speed Warnings, 0

-1 400, Speed Warnings, 1, 29.33, FllwWarn.Wav, 44, FLLWInstructions.Wav, 30, 10

-1 600, Speed Warnings, 1, 66, LowWarning.Wav, 95.33, HighWarning.Wav, 20, 10

-1 900, Speed Warnings, 0

-1 Slow Vehicles in the same lane 
$150, \mathrm{~V}, 19.44444,143.84,1.83,1, * 18 \sim 35$,

800, V, 19.44444, 115.76, 1.83, 1, *18 35,

-1 vehicles in the opposite direction

170, A, 25, 304.8, -1.83, *1 35;-8;-9;-16;-17;-3;-5, 4, 0, 48.77, .5

200, A, 25, 304.8, -1.83, *1 35;-8;-9;-16;-17;-3;-5, 4, 0, 48.77, .5

$230, \mathrm{~A}, 25,304.8,-1.83, * 30 \sim 34,4,0,48.77, .5$

250, A, 25, 304.8, -1.83, *1 35;-8;-9;-16;-17;-3;-5, 4, 0, 48.77, .5

290, A, 25, 304.8, -1.83, *1 35;-8;-9;-16;-17;-3;-5, 4, 0, 48.77, .5

-1------------EVENT---------PSD-1 slow vehicle to pass

-1 Availble $\mathrm{PSD}=520.61 \mathrm{~m}$ is enough for passing; $\mathrm{Vd}=90 \mathrm{~km} / \mathrm{h}$

150, PR, C:ISTISIM $\backslash P S D \_s o u n d \backslash s p e e d \_90 . w a v, ~ 0,10$

600, PR, C:ISTISIM \PSD_sound $\backslash$ safe_pass.wav, 0, 2

600, SIGN, 100, 100, C:ISTISIM\DatalEuroSigns\EuroSpeed_090.Lmm, 0, 0, 0

600, LS, 90, 100

$314.44, \mathrm{~A}, 25,285.56,-1.83, * 30 \sim 34,4,0,48.77, .5$

600, A, 25, 520.61, -1.83, *1 35;-8;-9;-16;-17;-3;-5, 4, 0, 48.77, .5

770, A, 25, 365.7, -1.83, *1 35;-8;-9;-16;-17;-3;-5, 4, 0, 48.77, .5

795, A, 25, 365.7, -1.83, *1 35;-8;-9;-16;-17;-3;-5, 4, 0, 48.77, .5

-1------------EVENT---------PSD-2 slow vehicle to pass

-1 Availble $\mathrm{PSD}=520.61 \mathrm{~m}$ is enough for passing; $\mathrm{Vd}=90 \mathrm{~km} / \mathrm{h}$

850, PR, C:ISTISIMIPSD_sound $\backslash$ speed_90.wav, 0, 10

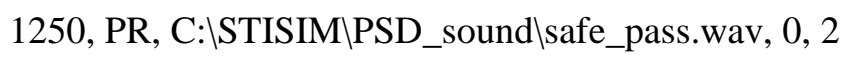

1250, SIGN, 100, 100, C:ISTISIM\DatalEuroSigns\EuroSpeed_090.Lmm, 0, 0, 0

1250, LS, 90, 100

$964.44, \mathrm{~A}, 25,285.56,-1.83, * 30 \sim 34,4,0,48.77, .5$

$1250, \mathrm{~A}, 25,520.61,-1.83, * 1 \sim 35 ;-8 ;-9 ;-16 ;-17 ;-3 ;-5,4,0,48.77, .5$ 
-1 Slow Vehicles in the same lane

$1400, \mathrm{~V}, 20.833333,143.84,1.83,1, * 18 \sim 35$

-1 1500, V, 19.44444, 143.84, 1.83, 1, *18 35

1574.84, A, 25, 267.71, -1.83, *1 35;-8;-9;-16;-17;-3;-5, 4, 0, 48.77, .5

1617.32, A, 25, 267.71, -1.83, *1 35;-8;-9;-16;-17;-3;-5, 4, 0, 48.77, .5

1681.12, A, 25, 267.71, -1.83, *1 35;-8;-9;-16;-17;-3;-5, 4, 0, 48.77, .5

1696.84, A, 25, 267.71, -1.83, *1 35;-8;-9;-16;-17;-3;-5, 4, 0, 48.77, .5

$1700, \mathrm{~A}, 25,267.71,-1.83, * 30 \sim 34,4,0,48.77, .5$

1730, A, 25, 267.71, -1.83, *1 35;-8;-9;-16;-17;-3;-5, 4, 0, 48.77, .5

-1------------EVENT---------No-PSD-1 slow vehicle to not pass

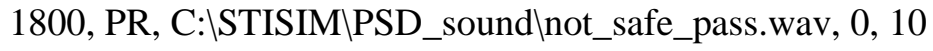

1800, SIGN, 100, 100, C:ISTISIM\DatalEuroSigns\EuroSpeed_090.Lmm, 0, 0, 0

1800, LS, 90, 100

-1 Availble PSD= $267.71 \mathrm{~m}$ is not enough for passing

$1541.44, \mathrm{~A}, 25,285.56,-1.83, * 30 \sim 34,4,0,48.77, .5$

1800, A, 25, 267.71, -1.83, *1 35;-8;-9;-16;-17;-3;-5, 4, 0, 48.77, .5

-1 intersection 01 (distance $2300 \mathrm{~m}$ from start), no turn allowed, non signalised

1960, I, 2, 340, 3, 0, 0

1960, SIGN, 13, 280, 0, 1, 0, 0

-1 Adding curve to the roadway

2400, C, 300, 30, 190, 30, .0025, 1, 4

-1------------EVENT---------PSD-3 slow vehicle to pass

2130, PR, C:ISTISIMIPSD_sound\speed_80.wav, 0, 10

2240, PR, C:ISTISIM IPSD_sound \safe_pass.wav, 0, 2

-1 2240, SIGN, 100, 100, C:ISTISIM\DatalEuroSigns\EuroSpeed_090.Lmm, 0, 0, 0

2240, LS, 80, 100 
-1 Availble PSD $=446.18 \mathrm{~m}$ is enough for passing; $\mathrm{Vd}=80 \mathrm{~km} / \mathrm{h}$

1994.47, A, 22.22222, 245.53, -1.83,*30 34, 4, 0, 48.77, .5

2240, A, 22.22222, 446.18, -1.83, *1 35;-8;-9;-16;-17;-3;-5, 4, 0, 48.77, .5

2356.64, A, 25, 446.18, -1.83, *1 35;-8;-9;-16;-17;-3;-5, 4, 0, 48.77, .5

2710, A, 25, 304.8, -1.83, *1 35;-8;-9;-16;-17;-3;-5, 4, 0, 48.77, .5

2750, A, 25, 366.74, -1.83, *1 35;-8;-9;-16;-17;-3;-5, 4, 0, 48.77, .5

$2820, \mathrm{~A}, 25,304.8,-1.83, * 30 \sim 34,4,0,48.77, .5$

$2945, \mathrm{~A}, 25,304.8,-1.83, * 1 \sim 35 ;-8 ;-9 ;-16 ;-17 ;-3 ;-5,4,0,48.77, .5$

2970, A, 25, 366.74, -1.83, *1 35;-8;-9;-16;-17;-3;-5, 4, 0, 48.77, .5

$3100, \mathrm{~A}, 25,304.8,-1.83, * 30 \sim 34,4,0,48.77, .5$

-1 Vehicles travelling on the same direction of the driver

$2815, \mathrm{~V}, 15.3,260,1.85,1,21$

$2980, \mathrm{~V}, 20,260,1.85,1, * 18 \sim 35$

-1 intersection 02 (distance $3350 \mathrm{~m}$ from start), full intersection, no turn allowed, non signalised

3010, I, 0, 340, 3, 2, 2

3010, SIGN, 13, 280, 0, 1, 0, 0

-1 no-passing zone from $3200 \mathrm{~m}$ to $3900 \mathrm{~m}$

3000, SIGN, 100, 100,C:ISTISIM\DatalEuroSigns\No_Passing.3ds

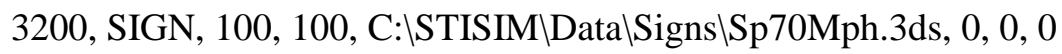

3200, LS, 70, 100

3200, PR, C:ISTISIMIPSD_soundlspeed_70.wav, 0, 10

-1 Conflict traffic on near lane (left lane of opposite direction)

$3135, \mathrm{~A}, 18,405,-1.85, * 18 \sim 35$

$3135, \mathrm{~A}, 18,420,-1.85, * 18 \sim 35$

$3135, \mathrm{~A}, 18,430,-1.85, * 18 \sim 35$

$3135, \mathrm{~A}, 19,440,-1.85, * 18 \sim 35$ 
$3135, \mathrm{~A}, 19,450,-1.85, * 18 \sim 35$

$3135, \mathrm{~A}, 19,465,-1.85, * 18 \sim 35$

$3135, \mathrm{~A}, 18,475,-1.85, * 18 \sim 35$

$3135, \mathrm{~A}, 18,490,-1.85, * 18 \sim 35$

$3135, \mathrm{~A}, 18,520,-1.85, * 18 \sim 35$

$3135, \mathrm{~A}, 19,540,-1.85, * 18 \sim 35$

-1 intersection 03 (distance $3750 \mathrm{~m}$ from start), full intersection, no turn allowed, non signalised 3410, I, 0, 340, 3, 2, 2

3410, SIGN, 13, 280, 0, 1, 0, 0

-1 Conflict traffic on near lane (left lane of opposite direction)

$3420, \mathrm{~A}, 22,262,-1.85, * 18 \sim 35$

$3430, \mathrm{~A}, 21,262,-1.85, * 18 \sim 35$

$3445, \mathrm{~A}, 21,262,-1.85, * 18 \sim 35$

$3470, \mathrm{~A}, 21,262,-1.85, * 18 \sim 35$

$3510, \mathrm{~A}, 21,262,-1.85, * 18 \sim 35$

$3525, \mathrm{~A}, 21,262,-1.85, * 18 \sim 35$

$3535, \mathrm{~A}, 21,315,-1.85, * 18 \sim 35$

-1 Add Tunnel to the road at $5,250 \mathrm{~m}$

3500, PDE, C:ISTISIM\PDEs\Tunnel2.pde

-1 Start passing zone from $3900 \mathrm{~m}$

3800, SIGN, 100, 100,C:ISTISIM\DatalSigns\PassingAllowed.3ds

-1------------EVENT---------PSD-4 slow vehicle to pass

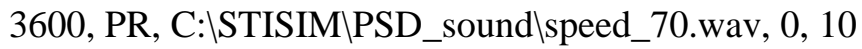

3900, PR, C:ISTISIMIPSD_soundlsafe_pass.wav, 0, 2

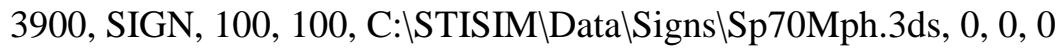

3900, LS, 70, 100 
-1 Availble PSD= $375.41 \mathrm{~m}$ is enough for passing; $\mathrm{Vd}=70 \mathrm{~km} / \mathrm{h}$

3692.43, A, 19.44444, 207.57, -1.83,*30 34, 4, 0, 48.77, .5

3900, A, 19.44444, 375.41, -1.83, *1 35;-8;-9;-16;-17;-3;-5, 4, 0, 48.77, .5

-1 Conflict traffic on near lane (left lane of opposite direction)

3994, A, 19, 304.8, -1.83, *1 35;-8;-9;-16;-17;-3;-5, 4, 0, 48.77, .5

4004, A, 18, 304.8, -1.83, *1 35;-8;-9;-16;-17;-3;-5, 4, 0, 48.77, .5

4019, A, 18, 304.8, -1.83, *1 35;-8;-9;-16;-17;-3;-5, 4, 0, 48.77, .5

4044, A, 18, 365.76, -1.83, *1 35;-8;-9;-16;-17;-3;-5, 4, 0, 48.77, .5

4056, A, 18, 365.76, -1.83, *1 35;-8;-9;-16;-17;-3;-5, 4, 0, 48.77, .5

4098, A, 18, 304.8, -1.83,*30 34, 4, 0, 48.77, .5

-1 intersection 04 (distance $4750 \mathrm{~m}$ from start), full intersection, no turn allowed, non signalised

4410, SL, -340, 78, 1, 2, 0, -3, 3, 1, 0

4410, I, 0, 340, 3, 2, 2

4410, SIGN, 13, 280, 0, 1, 0, 0

-1 Impeding Vehicle

$3500, \mathrm{~V}, 16.67,260,1.85,1, * 18 \sim 35$

$3800, \mathrm{~V}, 11.67,260,1.85,1, * 18 \sim 35$

-1------------EVENT---------PSD-5 slow vehicle to pass

4110, PR, C:ISTISIMIPSD_soundlspeed_60.wav, 0, 10

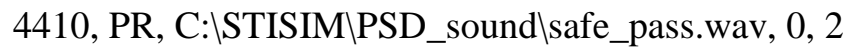

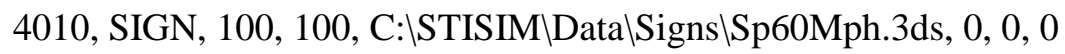

4010, LS, 60, 100

-1 Availble $\mathrm{PSD}=307.63 \mathrm{~m}$ is enough for passing; $\mathrm{Vd}=60 \mathrm{~km} / \mathrm{h}$

4238.31, A, 16.666667, 171.69, -1.83,*30 34, 4, 0, 48.77, .5

4410, A, 16.666667, 307.63, -1.83, *1 35;-8;-9;-16;-17;-3;-5, 4, 0, 48.77, .5

-1 Conflict traffic on near lane (left lane of opposite direction) 
4805, A, 13.88888, 265.76, -1.83, *1 35;-8;-9;-16;-17;-3;-5, 4, 0, 48.77, .5

4870, A, 13.88888, 265.76, -1.83, *1 35;-8;-9;-16;-17;-3;-5, 4, 0, 48.77, .5

4940, A, 13.88888, 204.8, -1.83,*30 34, 4, 0, 48.77, .5

-1 Impeding Vehicle

$4560, \mathrm{~V}, 10,260,1.85,1, * 18 \sim 35$

-1-----------EVENT---------PSD-6 slow vehicle to pass

-1 4940, PR, C:ISTISIM \PSD_soundlspeed_50.wav, 0, 10

5240, PR, C:ISTISIM \PSD_soundlsafe_pass.wav, 0, 2

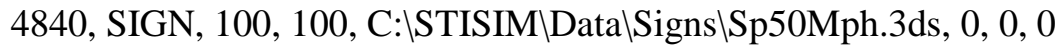

4840, LS, 50, 100

-1 Availble PSD $=243.86 \mathrm{~m}$ is enough for passing; $\mathrm{Vd}=50 \mathrm{~km} / \mathrm{h}$

$5102.11, \mathrm{~A}, 13.88888,137.89,-1.83, * 30 \sim 34,4,0,48.77, .5$

5240, A, 12, 208.78, -1.83, *1 35;-8;-9;-16;-17;-3;-5, 4, 0, 48.77, .5

-1 Conflict traffic on near lane (left lane of opposite direction)

5710, A, 14, 204.8, -1.83, *1 35;-8;-9;-16;-17;-3;-5, 4, 0, 48.77, .5

5770, A, 13, 204.8, -1.83, *1 35;-8;-9;-16;-17;-3;-5, 4, 0, 48.77, .5

5835, A, 13, 204.8, -1.83, *1 35;-8;-9;-16;-17;-3;-5, 4, 0, 48.77, .5

5935, A, 13.88888, 265.76, -1.83, *1 35;-8;-9;-16;-17;-3;-5, 4, 0, 48.77, .5

6000, A, 13.88888, 265.76, -1.83, *1 35;-8;-9;-16;-17;-3;-5, 4, 0, 48.77, .5

6070, A, 13.88888, 204.8, -1.83, *30 34, 4, 0, 48.77, .5

-1 Vehicles travelling on the same direction of the driver

$5640, \mathrm{~V}, 18,260,1.85,1,21$

$5805, \mathrm{~V}, 19,260,1.85,1, * 18 \sim 35$

Changing the road to 4-lane Arterial Road

6000, ROAD, 3.7, 4, 2, 2, 0.15, 0.85, .7, .12, .16, 37, -2, -2, -4, 1.83, -4, 1.83, 0, 1.52, 0, 1.52, 0, 0, 0, C:\STISIM\Data|Textures\Grass08.Jpg, 25, C:ISTISIM\Data\Textures\Road07.Jpg, 12, 
C:ISTISIM\DatalTextures\Grass08.Jpg, 25

-1 Conflict traffic on near lane (left lane of opposite direction)

$6220, \mathrm{~A}, 22,220,-1.85, * 18 \sim 35$

$6230, \mathrm{~A}, 21,220,-1.85, * 18 \sim 35$

$6245, \mathrm{~A}, 21,220,-1.85, * 18 \sim 35$

$6270, \mathrm{~A}, 21,220,-1.85, * 18 \sim 35$

6310, A, 21, 220, -1.85,*18 35

$6325, \mathrm{~A}, 21,220,-1.85, * 18 \sim 35$

$6335, \mathrm{~A}, 21,220,-1.85, * 18 \sim 35$

$6645, \mathrm{~A}, 22,262,-1.85, * 18 \sim 35$

$6670, \mathrm{~A}, 21,262,-1.85, * 18 \sim 35$

$6710, \mathrm{~A}, 21,262,-1.85, * 18 \sim 35$

$6725, \mathrm{~A}, 21,262,-1.85, * 18 \sim 35$

$6735, A, 21,262,-1.85, * 18 \sim 35$

-1 intersection 05; 4 way; straight only

6385, BSAV, 1, 0.04975, speed at intersection05, 1, 2,6,23

6435, ESAV

$0, \mathrm{I}, 0,6405,1,4,4$

-1 Stop Sign

0, SIGN, 7, -6405, 4, 0

-1 Street Sign

6029, SIGN, 100, 340, C:ISTISIM\DatalSigns\ParkSt.3ds, 0

-1 Two-lane Rural Road without passing zone

6565, ROAD, 3.7, 2, 1, 2, 0.15, 0.85, .7, .12, .16, 0, -2, -2, 0, 0, 0, 0, -8, 1.52, -8, 1.52, 0, 0, 0 , C:ISTISIM\DatalTextures\Grass08.Jpg, 25, C:ISTISIM\DatalTextures\Dirt03.Jpg, 12, C:ISTISIM\DatalTextures\Grass08.Jpg, 25 
-1 Two-lane Rural Road with passing zone

6765, ROAD, 3.7, 2, 1, 1, 0.15, 0.85, .7, .12, .16, 0, -2, -2, 0, 0, 0, 0, -8, 1.52, -8, 1.52, 0, 0, 0 ,

C:ISTISIM\DatalTextures\Grass08.Jpg, 25, C:ISTISIM\DatalTextures\Dirt03.Jpg, 12,

C:ISTISIM\DatalTextures\Grass08.Jpg, 25

-1 intersection 06; 4 way; straight only

6885, BSAV, 1, 0.04975, speed at intersection06, 1, 2,6,23

6935, ESAV

$6565, \mathrm{I}, 0,340,1,4,4$

-1 Stop Sign

0, SIGN, 7, -6565, 5, 0

-1 Street Sign

6549, SIGN, 100, 340, C:ISTISIM\DatalSigns\OakSt.3ds, 0

-1 intersection07; 4 way; straight only

7385, BSAV, 1, 0.04975, speed at intersection07, 1, 2,6,23

7435, ESAV

$7065, \mathrm{I}, 0,340,1,4,4$

-1 Street Sign

7049, SIGN, 100, 340, C:ISTISIM\DatalSigns \RanchSt.3ds, 0

-1 Vertical curve at distance $7350 \mathrm{~m}$ from start

7350, VC, 200, 0.02

7750, VC, 200, -0.02

-1 Impeding Vehicle

$6585, \mathrm{~V}, 17.778,260,1.85,1, * 18 \sim 35$

-1------------EVENT---------PSD-7 slow vehicle to pass

6765, PR, C:ISTISIMIPSD_sound\speed_80.wav, 0, 10

7065, PR, C:ISTISIM\PSD_sound\safe_pass.wav, 0, 2 
-1 7065, SIGN, 100, 100, C:ISTISIM\DatalEuroSigns\EuroSpeed_090.Lmm, 0, 0, 0

6565, LS, 80, 100

-1 Availble $\mathrm{PSD}=446.18 \mathrm{~m}$ is enough for passing; $\mathrm{Vd}=80 \mathrm{~km} / \mathrm{h}$

6819.47, A, 22.22222, 245.53, -1.83,*30 34, 4, 0, 48.77, .5

7065, A, 22.22222, 446.18, -1.83, *1 35;-8;-9;-16;-17;-3;-5, 4, 0, 48.77, .5

7335, A, 23, 304.8, -1.83, *1 35;-8;-9;-16;-17;-3;-5, 4, 0, 48.77, .5

7385, A, 22, 366.74, -1.83, *1 35;-8;-9;-16;-17;-3;-5, 4, 0, 48.77, .5

$7455, \mathrm{~A}, 22,304.8,-1.83, * 30 \sim 34,4,0,48.77, .5$

7570, A, 22, 304.8, -1.83, *1 35;-8;-9;-16;-17;-3;-5, 4, 0, 48.77, .5

7695, A, 22, 304.8, -1.83, *1 35;-8;-9;-16;-17;-3;-5, 4, 0, 48.77, .5

-1 Adding curve to the roadway

7225, C, 300, 30, 190, 30, .0025, 1, 4

-1 intersection 08 (distance $7665 \mathrm{~m}$ from start), full intersection, no turn allowed, non signalised

$7835, \mathrm{I}, 0,340,3,2,2$

7835, SIGN, 13, 280, 0, 1, 0, 0

-1 no-passing zone from $8025 \mathrm{~m}$ to $8725 \mathrm{~m}$

-1 7825, SIGN, 100, 100,C:ISTISIM\DatalEuroSigns\No_Passing.3ds

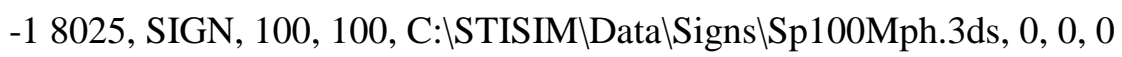

-18025, LS, 100, 100

-1 Impeding Vehicle

$7365, \mathrm{~V}, 23,160,1.85,1, * 18 \sim 35$

$7665, \mathrm{~V}, 23.888,260,1.85,1, * 18 \sim 35$

-1------------EVENT---------PSD-8 slow vehicle to pass

7765, PR, C:ISTISIM \PSD_sound\speed_100.wav, 0, 10

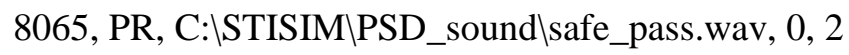

-1 7065, SIGN, 100, 100, C:ISTISIM\Data|EuroSigns\EuroSpeed_090.Lmm, 0, 0, 0 
7565, LS, 100, 100

-1 Availble PSD= $595.43 \mathrm{~m}$ is enough for passing; $\mathrm{Vd}=100 \mathrm{~km} / \mathrm{h}$

$7738.81, \mathrm{~A}, 27,326.19,-1.83, * 30 \sim 34,4,0,48.77, .5$

8065, A, 27.777, 595.43, -1.83, *1 35;-8;-9;-16;-17;-3;-5, 4, 0, 48.77, .5

-12356.64, A, $25,304.8,-1.83, * 1 \sim 35 ;-8 ;-9 ;-16 ;-17 ;-3 ;-5,4,0,48.77, .5$

8335, A, 23, 355.8, -1.83, *1 35;-8;-9;-16;-17;-3;-5, 4, 0, 48.77, .5

8385, A, 22, 483.72, -1.83, *1 35;-8;-9;-16;-17;-3;-5, 4, 0, 48.77, .5

$8455, \mathrm{~A}, 22,305.8,-1.83, * 30 \sim 34,4,0,48.77, .5$

8570, A, 22, 305.8, -1.83, *1 35;-8;-9;-16;-17;-3;-5, 4, 0, 48.77, .5

$-18695, \mathrm{~A}, 22,305.8,-1.83, * 1 \sim 35 ;-8 ;-9 ;-16 ;-17 ;-3 ;-5,4,0,48.77, .5$

$-18825, \mathrm{~A}, 22,305.8,-1.83, * 30 \sim 34,4,0,48.77, .5$

-1 Adding curve to the roadway

$8225, \mathrm{C}, 300,30,190,30, .0025,1,4$

-1 intersection 09 (distance $8665 \mathrm{~m}$ from start), non signalised

$8835, \mathrm{I}, 2,340,3,0,0$

8835, SIGN, 13, 280, 0, 1, 0, 0

-1 Impeding Vehicle

$8165, \mathrm{~V}, 28,260,1.85,1, * 18 \sim 35$

$8265, \mathrm{~V}, 25,260,1.85,1, * 18 \sim 35$

-1------------EVENT---------PSD-9 slow vehicle to pass

-1 8700, PR, C:ISTISIM $\backslash P S D \_s o u n d \backslash s p e e d \_110 . w a v, ~ 0,10$

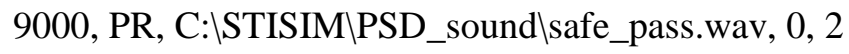

-1 8700, SIGN, 100, 100, C:ISTISIM\DatalEuroSigns\EuroSpeed_110.Lmm, 0, 0, 0

8665, LS, 110, 100

-1 Availble PSD= $673.18 \mathrm{~m}$ is enough for passing; $\mathrm{Vd}=110 \mathrm{~km} / \mathrm{h}$

8631.41, A, 30, 368.59, -1.83, *30 34, 4, 0, 48.77, .5 
9000, A, 30, 673.18, -1.83, *1 35;-8;-9;-16;-17;-3;-5, 4, 0, 48.77, .5

-1 Impeding Vehicle

$9265, \mathrm{~V}, 28,260,1.85,1, * 18 \sim 35$

$9365, \mathrm{~V}, 27,260,1.85,1, * 18 \sim 35$

-1------------EVENT---------PSD-10 slow vehicle to pass

-1 9700, PR, C:ISTISIM $\backslash P S D \_s o u n d \backslash$ speed_120.wav, 0, 10

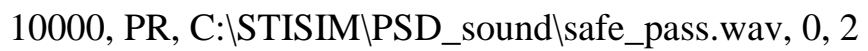

-1 9700, SIGN, 100, 100, C:ISTISIM\Data|EuroSigns\EuroSpeed_120.Lmm, 0, 0, 0

9700, LS, 120, 100

-1 Availble $\mathrm{PSD}=673.18 \mathrm{~m}$ is enough for passing; $\mathrm{Vd}=110 \mathrm{~km} / \mathrm{h}$

9287.23, A, 33, 412.77, $-1.83, * 30 \sim 34,4,0,48.77, .5$

10000, A, 33, 753.92, -1.83, *1 35;-8;-9;-16;-17;-3;-5, 4, 0, 48.77, .5

10050, A, 33, 753.92, -1.83, *1 35;-8;-9;-16;-17;-3;-5, 4, 0, 48.77, .5

10100, A, 33, 753.92, -1.83, *1 35;-8;-9;-16;-17;-3;-5, 4, 0, 48.77, .5

-1 vehicles in the opposite direction

10170, A, 25, 753.92, -1.83, *1 35;-8;-9;-16;-17;-3;-5, 4, 0, 48.77, .5

10200, A, 25, 753.92, -1.83, *1 35;-8;-9;-16;-17;-3;-5, 4, 0, 48.77, .5

10230, A, 25, 753.92, -1.83, *30 34, 4, 0, 48.77, .5

10250, A, 25, 753.92, -1.83, *1 35;-8;-9;-16;-17;-3;-5, 4, 0, 48.77, .5

10290, A, 25, 753.92, -1.83, *1 35;-8;-9;-16;-17;-3;-5, 4, 0, 48.77, .5

-1 Trees

0, TREE, 90, $0, * 1 \sim 18,9.45,18.29,0$

375, TREE, $80,0, * 1 \sim 18,9.45,18.29,0$

805, TREE, $95,0, * 1 \sim 18,9.45,18.29,0$

1275, TREE, $85,0, * 1 \sim 18,9.45,18.29,0$

1805, TREE, $75,0, * 1 \sim 18,9.45,18.29,0$ 
2290, TREE, $0,0, * 1 \sim 18,9.45,18.29,0$ 3365, TREE, 70, 0, *1 18, 9.45, 18.29, 0 3740, TREE, $0,0, * 1 \sim 18,9.45,18.29,0$ 3760, TREE, 70, 0, *1 18, 9.45, 18.29, 0 5170, TREE, $0,0, * 1 \sim 18,9.45,18.29,0$ 10365, TREE, 70, $0, * 1 \sim 18,9.45,18.29,0$ 10440, TREE, $0,0, * 1 \sim 18,9.45,18.29,0$ 10560, TREE, $70,0, * 1 \sim 18,9.45,18.29,0$ 10670, TREE, $0,0, * 1 \sim 18,9.45,18.29,0$ 10680, TREE, $90,0, * 1 \sim 18,9.45,18.29,0$ 10700, TREE, $80,0, * 1 \sim 18,9.45,18.29,0$ 10800, TREE, $95,0, * 1 \sim 18,9.45,18.29,0$ 11000, TREE, $85,0, * 1 \sim 18,9.45,18.29,0$ -1 Buildings

360, BLDG, 250, $-14.59, \mathrm{H}^{*} 2 ; 4 \sim 7 ; 9 ; 13$ 360, BLDG, 320, $-14.59, \mathrm{H}^{*} 2 ; 4 \sim 7 ; 9 ; 13$ 360, BLDG, 220, 14.59, $\mathrm{H}^{* 2 ; 4 ~ 7 ; 9 ; 13}$ 360, BLDG, 300, 14.59, H*2;4 7;9;13 3154.36, BLDG, 242.02, 17.99, G*1 13 3154.36, BLDG, 282.02, 17.99, B*1 5;9;13 15 3154.36, BLDG, 322.02, 17.99, B*1 5;9;13 15 3154.36, BLDG, 372.02, 17.99, B*1 5;9;13 15 3154.36, BLDG, 422.02, 17.99, B*1 5;9;13 15 3154.36, BLDG, 462.02, 17.99, G*1 13 3154.36, BLDG, 502.02, 17.99, B*1 5;9;13 15 3154.36, BLDG, 552.02, 17.99, G*1 13 
3154.36, BLDG, 612.02, 17.99, G*1 13

3154.36, BLDG, 662.02, 17.99, B*1 5;9;13 15

3154.36, BLDG, 722.02, 17.99, G*1 13

3154.36, BLDG, 812.02, 17.99, B*1 5;9;13 15

3154.36, BLDG, 892.02, 17.99, G*1 13

3154.36, BLDG, 247.02, -17.99, B*1 5;9;13 15

3154.36, BLDG, 285.02, -17.99, G*1 13

3154.36, BLDG, 326.02, -17.99, G*1 13

3154.36, BLDG, 372.02, -17.99, G*1 13

3154.36, BLDG, 432.02, -17.99, B*1 5;9;13 15

3154.36, BLDG, 522.02, -17.99, B4

3154.36, BLDG, 557.02, -17.99, B*1 5;9;13 15

3154.36, BLDG, 612.02, -17.99, G*1 13

3154.36, BLDG, 662.02, -17.99, G*1 13

3154.36, BLDG, 722.02, -17.99, G*1 13

3154.36, BLDG, 812.02, -17.99, G*1 13

3154.36, BLDG, 892.02, -17.99, G*1 13

3355, BLDG, 129.56, -16.29, $\mathrm{H}^{*} 2 ; 4 \sim 7 ; 9 ; 13$

3355, BLDG, 159.56, -16.29, $\mathrm{H}^{* 2 ; 4 ~ 7 ; 9 ; 13 ~}$

3355, BLDG, 199.56, -16.29, H*2;4 7;9;13

3355, BLDG, 239.56, -16.29, H*2;4 7;9;13

3355, BLDG, 269.56, -16.29, $\mathrm{H}^{* 2 ; 4 ~ 7 ; 9 ; 13}$

3355, BLDG, 339.56, -16.29, $\mathrm{H}^{*} 2 ; 4 \sim 7 ; 9 ; 13$

3355, BLDG, 129.56, 16.29, H*2;4 7;9;13

3355, BLDG, 169.56, 16.29, H*2;4 7;9;13

3355, BLDG, 199.56, 16.29, H*2;4 7;9;13 
3355, BLDG, 249.56, 16.29, H*2;4 7;9;13 3355, BLDG, 279.56, 16.29, $\mathrm{H}^{*} 2 ; 4 \sim 7 ; 9 ; 13$ 3355, BLDG, 339.56, 16.29, H*2;4 7;9;13 3755, BLDG, 129.56, -16.29, H*2;4 7;9;13 3755, BLDG, 159.56, -16.29, H*2;4 7;9;13 3755, BLDG, 199.56, -16.29, H*2;4 7;9;13 3755, BLDG, 239.56, -16.29, H*2;4 7;9;13 3755, BLDG, 269.56, -16.29, $\mathrm{H}^{*} 2 ; 4 \sim 7 ; 9 ; 13$ 3755, BLDG, 339.56, -16.29, $\mathrm{H}^{* 2 ; 4 ~ 7 ; 9 ; 13}$ 3755, BLDG, 379.56, -16.29, H*2;4 7;9;13 3755, BLDG, 439.56, -16.29, H*2;4 7;9;13 3755, BLDG, 129.56, 16.29, H*2;4 7;9;13 3755, BLDG, 169.56, 16.29, H*2;4 7;9;13 3755, BLDG, 199.56, 16.29, H*2;4 7;9;13 3755, BLDG, 249.56, 16.29, $\mathrm{H}^{* 2 ; 4 ~ 7 ; 9 ; 13 ~}$ 3755, BLDG, 279.56, 16.29, $\mathrm{H}^{* 2 ; 4 ~ 7 ; 9 ; 13 ~}$ 3755, BLDG, 339.56, 16.29, H*2;4 7;9;13 3755, BLDG, 389.56, 16.29, $\mathrm{H}^{* 2 ; 4 ~ 7 ; 9 ; 13}$ 3755, BLDG, 439.56, 16.29, H*2;4 7;9;13 4255, BLDG, 129.56, -16.29, H*2;4 7;9;13 4255, BLDG, 159.56, -16.29, $\mathrm{H}^{*} 2 ; 4 \sim 7 ; 9 ; 13$ 4255, BLDG, 199.56, -16.29, H*2;4 7;9;13 4255, BLDG, 239.56, -16.29, $\mathrm{H}^{*} 2 ; 4 \sim 7 ; 9 ; 13$ 4255, BLDG, 269.56, -16.29, $\mathrm{H}^{*} 2 ; 4 \sim 7 ; 9 ; 13$ 4255, BLDG, 339.56, -16.29, H*2;4 7;9;13 4255, BLDG, 389.56, -16.29, H*2;4 7;9;13 
4255, BLDG, 429.56, -16.29, H*2;4 7;9;13

4255, BLDG, 129.56, 16.29, H*2;4 7;9;13

4255, BLDG, 169.56, 16.29, H*2;4 7;9;13

4255, BLDG, 199.56, 16.29, H*2;4 7;9;13

4255, BLDG, 249.56, 16.29, $\mathrm{H}^{*} 2 ; 4 \sim 7 ; 9 ; 13$

4255, BLDG, 279.56, 16.29, $\mathrm{H}^{* 2 ; 4 ~ 7 ; 9 ; 13}$

4255, BLDG, 339.56, 16.29, H*2;4 7;9;13

4255, BLDG, 379.56, 16.29, $\mathrm{H}^{*} 2 ; 4 \sim 7 ; 9 ; 13$

4255, BLDG, 419.56, 16.29, H*2;4 7;9;13

4755, BLDG, 129.56, -16.29, H*2;4 7;9;13

4755, BLDG, 159.56, -16.29, H*2;4 7;9;13

4755, BLDG, 199.56, -16.29, H*2;4 7;9;13

4755, BLDG, 239.56, -16.29, $\mathrm{H}^{*} 2 ; 4 \sim 7 ; 9 ; 13$

4755, BLDG, 269.56, -16.29, H*2;4 7;9;13

4755, BLDG, 339.56, -16.29, H*2;4 7;9;13

4755, BLDG, 389.56, -16.29, H*2;4 7;9;13

4755, BLDG, 429.56, -16.29, $\mathrm{H}^{*} 2 ; 4 \sim 7 ; 9 ; 13$

4755, BLDG, 129.56, 16.29, $\mathrm{H}^{* 2 ; 4 ~ 7 ; 9 ; 13 ~}$

4755, BLDG, 169.56, 16.29, H*2;4 7;9;13

4755, BLDG, 199.56, 16.29, H*2;4 7;9;13

4755, BLDG, 249.56, 16.29, H*2;4 7;9;13

4755, BLDG, 279.56, 16.29, H*2;4 7;9;13

4755, BLDG, 339.56, 16.29, H*2;4 7;9;13

4755, BLDG, 379.56, 16.29, H*2;4 7;9;13

4755, BLDG, 419.56, 16.29, H*2;4 7;9;13

4755, BLDG, 479.56, 16.29, H*2;4 7;9;13 
4755, BLDG, 499.56, 16.29, H*2;4 7;9;13

5815, BLDG, 162.02, 22.99, B*1 5;9;13 15

5815, BLDG, 202.02, 22.99, B*1 5;9;13 15

5815, BLDG, 242.02, 22.99, G*1 13

5815, BLDG, 282.02, 22.99, B*1 5;9;13 15

5815, BLDG, 322.02, 22.99, B*1 5;9;13 15

5815, BLDG, 372.02, 22.99, B*1 5;9;13 15

5815, BLDG, 422.02, 22.99, B*1 5;9;13 15

5815, BLDG, 462.02, 22.99, G*1 13

5815, BLDG, 502.02, 22.99, B*1 5;9;13 15

5815, BLDG, 552.02, 22.99, G*1 13

5815, BLDG, 612.02, 22.99, G*1 13

5815, BLDG, 662.02, 22.99, B*1 5;9;13 15

5815, BLDG, 722.02, 22.99, G*1 13

5815, BLDG, 812.02, 22.99, B*1 5;9;13 15

5815, BLDG, 892.02, 22.99, G*1 13

5815, BLDG, 82.02, -22.99, B*1 5;9;13 15

5815, BLDG, 122.02, -22.99, G*1 13

5815, BLDG, 172.02, -22.99, B*1 5;9;13 15

5815, BLDG, 206.02, -22.99, G*1 13

5815, BLDG, 247.02, -22.99, B*1 5;9;13 15

5815, BLDG, 285.02, -22.99, G*1 13

5815, BLDG, 326.02, -22.99, G*1 13

5815, BLDG, 372.02, -22.99, G*1 13

5815, BLDG, 432.02, -22.99, B*1 5;9;13 15

5815, BLDG, 522.02, -22.99, B4 
5815, BLDG, 557.02, -22.99, B*1 5;9;13 15

5815, BLDG, 612.02, -22.99, G*1 13

5815, BLDG, 662.02, -22.99, G*1 13

5815, BLDG, 722.02, -22.99, G*1 13

5815, BLDG, 812.02, -22.99, G*1 13

5815, BLDG, 892.02, -22.99, G*1 13

6315, BLDG, 72.02, 22.99, G*1 13

6315, BLDG, 122.02, 22.99, G*1 13

6315, BLDG, 162.02, 22.99, B*1 5;9;13 15

6315, BLDG, 202.02, 22.99, B*1 5;9;13 15

6315, BLDG, 242.02, 22.99, G*1 13

6315, BLDG, 282.02, 22.99, B*1 5;9;13 15

6315, BLDG, 322.02, 22.99, B*1 5;9;13 15

6315, BLDG, 372.02, 22.99, B*1 5;9;13 15

6315, BLDG, 422.02, 22.99, B*1 5;9;13 15

6315, BLDG, 462.02, 22.99, G*1 13

6315, BLDG, 502.02, 22.99, B*1 5;9;13 15

6315, BLDG, 552.02, 22.99, G*1 13

6315, BLDG, 612.02, 22.99, G*1 13

6315, BLDG, 662.02, 22.99, B*1 5;9;13 15

6315, BLDG, 722.02, 22.99, G*1 13

6315, BLDG, 812.02, 22.99, B*1 5;9;13 15

6315, BLDG, 892.02, 22.99, G*1 13

6315, BLDG, 82.02, -22.99, B*1 5;9;13 15

6315, BLDG, 122.02, -22.99, G*1 13

6315, BLDG, 172.02, -22.99, B*1 5;9;13 15 
6315, BLDG, 206.02, -22.99, G*1 13

6315, BLDG, 247.02, -22.99, B*1 5;9;13 15

6315, BLDG, 285.02, -22.99, G*1 13

6315, BLDG, 326.02, -22.99, G*1 13

6315, BLDG, 372.02, -22.99, G*1 13

6315, BLDG, 432.02, -22.99, B*1 5;9;13 15

6315, BLDG, 522.02, -22.99, B4

6315, BLDG, 557.02, -22.99, B*1 5;9;13 15

6315, BLDG, 612.02, -22.99, G*1 13

6315, BLDG, 662.02, -22.99, G*1 13

6315, BLDG, 722.02, -22.99, G*1 13

6315, BLDG, 812.02, -22.99, G*1 13

6315, BLDG, 892.02, -22.99, G*1 13

6815, BLDG, 72.02, 22.99, G*1 13

6815, BLDG, 122.02, 22.99, G*1 13

6815, BLDG, 162.02, 22.99, B*1 5;9;13 15

6815, BLDG, 202.02, 22.99, B*1 5;9;13 15

6815, BLDG, 242.02, 22.99, G*1 13

6815, BLDG, 282.02, 22.99, B*1 5;9;13 15

6815, BLDG, 322.02, 22.99, B*1 5;9;13 15

6815, BLDG, 372.02, 22.99, B*1 5;9;13 15

6815, BLDG, 422.02, 22.99, B*1 5;9;13 15

6815, BLDG, 462.02, 22.99, G*1 13

6815, BLDG, 502.02, 22.99, B*1 5;9;13 15

6815, BLDG, 552.02, 22.99, G*1 13

6815, BLDG, 612.02, 22.99, G*1 13 
6815, BLDG, 662.02, 22.99, B*1 5;9;13 15

6815, BLDG, 722.02, 22.99, G*1 13

6815, BLDG, 812.02, 22.99, B*1 5;9;13 15

6815, BLDG, 892.02, 22.99, G*1 13

6815, BLDG, 82.02, -22.99, B*1 5;9;13 15

6815, BLDG, 122.02, -22.99, G*1 13

6815, BLDG, 172.02, -22.99, B*1 5;9;13 15

6815, BLDG, 206.02, -22.99, G*1 13

6815, BLDG, 247.02, -22.99, B*1 5;9;13 15

6815, BLDG, 285.02, -22.99, G*1 13

6815, BLDG, 326.02, -22.99, G*1 13

6815, BLDG, 372.02, -22.99, G*1 13

6815, BLDG, 432.02, -22.99, B*1 5;9;13 15

6815, BLDG, 522.02, -22.99, B4

6815, BLDG, 557.02, -22.99, B*1 5;9;13 15

6815, BLDG, 592.02, -22.99, G*1 13

6815, BLDG, 712.02, -22.99, G*1 13

6815, BLDG, 892.02, -22.99, G*1 13

7504.36, BLDG, 72.02, 22.99, G*1 13

7504.36, BLDG, 122.02, 22.99, G*1 13

7504.36, BLDG, 162.02, 22.99, B*1 5;9;13 15

7504.36, BLDG, 202.02, 22.99, B*1 5;9;13 15

7504.36, BLDG, 242.02, 22.99, G*1 13

7504.36, BLDG, 282.02, 22.99, B*1 5;9;13 15

7504.36, BLDG, 322.02, 22.99, B*1 5;9;13 15

7504.36, BLDG, 372.02, 22.99, B*1 5;9;13 15 
7504.36, BLDG, 422.02, 22.99, B*1 5;9;13 15

7504.36, BLDG, 462.02, 22.99, G*1 13

7504.36, BLDG, 502.02, 22.99, B*1 5;9;13 15

7504.36, BLDG, 552.02, 22.99, G*1 13

7504.36, BLDG, 612.02, 22.99, G*1 13

7504.36, BLDG, 662.02, 22.99, B*1 5;9;13 15

7504.36, BLDG, 722.02, 22.99, G*1 13

7504.36, BLDG, 812.02, 22.99, B*1 5;9;13 15

7504.36, BLDG, 892.02, 22.99, G*1 13

7504.36, BLDG, 82.02, -22.99, B*1 5;9;13 15

7504.36, BLDG, 122.02, -22.99, G*1 13

7504.36, BLDG, 172.02, -22.99, B*1 5;9;13 15

7504.36, BLDG, 206.02, -22.99, G*1 13

7504.36, BLDG, 247.02, -22.99, B*1 5;9;13 15

7504.36, BLDG, 285.02, -22.99, G*1 13

7504.36, BLDG, 326.02, -22.99, G*1 13

7504.36, BLDG, 372.02, -22.99, G*1 13

7504.36, BLDG, 432.02, -22.99, B*1 5;9;13 15

7504.36, BLDG, 522.02, -22.99, B4

7504.36, BLDG, 557.02, -22.99, B*1 5;9;13 15

7504.36, BLDG, 612.02, -22.99, G*1 13

7504.36, BLDG, 662.02, -22.99, G*1 13

7504.36, BLDG, 722.02, -22.99, G*1 13

7504.36, BLDG, 812.02, -22.99, G*1 13

7504.36, BLDG, 892.02, -22.99, G*1 13

8015, BLDG, 202.02, 22.99, B*1 5;9;13 15 
8015, BLDG, 242.02, 22.99, G*1 13

8015, BLDG, 282.02, 22.99, B*1 5;9;13 15

8015, BLDG, 322.02, 22.99, B*1 5;9;13 15

8015, BLDG, 372.02, 22.99, B*1 5;9;13 15

8015, BLDG, 412.02, 22.99, $\mathrm{B} * 1 \sim 5 ; 9 ; 13 \sim 15$

8015, BLDG, 442.02, 22.99, G*1 13

8015, BLDG, 522.02, 22.99, B*1 5;9;13 15

8015, BLDG, 572.02, 22.99, G*1 13

8015, BLDG, 612.02, 22.99, G*1 13

8015, BLDG, 662.02, 22.99, B*1 5;9;13 15

8015, BLDG, 722.02, 22.99, G*1 13

8015, BLDG, 812.02, 22.99, B*1 5;9;13 15

8015, BLDG, 206.02, -22.99, G*1 13

8015, BLDG, 247.02, -22.99, B*1 5;9;13 15

8015, BLDG, 285.02, -22.99, G*1 13

8015, BLDG, 326.02, -22.99, G*1 13

8015, BLDG, 372.02, -22.99, G*1 13

8015, BLDG, 412.02, -22.99, B*1 5;9;13 15

8015, BLDG, 542.02, -22.99, B4

8015, BLDG, 587.02, -22.99, B*1 5;9;13 15

8015, BLDG, 642.02, -22.99, G*1 13

8015, BLDG, 682.02, -22.99, G*1 13

8015, BLDG, 762.02, -22.99, G*1 13

8015, BLDG, 812.02, -22.99, G*1 13

8015, BLDG, 892.02, -22.99, G*1 13

8515, BLDG, 202.02, 19.99, B*1 5;9;13 15 
8515, BLDG, 242.02, 19.99, G*1 13

8515, BLDG, 282.02, 19.99, B*1 5;9;13 15

8515, BLDG, 322.02, 19.99, B*1 5;9;13 15

8515, BLDG, 372.02, 19.99, B*1 5;9;13 15

8515, BLDG, 572.02, 19.99, G*1 13

8515, BLDG, 622.02, 19.99, G*1 13

8515, BLDG, 662.02, 19.99, B*1 5;9;13 15

8515, BLDG, 722.02, 19.99, G*1 13

- 8515, BLDG, 812.02, 19.99, B*1 5;9;13 15

8515, BLDG, 892.02, 19.99, G*1 13

8515, BLDG, 206.02, -19.99, G*1 13

8515, BLDG, 247.02, -19.99, B*1 5;9;13 15

8515, BLDG, 285.02, -19.99, G*1 13

8515, BLDG, 326.02, -19.99, G*1 13

8515, BLDG, 372.02, -19.99, G*1 13

8515, BLDG, 432.02, -19.99, B*1 5;9;13 15

- 8515, BLDG, 522.02, -19.99, B4

8515, BLDG, 567.02, -19.99, B*1 5;9;13 15

8515, BLDG, 622.02, -19.99, G*1 13

8515, BLDG, 662.02, -19.99, G*1 13

8515, BLDG, 722.02, -19.99, G*1 13

- 8515, BLDG, 812.02, -19.99, G*1 13

8515, BLDG, 892.02, -19.99, G*1 13

9015, BLDG, 202.02, 19.99, B*1 5;9;13 15

9015, BLDG, 242.02, 19.99, G*1 13

9015, BLDG, 322.02, 19.99, B*1 5;9;13 15 
9015, BLDG, 372.02, 19.99, B*1 5;9;13 15

9015, BLDG, 422.02, 19.99, B*1 5;9;13 15

9015, BLDG, 462.02, 19.99, G*1 13

9015, BLDG, 502.02, 19.99, B*1 5;9;13 15

9015, BLDG, 552.02, 19.99, G*1 13

9015, BLDG, 612.02, 19.99, G*1 13

9015, BLDG, 662.02, 19.99, B*1 5;9;13 15

9015, BLDG, 722.02, 19.99, G*1 13

9015, BLDG, 812.02, 19.99, B*1 5;9;13 15

9015, BLDG, 892.02, 19.99, G*1 13

9015, BLDG, 206.02, -19.99, G*1 13

9015, BLDG, 247.02, -19.99, B*1 5;9;13 15

9015, BLDG, 336.02, -19.99, G*1 13

9015, BLDG, 372.02, -19.99, G*1 13

9015, BLDG, 432.02, -19.99, B*1 5;9;13 15

9015, BLDG, 522.02, -19.99, B4

9015, BLDG, 557.02, -19.99, B*1 5;9;13 15

9015, BLDG, 612.02, -19.99, G*1 13

9015, BLDG, 662.02, -19.99, G*1 13

9015, BLDG, 722.02, -19.99, G*1 13

9015, BLDG, 812.02, -19.99, G*1 13

9015, BLDG, 892.02, -19.99, G*1 13

9315, BLDG, 202.02, 19.99, B*1 5;9;13 15

9315, BLDG, 242.02, 19.99, G*1 13

9315, BLDG, 282.02, 19.99, B*1 5;9;13 15

9315, BLDG, 322.02, 19.99, B*1 5;9;13 15 
9315, BLDG, 372.02, 19.99, B*1 5;9;13 15

9315, BLDG, 502.02, 19.99, B*1 5;9;13 15

9315, BLDG, 552.02, 19.99, G*1 13

9315, BLDG, 612.02, 19.99, G*1 13

9315, BLDG, 662.02, 19.99, B*1 5;9;13 15

9315, BLDG, 722.02, 19.99, G*1 13

9315, BLDG, 812.02, 19.99, B*1 5;9;13 15

9315, BLDG, 892.02, 19.99, G*1 13

9315, BLDG, 206.02, -19.99, G*1 13

9315, BLDG, 247.02, -19.99, B*1 5;9;13 15

9315, BLDG, 285.02, -19.99, G*1 13

9315, BLDG, 326.02, -19.99, G*1 13

9315, BLDG, 372.02, -19.99, G*1 13

9315, BLDG, 522.02, -19.99, B4

9315, BLDG, 557.02, -19.99, B*1 5;9;13 15

9315, BLDG, 612.02, -19.99, G*1 13

9315, BLDG, 662.02, -19.99, G*1 13

9315, BLDG, 722.02, -19.99, G*1 13

9315, BLDG, 812.02, -19.99, G*1 13

9315, BLDG, 892.02, -19.99, G*1 13

9765, BLDG, 202.02, 19.99, B*1 5;9;13 15

9765, BLDG, 242.02, 19.99, G*1 13

9765, BLDG, 282.02, 19.99, B*1 5;9;13 15

9765, BLDG, 322.02, 19.99, B*1 5;9;13 15

9765, BLDG, 372.02, 19.99, B*1 5;9;13 15

9765, BLDG, 422.02, 19.99, B*1 5;9;13 15 
-9765, BLDG, 462.02, 19.99, G*1 13

9765, BLDG, 502.02, 19.99, B*1 5;9;13 15

9765, BLDG, 552.02, 19.99, G*1 13

9765, BLDG, 662.02, 19.99, B*1 5;9;13 15

9765, BLDG, 722.02, 19.99, G*1 13

9765, BLDG, 812.02, 19.99, B*1 5;9;13 15

9765, BLDG, 892.02, 19.99, G*1 13

9765, BLDG, 206.02, -19.99, G*1 13

9765, BLDG, 247.02, -19.99, B*1 5;9;13 15

9765, BLDG, 285.02, -19.99, G*1 13

9765, BLDG, 326.02, -19.99, G*1 13

9765, BLDG, 372.02, -19.99, G*1 13

9765, BLDG, 422.02, -19.99, B*1 5;9;13 15

9765, BLDG, 722.02, -19.99, G*1 13

9765, BLDG, 812.02, -19.99, G*1 13

9765, BLDG, 892.02, -19.99, G*1 13

10354.36, BLDG, 202.02, 19.99, B*1 5;9;13 15

10354.36, BLDG, 242.02, 19.99, G*1 13

10354.36, BLDG, 282.02, 19.99, B*1 5;9;13 15

10354.36, BLDG, 322.02, 19.99, B*1 5;9;13 15

10354.36, BLDG, 372.02, 19.99, B*1 5;9;13 15

10354.36, BLDG, 422.02, 19.99, B*1 5;9;13 15

-10354.36, BLDG, 462.02, 19.99, G*1 13

10354.36, BLDG, 502.02, 19.99, B*1 5;9;13 15

10354.36, BLDG, 552.02, 19.99, G*1 13

10354.36, BLDG, 612.02, 19.99, G*1 13 
10354.36, BLDG, 662.02, 19.99, B*1 5;9;13 15

10354.36, BLDG, 722.02, 19.99, G*1 13

10354.36, BLDG, 812.02, 19.99, B*1 5;9;13 15

10354.36, BLDG, 892.02, 19.99, G*1 13

10354.36, BLDG, 206.02, -19.99, G*1 13

10354.36, BLDG, 247.02, -19.99, B*1 5;9;13 15

10354.36, BLDG, 285.02, -19.99, G*1 13

10354.36, BLDG, 326.02, -19.99, G*1 13

10354.36, BLDG, 372.02, -19.99, G*1 13

-10354.36, BLDG, 432.02, -19.99, B*1 5;9;13 15

10354.36, BLDG, 522.02, -19.99, B4

10354.36, BLDG, 557.02, -19.99, B*1 5;9;13 15

10354.36, BLDG, 612.02, -19.99, G*1 13

10354.36, BLDG, 662.02, -19.99, G*1 13

10354.36, BLDG, 722.02, -19.99, G*1 13

10354.36, BLDG, 812.02, -19.99, G*1 13

10354.36, BLDG, 892.02, -19.99, G*1 13

$-1 * * * * * * * * * * * * * * * * * * * * * * * * * * * * * * * * * * * * * * * * *$

-1 PED crossing the street at intersection 10

5000, PED, 1396, 4, 2, 9, R, *1 10;-4;-5

5000, PED, 1393, 0, 0, -12, L, *1 10;-4;-5

5000, PED, 1420, 4, 2, -13, L, *1 10;-4;-5

0, PED, 3600, 0, 0, 9, R, *1 8

0, PED, 3610, 0, 0, 10, R, *1 8

0, PED, 3612, 0, 0, 13, R, *1 8

0, PED, 3620, 0, 0, 14, R, *1 8 
0, PED, 3625, 0, 0, 9, R, *1 8

0, PED, 3630, 0, 0, 10, R, *1 8

0, PED, 3635, 0, 0, 13, R, *1 8

0, PED, 3640, 0, 0, 14, R, *1 8

0, PED, 3645, 0, 0, 9, R, *1 8

0, PED, 3650, 0, 0, 10, R, *1 8

0, PED, 3655, 0, 0, 13, R, *1 8

0, PED, 3660, 0, 0, 14, R, *1 8

0, PED, 3665, 0, 0, 9, R, *1 8

0, PED, 3670, 0, 0, 10, R, *1 8

0, PED, 3675, 0, 0, 13, R, *1 8

0, PED, 3680, 0, 0, 14, R, *1 8

0, PED, 3622, 0, 0, 10, R, *1 8

0, PED, 3632, 0, 0, 13, R, *1 8

0, PED, 3642, 0, 0, 14, R, *1 8

0, PED, 6200, 0, 0, 9, R, *1 8

0, PED, 6210, 0, 0, 10, R, *1 8

0, PED, 6212, 0, 0, 13, R, *1 8

0, PED, 6220, 0, 0, 14, R, *1 8

0, PED, 6225, 0, 0, 9, R, *1 8

0, PED, 6230, 0, 0, 10, R, *1 8

0, PED, 6235, 0, 0, 13, R, *1 8

0, PED, 6240, 0, 0, 14, R, *1 8

0, PED, 6245, 0, 0, 9, R, *1 8

0, PED, 6250, 0, 0, 10, R, *1 8

0, PED, 6255, 0, 0, 13, R, *1 8 
0, PED, 6260, 0, 0, 14, R, *1 8

0, PED, 6265, 0, 0, 9, R, *1 8

0, PED, 6270, 0, 0, 10, R, *1 8

0, PED, 6275, 0, 0, 13, R, *1 8

0, PED, 6280, 0, 0, 14, R, *1 8

0, PED, 6222, 0, 0, 10, R, *1 8

0, PED, 6232, 0, 0, 13, R, *1 8

0, PED, 6242, 0, 0, 14, R, *1 8

5600, PED, 793, 0, 0, -12, L, *1 10;-4;-5

5600, PED, 820, 4, 2, -13, L, *1 10;-4;-5

11500, ES 


\section{Appendix E: Field Data Summary}

\begin{tabular}{|c|c|c|c|c|c|c|c|c|c|c|c|c|}
\hline No & $\begin{array}{c}\mathrm{Vp} \\
(\mathrm{m} / \mathrm{s})\end{array}$ & $\begin{array}{l}\mathrm{m} \\
\mathrm{m} / \mathrm{s})\end{array}$ & $\begin{array}{c}\mathrm{a} \\
(\mathrm{m} / \mathrm{s} 2)\end{array}$ & $\begin{array}{c}\mathrm{t}_{1} \\
\text { (s) }\end{array}$ & $\begin{array}{l}\mathrm{t}_{2} \\
\text { (s) }\end{array}$ & $\begin{array}{c}\text { TTC } \\
\text { (s) }\end{array}$ & $\begin{array}{c}\mathrm{d}_{1} \\
(\mathrm{~m})\end{array}$ & $\begin{array}{c}\mathrm{d}_{2} \\
(\mathrm{~m})\end{array}$ & $\begin{array}{c}\mathrm{d}_{3} \\
(\mathrm{~m}) \\
\end{array}$ & $\begin{array}{c}\mathrm{d}_{4} \\
(\mathrm{~m}) \\
\end{array}$ & $\begin{array}{l}\text { PSD } \\
(\mathrm{m})\end{array}$ & $\begin{array}{l}\text { PT } \\
\text { (s) }\end{array}$ \\
\hline 1 & 9.94 & 298 & 068 & 3.00 & 8.08 & 10.86 & 44.46 & 178.01 & 43.29 & 192.79 & 458.55 & 21.94 \\
\hline 2 & .55 & 68 & & & 77 & 0.57 & 3.48 & 78.28 & 44.61 & 19.24 & 95 & 20.64 \\
\hline 3 & .83 & 57 & & & 51 & 3.98 & 5.29 & 190.35 & 48.55 & 494.97 & 799.16 & 34.49 \\
\hline 4 & 3.81 & 1.60 & 37 & 50 & 5.71 & 7.00 & 33.60 & 135.42 & 44.09 & 106.64 & 319.75 & 15.21 \\
\hline 5 & 2.82 & 4.02 & 0.04 & 2.50 & 9.03 & 0.00 & 45.81 & 208.76 & 45.09 & 179.64 & 479.30 & 21.53 \\
\hline 6 & 1.17 & 2.49 & 0.44 & 2.50 & 11.86 & 12.02 & 33.63 & 270.55 & 45.00 & 222.46 & 571.64 & 26.38 \\
\hline 7 & .24 & 3.95 & & $\pi 0$ & 10.05 & 6.63 & 50.75 & 217.14 & 44.85 & 90.81 & 403.55 & 19.18 \\
\hline 8 & .73 & 2.88 & & 0 & 15.00 & 9.63 & 28.39 & 291.26 & 42.89 & 150.34 & 512.88 & 26.81 \\
\hline 9 & .59 & 2.92 & & & 14.58 & 7.00 & 2.53 & 291.21 & 3.29 & 22.33 & 79. & 34.08 \\
\hline 10 & .36 & .07 & & & & 8.52 & 6.98 & 100.14 & 3.13 & 20.70 & 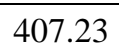 & 20.23 \\
\hline 11 & .76 & - & & & & 7.00 & .40 & . & 1.07 & 110 & 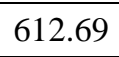 & 1.69 \\
\hline 12 & .22 & 5.59 & & & 10.26 & 5.50 & 0 & 214.32 & 8.95 & 122.14 & 1 & 19.26 \\
\hline 13 & .24 & 3 & & & 8 & 7.43 & 43.17 & 189.84 & 42.73 & 108.98 & 384.72 & 19.71 \\
\hline 14 & .33 & 3.66 & & 4.00 & 9.33 & 3.38 & 69.61 & 222.95 & 47.96 & 43.45 & 383.97 & 16.71 \\
\hline 15 & .80 & 5.01 & & 00 & 9.19 & 3.57 & 61.86 & 198.95 & 53.72 & 77.78 & 392.31 & 16.76 \\
\hline 16 & .38 & 4.62 & & & 9.11 & 2.48 & 36.89 & 198.20 & 54.51 & 52.46 & 342.06 & 14.59 \\
\hline 17 & .04 & 3.52 & & & 8.74 & 3.50 & 48.40 & 162.33 & 51.46 & 74.41 & 336.60 & 15.74 \\
\hline 18 & .16 & 3.97 & & 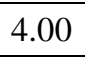 & 8 & 5.08 & 66.77 & 211.49 & 49.23 & 93.54 & 421.03 & 16.96 \\
\hline 19 & .18 & 2.25 & & & 0.05 & 22 & 7.68 & 227 & 4.14 & 84.86 & 51 & 21.07 \\
\hline 20 & 7 & & & & & & 5 & 257.09 & 45.38 & & 460.60 & 28 \\
\hline 2 & & & & & & & & & & & & \\
\hline 2 & 83 & & & & & 2.18 & 20 & 46 & 2.29 & 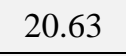 & 396.58 & 19.59 \\
\hline 23 & 81 & & & & & 38 & 9 & 260.93 & 43.39 & & 416.16 & 19.06 \\
\hline 24 & 9.99 & 3.7 & 040 & 5. & 10.29 & 9.59 & 76.69 & 221.69 & 43.18 & 132.39 & 473.95 & 25.10 \\
\hline 25 & 0.42 & 4.1 & 0.65 & 4. & 9 & 16.91 & 66.20 & 213.95 & 44.47 & 288.03 & 612.65 & 30.31 \\
\hline 26 & .12 & 3.72 & 076 & 4.00 & 9 & 9.04 & 63.06 & 187.16 & 43.24 & 149.23 & 442.69 & 22.16 \\
\hline 27 & .90 & 2.79 & & 5 & 9 & 9.60 & 73.76 & 191.05 & 42.14 & 146.72 & 453.67 & 24.14 \\
\hline 28 & 18.29 & 1.8 & & 4. & 1 & 4.11 & 56.35 & 390.41 & 34.03 & 31.24 & 512.03 & 27.47 \\
\hline 29 & 19.83 & 2.8 & & & & 4.68 & 72.12 & 324.98 & 40.07 & 38.78 & 475.95 & 24.39 \\
\hline 30 & .79 & 2.50 & דינו & 4.0 & 13.40 & 3.48 & 72.78 & 322.55 & 40.03 & 39.49 & 474.85 & 22.96 \\
\hline 31 & 19.54 & 2.76 & & 4.0 & 2.37 & 5.44 & 74.00 & 259.09 & 39.03 & 77.25 & 449.37 & 22.81 \\
\hline 32 & 15.85 & 2.28 & 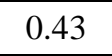 & 4.0 & 12.90 & 7.84 & 46.31 & 184.86 & 36.74 & 112.48 & .39 & 24.74 \\
\hline 33 & .50 & 2.86 & & 3. & .00 & 3.04 & 61.29 & 174.44 & 0.23 & 20.11 & 96.07 & 15.26 \\
\hline 34 & 8.71 & 2.40 & 0.43 & 3.56 & 14.60 & 3.96 & .76 & 260 & 2 & 63.26 & 411.61 & 22.12 \\
\hline
\end{tabular}




\begin{tabular}{|c|c|c|c|c|c|c|c|c|c|c|c|c|}
\hline 35 & 18.21 & 2.39 & 0.48 & 3.50 & 15.75 & 0.70 & 42.44 & 297.59 & 21.14 & 21.28 & 382.45 & 19.95 \\
\hline 36 & 21.28 & 3.21 & 1.79 & 3.00 & 8.35 & 2.99 & 47.69 & 185.43 & 43.99 & 42.02 & 319.13 & 14.34 \\
\hline 37 & 22.91 & 4.32 & 0.62 & 3.00 & 8.77 & 9.35 & 54.71 & 207.46 & 49.25 & 169.75 & 481.17 & 21.12 \\
\hline 38 & 23.52 & 3.33 & 0.71 & 3.00 & 8.00 & 10.00 & 55.61 & 187.71 & 50.40 & 200.18 & 493.90 & 21.00 \\
\hline 39 & 21.45 & 3.49 & 0.69 & 3.00 & 10.00 & 8.13 & 50.50 & 217.49 & 46.47 & 136.04 & 450.50 & 21.13 \\
\hline 40 & 21.71 & 2.74 & 0.58 & 4.00 & 12.79 & 3.30 & 68.28 & 296.72 & 46.57 & 22.52 & 434.09 & 20.09 \\
\hline 41 & 23.06 & 3.92 & 0.59 & 3.00 & 10.54 & 6.83 & 55.80 & 232.64 & 49.40 & 123.34 & 461.18 & 20.37 \\
\hline 42 & 21.90 & 3.95 & 0.62 & 4.00 & 8.96 & 1.00 & 74.04 & 204.43 & 24.97 & 25.01 & 328.45 & 13.96 \\
\hline 43 & 24.00 & 3.48 & 0.66 & 3.00 & 13.38 & 14.73 & 54.24 & 313.73 & 54.10 & 297.91 & 719.98 & 31.11 \\
\hline 44 & 22.35 & 4.32 & 0.66 & 3.00 & 11.11 & 3.46 & 53.46 & 250.33 & 49.25 & 49.22 & 402.26 & 17.57 \\
\hline 45 & 21.54 & 5.12 & 1.21 & 3.00 & 7.06 & 2.78 & 45.39 & 180.12 & 50.95 & 25.10 & 301.56 & 12.84 \\
\hline 46 & 23.66 & 3.32 & 0.74 & 3.50 & 11.51 & 6.91 & 54.29 & 260.04 & 55.08 & 127.38 & 496.79 & 21.92 \\
\hline 47 & 17.91 & 1.53 & 0.65 & 4.00 & 10.13 & 8.43 & 55.17 & 190.29 & 38.88 & 109.64 & 393.98 & 22.56 \\
\hline 48 & 19.30 & 1.90 & 0.56 & 5.00 & 8.63 & 5.57 & 86.71 & 161.58 & 40.12 & 78.20 & 366.61 & 19.20 \\
\hline 49 & 19.31 & 1.62 & 0.46 & 4.50 & 8.67 & 6.24 & 83.63 & 160.96 & 41.51 & 80.82 & 366.92 & 19.41 \\
\hline 50 & 19.23 & 2.09 & 0.33 & 4.50 & 10.63 & 2.43 & 87.46 & 199.98 & 19.84 & 38.80 & 346.08 & 17.56 \\
\hline 51 & 11.75 & 2.49 & 0.55 & 3.50 & 8.21 & 10.00 & 26.82 & 96.34 & 27.72 & 95.93 & 246.81 & 21.71 \\
\hline 52 & 13.56 & 4.58 & 0.35 & 3.50 & 8.20 & 1.64 & 47.40 & 113.47 & 14.54 & 14.46 & 189.87 & 13.34 \\
\hline 53 & 13.95 & 1.08 & 0.33 & 3.50 & 8.87 & 10.00 & 57.83 & 133.01 & 34.29 & 81.78 & 306.91 & 22.37 \\
\hline 54 & 15.79 & 4.24 & 0.37 & 4.00 & 8.57 & 1.81 & 56.94 & 133.17 & 16.92 & 13.98 & 221.01 & 14.38 \\
\hline 55 & 17.98 & 2.56 & 0.58 & 4.00 & 13.16 & 2.58 & 59.09 & 249.00 & 17.87 & 33.60 & 359.56 & 19.74 \\
\hline 56 & 16.04 & 2.60 & 0.77 & 4.50 & 7.97 & 0.36 & 75.82 & 135.10 & 0.00 & 13.68 & 224.60 & 12.83 \\
\hline 57 & 15.83 & 1.52 & 0.37 & 3.00 & 14.06 & 10.00 & 41.38 & 233.44 & 34.08 & 118.53 & 427.43 & 27.06 \\
\hline 58 & 17.11 & 2.53 & 0.27 & 4.50 & 11.12 & 8.74 & 81.21 & 196.58 & 35.11 & 97.73 & 410.63 & 24.36 \\
\hline 59 & 14.23 & 0.85 & 0.55 & 3.50 & 13.92 & 14.66 & 48.07 & 231.24 & 32.60 & 143.33 & 455.24 & 32.08 \\
\hline 60 & 16.00 & 3.90 & 0.75 & 4.50 & 8.71 & 3.64 & 62.39 & 154.43 & 17.82 & 37.27 & 271.91 & 16.85 \\
\hline 61 & 20.65 & 4.95 & 0.75 & 3.00 & 7.35 & 1.60 & 52.52 & 173.43 & 21.48 & 21.07 & 268.50 & 11.95 \\
\hline 62 & 20.84 & 3.89 & 0.47 & 3.00 & 8.78 & 1.55 & 55.86 & 215.45 & 20.84 & 20.43 & 312.58 & 13.33 \\
\hline 63 & 20.34 & 3.41 & 0.82 & 4.00 & 8.53 & 6.41 & 68.96 & 192.29 & 41.50 & 104.13 & 406.88 & 18.94 \\
\hline 64 & 20.40 & 3.95 & 0.49 & 3.50 & 8.23 & 5.86 & 74.00 & 191.65 & 41.18 & 60.39 & 367.22 & 17.59 \\
\hline 65 & 21.80 & 5.36 & 0.56 & 2.50 & 6.89 & 1.50 & 57.93 & 160.57 & 21.79 & 21.35 & 261.64 & 10.89 \\
\hline 66 & 21.23 & 7.43 & 0.52 & 2.32 & 7.86 & 17.54 & 47.67 & 161.48 & 44.01 & 341.27 & 594.43 & 27.72 \\
\hline 67 & 17.15 & 2.56 & 0.66 & 3.50 & 8.17 & 13.84 & 46.56 & 190.29 & 34.29 & 191.88 & 463.02 & 25.51 \\
\hline 68 & 19.20 & 2.87 & 0.62 & 3.50 & 7.80 & 8.06 & 75.61 & 164.64 & 37.14 & 106.61 & 384.00 & 19.36 \\
\hline 69 & 19.39 & 2.40 & 0.37 & 3.50 & 7.82 & 8.40 & 78.12 & 167.95 & 38.66 & 122.38 & 407.11 & 19.72 \\
\hline 70 & 21.08 & 4.74 & 0.81 & 3.00 & 6.65 & 0.79 & 56.82 & 132.66 & 21.49 & 20.95 & 231.92 & 10.44 \\
\hline 71 & 17.95 & 4.98 & 0.84 & 3.00 & 7.64 & 10.00 & 34.07 & 156.87 & 39.52 & 164.51 & 394.97 & 20.64 \\
\hline 72 & 24.68 & 6.68 & 0.75 & 3.00 & 7.69 & 9.34 & 58.71 & 195.13 & 51.77 & 212.70 & 518.31 & 20.03 \\
\hline 73 & 22.89 & 7.63 & 0.88 & 2.00 & 7.33 & 10.00 & 34.36 & 185.86 & 48.26 & 189.28 & 457.76 & 19.33 \\
\hline 74 & 24.79 & 9.21 & 0.38 & 3.50 & 7.68 & 2.52 & 90.45 & 201.14 & 26.63 & 53.66 & 371.88 & 13.70 \\
\hline
\end{tabular}




\begin{tabular}{|c|c|c|c|c|c|c|c|c|c|c|c|c|}
\hline 75 & 23.27 & 8.91 & 0.42 & 3.22 & 6.89 & 1.87 & 86.86 & 166.98 & 24.24 & 24.37 & 302.45 & 11.98 \\
\hline 76 & 25.61 & 9.23 & 0.50 & 3.50 & 9.62 & 2.82 & 98.75 & 263.33 & 24.71 & 48.59 & 435.38 & 15.94 \\
\hline 77 & 18.63 & 2.32 & 0.45 & 3.50 & 8.09 & 10.00 & 72.26 & 187.31 & 38.17 & 130.86 & 428.60 & 21.59 \\
\hline 78 & 20.27 & 5.51 & 0.62 & 4.50 & 8.46 & 1.48 & 87.65 & 173.87 & 21.68 & 20.78 & 303.98 & 14.44 \\
\hline 79 & 19.99 & 4.92 & 0.80 & 4.50 & 6.62 & 1.41 & 87.16 & 153.66 & 19.91 & 19.09 & 279.82 & 12.53 \\
\hline 80 & 18.84 & 3.32 & 0.20 & 3.18 & 12.88 & 15.69 & 57.65 & 240.74 & 37.41 & 229.37 & 565.17 & 31.75 \\
\hline 81 & 15.34 & 0.75 & 0.27 & 3.50 & 8.16 & 0.38 & 56.18 & 125.99 & 0.00 & 17.22 & 199.39 & 12.04 \\
\hline 82 & 18.86 & 4.00 & 0.65 & 3.50 & 7.94 & 0.44 & 67.66 & 139.43 & 19.13 & 18.92 & 245.14 & 11.88 \\
\hline 83 & 18.79 & 4.93 & 0.51 & 4.00 & 6.39 & 1.27 & 83.50 & 120.58 & 20.27 & 19.86 & 244.21 & 11.66 \\
\hline 84 & 21.85 & 5.33 & 0.24 & 4.00 & 9.41 & 0.60 & 84.80 & 201.77 & 20.83 & 20.33 & 327.73 & 14.01 \\
\hline 85 & 19.28 & 2.11 & 0.46 & 4.00 & 10.73 & 4.54 & 75.50 & 206.80 & 37.95 & 65.42 & 385.67 & 19.27 \\
\hline 86 & 20.76 & 4.89 & 0.34 & 4.00 & 8.35 & 2.24 & 76.90 & 171.23 & 21.48 & 41.75 & 311.36 & 14.59 \\
\hline 87 & 18.16 & 1.36 & 0.53 & 3.50 & 12.14 & 10.00 & 55.77 & 241.35 & 37.66 & 119.13 & 453.91 & 25.64 \\
\hline 88 & 19.73 & 3.82 & 0.45 & 3.50 & 8.22 & 1.52 & 70.94 & 162.46 & 20.87 & 41.63 & 295.90 & 13.24 \\
\hline 89 & 21.69 & 5.64 & 0.60 & 4.00 & 7.30 & 0.56 & 82.75 & 155.79 & 21.73 & 21.64 & 281.91 & 11.86 \\
\hline 90 & 19.69 & 3.66 & 0.14 & 3.50 & 8.59 & 3.49 & 76.34 & 180.27 & 39.46 & 38.61 & 334.68 & 15.58 \\
\hline 91 & 22.20 & 5.83 & 0.01 & 3.50 & 6.12 & 1.12 & 90.76 & 131.98 & 22.54 & 43.32 & 288.60 & 10.74 \\
\hline 92 & 20.43 & 4.68 & 0.07 & 4.00 & 8.19 & 1.61 & 81.39 & 163.28 & 20.60 & 41.22 & 306.49 & 13.80 \\
\hline 93 & 20.26 & 3.29 & 0.11 & 3.50 & 8.41 & 1.39 & 79.20 & 160.77 & 21.06 & 42.81 & 303.84 & 13.30 \\
\hline 94 & 22.05 & 5.39 & 0.85 & 3.50 & 7.95 & 10.82 & 58.89 & 186.97 & 45.74 & 193.50 & 485.10 & 22.27 \\
\hline 95 & 20.78 & 3.63 & 0.54 & 3.50 & 10.55 & 6.05 & 69.77 & 240.01 & 42.45 & 104.82 & 457.05 & 20.10 \\
\hline 96 & 21.62 & 3.86 & 0.50 & 3.00 & 7.94 & 10.60 & 60.97 & 201.68 & 42.97 & 169.97 & 475.59 & 21.54 \\
\hline 97 & 22.09 & 5.40 & 0.23 & 3.50 & 9.23 & 1.20 & 84.65 & 204.24 & 21.38 & 21.05 & 331.32 & 13.93 \\
\hline 98 & 20.95 & 4.26 & 0.26 & 3.50 & 8.39 & 5.38 & 79.80 & 169.43 & 42.35 & 106.49 & 398.07 & 17.27 \\
\hline 99 & 20.77 & 4.76 & 0.20 & 4.00 & 9.55 & 3.86 & 78.69 & 187.47 & 42.19 & 65.59 & 373.94 & 17.41 \\
\hline $\begin{array}{c}10 \\
0 \\
\end{array}$ & 18.25 & 1.76 & 0.90 & 4.00 & 10.15 & 7.05 & 65.98 & 224.29 & 34.71 & 76.51 & 401.49 & 21.20 \\
\hline $\begin{array}{c}10 \\
1 \\
\end{array}$ & 21.91 & 4.15 & 0.73 & 3.50 & 7.72 & 3.81 & 75.52 & 185.55 & 46.08 & 43.45 & 350.60 & 15.03 \\
\hline $\begin{array}{c}10 \\
2 \\
\end{array}$ & 20.37 & 4.18 & 0.62 & 4.00 & 8.04 & 4.39 & 71.34 & 171.82 & 42.55 & 80.93 & 366.64 & 16.43 \\
\hline $\begin{array}{c}10 \\
3 \\
\end{array}$ & 21.80 & 5.71 & 0.81 & 3.50 & 8.28 & 2.31 & 71.80 & 184.55 & 24.12 & 46.50 & 326.97 & 14.09 \\
\hline $\begin{array}{c}10 \\
4\end{array}$ & 19.96 & 4.67 & 0.53 & 4.00 & 7.77 & 3.40 & 71.61 & 167.21 & 41.48 & 39.12 & 319.42 & 15.17 \\
\hline $\begin{array}{c}10 \\
5\end{array}$ & 20.11 & 5.44 & 0.57 & 3.00 & 7.05 & 2.97 & 52.62 & 145.67 & 42.20 & 41.03 & 281.52 & 13.02 \\
\hline
\end{tabular}




\section{Appendix F: Simulink Library Model Description}

Block 1: Based on Simulink library model of single vehicle 2D steerability.

Block 2: Input vector defining initial location and yaw rotation according to degrees of freedom.

Block 3: Input vector defining initial velocities and yaw rate according to degrees of freedom.

Block 4: Input signal to control the vehicle's current longitudinal speed.

Block 5: Input signal to control the vehicle's current steering wheel angle.

Block 6: Output vector of accelerations (longitudinal and lateral) in the local coordinate system.

Block 7: Output vector of velocities (longitudinal and lateral) in the local coordinate system.

Block 8: Output vector of displacements and yaw rotation in the global coordinate system.

Block 9: Output vector of steered front wheel angles.

Block 10: Initial conditions and signal generation.

Block 11: Displaying results.

\section{Simulink Block Input and Results}

Block 1: Input vector of the mass center's initial position and the yaw angle $\left[\mathrm{X}_{0}, \mathrm{Y}_{0}, \Phi_{0}\right]$.

Block 2: Input vector of initial velocities and the yaw rate $\left[\mathrm{V}_{\mathrm{x} 0}, \mathrm{~V}_{\mathrm{y} 0}, \omega_{0}\right]$.

Block 3: Input of desired longitudinal speed.

Block 4: Input of current steering wheel angle.

Block 5: First-order integrator of second order derivatives. 
Block 6: Selector of second specified element (lateral velocity $\mathrm{V}_{\mathrm{y}}$ ) of three-dimensional input signal.

Block 7: Selector of first specified element (longitudinal velocity $\mathrm{V}_{\mathrm{x}}$ ) of three-dimensional input signal.

Block 8: Multiplication on -1.

Block 9: Input constant 0.

Block 10: Selector of third specified element (yaw rate $\omega$ ) of three-dimensional input signal.

Block 11: Concatenate vector $\left[\mathrm{V}_{\mathrm{y} 0},-\mathrm{V}_{\mathrm{x} 0}, 0\right]$.

Block 12: Product.

Block 13: Sum.

Block 14: Selector of two first elements (accelerations) of three-dimensional input signal.

Block 15: Output vector of accelerations (longitudinal and lateral) in the local coordinate system.

Block 16: Gain.

Block 17: Definition of the vector of external force factors.

Block 18: Product.

Block 19: Input constant - inverse mass matrix.

Block 20: One sample time unit delay arrangement.

Block 21: Sum.

Block 22: Selector of two first elements (velocities) of three-dimensional input signal.

Block 23: Output vector of velocities (longitudinal and lateral) in the local coordinate system.

Block 24: Selector of third specified element (yaw rate $\omega$ ) of three-dimensional input signal. 
Block 25: Matrix multiplication.

Block 26: Matrix concatenate.

Block 27: First-order integrator of first order derivatives.

Block 28: Output vector of displacements and yaw rotation in the global coordinate system.

Block 29: Selector of third specified element (yaw angle $\Phi$ ) of three-dimensional input signal.

Block 30: Transition matrix from local to global coordinates. 


\section{REFERENCES}

Alexander, J., Barham, P. and Black, I. (2002). "Factors influencing the probability of an incident at a junction: results from an interactive driving simulator." Accident Analysis and Prevention Vol. 34, pp. 779-792.

Alicandri, E. (1994). The Highway Driving Simulator (HYSIM): the next best thing to being on the road. Public Roads, 57(3), pp. 19-23.

Allen, R. W., Park, G., Rosenthal, T. J. and B. L. Aponso, "A Process for Developing Scenarios for Driving Simulations," presented at IMAGE 2004 Conference, Scottsdale, AZ, July 2004. (STI-P-632).

American Association of State Highway Officials (1940). A Policy of Marking and Signing of No-Passing Zones on Two- and Three-Lane Roads. AASHTO, Washington, DC.

American Association of State Highway and Transportation Officials (1984). A Policy on Geometric Design of Highways and Streets. AASHTO, Washington, D.C.

American Association of State Highway and Transportation Officials. (1994). A Policy on Geometric Design for Highways and Streets. AASHTO, Washington, D. C.

American Association of State Highway and Transportation Officials.(2001). A Policy on Geometric Design for Highways and Streets. AASHTO, Washington, D. C.

American Association of State Highway and Transportation Officials.(2004). A Policy on Geometric Design for Highways and Streets. AASHTO, Washington, D. C.

American Association of State Highway and Transportation Officials.(2011). A Policy on Geometric Design for Highways and Streets. AASHTO, Washington, D. C.

Ang, A. \& Tang, W. (1984). Probability Concepts in Engineering Planning and Design, JohnWiley, Toronto, Canada.

Bar-Gera, H., and D. Shinar (2005). The Tendency of Drivers to Pass Other Vehicles. Transportation Research Part F, Vol. 8, No. 6, pp. 429-439.

Basilio, N., Morice, a.H.P., Marti, G., et al. (2015). "High- and low-order overtaking-ability affordances: drivers rely on the maximum velocity and acceleration of their cars to perform overtaking maneuvers", Human Factors, 57, (5), pp. 879-894.

Bella, F., Garcia, A., Solves, F., Romero, M.A. (2007). Driving simulator validation for 
deceleration lane design. Proc. 86th Annual Meeting of the Transportation Research Board, Washington, D.C., USA.

Blaauw, G. J. (1982). Driving experience and task demands in simulator and instrumented car: a validation study. Human Factors, Vol. 24(3), pp. 473-486.

Blana, E. (1996). A survey of driving research simulators around the world (Working paper No. 481). Leeds, England: University of Leeds. Bravo, M., and Nakayama.

Bonneson, J.A. (1992). Modeling queued driver behavior at signalized junctions. Transportation Research Record 1365, 99-107.

Brown, R.L., and Hummer, J.E. (2000). Determining the best method for measuring no-passing zones. Transportation Research Record 1701, TRB, National Research Council, Washington, D.C., pp. 61-67.

Brown, T. L., Lee, J. D., and McGehee, D. V. (2001).” Human performance models and rear-end collision avoidance algorithms." Human Factors, 43(3), 462-482.

Burgett, A.L. (1994). "Methodologies for Evaluating the Impact on Safety of Intelligent Vehicle Highway Systems." 14th Int. Tech. Conf. on Enhanced Safety of Vehicles, No. 94 S3 012 , Munich, USA.

Campbell, J. L., Carney, C., and Kantowitz, B. H. (1998). Human factors design guidelines for advanced traveler information systems (ATIS) and commercial vehicle operations (CVO). Federal Highway Administration, Washington, DC.

Carlson, P. J., J. D. Miles, and P. K. Johnson. (2006). Daytime High-Speed Passing Maneuvers Observed on Rural Two-Lane, Two-Way Highway: Findings and Implications. In Transportation Research Record: Journal of the Transportation Research Board, No. 1961, pp. 9-15, Washington, D.C.

Cimbala, J. M. (2011). Outliers: Outliers in a sample of a single variable, Penn State University, USA. Website: http://www.mne.psu.edu/cimbala/me345/Lectures/Outliers.pdf

Clarke, D. D., P. J. Ward, and J. Jones (1998). Overtaking Road-Accidents: Differences in Maneuver as a Function of Driver Age. Accident Analysis\& Prevention, Vol. 30, No. 4, pp. $455-467$.

Clarke, D.D., Ward, P.J., and Jones, J. (1999). Processes and countermeasures in overtaking road accident. Ergonomics, Vol. 42, No. 6, pp. 846-867. 
Dabbour, Essam (2009). Development of in-vehicle collision warning system for intersections. Ph.D thesis, Ryerson University, Toronto, Canada.

Dabbour, Essam and Easa, Said M. (2014). "Proposed collision warning system for right-turning vehicles at two-way stop-controlled rural intersections," Elsevier Journal for Transportation Research, Part C 42. Vol. 121-131.

Denton, G. G. (1980). The influence of visual pattern on perceived speed. Perception, 9, 393402.

Desmond, P. A., and Matthews, G., (1997). Implication of task-induced fatigue effects for invehicle countermeasures to driver fatigue. Accident Analysis and Prevention, Vol. 29, No. 4, pp. 515 - 523.

Drew, D.R., (1968). Traffic Flow Theory and Control. McGraw-Hill Inc., New York, NY.

Dorofeev, Sergey and Grant, Peter (2006). Statistics for Real-Life Sample Surveys, Non-SimpleRandom Samples and Weighted Data. Cambridge University Press, Cambridge, UK

Dutta, A., Fisher, D., and Noyce, D. (2004). Use of a driving simulator to evaluate and optimize factors affecting understandability of variable message signs. Transportation Research Part F: 7, pp. 209-227, Transportation Research Board, Washington D.C., USA.

Easa, S. (1994). Reliability-based design of sight distance at railroad crossings. Transportation Research, 28A (1), 1-15.

Easa, S. (2000). "Reliability approach to intersection sight distance design." Transportation. Journal page numbers. Research, Record 1701, pp42-52, National Research Council, Washington D.C.

Easa, S., and Cheng, J. (2013).” Reliability Analysis of Minimum Pedestrian Green Interval for Traffic Signals.” Journal of Transportation Engineering, Vol. 139, No.7, Washington D.C. Economist Newspaper Group Ltd (ENG). (2001) Beyond Cruise Control. http://www.gavrila.net/Computer_Vision/Smart_Vehicles/Media_Coverage/economist.pf El-Bassiouni, S., \& Sayed, T. (2010). Design Requirements for Passing Sight Distance: RiskBased Approach. Presented at the 89th Annual Meeting of the Transportation Research Board, Washington, D.C.

Ellingrod, V. L., Perry, P. J., Yates, R. W., Maclnodoe, J. H., Watson, G., Arnalt, S., and Holman, T.L., (1997). The effects of anabolic steroids on driving performance as 
assessed by the Iowa Driver Simulator. American Journal of Drug and Alcohol Abuse, Vol. 23, No. 4, pp. 623-637.

El Khoury, John (2005) “Accounting for Risk and Level of Service in the Design of Passing Sight Distances." Ph.D thesis, Virginia Polytechnic Institute and State University, Virginia, USA.

El Khoury, John \& Hobeika, Antoine (2007) "Incorporating Uncertainty into the Estimation of the Passing Sight Distance Requirements." Computer-Aided Civil and Infrastructure Engineering. Published by Blackwell Publishing, 350 Main Street, Malden,MA02148, USA, and 9600 Garsington Road, Oxford OX4 2DQ, UK.

El Khoury, J. \& Hobeika, A. (2012). “Integrated Stochastic Approach for Risk and Service Estimation: Passing Sight Distance Application.” Journal of Transportation Engineering, Vol. 138, No. 5, ASCE, USA.

Farah, Haneen (2009). Development of Models to Evaluate Safety of Two-Lane Highways Based on Infrastructure, Traffic Characteristics and Drivers' Behavior. Ph.D thesis.

Farah, H., A. Polus, S. Bekhor, and T. Toledo (2009). A Passing Gap Acceptance Model for Two-Lane Rural Highways. Transportmetrica, Vol. 5, No. 3, pp. 159-172.

Farah, H. (2013). Modeling drivers' passing duration and distance in a virtual environment. International Association of Traffic and Safety Sciences. Production and hosting by Elsevier Ltd. Research 37, pp. 61-67.

Farber, E., and Silver, C.A., (1967). Knowledge of oncoming car speed as a determiner of drivers' passing behavior. Highway Research Record, Vol. 195, pp. 52-65.

Federal Highway Administration (FHWA) (1994). The Magnitude and Severity of Passing Accidents on Two-Lane Rural Roads (HSIS Summary Report). Report FHWA-RD-94068. Federal Highway Administration, US Department of Transport, McLean, VA, USA.

Federal Highway Administration (FHWA) (2000). Manual on Uniform Traffic Control Devices for Streets and Highways, USA.

Federal Highway Administration (FHWA) (2003). Manual on Uniform Traffic Control Devices for Streets and Highways, USA.

Federal Highway Administration (FHWA) (2009). Manual on Uniform Traffic Control Devices for Streets and Highways, USA. 
Federal Highway Administration [FHWA] (2013). Highway Statistics Series: 2013 data. Available online at < https://www.fhwa.dot.gov/policyinformation/statistics.cfm > [last visited September 3, 2015]

Flexman, R.E. and Stark, E.A., (1987). Training simulators. Handbook of Human Factors, (G. Salvendy ed.), Wiley andSons, New York, N.Y., pp. 1012-1038.

Fraser, D. A., Hawken, R. E., and Warnes, A. M. (1994). Effects of extra signals on drivers' distance keeping ----- a simulation study. IEEE transaction on vehicular technology, 43(4), pp. 1118 - 1124.

Fuerstenberg, K., Chen, J. (2007). New European approach for intersection safety - results of the EC project INTERSAFE. In: Proceedings of the International Forum on Advanced Microsystems for Automotive Applications. Springer-Verlag, Berlin. ISBN:978-3-54071324-1.

Fuerstenberg, K. \& Roessler, B. (2008). Results of the EC-project INTERSAFE. In: Proceedings of the Advanced Microsystems for Automotive Applications. Springer-Verlag, Berlin. ISBN:978-3-540-77979-7.

Gattis, J.L., Alguire, M.S., Townsend, K., Rao, S., (1997). Rural two-lane passing headways and platooning. Transporation Research Record 1579, pp. 27-34.

Glennon, J. C. (1988). New and improved model of passing sight distance on two-lane highways.Transportation Research Record: Journal of the TRB,1195, TRB, National Research Council, Washington, DC.

Godley, S., Triggs, J., and Fildes, B. (2002). Driving simulator validation for speed research. Accident Analysis and Prevention, Vol. 34(4), pp. 589-600.

Gordon, D.A., and Mast, T.M., (1968). Drivers' decision in overtaking and passing. Highway Research Record, Vol. 247, pp. 42-50.

Granet, F.; Picado, R.; and Smith, L. (2003). “Longitudinal Collision Avoidance.” Institute of Transportation Studies at the University of California at Berkeley, CA, USA. http://www.calccit.org/itsdecision/serv_and_tech/Collision_avoidance/long_collision_av oidance_report.html

Gray, R., Regan, D.M. (2005). "Perceptual processes used by drivers during overtaking in a driving simulator", Human Factors, 47, (2), pp. 394-417. 
Halati, A., H. Lieu, and S. Walker. (1997). CORSIM- Corridor Traffic Simulation Model. In Traffic Congestion and Traffic Safety in the 21st Century: Challenge, Innovations, and opportunities, American Society of Civil Engineers, pp. 570-576, New York.

Haldar, A. \& Mahadevan, S. (2000). Probability, Reliability and Statistical Methods in Engineering Design. John Wiley \& Sons. Inc., pp 1-273.

Hanley, P. F., and D. J. Forkenbrock (2005). Safety of Passing Longer Combination Vehicles on Two-Lane Highways. Transportation Research Part A, Vol. 39, pp. 1-15.

Harwood, D. W., and J. C. Glennon (1976). "Framework for Design and Operation of Passing Zones on Two-Lane Highways." Transportation Research Record 601, Transportation Research Board, 1976.

Harwood, D.W. \& Glennon, J. C. (1989). “ Passing sight distance design for passenger cars and Trucks.", in Transportation Research Record: Journal of the TRB , No 1208, TRB, National Research Council, Washington, DC.

Harwood, D. W., Fambro, D. B., Fishburn, B., Joubert, A., Lamm, R., \& Psarianos, B. (1998). International Sight Distance Design Practices. TRB, National Research Council, Washington, D.C., USA.

Harwood, D. W., D. K. Gilmore, K. R. Richard, J. M. Dunn, and C. Sun.(2007). NCHRP Report 605: Passing Sight Distance Criteria. Transportation Research Board of the National Academies, Washington, D.C.

Harwood, D. Gilmore, R.K. Richard, M.J. Dunn, C. Sun. (2008). "Passing Sight Distance Criteria, Traffic Safety," Washington, DC, (doi: NCHRP Report 605).

Harwood, D. W., D. K. Gilmore, and K. R. Richard (2010). Criteria for Passing Sight Distance for Roadway Design and Marking. In Transportation Research Record: Journal of the Transportation Research Board, No. 2195, pp. 36-46, Washington, D.C.

Hassan,Y., Easa, S., El Halim, A. (1996). "Passing sight distance on two-lane highways: review and revision." Transportation Research Record, Vol. 30, No. 6. pp.,1-i3 467, Canada. Hasofer, A.M., and Lind, N.C.(1974). "Exact and Invariant Second Moment Code Format." Journal of Engineering Mechanics Division, ASCE, Vol. 100, No. EMI, pp. 111-121. Hegeman, G. (2004). Overtaking Frequency and Advanced Driver Assistance Systems. Proc., IEEE Intelligent Vehicles Symposium, Parma, Italy, pp. 14-17. 
Hegeman, G., S. Hoogendoorn, and K. Brookhuis (2008). Observations Overtaking Manoeuvres on Bi-Directional Roads. In Advanced OR and AI Methods in Transportation, pp. 505510.

Holux Technology Inc., 2014. Holux RCV-3000 GPS Logger User Manual.

Horberry, T., Anderson, J., and Regan, M. A. (2006). The possible safety benefits of enhanced road markings: a driving simulator evaluation. Transportation Research Part F: 9, pp. 7787, National Research Council, Washington, D.C. USA.

Isermann, R., Mannale, R., Schmitt, K. (2012). “Collision-avoidance systems PRORETA: Situation analysis and intervention control”, Control Eng. Pract., Vol. 20, pp. 1236-1246.

ITS America. (2002), The National ITS Program Plan: A Ten-year Vision. Delivering the Future of Transportation (www.itsa.org/research.html)

Jamson, H. (1999). Curve negotiation in the Leeds Driving Simulator: the role of driver experience. Engineering in Psychology and Cognitive Ergonomics, Vol. 3, pp. 351-358.

Jenkins, Jacqueline Marie (2004). Modeling the Interaction Between Passenger Cars and Trucks. Ph.D thesis, Texas A\&M University, Texas, USA.

Jenkins, J. M., and L. R. Rilett (2004). Application of Distributed Traffic Simulation for Passing Behavior Study. Transportation Research Record, No. 1899, pp. 11-18, Transportation Research Board, Washington, D.C.

Jenkins, J., Rilett, L. (2005). Classifying passing maneuvers: a behavioral approach.

Transportation Research Record, No. 1937, 14-21, Transportation Research Board, Washington, D.C., USA.

Jones, H.V., and Heimstra, N.W., (1966). Ability of Drivers Judgments, Highway Research Record, Vol. 122, HRB, pp. 89-92, National Research Council, Washington, D.C.

Kaptein, N.A., Theeuwes, J., and Horst, A.R.A. van der. (1996). Driving simulator validity: Some considerations. Transportation Research Record No. 1550, Washington, D.C., pp. 30-36.

Kiefer, R., LeBlanc, D., Palmer, M., Salinger, J., Deering, R., and Shulman, M. (1999). Development and Validation of Functional Definitions and Evaluation Procedures for Collision Warning/Avoidance Systems (Report No. DOT HS 808 964). Washington, D.C.: National Highway Traffic Safety Administration. 
Kretschmer, M., Neubeck, J., and Wiedemann (2005). "Combining Vehicle Dynamics Control and Decision Making Procedures Towards Safe Overtaking Maneuvers." SAE International Journal, 01-0412.

Lieberman, E. B. (1982). "Model for calculating safe passing sight distance on two-lane rural Roads." Transportation Research Record: Journal of the TRB, No 869, TRB, National Research Council,Washington, DC.

Lieberman, E. and Rathi, A. K. (2002). Traffic Flow Theory: State-of-the-Art Report Chapter 10: Traffic Simulation. http://www.tfhrc.gov/its/tft/chap10.pdf

Liebermann, D.G., Ben-David, G., Schwietzer, N., Apter, Y., and Parush, A. (1995) A Field Study on Braking Responses During Driving. I Triggering and Modulation. Ergonomics, 38 (9), pp.1894-1902.

Liu, C., and R. Herman, (1996). "Passing sight distance and overtaking dilemma on two-lane roads." Transportation Research Record: Journal of the Transportation Research Board, No. 1566, TRB, National Research Council, Washington, D. C., pp. 64-70.

Llorca, C., and A. García. (2011). "Evaluation of Passing Process on Two-Lane Rural Highways in Spain with New Methodology Based on Video Data.” In Transportation Research Record: Journal of the Transportation Research Board, No. 2262 , pp. 42-51, Washington, D.C.

Llorca, C., Moreno, A. T., Sayed, T. and García, A. (2014). "Sight Distance Standards Based on Observational Data Risk Evaluation of Passing." Transportation Research Record, No. 2404, pp. 18-26, Washington, D.C.

Llorca, C. and Farah, H. (2016). "Passing Behavior on Two-Lane Roads in A Real and in A Simulated Environment.” Transportation Research Board Annual Meeting, Washington, D.C., USA.

Long, G., (2000). Acceleration characteristics of starting vehicles. Transportation Research Record 1737, 58-70.

Mahdi, T.A. (1991). The Effect of Overtaking Provision on the Operating Characteristics of Single Carriageway Roads, PhD thesis University of Wales College of Cardiff.

Mannering, Fred L., Walter P. Kilareski and Scott S. Washburn (2005). Principles of Highway Engineering and Traffic Analysis. Third Edition. John Wiley \& Sons Inc. 
Manser, M. P., \& Hancock, P. A. (2007). The influence of perceptual speed regulation on speed perception, choice, and control: Tunnel wall characteristics and influences. Accident Analysis \& Prevention, 39, 69-78.

Mathworks (2004) Simulink (C) 6 Simulation and Model Based Design. https://tagteamdbserver.mathworks.com/ttserverroot/Download/18692_SL_9320v05.pdf

McAvoy, D., Schattler, K., and Datta, T. (2007). Driving simulator validation for nighttime construction work zone devices. Proc. The 86th Annual Meeting of the Transportation Research Board, Washington, D.C., USA.

McKnight, J., Adams, B.B.(1970). "Driver education task analysis, Task Descriptions," Human Resources Research Organization (HumPRO), vol. 1, Alexandria. http://www.civil.uwaterloo.ca/saccomanno/Publications/trbpaper \%2001-2346.doc

Mehmood, A. \& Easa, S M. (2009). "Modeling reaction time in car-following behavior based on human factors." International Journal of Applied Science, Engineering and Technology, 5(2), 93-101.

Mehmood, Atif (2010). Development of framework for in-vehicle rear-end collision warning system considering driver characteristics. Ph.D thesis, Ryerson University, Toronto, Canada.

Molinero, A., Carter, E., Naing, C., et al. (2008). “Accident causation and pre-accidental driving situations." Part 1. Overview and general statistics, TRACE - Traffic Accident Causation in Europe Report.

Morice, A.H.P., Diaz, G.J., Fajen, B.R., et al. (2015). “An affordance-based approach to visually guided overtaking”, Ecolog. Psychol., 27, (1), pp. 1-25

Moser, C. A. and Kalton, G. (1971). Survey Methods in Social Investigation. $2^{\text {nd }}$ Edition. Heinemann Educational Books, Portsmouth, NH, USA.

Mousa, R.M., (2002). “Analysis and modeling of measured delays at isolated signalized intersections." Journal of Transportation, 128 (4), 347-354.

Najm, W.G. and J. Koopmann. "Analysis of Crossing Path Collision Countermeasure Systems." Draft dated September, 2000. http://fresno.ts.odu.edu/newitsd/ITS_Serv_Tech/ collision_avoidance/coll_avoid_inter/collision_avoidance_intersection_summary2.html 
Najm, W. G., Sen, B., Smith, J. D., \& Campbell, B. N. (2003). Analysis of Light Vehicle Crashes and Pre-crash Scenarios based on the 2000 General Estimates System.

Washington D.C.: U.S. Department of Transportation, report no. DOT-VNTSCNHTSA-02-04

Najm, W. G. and Smith, D. L. (2004). Modeling Driver Response to Lead Vehicle Decelerating. http://www-nrd.nhtsa.dot.gov/departments/nrd-12/ModelingDriver/images/ SAE\%20FINAL\%20PDF\%202004-01-0171.pdf

Navin, P. D. F., (1990). "Safety Factors for Road Design: Can they be estimated?" Transportation Research Record 1280, pp 181 - 189.

NCHRP (2005). Passing Sight Distance Criteria. TRB Project 15-26. TRB web site: http://www4.trb.org/trb/crp.nsf/All+Projects/NCHRP+15-26

NCHRP (2008). Passing Sight 12 Distance Criteria. Report 605, Transportation Research Board. http://onlinepubs.trb.org/onlinepubs/nchrp/nchrp_rpt_605.pdf

Nilsson L., Alm H. and Janssen W.H. (1991). "Collision avoidance systems: Effects of different levels of task allocation on driver behaviour.” Driver Project V1041 Haren, The Netherlands: Generic Intelligent Driver Support System, Deliverable GIDS / Man3, Traffic Research Center.

Nilsson, L. (1993). "Behavioural research in an advanced driving simulator experiences of the VTI system.” Proc. Human Factors and Ergonomics Society 37th Annual Meeting, pp. 612-616.

Palisade Corporation (2016). @ RISK User Guide. Retrieved from https://www.palisade.com/downloads/manuals/6/EN/PTree6_EN.pdf

Perco, P., Marchionna, A., Falconetti, N., (2012). "Prediction of the operating speed profile approaching and departing intersections." Journal of Transportation Engineering, 138 (12), 1476-1483.

Persaud, B.N., Retting, R.A., Lyon, C.A. (2004). "Crash reduction following installation of centerline rumble strips on rural two-lane roads." Accident Analysis and Prevention, 36 (6) 1073-1079.

Pierowicz, J., Jocoy, E., Lloyd, M., Bittner, A., Pirson, B. (2000). Intersection Collision Avoidance Using ITS Countermeasures. Task 9: Final Report. Report No. DOT HS 809 171. National 
Highway Traffic Safety Administration, Washington, DC.

Polus, A., M. Livneh, and B. Frischer.(2000). "Evaluation of the Passing Process on Two-Lane Rural Highways.” In Transportation Research Record: Journal of the Transportation Research Board, National Research Council, No. 1701, pp. 53-60, Washington, D.C.

Rakauskas, M.E., Gugerty, L.J., and Ward, N.J. (2004). "Effects of naturalistic cell phone conversations on driving performance." Journal of Safety Research, Vol. 35, pp. 453-464.

Rakha, Hesham, Snare, Matthew, and Dion, Francois (2004). "Vehicle dynamics model for estimating maximum light-duty vehicle acceleration levels." Transportation Research Record 1883, pp. 40-49, Transportation Research Board, Washington, D.C., USA.

Rao, S.K., Madugula, K.S. (1986). "Acceleration characteristics of automobiles in the determination of sight distance at stop-controlled intersections." Civil Engineering for Practicing and Design Engineers 5, 487-498.

Retting, R. A., McGee, H. W., \& Farmer, C. M. (2000). "Influence of experimental pavement markings on urban freeway exit-ramp speeds.” Transportation Research Record, 1705, $116-121$.

Rizzo, M., McGehee, D. V., Dawson, J. D. and Anderson, S. N., (2001). "Simulated car crashes at intersections in drivers with Alzheimer disease." Alzheimer Disease and Associated Disorders, 15(1), pp. 10-20.

Rocci, S.(1998). “A system for no passing zones signing and marking setup.” Transp. Res. Board Circular, E-C003, pp. 1-11.

Romana, M.G., (1999). "Passing activity on two-lane highways in Spain." Transportation Research Record 1678, pp. 90-95.

Ruiz, J.A., Gil, J.J., Naranjo, J.E., Su'arez, J.I., and Vinagre, B. (2007). “Cooperative Maneuver Study Between Autonomous Cars: Overtaking.” Springer-Verlag Berlin Heidelberg, LNCS 4739, pp. 1151-1158.

Pollatschek, M. A., and A. Polus (2005). "Modeling Impatience of Drivers in Passing Maneuvers." Transportation and Traffic Theory: Flow, Dynamics and Human Interaction (H. S. Mahmassani, ed.), Emerald Group Publishing, Bingley, pp. 267-279, UK.

Polus, A., M. Livneh, and B. Frischer (2000). "Evaluation of the Passing Process on Two-Lane Rural Highways.” Transportation Research Record: Journal of the Transportation 
Research Board, No. 1701, TRB, National Research Council, pp. 53-60, Washington, D.C.

Rural Road Safety in Canada (2010). Traffic Collision Trends and Recommended Strategies. Ottawa, Canada.

Salaani, M. K. and Heydinger, G. J. (2000).” Model Validation of the 1997 Jeep Cherokee For the National Advanced Driving Simulator." SAE Paper No. 2000-01-0700, SAE World Congress, Detroit, MI, USA.

Samuel G. Charlton, Nicola J. Starkey (2011). “ Driving without awareness: The effects of practice and automaticity on attention and driving." Elsevier Ltd., Transportation Research Part F, 1369-8478.

SAS (2015). SAS: Enterprise Guide. Retrieved from http://www.sas.com/technologies/bi/query_reporting/guide/

Smith, P.; Shah, M.; Da Vitoria Lobo, N. (2000). "Monitoring Head/Eye Motion for Driver Alertness with One Camera." Proc., 15th International Conference on Pattern Recognition (ICPR 2000), Barcelona, Spain.

Smith, D., Najm, W., and Glassco, R. (2002). "Feasibility of driver judgment as a basis for crash avoidance database development." Transportation Research Record 1784. Transportation Research Board, Washington D.C., USA. http://www.cs.ucf.edu/ vision/projects/DriverAlertness/ 1315_smith.pdf

Sparks, B.G.A., Neudorf, R.D., Robinson, J.B.L., et al. (1993). "Effect of vehicle length on passing operations," J. Transp. Eng., 119, (2), pp. 272-283.

STISIM (2009). STISIM User's Guide. Systems Technology Inc., Hawthorne CA.

St. John, A. D., and Harwood, D. W. (1986). TWOPAS User's Guide. FHWA, U.S. Department of Transportation.

SYMEO GmbH (2016). Access on December 30, 2016.

http://www.symeo.com/en/applications/distance-measurement/index.html

Taylor, Sarah J. (2005). Development of a Bayesian Decision Theory Framework to Enhance The Design of Rear-end Collision Warning Systems. Ph.D. thesis, Carleton University, Ottawa, Ontario, Canada.

Tornros, J. (1998). "Driving behaviour in a real and a simulated road tunnel-a validation study." 
Accident Analysis and Prevention, Vol. 30(4), pp. 497-503.

Transportation Association of Canada (2007). Geometric Design Guide for Canadian Roads.

Transportation Association of Canada", Ottawa, ON, Canada.

Transport Canada (TC) (2003) Strategies for Reducing Driver Distraction from In-Vehicle

Telematics Devices: A Discussion Document TP 1413. http://www.tc.gc.ca/

roadsafety/tp/tp14133/pdf/tp14133e.pdf

Transport Canada (TC) (2010). Vision 2010 Canada's Safety Targets to 2010 (TP 13736 E),

Ottawa. http://www.ccmta.ca/english/pdf/2010_e.pdf

Transport Canada (TC) (2016). "Canadian Motor Vehicle Traffic Collision Statistics."

Transport Canada. http://www.tc.gc.ca/eng/motorvehiclesafety/menu.htm.

Treat, J. R., Tumbas, N. S., McDonald, S .T., Shinar, D., Hume, R. D., Mayer, R. E., Stanisfer, R. L., and Castillan, N. J. (1977). Tri-level study of the causes of traffic accidents. Report No. DOT-HS-034-3-535-77, Indiana University.

Van der Winsum, W., (1996). "Speed choice and steering behavior in curve driving." Human Factor, 38(3), pp. 343- 351.

Van der Winsum, W., and Brouwer, W., (1997). "Time headway in car following and operational performance during unexpected braking.” Perceptual and Motor Skills, 84, pp. 1247 1257.

VORAD Collision Warning System, produced by EATON (2009). Website www.vorad.com

VORAD Collision Warning System, produced by EATON (2017). Website www.vorad.com

Wang, Hui et al., "Safer Roads Thanks to ITS," Public Roads.

Wang, Y., and M. P. Cartmell (1998). "New Model for Passing Sight Distance on Two-Lane Highways.” ASCE Journal of Transportation Engineering, Vol. 124, No. 6.

Wang, J., Dixon, K.K., Li, H., Ogle, J., (2004). "Normal acceleration behavior of passenger vehicles starting from rest at all-way stop-controlled intersections." Transportation Research Record 1883, 158-166.

Yan, Xuedong, Abdel-Aty, Mohamed, and Radwan, Essam (2008). "Validating a driving simulator using surrogate safety measures.” Accident Analysis and Prevention, Vol. 40(1), pp. 274-288. 
Zheng, N-N.; Tang, S.; Cheng, H.; Li, Q.; Lai, G.; and Wang, F-Y. (2004). Toward intelligent Driver Assistance and Safety Warning System. IEEE Intelligent Systems 9(2), pp8-11. 